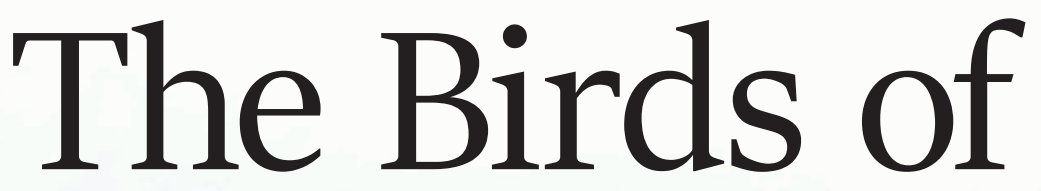

Nebraska

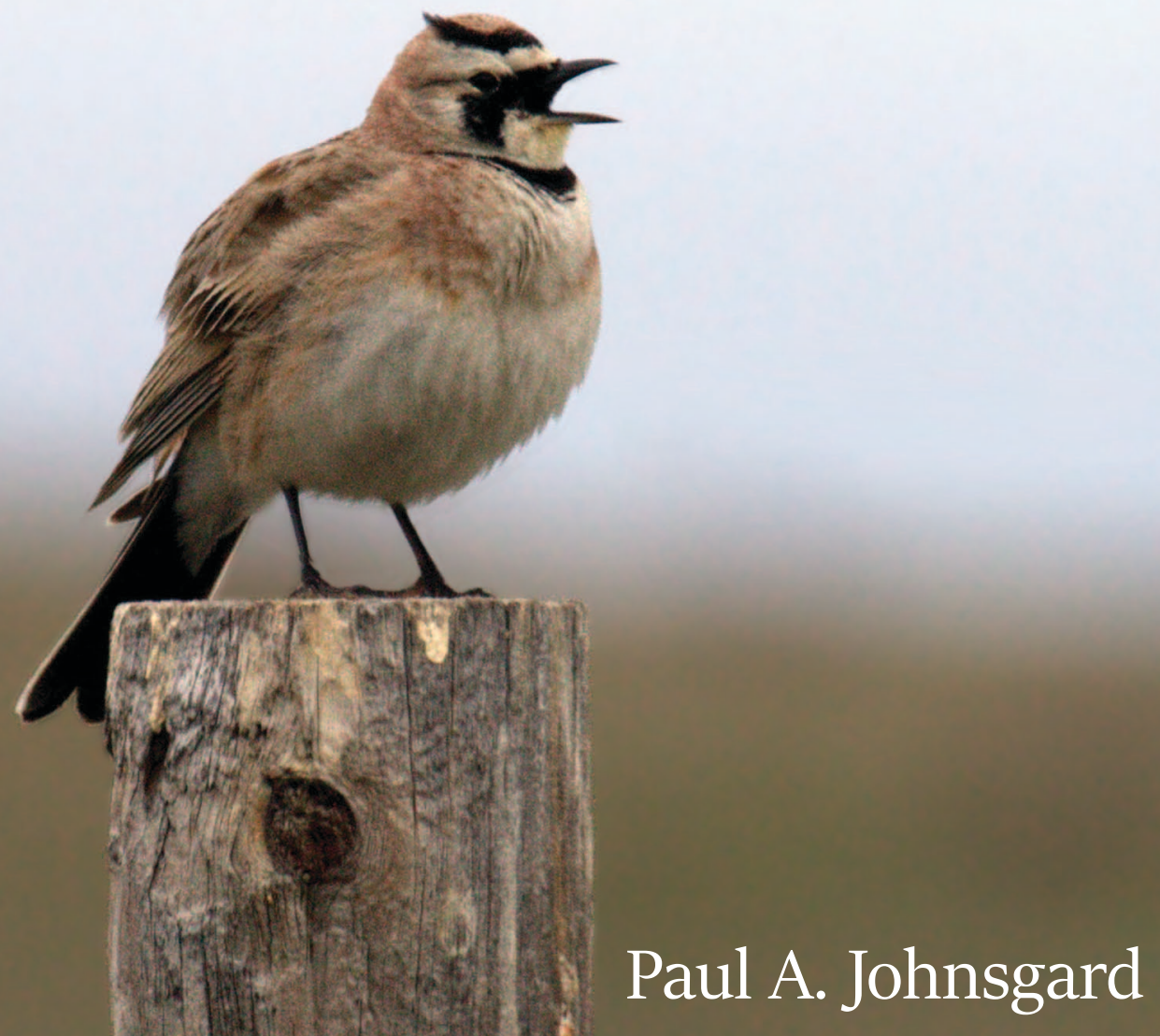




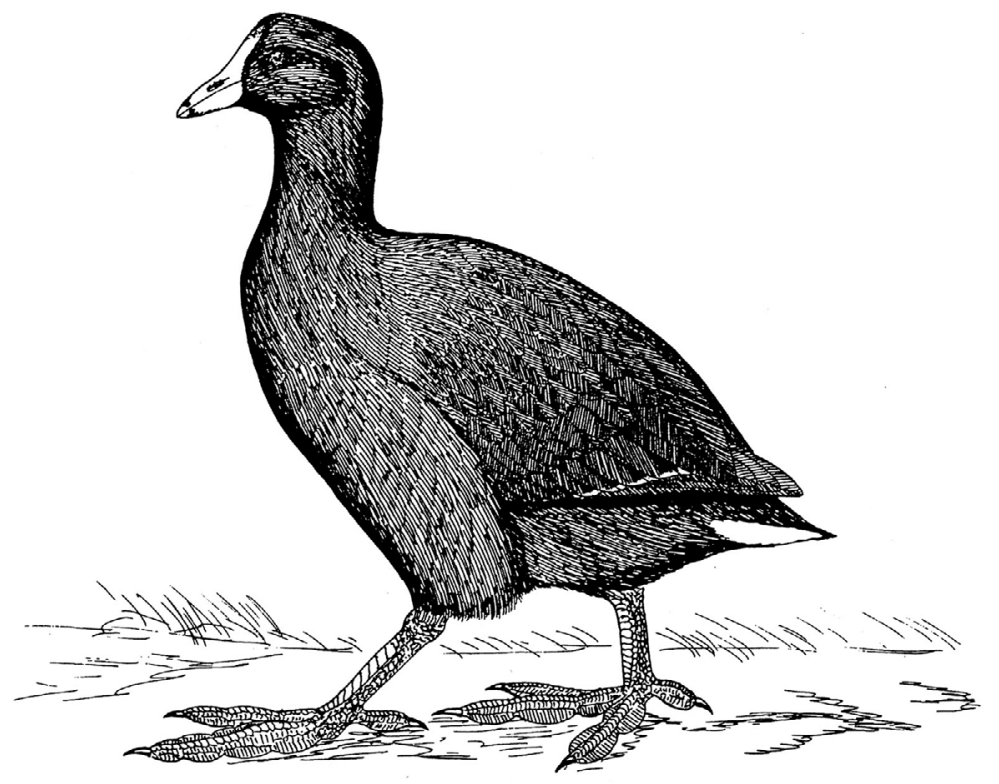

This annotated list of the birds of Nebraska has been updated to conform with the most recent (2017) major revision of the American Ornithologists' Society's Checklist of North American Birds (Chesser et al., 2017). It has also been modified to conform very closely to the most recent "Official List of the Birds of Nebraska” by the Nebraska Ornithologists' Union (Gubanyi, 1997, and later supplements in the Nebraska Bird Review, to 84:138-150).

The NOU's official state list of birds (461 species as of 2017) is based on actual specimen evidence or some other convincing basis of each species' proven occurrence in the state. That list includes 337 "regular" species, 29 "casual" species, 90 "accidental" species, and 5 extinct or extirpated species. In this edition the author has classified 368 of the 461 species of Nebraska birds as ranging in relative frequency of occurrence as "abundant" to "rare." There are also 61 species considered to be of "accidental" occurrence, having been reliably reported in Nebraska no more than five times, 20 that are considered "extremely rare" or "very rare," if reported from six to 25 times. There are also three extinct, four extirpated, and five unsuccessfully introduced species. Thirteen hypothetical species of dubious origin or identification are mentioned parenthetically.

The text includes more than 123,000 words, nearly 200 literature references, and 19 pages of drawings and maps.

Cover: Horned Lark; back cover: American Coot

Photos and drawings by Paul A. Johnsgard

Zea Books, Lincoln, Nebraska 


\section{The Birds of}

Nebraska

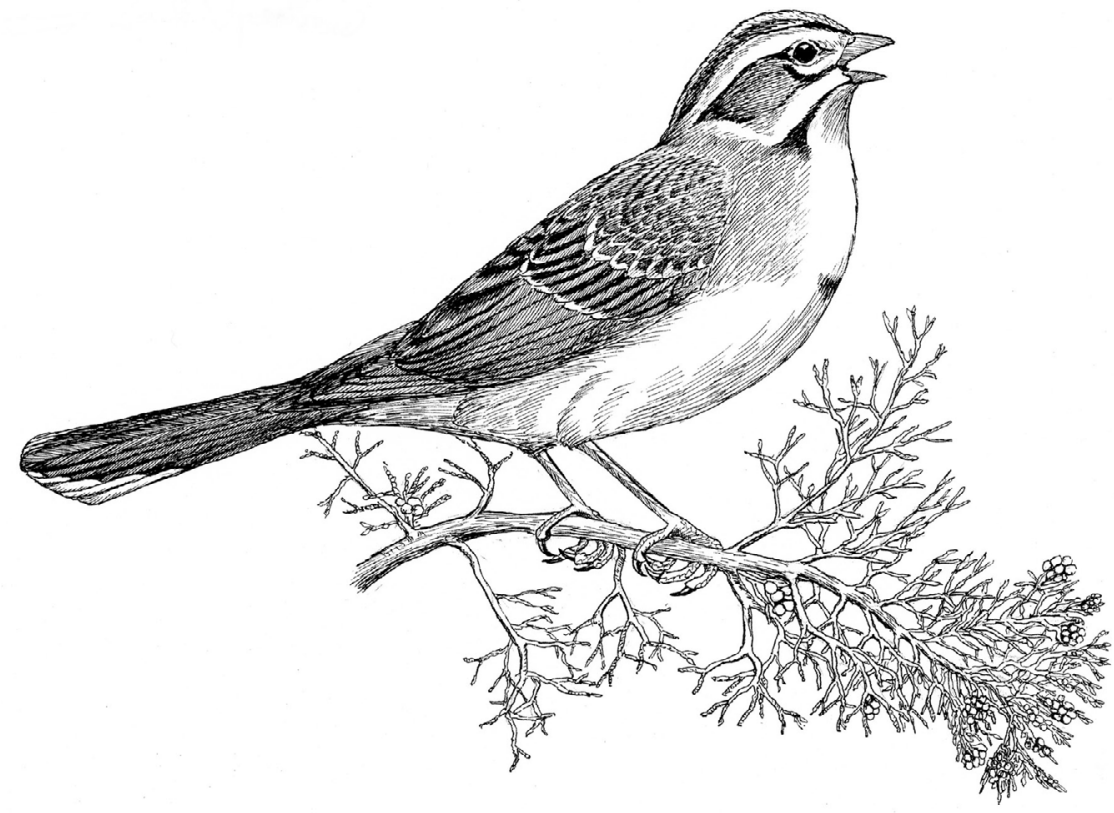

Paul A. Johnsgard

School of Biological Sciences

University of Nebraska-Lincoln

Zea Books, Lincoln, Nebraska: 2018 
Copyright (C) 2013, 2018 Paul A. Johnsgard

Second digital edition, 2018

ISBN: 978-1-60962-128-5

doi 10.13014/K2B56GX2

Composed in Sitka types.

Zea Books are published by the

University of Nebraska-Lincoln Libraries

Electronic (pdf) edition available online at

https://digitalcommons.unl.edu/zeabook/

Print edition available from

http://www.lulu.com/spotlight/unllib

UNL does not discriminate based upon any protected status.

Please go to http://www.unl.edu/equity/notice-nondiscrimination

\section{Nebraska \\ Lincoln}




\section{Abstract}

This annotated list of the birds of Nebraska grew gradually out of research associated with my writing of the Birds of the Great Plains: Breeding Species and Their Distribution (Johnsgard, 1979a). It expands and updates an earlier version that was published in 2013 by the University of Nebraska-Lincoln Libraries DigitalCommons' Zea Books (Johnsgard, 2013a). It has been updated and modified in its current revision to conform with the most recent (2017) major revision of the American Ornithologists' Society's Checklist of North American Birds (Chesser et al., 2017). It has also been modified in its current revision to conform very closely to the most recent "Official List of the Birds of Nebraska" by the Nebraska Ornithologists' Union (Gubanyi, 1997, and later supplements in the $\mathrm{Ne}$ braska Bird Review, to 84:138-150).

The NOU's official state list of birds ( 461 species as of 2017) is based on actual spec- imen evidence or some other convincing basis of each species' proven occurrence in the state. That list includes 337 "regular" species, 29 "casual" species, 90 "accidental" species, and 5 extinct or extirpated species. In this edition I have classified 368 of the 461 species of Nebraska birds as ranging in relative frequency of occurrence as "abundant" to "rare." There are also 61 species considered to be of "accidental" occurrence, having been reliably reported in $\mathrm{Ne}$ braska no more than five times, 20 that are considered "extremely rare" or "very rare," if reported from six to 25 times. There are also three extinct, four extirpated, and five unsuccessfully introduced species. Thirteen hypothetical species of dubious origin or identification are mentioned parenthetically.

The text includes more than 123,000 words, nearly 200 literature references, and 19 pages of drawings and maps. 


\section{Contents}

List of Figures . . . . . . . . . 6

Acknowledgments . . . . . . . . 7

\section{Part 1. Introduction}

Bird-watching through the Year in Nebraska . . . . . . . . 9

Fundamentals of

Bird-watching. . . . . . . 17

Optical Equipment and

Acoustic Aids . . . . . . . 18

Reference Materials . . . . . . 22

Electronic Information

Sources . . . . . . . . 25

Vernacular and Technical

Names of Birds . . . . . . 26

Monitoring Nebraska Bird

Populations . . . . . . . 28

Participating in Nebraska Birding and Citizen Research . . . . . 32

Backyard Birding

Opportunities . . . . . . . 34

Information Sources on Nebraska

Birding and Tourism . . . 36

\section{Part 2. The Birds of Nebraska}

Introduction . . . . . . . . 39

Vegetation and Topography

of Nebraska . . . . . . . . 42

Definitions of Terms Used

in the Text. . . . . . 50

List of Nebraska Bird Species

Family Tinamidae

(Tinamous) . . . . . 51

Family Anatidae

(Waterfowl) ..... 51

Family Odontophoridae

(New World Quails) . . . 75

Family Phasianidae

(Pheasants, Grouse,

and Turkeys). . . . . . 76
Family Podicipedidae

(Grebes) . . . . . . 80

Family Columbidae

(Pigeons and Doves) . . . . 83

Family Cuculidae

(Cuckoos) ....... 86

Family Caprimulgidae

(Nightjars). . . . . . . 87

Family Apodidae

(Swifts) . . . . . . 91

Family Trochilidae

(Hummingbirds). . . . . 93

Family Rallidae

(Rails and Coots) . . . . 95

Family Gruidae

(Cranes) ....... 101

Family Charadriidae

(Plovers)...... . 104

Family Recurvirostridae

(Stilts and Avocets) . . 108

Family Scolopacidae

(Sandpipers, Snipes,

and Phalaropes) . . . . 110

Family Stercorariidae

(Jaegers) . . . . . . 126

Family Alcidae

(Auks) . . . . . . 127

Family Laridae

(Gulls and Terns) . . . . 127

Family Gaviidae

(Loons). . . . . . . 135

Family Ciconiidae

(Wood Storks) . . . . . . 137

Family Phaethontidae

(Tropicbirds). . . . . . 137

Family Fregatidae

(Frigatebirds) . . . . . 137

Family Sulidae

(Gannets and Boobies). . 137

Family Phalacrocoracidae

(Cormorants) . . . . 138

Family Anhingidae

(Anhingas) . . . . . 139 
Family Pelecanidae

(Pelicans) . . . . . . . 139

Family Ardeidae

(Herons and Egrets). . . 140

Family Threskiornithidae

(Ibises and Spoonbills) . 148

Family Cathartidae

(New World Vultures) . . 149

Family Pandionidae

(Ospreys) .... . 150

Family Accipitridae

(Hawks and Eagles) . . . 151

Family Tytonidae

(Barn Owls) . . . . . . . 161

Family Strigidae

(Typical Owls) . . . . . . 161

Family Alcedinidae

(Kingfishers). . . . . . . 167

Family Picidae

(Woodpeckers). . . . . 168

Family Falconidae

(Falcons). . . . . . 174

Family Psittacidae

(Parrots) . . . . . . 177

Family Tyrannidae

(New World Flycatchers) 178

Family Laniidae

(Shrikes). . . . . . 187

Family Vireonidae

(Vireos) . . . . . . . 189

Family Corvidae

(Crows, Jays, and

Magpies) . . . . . . . . 193

Family Alaudidae

(Larks) . . . . . . . . . 197

Family Hirundinidae

(Swallows). . . . . . 198

Family Paridae

(Chickadees and

Titmice) . . . . . . 203

Family Sittidae

(Nuthatches). . . . . 204

Family Certhiidae

(Creepers) . . . . 206
Family Troglodytidae

(Wrens) ...... . 207

Family Polioptilidae

(Gnatcatchers) . . . . . 212

Family Cinclidae

(Dippers). . . . . . . 212

Family Regulidae

(Kinglets) . . . . . . 213

Family Turdidae

(Thrushes). . . . . . . 214

Family Mimidae

(Mockingbirds, Thrashers,

and Catbirds) . . . . 220

Family Sturnidae

(Starlings) . . . . . . . . .222

Family Bombycillidae

(Waxwings) . . . . 223

Family Ptilogonatidae

(Silky Flycatchers). . . . 224

Family Passeridae

(Old World Sparrows) . . 224

Family Motacillidae

(Pipits). . . . . . 225

Family Fringillidae

(Finches). . . . . . 226

Family Calcariidae

(Longspurs and Snow

Buntings) . . . . . 232

Family Emberizidae

(Sparrows). . . . . 236

Family Icteriidae

(Chats). . . . . . 252

Family Icteridae

(Blackbirds, Orioles, and Meadowlarks). . . 253

Family Parulidae

(New World Warblers) . 262

Family Cardinalidae

(Cardinals, Tanagers,

and Grosbeaks) . . . . 279

References . . . . . . . 287

Index of species . . . . . 302 


\section{Figures}

1. Landforms of Nebraska . . 44

2. Native vegetation of Nebraska . . . . . . . 46

3. Nebraska counties . . . 48

4. Sharp-tailed grouse and greater prairie-chicken . . 78

5. Common poor-will and mourning dove . . . . 89

6. White-throated swift and chimney swift . . . . . . 92

7. American coot and sora . . 99

8. Sandhill crane . . . . . 102

9. Wilson's phalarope and long-billed curlew . . . . 124

10. Wetland birds:

American bittern, double-crested cormorant, and pied-billed grebe . . . 141
11. Barn owl, short-eared owl, barred owl, and burrowing owl. . . . . . 164

12. Grassland songbirds: lark bunting, McCown's longspur, chestnut-collared longspur, and horned lark . . . . . 235

13. Grassland songbirds:

Henslow's sparrow, dickcissel, Cassin's sparrow, Brewer's sparrow, grasshopper sparrow, and clay-colored sparrow . . 246

14. Parental and hybrid species: spotted and eastern towhees, black-headed and rose-breasted grosbeaks, and lazuli and indigo buntings . . . . . 283 


\section{Acknowledgments}

Over its many years of additions and changes, the evolution of this book has been made possible by numerous persons who variously have helped or advised me personally. There are also the efforts of the countless people who constructed our historic database for Nebraska birds, starting with such early twentieth-century pioneers as Lawrence Bruner, Robert Wolcott, and Myron Swenk. Since its inception in the 1930s, the Nebraska Bird Review has been my primary reference source for documenting Nebraska's avifauna. Still more recently, Roger Sharpe, Ross Silcock, and Joel Jorgensen (2001) have blessed Nebraska with its first comprehensive "state bird book." Since then, Ross Silcock's continuing devotion to maintaining a published record of our state's bird data in the Nebraska Bird Review has provided a critical source of contemporary information for me. Additionally, Wayne Mollhoff's comparably valuable work on organizing and carrying out and publishing two atlases on the breeding birds of Nebraska has filled a major gap in our knowledge of Nebraska's breeding birds and their distribution. To all these people (and opportunistically speaking for all other lovers of Nebraska birds), I offer a boundless debt of gratitude. I also extend my continuing personal thanks to the University of Nebraska's indefatigable DigitalCommons coordinator, Paul Royster, and to his priceless editorial assistant, Linnea Fredrickson.

Paul A. Johnsgard 


\section{Part 1}

\section{Introduction}
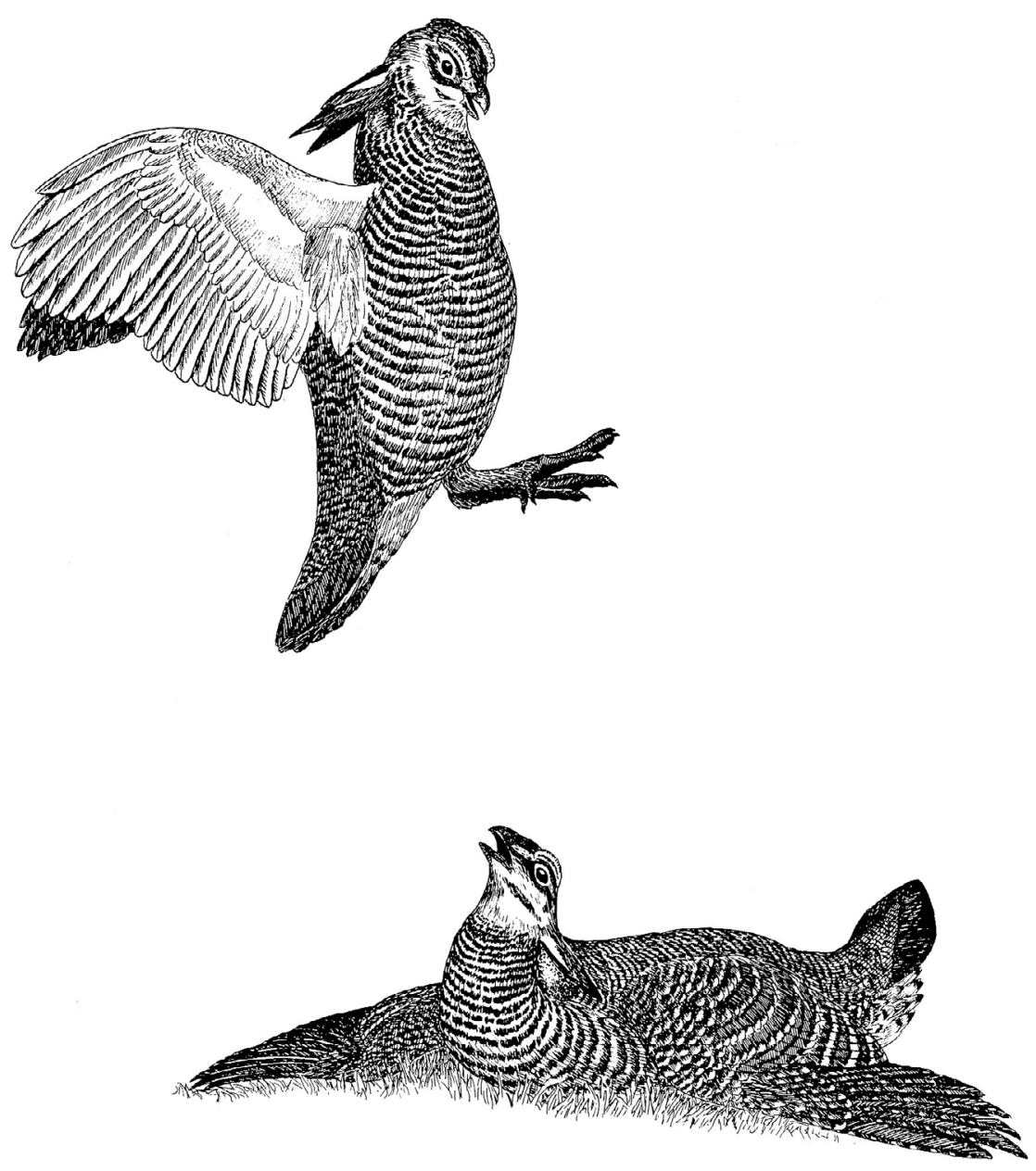


\section{Bird-watching through the Year in Nebraska}

It has been estimated that bird-watching activities in the United States increased $155 \%$ during the decade ending in 2004 , or at a more rapid rate than all other outdoor sports including walking, skiing, and hiking, whereas fishing, hunting, and tennis have all declined in popularity. Money now spent on wildlife recreation (about $\$ 150$ billion in 2016 versus $\$ 100$ billion in 2000) now exceeds total cash receipts from all livestock sales ("Wildlife Recreation," in The Main Street Economist, April 2004). About 86 million people in the United States fed, photographed, or watched wildlife and spent $\$ 79.6$ billion (nearly $\$ 900$ per person) on these activities during 2016 (US Department of Interior et al., 2016), or more than the total $\$ 71$ billion spent on hunting and fishing activities combined. By the late 1990s there were at least 45 million adult bird-watchers, and in Nebraska alone an estimated \$23.1 million per year were being spent by them on nonconsumptive bird-related activities (Bird Conservation, spring 1997, pp. 6-8). The current (2017) economic impact of visitors coming to the Platte River valley to witness the crane migration has been estimated at more than \$14 million annually (Dority et al., 2017).

Many Nebraskans are unaware that they are residing in one of the prime locations in the entire world for observing and enjoying some of the most aesthetically appealing of all the world's biological attractions. The state's central Platte River val- ley and its adjoining counties, for example, are known to have attracted more than 370 bird species (Brown \& Johnsgard, 2013), making it one of the most species-rich bird regions in the interior United States. More impressively, the spring congregations of a half million cranes and about 10 million waterfowl along the Platte River valley were ranked by Roger Pasquier (Forbes Magazine, 1997) as the greatest bird spectacle on earth.

Although spring birding in Nebraska's Platte Valley is our state's prime natural history attraction (Johnsgard, $2007 \mathrm{~b}$ ), every month of the year has some bird-related attractions across the entire state (Johnsgard, 2009b), as the following monthly bird and human activities list will suggest.

\section{January}

January in Nebraska is the coldest and dreariest month, and a good time for feeding birds and enjoying them through the windows. White-throated and white-crowned sparrows are welcome visitors to feeders now, as are American goldfinches and other finches, such as house finches and, less frequently, purple finches (Johnsgard, 2011a, 2013d). Dark-eyed juncos and spotted towhees scratch industriously in the snow for food, and in the countryside species such as horned larks, American tree sparrows, Harris's sparrows, and sometimes Lapland longspurs gather in open fields to search for seeds. During some years, red-breasted nuthatches ap- 
pear at suet feeders to join wintering downy, hairy, and (in the east) redbellied woodpeckers, and even less often red crossbills and (rarely) evening grosbeaks make their appearances, especially in western parts of the state. In the Panhandle and Pine Ridge region, other winter visitors might include Steller's jays, Bohemian waxwings, Clark's nutcrackers, mountain chickadees, Cassin's finches, and graycrowned rosy-finches (Rosche, 1982; Johnsgard, 2012a). Eurasian collareddoves and northern cardinals now begin to sense the lengthening days, and by mid-January a few males may begin to sing, to be joined later in the month by European starlings and sometimes a few precocious house finches.

For the adventurous birders, this month offers the temptation to drive to Kingsley Dam near Ogallala for the spectacle of several hundred bald eagles that annually gather at Lake McConaughy (Rosche \& Johnsgard, 1984; Brown \& Brown, 2001; Brown, Dinsmore, \& Brown, 2012; Johnsgard, 2012e) and the chance to see some rare waterfowl, loons, or gulls as well. This is the best time for seeing rough-legged hawks and other uncommon to rare northern visitors, such as snowy owls, snow buntings, and Lapland longspurs.

\section{February}

By February the days are perceptibly lengthening, and the end of winter seems almost in sight. Winter birds still gather at feeders, but American crows are on the move northward, as are vanguard individuals of American robins, red-winged blackbirds, and bluebirds. Great horned owls begin nesting in February and should not be disturbed by playback of owl calls from this point onward through their nesting period (Johnsgard, 2002b, 2012f).

Cornell University's Lab of Ornithology's popular annual Great Backyard Bird Count is held in mid-February and provides a good reason for getting out of the house and helping to generate a contemporary overall view of midwinter birds both in the state and nationally (and internationally). Based on the number of Nebraska observation points reporting the species in 2011, the state's ten most widely reported birds were (in descending order) American robin, American goldfinch, downy woodpecker, house sparrow, blue jay, house finch, blackcapped chickadee, Canada goose, European starling, and mourning dove (Johnsgard, 2011a). For comparison, the ten most widely recorded species observed nationally in 2017 were northern cardinal, American crow, mourning dove, dark-eyed junco, downy woodpecker, blue jay, blackcapped chickadee, house finch, house sparrow, and white-breasted nuthatch. The ten most abundant species reported nationally in 2017 were (in descending order) snow goose, redwinged blackbird, Canada goose, European starling, mallard, ring-billed gull, American coot, greater whitefronted goose, common grackle, and American crow.

By Valentine's Day the first sandhill cranes can be expected to arrive on the Platte River, at least if it has become ice-free. They usually arrive on a south wind and with clearing skies, 
probably having flown from their wintering regions in Texas and New Mexico in a single day. Common mergansers begin to appear on the Platte too, as well as on larger reservoirs. Almost simultaneously common goldeneyes start to appear in these same locations.

As lakes and reservoirs slowly become ice-free, bald eagles appear along the state's waterways. They feast on winter-killed fish that become available, often perching on ice blocks or trees along the shoreline. Harlan County Reservoir and Sutherland Reservoir, in south-central Nebraska, are good places to look for eagles, as is Lake McConaughy near the Panhandle and larger eastern reservoirs, such as Lewis and Clark Lake, Branched Oak Lake, and Cunningham Lake. DeSoto National Wildlife Refuge often has good numbers of bald eagles in February, and its visitor center allows for easy and comfortable eagle watching, as does the J-2 hydropower plant near Lexington (Johnsgard, 2012d). Wintering trumpeter swans gather on ice-free Sandhills rivers and wetlands, and on some eastern lakes such as Carter Lake in Omaha (Johnsgard, 2013f, 2016e).

\section{March}

March is perhaps the most exciting month of the year for Nebraska's birders. By the first week or two of March hundreds of thousands if not millions of geese (snow, Ross's, Canada, cackling, and greater white-fronted) will have arrived in the eastern Rainwater Basin of southeastern Nebraska (centering on Clay County) and on other basins farther west, such as Funk Lagoon Waterfowl Production Area in Phelps County. Unbelievable hordes of geese, as well as early duck migrants such as northern pintails and mallards, crowd these marshes and the skies above, performing dizzying courtship flights and endless feeding flights to nearby fields for foraging. These great flocks of waterfowl usually will have peaked before the middle of March (Johnsgard, 2009c).

During March the sandhill crane count builds up to a peak of about a half million birds in the central Platte Valley by late March. They spend the daylight hours feeding in cornfields and wet meadows, and roost in shallow water around sandbars and islands in the wider portions of the river. Flights to and from their roosts occur at about sunset and sunrise, although cloudy skies may cause earlier evening flights and later morning departures, just as clear skies and a full moon may allow the birds to remain in fields for a longer period (Brown \& Johnsgard, 2013; Johnsgard \& Gil, 2011).

The weekend nearest the March equinox is the target date for the Audubon Society's annual Crane Festival at Kearney, which draws birders from around the country and the world. Finding space in one of the several crane-observing blinds at Rowe Sanctuary or the Crane Trust is difficult then, but crane viewing from the road or from free viewing platforms near Alda, Gibbon, and a hikebike bridge near Fort Kearny are all options (Johnsgard, 2015b). All of these experiences are memorable, but watching thousands of cranes land 
near a blind at an evening roost, or seeing them depart at sunrise, provides a thrill unmatched anywhere in the world.

As March draws toward a close, the second wave of duck migrants arrive, including the American wigeon, gadwall, wood duck, greenwinged teal, redhead, canvasback, ring-necked duck, bufflehead, and hooded merganser. The final wave, with the blue-winged teal, northern shoveler, ruddy duck, and (in western Nebraska) cinnamon teal, complete the usual roster (Johnsgard, 2016d, 2017a, 2017c). Other water birds also arrive in March, including American coot; pied-billed, eared, and western grebes; plus American white pelicans and double-crested cormorants (Johnsgard, 2013e).

During March the resident redtailed hawk population is supplemented by migrant red-tails, while the rough-legged hawks begin to head north and northern harriers (males first) begin to appear in the state. This is a good time to watch male harriers perform their circular territorial display flights (from which their generic name Circus derives) and to start looking for nest-building behavior in redtails. Ospreys begin to funnel through the state in locations where bald eagles have been prevalent, and prairie grouse (sharp-tailed grouse and greater prairie-chickens) begin to assemble at their traditional display grounds, or leks (Johnsgard, 2011b).

\section{April}

The first half of April marks the mass departure of sandhill cranes from the
Platte Valley, the arrival of whooping cranes, and the peak of mating activities by the prairie grouse. Seeing the great flocks of sandhill cranes rise up from the river one clear morning, circling while calling excitedly, gradually gaining altitude, and finally disappearing from view even though their great trumpeting voices still drift down like a vast but unseen angelic chorus, is an experience of a lifetime.

Whooping cranes drift into the state in small family groups or flocks of up to about ten in size, stopping in the Platte Valley or in other wetland areas such as rivers in the Nebraska Sandhills or the Niobrara Valley. Rarely they may feed in the company of sandhill cranes, or roost among them at night (Johnsgard \& Gil, 2011).

The second week of April (often the third week in northern $\mathrm{Ne}$ braska) is the best period for seeing prairie grouse display, for during this rather short time the majority of females visit the leks for mating. This sets off a frenzy of display activity and fighting among the males, to determine which will gain the opportunity to fertilize the suddenly available females. Somehow the females can determine the identity of the most virile and dominant male of each lek and seek out this individual for their mating. Their leks are usually in areas of native grassland that are well away from tall trees and often on shortgrass-covered hilltops. Public-access blinds are available at locations such as the Bessey and McKelvie divisions of the Nebraska National Forest, Crescent Lake, and the Valentine and Fort Niobrara national wildlife refuges, and they provide excellent sites for 
watching these activities (Johnsgard, 2010a, 2012a).

Flocks of up to nearly a thousand migrating American white pelicans and double-crested cormorants rest on large lakes such as the Harlan County and Calamus reservoirs in late April and early May, as they approach breeding grounds in the Dakotas, and hundreds of bald eagles sometimes gather briefly to feed on winter-killed fish at these same locations. The second half of April usually coincides with the peak of shorebird migration in Nebraska (Jorgensen, 2004; Johnsgard, 2011e) as well as the arrival of the first insectivorous songbirds, such as the swallows, vireos, and warblers. This is an exciting period, as waves of plovers and sandpipers begin to arrive at wetlands such as the Rainwater Basin, and the skies overhead become clotted with many thousands of migrating Franklin's gulls and swallows of several species. The blooming wild plums begin to reverberate with the songs of house wrens, rosebreasted grosbeaks, brown thrashers, and other early-arriving insectivores such as yellow-rumped warblers and eastern phoebes.

\section{May}

May is simply magical in Nebraska. During the first two weeks of this month the peak of songbird and shorebird migration occurs, with gorgeously plumaged warblers and plainer sparrows of infinite variety frustrating the observer by quickly scurrying about among tree canopies or skulking in the grass. Often one beautiful species will be present in a woodland or prairie on one day, only to be replaced on the next day with another that is new and equally interesting. Butterflies such as mourning cloaks and early spring flowers such as yellow violets begin to appear, and persons tending their bluebird nest boxes can expect to peer in one day and see the female huddled down on a brood of squirming youngsters. Broods of Canada geese start to materialize on farm ponds and in city park lagoons, and in city backyards house wrens are simultaneously singing and feeding new broods.

Mid-May marks the International Migratory Bird Day and the time of the annual Audubon Birdathon in Nebraska. Then participating birders may compete to try to produce the largest single-day bird list possible, with donors providing challenges for donating money to the local Audubon chapters. These funds aid prairie preservation and the purchase of instructional materials dealing with nature for distribution to grade schools.

\section{June}

June is the perfect time to be in the field in Nebraska. The long days allow for after-work birding, and this too is the month when North American Breeding Bird Surveys (https:// www.pwrc.usgs.gov/bbs/) need to be carried out. People monitoring bluebird trails are also busy; first or even second broods of bluebirds and tree swallows are likely to be appearing, and boxes need to be patrolled to try to prevent depredations by raccoons or invading house wrens or house sparrows. 
By the first of June the tardiest of the spring migrants, the common nighthawk and the black-billed and yellow-billed cuckoos, will have arrived in Nebraska, and the last Arctic-breeding shorebirds should have departed. (By the end of June the appearance of any Arctic shorebirds in the state may represent early fall migrants, mostly those individuals that were unsuccessful breeders and are already heading back south.)

Summer evenings in eastern Nebraska are enriched by the distinctive territorial calls of nighthawks, chuckwill-widows, and whip-poor-wills, while in western Nebraska poor-wills are more likely to be heard. Yellowbilled and black-billed cuckoos (often called "rain crows" in Nebraska) may call from their hidden locations as evening twilight or afternoon thunderstorms approach. Generally, however, singing by birds diminishes in June as the birds become preoccupied with nesting, and only such multiple-nesting species as house wrens, or those males that lost their initial mates and must quickly acquire new ones, are likely to be singing at full strength.

\section{July}

July is too hot for most outside activities in Nebraska, and birding is best confined to early morning walks, when a few die-hard songsters such as house finches may still be active. Second broods of many species will now be appearing, and early fall migrants such as long-billed curlews and cliff swallows will be gathering for migration. It is amazing that the young of birds such as these can be ready to under- take flights of up to several thousand miles, only a few weeks after hatching in the case of swallows and some shorebirds. Some multiple-brooding birds such as mourning doves and barn swallows will still be industriously fledging early broods and starting new ones soon thereafter, the doves producing four or perhaps even five broods in a single season before running out of time, and the swallows typically raising two. Often there is an influx of marsh wrens and sedge wrens that seemingly arrived from farther north and quickly set about a possible second nesting. On the other hand, trumpeter swan cygnets being reared in Sandhills marshes will be only about half-grown by July. The approximate one-hundredday fledging period will require much of the summer before the cygnets are able to take their first flights in September (Johnsgard, 2013f, 2016e).

By early July the brown-headed cowbird females, which may have already laid forty or more eggs in the nests of unlucky hosts, will finally have become too exhausted for further laying. Thus, late-nesting songbirds may avoid the fate of having to raise a cowbird chick with their own young, which often results in the starvation of the host's chicks because of the cowbird's gluttonous appetite and persistent begging (Johnsgard, 2012b).

\section{August}

With the arrival of August the first sense that summer is almost over begins to take hold; the cooler mornings and the gathering flocks of swallows along telephone lines provides 
an early warning that the good times are nearly over. This is a period when many Arctic-nesting shorebirds are sprinkled across wetlands that have muddy and sandy shorelines, and a chance for the birder to test his or her skills at identifying the maddeningly similar immature and fall-plumaged "peep" sandpipers, or the equally frustrating fall warblers. August is a perfect time for 10-power binoculars or spotting scopes and tripods, with their magnifications set at maximum power, and all available field guides close at hand.

\section{September}

The blue skies of September bring not only occasional cumulus clouds to Nebraska but also clouds of early fall migrant "blackbirds" (red-winged blackbirds, grackles, cowbirds, and starlings). As tree foliage begins to turn color the first frosts send insecteaters such as warblers and vireos scurrying southward, and set the stage for the great migrations of the larger birds. Migratory hawk species, such as Swainson's hawks, some nonresidential red-tailed hawks, and Mississippi kites and turkey vultures begin to assemble and ghost southwardly. A keen observer may scan the sky with binoculars for skeins of geese or ducks, or perhaps may train a spotting scope on the face of a full moon some evening, and see fleeting silhouettes of distant birds crossing in front of it.

This is a good time to wander aimlessly through the prairies or woods; mosquitoes and chiggers are less of a problem, and the dying leaves begin to allow a better look into the up- per levels of the forest canopy, where flocks of blackbirds and grackles are gathering prior to their migration southward. The tall-grass prairies of late September are aglow with their last fall flowers, such as New England asters and downy gentians, and are spray-painted with the rusty and bronze tints of bluestem and Indiangrass, in which occasional migrating LeConte's sparrows effectively blend (Johnsgard, 2001b). Escaping into the country also permits birders to avoid the hordes of football fans that are attracted to stadiums like ants to honey, mostly wholly unaware that the greatest visual spectacle on earth is passing by overhead.

\section{October}

October is the most colorful month of the year in Nebraska; the peak of fall color occurs about the middle of the month, and many wonderful birds are moving through the state's woodlands at the same time. Not long ago, the peak of the Arctic goose migration occurred in October, as several million snow geese would funnel down the Missouri Valley, and Canada and greater white-fronted geese would appear in the central and western parts of the state. Recently, however, the fall migrations of these geese have peaked later, often during the second half of November, as a reflection of global warming trends (Johnsgard, 2009b, 2010c, 2016b).

Nevertheless, October brings with it a major movement of larger migrants, from hawks to the early duck migrants, such as the blue-winged teal and northern shoveler, and many of 
the more tardy shorebirds. Sandhill cranes begin to appear in marshes of the Nebraska Sandhills. Few of them use the Platte Valley, since intensive waterfowl hunting activities there make the area unsafe for cranes, herons, cormorants, or any other birds bearing even a distant similarity to waterfowl. Ironically, some important first records of rare birds in Nebraska have come from their having been shot by ill-informed hunters who had mistaken them for legal game. Perhaps the first whooping crane to ever lay eggs in captivity was a female that had been shot and wounded by a Nebraska hunter but was rescued and eventually placed in a zoo.

\section{November}

During November the good birding season comes almost to a close; a few northern shrikes and rough-legged hawks are now arriving, and migratory sparrows such as American tree sparrows and Harris's sparrows start to materialize in shrubbery and thickets. Bald eagles, especially immatures, invade the state in good numbers, tagging along with the flocks of ducks and geese, occasionally snagging a sick or wounded individual. On clear and calm evenings great flocks of geese can be heard overhead, bound for unknown destinations using clues that we can only imagine. Even larger numbers of songbirds are migrating by celestial information also beyond our understanding.

Owls begin to announce their breeding territories now. Hardy birders will find that this is a good time for playing recordings of var- ious owls after dark, then listening for responses. Barred owls respond especially well, often flying into a tree directly above the sound device (Johnsgard, 2012f).

\section{December}

December is in many ways the cruelest month for birders; the days are so short that there is little time after work to go afield, and few birds to see when one does so. Yet it is a month for planning and participating in a Christmas Bird Count with friends (Johnsgard, 1998b), feeding backyard birds (Johnsgard, 2013d), and perhaps making out a Christmas list of bird-related gifts to present to friends and family. It is also a time to repair and replenish feeding platforms and other bird feeders, and to hope to eventually find a way to exclude squirrels from foods intended only for birds.

December is also the time to make out summaries of earlier bird lists, at least for people who keep such lists, and a time to start planning birdwatching trips for the following year. It is also not a bad time to consider a trip to Florida, southern Texas, or even the tropics of Costa Rica for a chance to get a flavor of how rich the bird life can be in places such as these. It is a time to look back on all the wonderful experiences of the previous year, such as that stunning scarlet tanager singing in the treetops, the spine-tingling sounds of sandhill cranes approaching their roosts, or a ruby-throated hummingbird that danced momentarily in the sunlight like a tiny sprite before it disappeared in the twinkling of an eye (Johnsgard, 2012c). 
In recent decades bird-watching has become one of the major recreational activities engaged in by Americans, with more than 60 million persons now participating in this combination of intellectual activity, exercise, sport, and, in its most academic form, ornithological science. Its attractions include that it can be equally enjoyed by absolute novices or lifelong devotees, it can be practiced by people ranging in age from a few years to elder citizens, and it requires very little in terms of special equipment, the minimum being attentively using one's eyes and ears. Finally, birding is an activity of inexhaustible interest, given that there are more than ten thousand species of living birds in the world, and nobody could ever live long enough to learn about or even observe more than a small portion of them.

Many bird-watchers are determined to see as many species as possible and develop "life lists" that may be subdivided into state lists, yearly lists, or other categories. Such persons tend to call themselves "birders," and for them "birding" often has a competitive aspect, in which a maximum number of species that can be detected (seen or heard) and identified in a single day or year has a particular attraction.
Others are content simply to enjoy the birds attracted to nest boxes, feeders, or water sources set up in their backyards, thus reveling in the fascinating behaviors, diverse plumages, nesting activities, or other facets of bird life that may be visible from their patio deck or through their windows (Johnsgard, 2013d). Still others become avid bird-banders, engaging in a kind of avian lottery, trying to recapture birds already banded by themselves or others. By banding and releasing birds they hope that, like placing a message in a bottle, somebody in the future may find the bird's carcass or perhaps recapture it, and by reporting it provide evidence of the bird's movements and longevity following its banding.

Finally, there are the professional ornithologists who, like other zoologists, might be interested in anatomy, genetics, physiology, classification, ecology, behavior, or any of the other branches of biological science, and tend to be educators or museum scientists. There are only a few thousand such persons, and perhaps a few hundred additional bird-related professionals who lead bird-watching tours all over the world. Still others may write about or photograph birds for a living, or perhaps draw, paint, sculpt, carve, or otherwise depict birds in some art-related field. 


\section{Optical Equipment and Acoustic Aids}

Depending on one's area of interest, different kinds of equipment and resource materials may be needed. The most popular type of bird appreciation, field observation and identification, requires only a minimum of equipment. Probably the most important of these are a pair of binoculars and an identification reference, or field guide.

All binoculars are identified by their magnification power and the diameter of their front ("objective") lenses; thus a pair of $8 \times 40$ binoculars have 8 -power magnification and a front-lens diameter of $40 \mathrm{~mm}$. Doubling the diameter of the objective lens quadruples the light transmission of the lens but also increases its weight; the magnification of the binoculars does not influence their weight. Generally, to ensure adequate light-gathering power under dimlight conditions, the objective lens should be at least five times greater than the magnification. This ratio (which would be 5.0 in $8 \times 40$ binoculars) is called the "exit pupil" index because it is a measure of the diameter of the circle of light exiting the rear of the binocular and thus entering one's pupil. "Relative brightness" is calculated as the square of the exit pupil index. However, this index (the larger the better for maximum brightness under dim conditions) provides only a general guide to actual image brightness, and unless a person is using the glasses in dark forests, it is not a major consideration in choosing binoculars.
Often of greater interest than the exit pupil index is the binoculars' angle of view, or maximum visual field, which is usually indicated in degrees. Binoculars typically have fields of view ranging from 5 degrees ( 26 feet at 100 yards) to 8.5 degrees (45 feet at 100 yards). "Wide-angle" binoculars (with fields generally of 7 degrees or more) are generally better choices but often are heavier than standard binoculars because of their larger prisms. Wideangle binoculars sometimes also have increased distortion at the edges of the field of view. Minimum focus distance is an important consideration if you wish to also examine objects closer than about 7 to 8 feet away; a few models focus to about 5 feet and can be used on flowers and insects.

Choosing a suitable pair of binoculars requires special care, not only because a substantial outlay of money is involved but also the choice made plays a large role in determining how effectively a person will be able to locate and identify birds. They may be moving rapidly, mostly hidden by foliage, or so far away that considerable magnification is needed to observe their critical identification features.

The subject of binocular choice is thus a complex topic, dictated in part by one's budget and in part by the kind of primary bird-watching that is contemplated (for example, in forests, along lakes, or under dim-light conditions). The price of binoculars ranges from less than $\$ 50$ to $\$ 2,500$. Several friends have pairs costing more than $\$ 1,000$, and at times I envy them, but 
generally a suitable pair can be found for much less. My binoculars include a Vortex Viper, purchased several years ago for less than $\$ 200$ (now over \$400), that has been ranked by birders almost as highly as others costing two or three times that amount, and this is my most-used pair. Birder magazines, such as Birder's World, often rank binoculars for usability and relative birding value. Many rankings of binoculars can be found on internet sites such as allbinos.com, outdoorgearlab.com, and audubon.org/ gear/binocular-guide. Some top-rated models in descending price categories include the Zeiss Victory, Leica Trinovid, Nikon Monarch, and Vortex Viper.

When handling a pair of binoculars, a prospective buyer should test for double images (produced when the paired optics are out of perfect alignment), colored fringes around the surfaces of objects visible at the edges of the field (a sign of chromatic aberration), apparent curvature of straightline objects such as rooftops or utility poles (a sign of optical defects), and distortion, fuzziness, or light flare at the edge of the field when looking at a bright point of light such as a star. The ease of turning the focusing wheel (especially in cold weather) may be important, and the adjustment hinge for maintaining proper interpupillary distance (to correspond with the width of one's eye spacing) should not be too loose. A comfortable grip and weight are also considerations, and the neck strap should be sturdy and comfortable as well. Better quality binoculars have antireflection coatings on all internal surfaces, are water resistant, and may be internally "purged" with gases that prevent fogging in wet or humid weather.

For eyeglass wearers, the eye-relief distance (the distance between the binoculars' rear lens and the farthest point behind the lens at which the binoculars' entire field is visible) is more important than the binoculars' actual field of view. An eye relief of about $20 \mathrm{~mm}$ is needed for the eyeglass user to see the entire optical field and avoid tunnel-vision (vignetting) effects. This eye-relief measure is rarely indicated in the binocular's specifications, but possible vignetting effects should always be personally checked by prospective buyers who wear eyeglasses. Long eye-relief binoculars are usually limited to lowerpower models and generally lack wide-angle capabilities, so there is a trade-off in making such selections.

My own preferences are either 8-power or 10-power binoculars. The higher-power glasses tend to be heavier, have a reduced field of view, and are harder to hold steady, but they are excellent for viewing distant objects. Seven-power binoculars with a large exit-pupil ratio (of at least 6.0) may be favored by people who usually bird-watch in dense forests and require maximum light transmission capabilities. Armored binoculars (with a rubber coating) are more resistant to water and physical shocks, and may be easier to hold, but are about 2 ounces heavier than nonarmored models.

Binoculars with roof prisms are straight-tube in shape; those with a regular prism design ("porro-prisms") are usually wider at the front than in back. Occasionally, very small glasses 
are wider at the rear than in front. Roof-prism models are always more expensive and often have narrower fields of view than porro-prism models. Yet, they average somewhat lighter and are less likely to go out of alignment, a condition that results in a double-image visual effect that will produce eyestrain.

Don't confuse cheap straight-tube opera glasses with binoculars-they lack prisms and have a maximum magnification of only 2- to 3-power. Also avoid zoom binoculars with variable power; they are always heavy and tend to have terrible optics. Likewise, avoid binoculars with tilt-lever focusing; they usually don't focus very closely, and, being generally cheap, tend to be loosely and poorly constructed. Similarly, avoid "universal focus" or "focus-free" optics that are prefocused for moderate distance; it is impossible to adjust the focus for close or extremely distant objects. Other binocular types to be avoided are those with individual focus (as opposed to central focus), and those that are either too small or too large to be easily hand held and focused.

Image-stabilized binoculars might help users with unsteady hands, but these are more expensive and heavier than nonstabilized types. Birders should buy binoculars that focus at least as close as about 10 feet or so; some models now focus down to about 5 feet, which are perfect for insect viewing. Persons with small hands or children may find small glasses more comfortable than those of a standard size. Porter and Porter (2018) provided a useful review of pocket-sized binoculars, which are convenient to carry in a car's glove compartment for occasional or emergency use.

Many "hard-core" bird-watchers own at least two pairs of binoculars with different designs and powers, and some also invest in spotting scopes rather than very highpower binoculars. Scopes are usually 20-power to 30-power with front lens diameters of at least $70 \mathrm{~mm}$. When used with a sturdy tripod, they are wonderful for identification of birds at great distances. However, they are quite expensive; the better models usually cost $\$ 500$ to $\$ 1,000$ or more, and weigh several pounds. Zoom optics on the best of these scopes can be excellent, but there is a reduction in light transmission at the higher magnifications. Various models of Kowa scopes (TSN-2, TSN-4) with long eyerelief eyepieces are especially favored by birders but are fairly expensive. Celestron calls theirs "long view" eyepieces and Kowa's are called "LER" (long eye-relief) eyepieces. A solid tripod, such as the 8-pound Bogen 3021 or the lighter Davis \& Sandford RTS, is essential for use with spotting scopes.

Based on my experience, B\&H Photo of New York (80o-6o6-6969 or 212-444-6615; https://www.bhphotovideo.com/) is one of the most trustworthy New York discount houses, but considerable care should be exercised when dealing with any of these outlets, a few of which are notorious for their bait-and-switch tactics. Although I have not personally used it, the National Camera Exchange (930o Olson Memorial Highway, Golden Valley, MN 55427, 800-624-8107) sells a wide variety of both new and used photographic equipment. 
Besides optical equipment, many bird-watchers use digital recorders or apps for the cell phone or portable electronic device. Prerecorded tapes are extremely useful for learning bird songs and other vocalizations and may also be valuable tools for playback in the field to stimulate responses from species that are normally difficult to see, such as rails or owls. Indeed, for such birds playback of vocalizations may be the only practical means of detecting the species' presence in an area.

Many recorded "field guides" to bird songs are now commercially available, including both CDs and DVDs. There is also software that provides both vocalizations and illustrations, usually along with individual range maps and other information on each species. One of these is the excellent "Birds of North America" by Thayer Birding Software (now available for Windows and Mac computers) that not only provides more than 1,500 bird songs but also has 6,505 photographs, 552 video quizzes, and 700 self-quiz exercises. There are also side-by-side species comparisons and the entire 70o-page text of The Bird- er's Handbook by Paul Erlich et al. (see next section).

Two audio CDs of the long-familiar Peterson Field Guide series of bird sounds are also available: $A$ Field Guide to Bird Songs: Eastern and Central North America (with 267 species), and A Field Guide to Western Bird Songs: Western North America (with 522 species). A related audio $\mathrm{CD} /$ audiobook guide in the same Peterson Field Guide series is Birding by Ear: Western North America. In it, 92 common species are described for easy learning by grouping them into “intelligible learning groups.” An eastern counterpart, Birding by Ear: Eastern/Central, has 85 species similarly analyzed. There are also the Stokes Field Guide to Bird Songs: Eastern Region and the Stokes Field Guide to Bird Songs: Western Region in audiobook or audio CD form. I have not used any of these. Some birding apps also offer convenient regional checklists for personal record-keeping, or provide national, continental, or even worldwide checklists or distributional information in computerized form. There are obviously many difficult choices available for interested persons. 


\section{Reference Materials}

Besides optical equipment, every person interested in birds needs some references for aid in identifying birds and, depending on level of interest, learning more about them than their names. At minimum, a field guide suitably sized for carrying along in a pocket or pouch is needed. Since the development of the first modern field guide by Roger T. Peterson in the 1930s, a rich diversity of North American field guides have been published that differ greatly in geographic coverage and ease of use.

Birders in Nebraska are faced with the fact that our state lies in the transition zone between North American eastern and western avifaunas, and as a result neither R. T. Peterson's eastern or western field guide is entirely adequate for this region. During 40 years of teaching ornithology, I suggested that beginning students use Birds of North America by Chandler Robbins and others, published by Golden Books. It is relatively inexpensive, easy to use, and covers all regularly occurring North American birds. Its paintings and range maps are adequate and its text is concise.

For more advanced birders, I recommend the National Geographic Society's Field Guide to the Birds of North America. It is larger and considerably more expensive than the Golden Books guide but has 3,500 paintings and 900 range maps covering all 1,023 species likely to be seen north of Mexico. It illustrates a much larger number of plumage variations (ages, races, and plumage "morphs" such as melanis- tic or leucistic variants) and has better maps than the Golden Guide. The 2017 (7th) edition has the currently accepted (if initially confusing) scientific taxonomy that corresponds with this book's sequences of avian orders, families, and species. Beware that the Geographic guide is somewhat daunting for beginning birders and is thus not a good "starter" choice.

One easily used photo-based guide is Kenn Kaufman's Field Guide to Birds of North America, an excellent choice for birding newcomers, as it is small, well organized, and comprehensive. Another popular book, by David Allen Sibley, is The Sibley Guide to Birds, and it is notable for its many painted views of diverse plumages and different viewing angles. It is published by the National Audubon Society and A. A. Knopf. Eastern and western versions are also available; in Nebraska the western guide is slightly more comprehensive. None of these guides have, as of early 2018, adopted the currently accepted taxonomic classification of North American birds. Experienced birders will probably find the older arrangement more familiar and easy to use.

Bird-finding guides to many states are now becoming increasingly popular. More than 400 Nebraska birding sites are posted on the website http://www.nebraskabirdingtrails. com, which I wrote for the Nebraska Partnership for All-Bird Conservation and duplicates much of the information I had previously provided elsewhere (Johnsgard, 2009b). The lo- 
cations on the website include some information that is not in my $\mathrm{A} \mathrm{Ne}$ braska Bird-Finding Guide, and they often have detailed site maps and tourism-related information, such as distances to nearby accommodations.

In 2004 the Nebraska Game and Parks Commission (NGPC) published a special 178-page issue of NEBRASKAland titled Birding Nebraska, which details more than sixty major birding sites in the state and has a fairly complete checklist of the state's birds. The NGPC also annually publishes a free Public Access Atlas with maps showing the locations of hundreds of freeaccess sites in all 93 counties. An online version can be found by visiting http://outdoornebraska.gov/publicaccessatlas/. The NGPC website also provides much useful information for birders, including the Nebraska Bird Library (see www.nebraskabirdlibrary.org) with a photo gallery of Nebraska birds.

Bird enthusiasts in Nebraska mostly have long had a very limited choice of state and regional references to exploit. The 200-plus breeding species occurring in Nebraska was first documented in my 1979 book Birds of the Great Plains: Breeding Species and Their Distribution (University of Nebraska Press). A later (2001) comprehensive review of $\mathrm{Ne}$ braska's birds, Birds of Nebraska: Their Distribution and Temporal Occurrence, by Roger S. Sharpe, W. Ross Silcock, and Joel G. Jorgensen is out of print but a wholly new online version is being updated by Silcock and Jorgenson, as noted in the introduction to part 2. A county-by-county historical summary of the breeding birds of the state can be found in James E. Ducey's Nebraska Birds: Breeding Status and Distribution (see references for complete citations).

Magazines and other periodicals offer a more up-to-date source of information than books, and there are several to choose from. One of the best bird magazines for amateur birders is BirdWatching, a beautifully illustrated monthly magazine published by Birder's World, Inc., 44 E. 8th Street, Suite 410, Holland, MI 494233502. Two other attractive magazines, Birding and Birder's Guide, are published for members by the American Birding Association (ABA), Box 744, Delaware City, DE 19706, 800850-2473. As noted earlier, the ABA also sells a large variety of bird-oriented items online, with member discounts, at http://shop.aba.org/. The bimonthly Bird Watcher's Digest, published in Marietta, Ohio, is produced in a format similar to Reader's Digest and has less space devote to colored illustrations but many interesting articles. Its online shop also sells a large variety of birding-related products at https://redstartbirding.com/.

An attractively illustrated quarterly magazine, The Living Bird, is sent to members of Cornell University's Lab of Ornithology, 159 Sapsucker Woods Road, Ithaca, NY 14850. It is similar to Birder's World in format but often includes updates on the laboratory's various research and bird-monitoring programs, such as Project FeederWatch, Project Tanager, and the NestWatch. The Lab of Ornithology has also placed the still-evolving series of life histories of more than 700 species of North American birds online (Birds 
of North America Online, https://birdsna.org/Species-Account/bna/home), and these are individually accessible at modest costs and for varying lengths of time.

The National Audubon Society publishes results of the annual Christmas Bird Count surveys, which began in 1900 nationally and were first undertaken in Nebraska in about 1910. Lincoln and Omaha have the longest series of counts, and Scottsbluff is not far behind. For 2015-16, counts were conducted in 15 localities, 147 species were identified, and more than 236 , ooo birds were tallied. Six of the counts tallied more than 80 species, with a maximum of 107 species found at Lake McConaughy. The long-running Christmas counts in Nebraska and the Great Plains have provided crucial data for many research studies (e.g., Johnsgard, 2009a, 2015c).

For serious-minded readers there are several organizations and related journals from which to choose. In Nebraska, birders may wish to join the Nebraska Ornithologists' Union (NOU), and receive the quarterly Nebraska Bird Review, which summarizes recent observations on Nebraska bird species and populations. The extensive NOU li- brary is located within the State $\mathrm{Mu}$ seum bird specimen collection in the University of Nebraska-Lincoln's Nebraska Hall (4th floor) and is available to NOU members on request. The NOU also publishes a periodic newsletter and has spring and fall meetings held at various locations around the state. Applications for membership can be found at the NOU website http://noubirds.org/. All the 80-plus volumes of the Nebraska Bird Review, except for the five years prior to the most recent volume, can be accessed through the University of Nebraska-Lincoln DigitalCommons at https://digitalcommons.unl.edu/nebbirdrev/.

There are also several national organizations for professional ornithologists and serious birders, particularly the American Ornithological Society. The AOS publishes The Auk: Ornithological Advances, a technically written quarterly journal containing basic research papers on birds as well as annual changes in the official taxonomy of North American birds. It also publishes The Condor: Ornithological Applications, which is more oriented toward the application of research to the conservation and management of birds. 
The website of the NOU contains a great deal of useful bird information. Click "Birds" in the top menu to find bird checklists for all 93 counties and lists of relevant publications. Rare birds seen in Nebraska should be described and reported to the NOU for documentation in its quarterly journal the Nebraska Bird Review (editor: Janice Paseka, email paseka76@ gmail.com). The NOU also publishes periodic newsletters for its members, and has spring and fall meetings, usually in September and May, at locations favorable for seasonal birding. Membership is \$25.00 yearly. To join, contact the treasurer, Jan Johnson, at janbirder@gmail.com.

NE Birds is a Listserv for reporting recent Nebraska bird sightings and sharing bird information. It is accessible by free subscription by going to the following website: http://groups. yahoo.com/group/NEBirds/. Click the link labeled "Join This Group" and provide the requested information. (You will have to become a Yahoo member before you can join any group. When you fill out the Yahoo membership information uncheck the boxes relating to receiving information from Yahoo if you want to avoid spam from Yahoo advertisers.) Up-todate information on the sightings of unusual birds in Nebraska (and other states or regions) is also available on the internet via the general birding website http://birdingonthe.net/namerica.html.

The international eBird website (https://ebird.org/home) has become a favorite way of inserting personal records into a worldwide permanent database, and it allows a birder to quickly learn where rare birds have been reported (eBird, 2017).

The Patuxent Wildlife Research Center has a valuable "Patuxent Bird Identification InfoCenter" with photos, songs, videos, maps, and life history information on most North American birds at its website https://www. mbr-pwrc.usgs.gov/infocenter/.

A corresponding and equally useful identification guide is available through Cornell University's Lab of Ornithology website, https://www. allaboutbirds.org/. The Laboratory of Ornithology also offers a free application download called Merlin that helps identify unknown species of birds seen, based on a series of questions posed, such as its size, appearance, and where it was seen. Depending on one's answers, Merlin then provides a list of possible species, together with several photos and text describing the species' appearance, behavior and habitat. One may also listen to the prospective species' songs and calls, and Merlin references your identification choice to information in the eBird database as to the species' sightings over the previous three years and within a 30-mile radius of your sighting location. Merlin is designed for iOS and Android smartphones as well as tablets. Directions for downloading it can be found at http://merlin.allaboutbirds.org/. 
In scanning any field guide or other reference on birds, the reader will soon encounter two sets of names. One will be the English vernacular or common name, such as American robin. Such names (often capitalized in bird books and magazines) are the official names given the species by a group such as the American Ornithological Society or the American Birding Association. Such uniform names are needed to avoid confusion, like that caused by having several commonly used names for a single species such as the red-tailed hawk (for example, the eastern red-tailed hawk, western red-tailed hawk, Harlan's hawk, Krider's hawk, Fuertes' red-tail, and even, in rural areas, the inappropriate name "chicken hawk"). Occasionally changes are necessary in vernacular names, such as when what had been considered a single species is "split" into two species (for example, the previously recognized northern oriole being replaced with the Baltimore and Bullock's orioles). Conversely, what had been two or more previously recognized species are "lumped" into a single species (for example, the slatecolored, white-winged, gray-headed, and Oregon juncos being replaced with the currently recognized darkeyed junco). This may cause some confusion, but it is sometimes necessary in order to keep the vernacular names of birds in line with current ornithological research.

Even more confusing to most birdwatchers are the "scientific" or technical names of birds. These Latin or
Latinized names are needed for scientists around the world who speak diverse national languages to be able to communicate effectively. Thus, the European robin is known as the Rotkelchen in Germany and the rougegorge in France but is recognized by scientists as Erithacus rubecula in all countries. Even among Englishspeaking countries potential confusion exists. Thus, the European robin is a quite different species from the American robin (Turdus migratorius), and in Australia the so-called magpies (Gymnorhina) are totally different from the magpies (Pica) of North America. To avoid such confusion and to provide a basis for a universal nomenclature, scientists have given all of the "kinds" of animals and plants names. These names are a combination of a general or "generic" name $($ singular $=$ genus, plural $=$ genera $)$ and a specific name (the species, which is the same in singular and plural). The combination of a generic name and specific name represents a unique two-part or "binomial name," such as Turdus migratorius for the American robin and Erithacus rubecula for the European robin. Of these two components, the generic name comes first and is always capitalized, and the specific name comes second and is never capitalized. Sometimes a third name is added, which designates a recognizable geographic race or subspecies. Like the species, this name is never capitalized and sometimes is exactly the same as the species' name, as in the eastern race of the Ameri- 
can robin, Turdus migratorius migratorius, and its western race, Turdus migratorius propinquus. Such triple names are called trinomials.

There may also be plumage variations that are not given formal recognition in the scientific name, such as genetically variable plumage morphs (commonly also called "phases"). Thus the "blue goose," a genetically controlled morph of the lesser snow goose, is not now recognized as a separate subspecies, although it once was. Occasionally distinctive subspecies or genetically recognizable morphs are given separate but unofficial vernacular designations, such as the greater and lesser races of the snow goose and sandhill cranes, or the variably melanistic (Harlan's) and albinistic (Krider's) morphs of the redtailed hawk.

At "higher" levels of scientific nomenclature representing categories "above" that of the genus, one encounters progressively larger classification categories that usually contain varied numbers of species and genera, such as the subfamily (which consistently ends in the suffix "inae"), the still larger family (which always ends in "idae"), and the even larger order (which generally ends in "iformes"). Although learning scientific names may seem daunting, at least by knowing that all the species within a sin- gle genus are believed by scientists to be close relatives, some understanding of basic bird relationships may be gained. The same applies to genera within a family or families within an order. In rare cases a species may be so unique it is placed in a genus, subfamily, or even a family of its own; these single-species groups are called monotypic.

National and international committees on biological nomenclature make recommendations as to the most appropriate sequence for listing all such categories and naming their component subdivisions. Complete agreement on these matters and their adoption has yet to be reached by the appropriate committees of all the world's ornithological organizations. Nevertheless, the familiar so-called "Wetmore" sequence (after its originator, Alexander Wetmore), beginning with flightless birds and loons, and ending with the sparrows and finchlike birds, has traditionally been used in North America and is still followed by many field guides and species lists. Recent advances in molecular taxonomy have forced major changes in our understanding of evolutionary relationships that are reflected in shifts in the composition and sequences of families, genera, and species that are apparent in the present edition of this book. 
Bird-banding data have proven abundantly that birds often have rather short lives; a five-year-old American robin is unusual, and a ten-year-old is almost unheard of. A few groups of birds, generally larger species that are effectively protected by habitat or law, such as many seabirds, swans, cranes, and some others, may have lifespans that approach those of humans. Yet, accidents, diseases, predators, starvation, and inclement weather all take their toll on wild bird populations, regardless of human efforts to help. In many regions of North America, the brown-headed cowbird, a "brood parasite" that lays its eggs in other species' nests and reduces the breeding success of its unwitting hosts, has had devastating effects on many native songbirds, as it has expanded its range out of its native Great Plains (Johnsgard, 1997). Although adapted to prairie and forest edge habitats, forest fragmentation caused by lumbering, road construction, and similar activities has placed many forest-adapted species at risk to such parasitism.

Grassland-adapted species have declined greater nationally than have any other of the ecological categories recognized by the US Fish and Wildlife Service, with nearly 90\% of the approximately thirty grassland species undergoing population declines. These long-term declining grassland-dependent species include the Henslow's sparrow, grasshopper sparrow, short-eared owl, greater prairiechicken, field sparrow, eastern and western meadowlarks, Brewer's sparrow, chestnut-collared and McCown's longspurs, and lark sparrow (Johnsgard, 2001b).

Of 220 species that probably or certainly currently breed in Nebraska, national Breeding Bird Surveys suggest that 90 of them have shown survey-wide population increases between 1966 and 2015, whereas 130 have exhibited probable population declines. It is notable that among Nebraska's mostly insectivorous passerines, more than twice as many species are declining than are increasing, suggesting that insecticides and other agricultural biocides are taking a heavy toll on Nebraska's bird populations.

Nebraska breeding species showing the highest rates of annual survey-wide decline are the bank swallow (5.33\%), McCown's longspur (4.19\%), pinyon jay (3.69\%), northern bobwhite (3.48\%), mountain plover $(3.41 \%)$, pine siskin $(3.67 \%)$, and Lewis's woodpecker (3.42\%). Although not currently known to be an in-state breeder, the greater sagegrouse also had a $3.41 \%$ annual rate of survey-wide decline. The five currently most common breeding species in Nebraska are the mourning dove, brown-headed cowbird, eastern kingbird, red-winged blackbird, and barn swallow (Mollhoff, 2016); all appear to be declining.

Nebraska breeding species showing the highest rates of current annual survey-wide increase are the Eurasian collared-dove (27.18\%), Canada goose (9.17\%), wild turkey (7.5\%), sandhill 
crane (4.74\%), glossy ibis (4.24\%), hooded merganser (3.89\%), and double-crested cormorant (3.76\%). The surprisingly high rate of increase of the sandhill crane largely reflects range expansion and markedly increased numbers of the greater sandhill cranes, especially its eastern population. Although not a current Nebraska breeder, the American white pelican also had a notable (4.82\%) rate of annual increase, and an expansion of this species into the Nebraska Sandhills from South Dakota's nearby breeding population at LaCreek National Wildlife Refuge would not be surprising.

The first statewide breeding-bird surveys were done in Nebraska during the 1980s (1984-89) and were published in 2001 (Mollhoff, 2001). These surveys involved the study of 443 survey blocks (each three miles square) involving every county. Two decades later, a second survey, covering the field-work years 2006-11 and including 557 survey blocks, was undertaken (Mollhoff, 2016). Note that when comparing total confirmed nestings between the two surveys this approximate $25 \%$ increase in survey sample sizes should be taken into consideration. Additionally, the number of hours of observer time per block increased by an average of 31\% during the second survey, probably significantly increasing the probabilities of species encounters.

The 2016 survey summary includes species accounts of all Nebraska's 204 then-proven currently breeding birds, and an additional 18 probable nesting species. In the first atlas, 191 species accounts of proven breeders were in- cluded, while in the second atlas 225 species accounts were provided.

During the 16 years between the two surveys, seven species were added to the state's list of breeding species (Mississippi kite, snowy plover, Eurasian collared-dove, whitewinged dove, pileated woodpecker, Savannah sparrow, and Henslow's sparrow), and three additional species were established as breeders during the second atlasing surveys (ashthroated flycatcher, sage thrasher, and lesser goldfinch).

The least frequently documented known or presumptive Nebraska breeders appearing in the state's second breeding birds survey were (in ascending sequence of block occurrences): the gray partridge, Clark's grebe, snowy plover, Lewis's woodpecker, prothonotary warbler, common merganser, chestnut-collared longspur, lesser goldfinch, mountain plover, cerulean warbler, common gallinule, and sage thrasher.

The second survey's most frequently reported Nebraska breeders (in descending sequence of block occurrences) were the morning dove, brown-headed cowbird, eastern kingbird, red-winged blackbird, barn swallow, American robin, orchard oriole, common grackle, western meadowlark, killdeer, brown thrasher, red-tailed hawk, and European starling. Compared with the first Nebraska survey of the 1980s, the eastern meadowlark had dropped from being the fourth most-reported species to the ninth, whereas the brown-headed cowbird rose from being the seventh most-reported species to the second. Two species, the 
mourning dove and eastern kingbird, retained their respective first- and third-place positions.

Species that increased most strongly in their relative breeding season presence, as judged by the differing number of counties (out of the 93 total) in which they were encountered between the two surveys included the Eurasian collared-dove (86), Canada goose (57), house finch (57), tree swallow (53), bald eagle (44), Cooper's hawk (43), red-eyed vireo (36), song sparrow (32), cedar waxwing (31), great-tailed grackle (29), vesper sparrow (28), wild turkey (27), sedge wren (24), whitefaced ibis (23), willow flycatcher (23), and blue-gray gnatcatcher (23). Species that decreased most strongly by the reduced number of counties of occurrence in the second of the two surveys included the black-billed cuckoo (35), black-billed magpie (29), eastern screech-owl (19), blackcapped chickadee (15), lark bunting (12), northern pintail (11), and common nighthawk (10).

Comparing the data from the 443 blocks surveyed during both survey periods, and including only those species for which there were at least 100 block occurrences during each of the two periods, the most apparently increasing species, based on percentage increase of total block occurrences in the second of the two survey periods were the turkey vulture (144\%), wild turkey (133\%), chipping sparrow $(131 \%)$, eastern phoebe (84\%), eastern bluebird $(76 \%)$, blue grosbeak $(68 \%)$, red-tailed hawk $(61 \%)$, red-bellied woodpecker (58\%), Bell's vireo $(50 \%)$, horned lark (43\%), northern cardinal (43\%), cliff swallow $(41 \%)$, great crested flycatcher (35\%), lark sparrow (28\%), bobolink (28\%), yellow warbler (26\%), great blue heron $(25 \%)$, American kestrel (24\%), European starling (19\%), wood duck (19\%), field sparrow (19\%), blue-winged teal (19\%), grasshopper sparrow (18\%), dickcissel $(17 \%)$, warbling vireo $(17 \%)$, orchard oriole (16\%), rock pigeon (15\%), gray catbird $(15 \%)$, white-breasted nuthatch (15\%), indigo bunting (14\%), downy woodpecker (14\%), northern flicker (12\%), brown thrasher (10\%), rose-breasted grosbeak (10\%), upland sandpiper (9\%), mallard (8\%), western kingbird (7\%), brown-headed cowbird ( $7 \%$ ), ring-necked pheasant (6\%), house wren (6\%), killdeer (5\%), northern rough-winged swallow (5\%), American robin (4\%), and American goldfinch (4\%).

By the same criteria, the most apparently decreasing species as measured by comparing percentage differences in total block occurrences between the two surveys were lark bunting (35\%), loggerhead shrike (24\%), yellow-billed cuckoo (18\%), belted kingfisher $(13 \%)$, chimney swift ( $8 \%)$, great horned owl $(7 \%)$, house sparrow (6\%), common nighthawk (4\%), western meadowlark $(4 \%)$, northern bobwhite $(3 \%)$, Swainson's hawk (3\%), blue jay (2\%), American crow (2\%), and common yellowthroat ( $2 \%)$.

It should be apparent that because of (1) the $20 \%$ increase in geographic coverage during the second survey, and (2) the $31 \%$ increase in number of hours of observer time per survey block, the estimated population 
changes during the approximate twodecade interval between surveys are exaggerated both by the increased percentage of total blocks surveyed and the increased amount of observer time per block. Thus, these estimates of population changes of any seemingly increasing species should be reduced by about $55 \%$, whereas the estimated population changes of any seemingly decreasing species should be increased by about 55\%. Thus, for example, by these criteria the breeding Nebraska turkey vulture population may have increased about $78 \%$ (rather than $142 \%$ ) during the two decades between the two survey periods, or about $4 \%$ annually, and the black-capped chickadee population may have declined by about $21 \%$ (rather than $39 \%$ ), or about $1 \%$ annually.

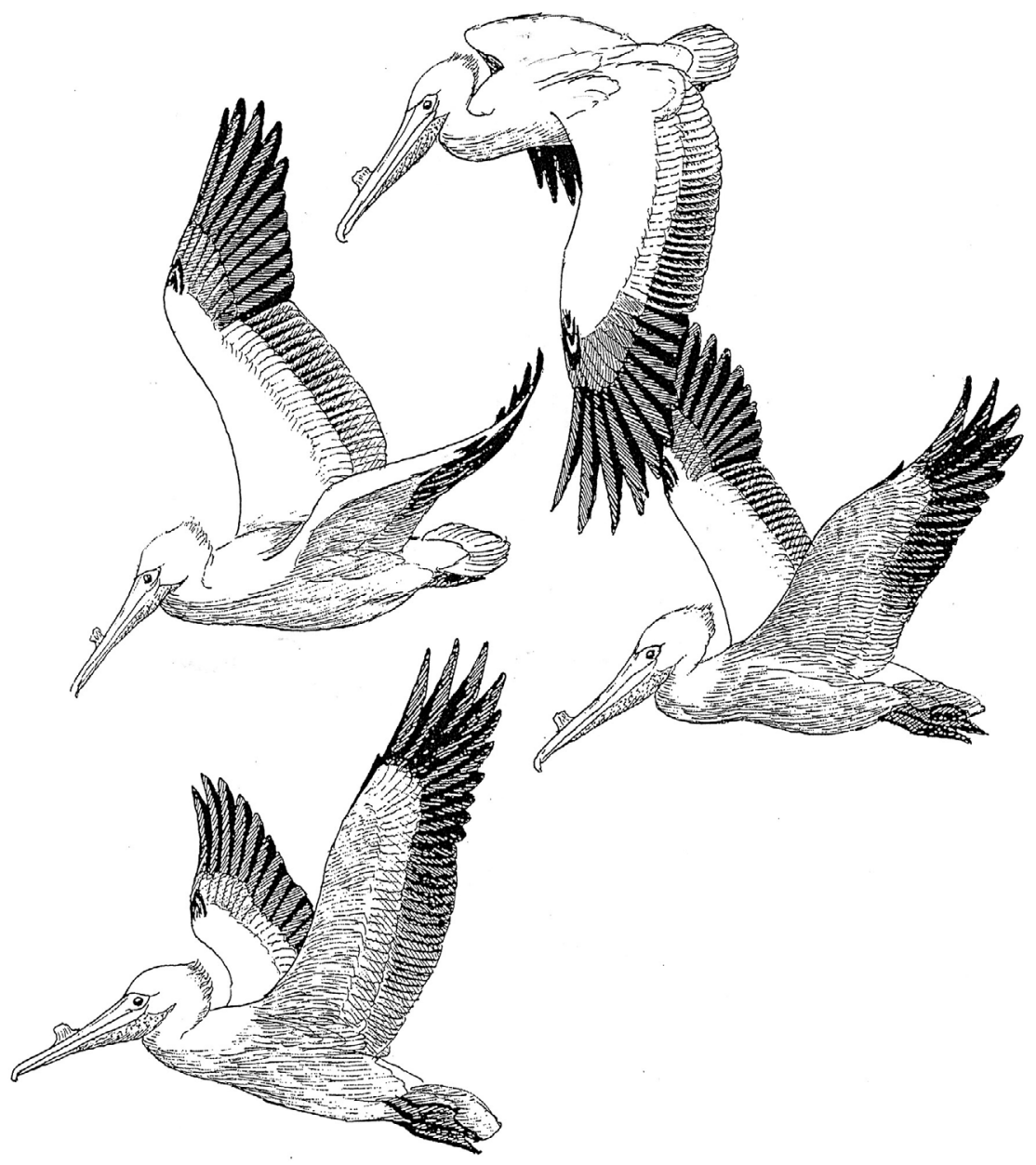




\section{Participating in Nebraska Birding and Citizen Research}

Monitoring populations of legally hunted species is the responsibility of national conservation groups such as the US Fish and Wildlife Service, but little effort is made by such groups to monitor populations of songbirds. Here the amateur birder can actively assist by participating in annual Christmas Bird Counts or Breeding Bird Counts (National Audubon Society), doing North American Breeding Bird Surveys during June (Patuxent Wildlife Research Center, Biological Resources Division, USGS), helping with systematic counts at bird feeders (Project FeederWatch of the Lab of Ornithology), or maintaining longterm records of the bird populations of a specific location.

The Migratory Bird Program of the US Fish and Wildlife Service sponsors the Partners in Flight (https://www. partnersinflight.org/), which concentrates on needs for monitoring and conserving populations of migratory birds; its activities include organizing workshops, educational programs, and bird-related outdoor activities. In conjunction with this program, the Nebraska Game and Parks Commission participates in the International Migratory Bird Day in mid-May. This typically occurs during the same weekend as the Audubon Society's annual Birdathon weekend, which encourages a variety of conservation and bird-awareness activities at the peak of spring migration.

Bird-banding activities go on at various nature centers, such as at Fontenelle Forest in Bellevue, Neale
Woods in Omaha, and Pioneers Park Nature Center in Lincoln. Sometimes volunteers are able to become trained to help remove captured birds from nets or traps for banding. Holding a wild bird and releasing it again is a rare and joyful experience for many people and serves a valuable scientific purpose as well.

Many states have raptor rehabilitation centers that try to heal and release wild hawks and owls that have met with accidents or been shot by thoughtless hunters. In Nebraska, Fontenelle Forest Raptor Recovery is the state headquarters of these important activities (toll-free hotline 866888-7261).

Bird diseases, such as the bacterially carried eye disease that mainly affects the vision of house finches in eastern and central states, and the fowl cholera outbreaks that have periodically occurred during spring among waterfowl in south-central Nebraska, are some of the conspicuous avian mortality factors that can be observed and documented fairly easily. For example, persons observing at birdfeeders have helped to document the spread of eye disease among house finches in midwestern and eastern states. Accidents such as deaths caused by birds flying into windows can be avoided or at least ameliorated by affixing parallel strips of conspicuously colored tape along the inner surface of the window (silhouette cutouts of owls or hawks do little good) or by allowing similar plastic strips to hang down freely from the tops of 
windows. Free-ranging cats kill millions of wild birds every year; declawing pet cats helps to reduce such needless mortality.

Members of the Lincoln (Wachiska) chapter of the National Audubon Society organize birding outings, Birdathons, rare bird alerts, bird-identification classes, prairie preservation and appreciation activities, and with Nebraska Game and Parks Commission personnel plan Christmas Bird Counts (4547 Calvert St., Ste. 10, Lincoln, NE 68506, 402-486-4846, https://www. wachiskaaudubon.org/). In Omaha, similar activities are performed by the Audubon Society of Omaha (PO Box 3542, Omaha, NE 68103, 402-4454138, http://audubon-omaha.org/) and in Kearney by the Big Bend chapter (PO Box 1575, Kearney, NE 68848) helps the Nebraska Audubon staff prepare for Kearney's annual spring Crane Festival. There is also a Wildcat Audubon chapter in Scottsbluff (PO Box 22, Scottsbluff, NE 69363, http:// wildcataudubon.org $/$ ), and a Loess
Hills chapter in Sioux City (PO Box 5133, Sioux City, IA 51102, http://lhas. tripod.com/). Phone numbers or contact people for these regional groups can be obtained from their websites or Audubon Nebraska (PO Box 117, Denton, NE, 402-797-2301, http:// ne.audubon.org/). The Audubon staff at Spring Creek Prairie Audubon Center near Denton also organizes the annual spring Crane Festival in Kearney that is held during late March, usually during the third weekend.

Establishing and patrolling bluebird nest box trails has had a major effect on restoring the eastern bluebird as a breeding species in Nebraska, and has also similarly benefited tree swallows, which readily use bluebird boxes. The state-based organization Bluebirds Across Nebraska is the sponsor of this program throughout the state and is an affiliate of the larger national group the North American Bluebird Society. Contact people can be reached through the Nebraska group's website (http://bbne.org/). 
For birders not interested in traveling far afield to do their bird-watching, many opportunities exist for backyard observations. Feeding wild birds is an increasingly popular pastime and usually allows for close-up viewing of many species, especially during winter. Most feeders accommodate large sunflower seeds (for cardinals and other sparrow-like birds with crushing bills). House sparrows, by the way, can be deterred from using such feeders by attaching free-hanging monofilament lines around their perimeters. There are also feeders designed to hold small seeds, like thistle seed (suitable for goldfinches and other small-billed finches), and others that dispense sugar water for hummingbirds. Few hummingbirds stop in Nebraska except along the Missouri River, but once they start to visit a feeder they are likely to remember its location from season to season.

Several good books on bird feeding exist, such as Birds at Your Feeder by Erica H. Dunn and Diane L. TessagliaHymes (Norton, 1999) and Wild About Birds: The DNR Bird Feeding Guide by Carrol L. Henderson, published in 1995 by the Minnesota Department of Natural Resources. Project FeederWatch of Cornell's Lab of Ornithology (mentioned earlier) provides a way of contributing useful information about backyard birds to a national database.

Just as important as regularly maintained feeders is a clean water source, such as a birdbath or pool. Heated birdbaths, fountains, and pools that provide a source of constantly dripping or flowing water are especially attractive to birds. Moving water provides a seemingly irresistible attraction for many birds, especially during migration periods. Although "drippers" and "misters" (which spray a fine mist on nearby leaves) are commercially available, simple but effective drippers can be easily made by using a one- or two-gallon jug, poking one or two tiny holes in its lid, filling it with water, and hanging it above a birdbath, so the water slowly drips down to the basin below. Different species (such as hummingbirds) seem to be more attracted to misters, but both are very effective as bird attractants.

Nest boxes offer an additional way of attracting birds during the breeding season. These include (especially on acreages) bluebird houses, owl houses, wood duck houses, and other nest sites for hole-nesting birds. Bird houses for passerines should have a door by which they can be opened and cleared out and should be firmly attached to a substrate rather than hanging from a cord. Various books on attracting birds to artificial nest sites, such as How to Attract Birds, published by Ortho Books and often sold in garden supply houses, provide directions. The Wild Bird Habitat Store of Lincoln and Omaha usually have this or similar publications, and also offer a wide array of bird foods and other reference materials.

It is important to know that attracting house wrens to one's property by putting up nest boxes for them will 
likely cause severe nest losses to other small bird species, especially cavity nesters like bluebirds. This problem is a result of the wrens' tendency to take over other birds' nests, often piercing their eggs or even killing the young or adults in th process. Because of this, making an effort to attract house wrens is discouraged, especially if bluebirds, chickadees, tree swallows, and similar cavity-nesting species are desired.

Brush piles of dead branches and twigs are attractive to many small birds because these piles offer protec- tion from the cold and from certain predators, such as accipiter hawks. Likewise dead trees, although they may be an eyesore or potential hazard on a small lot, are favored by cavity nesters, and on large acreages can be very attractive. An excellent habitat-related booklet is Landscaping for Wildlife, published in 1987 by the Minnesota Department of Natural Resources. This department has also published Woodworking for Wildlife: Homes for Birds and Mammals (1992) with many nest box designs and construction diagrams. 


\section{Information Sources on Nebraska Birding and Tourism}

My self-published A Nebraska BirdFinding Guide (Johnsgard, 2005) has nearly fifty county maps and lists more than four hundred public-access birding sites in the state. It is "out of print" but may be downloaded for free at https://digitalcommons.unl. edu/biosciornithology/51/ and now https://digitalcommons.unl.edu/zeabook/5/. Much of the same information on finding birds is also now freely available at Nebraska Birding Trails, http://nebraskabirdingtrails. com/. This is an interactive website, with many individual site maps as well as regional and statewide maps and various searching modes. Other free downloads of probable value to Nebraska birders are:

Birds of the Cedar Point Biological Station Area, Keith and Garden Counties, Nebraska: Seasonal Occurrence and Breeding Data. 1996. C. R. Brown, M. B. Brown, P. A. Johnsgard, J. Kren, and W. C. Scharf. 61 pp. https://digitalcommons.unl.edu/biosciornithology/24/

Birds of the Central Platte River Valley and Adjacent Counties. 2013. M. B. Brown and P. A. Johnsgard. 180 pp. https://digitalcommons. unl.edu/zeabook/15/

A Guide to the Natural History of the Central Platte Valley of Nebraska. 2007. P. A. Johnsgard. 156 pp. https://digitalcommons.unl.edu/ biosciornithology/40/
Birding Nebraska's Central Platte Valley and Rainwater Basin. 2015. P. A. Johnsgard. 54 pp. https://digitalcommons.unl.edu/zeabook/36/

Birds of the Rainwater Basin, Nebraska. 2012. J. G. Jorgensen. Nongame Bird Program, Nebraska Game and Parks Commission. https://digitalcommons.unl.edu/ nebgamestaff/55/

Wetland Birds of the Central Plains: South Dakota, Nebraska and Kansas. 2012. P. A. Johnsgard. 275 pp. https://digitalcommons.unl.edu/ zeabook/8/

Wings over the Great Plains: Bird Migrations in the Central Flyway. 2012. P. A. Johnsgard. 249 pp. https://digitalcommons.unl.edu/ zeabook/13/

Individual county road maps (scale 1 " or $1 / 4$ " per mile), available from the Nebraska Department of Transporation at https://dot.nebraska.gov/ travel/map-library/county/, are also extremely useful when exploring backcountry areas. The Nebraska Atlas and Gazetteer is an atlas of 79 topographic maps of the entire state (scale 1:200,000, or ca. 1/3" per mile) published by DeLorme. This atlas also shows national lands, state parks and recreation areas, campgrounds, wildlife viewing, fishing and hiking areas, and other attractions.

The Nebraska Game and Parks Commission website (http://outdoor- 
nebraska.gov/) has much useful information for birders. The commission's Public Access Atlas includes maps and a list of areas owned or leased by the commission in every Nebraska county and available for public access and recreational use. It can be accessed at http://outdoornebraska.gov/publicaccessatlas/.

The Nebraska Tourism Commission (301 Centennial Mall South, Lincoln, NE 68509-8907, 402-471-3796, https://visitnebraska.com/) can provide free information on general tourist attractions. Tourism information and free state highway maps are also available at most I-80 rest areas. Road information can be obtained by calling 511 or $800-906-9069$ in Nebraska (see http://www.511.nebraska.gov/).

The numerous state recreation areas and state parks typically offer highly developed recreational facilities and modern camping. Annual Nebraska park entry permits or more information can be obtained from the Game and Parks Commission at http://outdoornebraska.gov/parks/ or PO Box 30370, Lincoln, NE 68503 or calling 402-471-0641.

Nebraska's rivers are publicly owned, but the adjoining shorelines are usually in private ownership. Birding from a canoe is possible on several rivers (Niobrara, Dismal, Calamus, Missouri, Platte, Republican), but access points are often limited. The longest stretch of river ideal for canoebased birding is the 76-mile section of the Niobrara designated as a National Scenic River. The Platte is too shallow over much of its length for good canoeing. Some refuge lakes at Valentine
National Wildlife Refuge (NWR) also offer wonderful birding opportunities from a canoe. Those at Crescent Lake NWR are closed to these activities.

Most federally owned birding areas in Nebraska consist of national historic sites, national wildlife refuges, and national monuments. Federally owned areas also include waterfowl production areas (WPAs). State-owned sites include state parks, state recreation areas (SRAs), and wildlife management areas (WMAs). Typically no permit is needed to enter WPAs or WMAs, but annual (or daily) state park entry permits are needed for SRAs, state parks, and state historical parks. One $\mathrm{Ne}$ braska national wildlife refuge (DeSoto NWR) also charges a small daily entry fee, but the others are free. All state wildlife management areas offer free, unrestricted birding or other nature study opportunities. They sometimes provide primitive camping facilities, and most are open to seasonal hunting and fishing.

Nebraska has numbered its 93 counties relative to their historic population size ( $1=$ largest, $93=$ smallest). The preliminary numbers on car licenses correspond to these numbers, except for a few eastern counties (Lancaster, Douglas, and Sarpy), for which random three-letter, threenumber combinations are used. The state's emergency highway help line is $800-525-5555$. Its cellular phone hotline is * 55 . Road reports are available in-state via 800-906-9069. The State Patrol Citizen Band's call letters are KNE 0911. The statewide Nebraska Crime Stoppers number is 800-422-1494. 


\section{Part 2}

\section{The Birds of Nebraska}

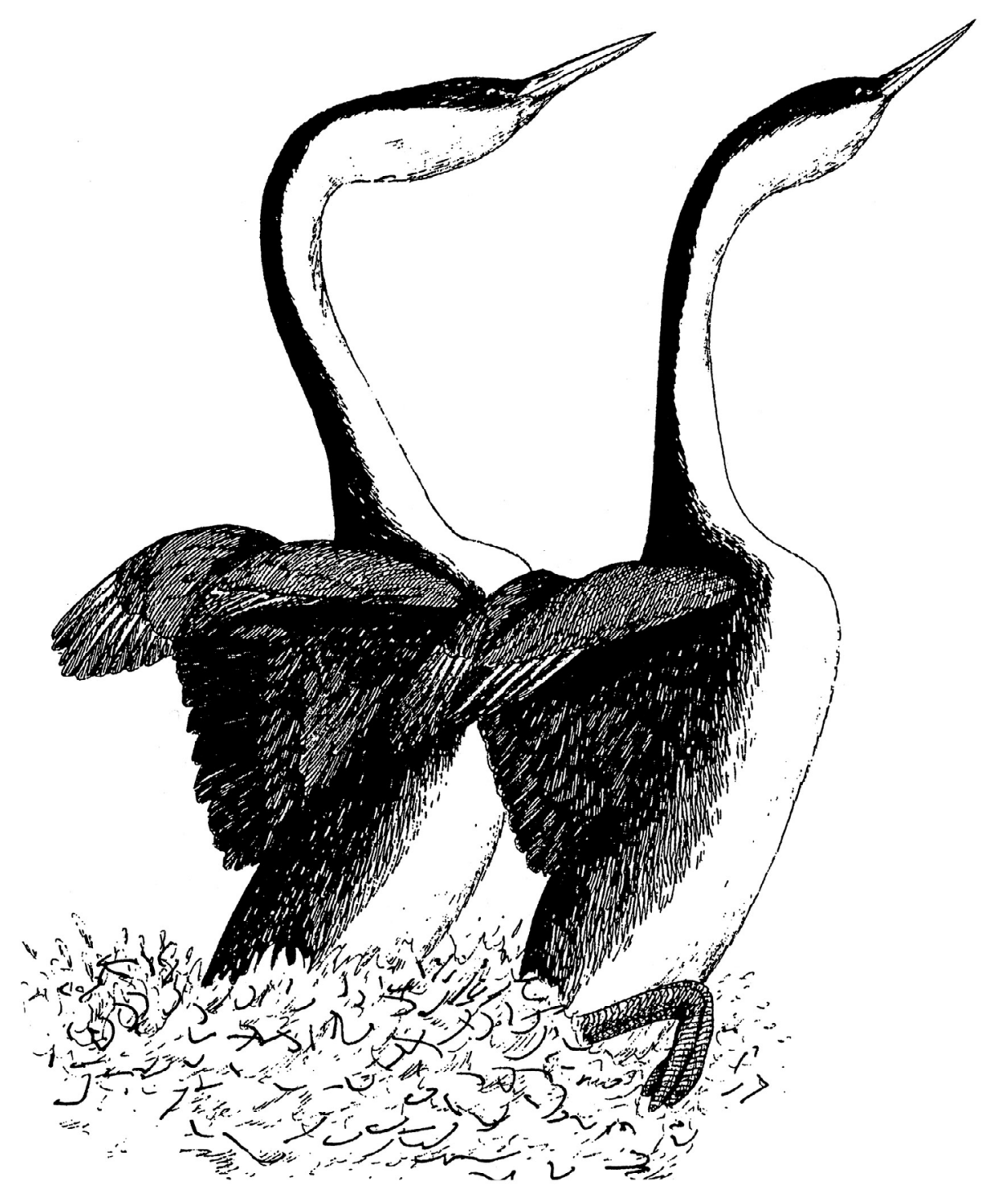




\section{Introduction}

This relatively brief overview of the birds of Nebraska grew out of my research associated with the writing of Birds of the Great Plains: Breeding Species and Their Distribution (Johnsgard, 1979a). Inasmuch as the only previous comprehensive summary of Nebraska's birds, the "Revised Checklist of Nebraska Birds" (Rapp et al., 1958) was then about forty years old, with a total of only 343 species documented for the state, it seemed apparent to me that a completely new list of birds of the state should be prepared. My 1980 summary initially appeared in photocopied format as $A R e$ vised List of the Birds of Nebraska and Adjoining Plains States. That survey of Nebraska's birds was updated every few years between 1980 and 2010, when both digital and print versions were published under its present title as a Zea Book through the University of Nebraska-Lincoln Libraries' DigitalCommons (browse https://digitalcommons.unl.edu/zeabook/).

This present summary of Nebraska's birds is restricted to those species that have been convincingly reported at least once in Nebraska from historic time to the present. It has been modified in this revision to use the most recent classification of the American Ornithological Society (AOS) Checklist of North American Birds (Chesser et al., 2017), and to conform very closely in that regard to the most recent Nebraska Ornithologists' Union's (NOU) "Official List of the Birds of Nebraska” (Brogie, 2009; Nebraska Ornithologists' Union Re- cords Committee, 1987-2016, and periodic updates). I have added one additional species (the Pacific wren) to the 461 Nebraska species recognized by the NOU as of 2017 , based on the seemingly convincing evidence for a single specimen's mensural traits. After this book went into editing (April 2018) the Nebraska Ornithologists' Union added the Anna's hummingbird to its official list of Nebraska species in its periodic updating of taxonomic and status changes among Nebraska birds (Nebraska Bird Review 85:179$197,2018)$, resulting in a revised total state list of 462 species. The Nebraska status of the Pacific wren and the recent merger of Thayer's gull and Iceland gull have been addressed.

The most important contemporary records of Nebraska's birds are published quarterly in the official journal of the NOU, the Nebraska Bird Review. The seasonal reports in the Nebraska Bird Review are by far the most complete and most valuable record of current bird life in Nebraska, and fortunately this journal is now being archived in the University of Nebraska-Lincoln Libraries' DigitalCommons repository (https://digitalcommons.unl.edu/nebbirdrev/).

In 2001, a comprehensive Birds of Nebraska by Roger Sharpe, Ross Silcock, and Joel Jorgensen was published by the University of Nebraska Press, but it is now (2018) nearly two decades out of date as well as being out of print. After this book went into editing, the first phase of an online revised version of The Birds of Nebraska 
(Sharpe, Silcock, \& Jorgensen, 2001) by Ross Silcock and Joel Jorgensen was announced: Birds of Nebraska Online at www.birdsofnebraska.org. It allows for species searches by common or Latin names and provides range maps, color photographs, and detailed status accounts for each species (texts were completed through the dove family Columbidae as of April 2018).

Because of the remarkable proliferation of new records (and birders) since the early 200os, it was impossible for me to cite individually all of the post-200o records that have been published in the Nebraska Bird Review except for those I considered most important. Nor have I included eBird or NEBirds reports, as they receive only slight if any peer review. Instead, I have emphasized recent changes in the population status and distributions of Nebraska's birds as of early 2018, based mostly on the Nebraska Bird Review. I have also excluded from consideration some records of species that most probably resulted from escapes from captivity. These include such exotic species as the Asian mandarin duck (many reports; free-flying individuals are rarely seen among wild wood duck flocks), the Egyptian goose (at least eight reports, perhaps coming from a feral Arkansas population), the Eurasian ruddy shelduck (a few old reports, almost certainly escapes from captivity), and the African collared-dove (a near relative of the invasive Eurasian collared-dove that is commonly bred by aviculturists).

The NOU's official state list of birds (461 species as of 2018) is based on actual specimen evidence or some other convincing basis of each species' proven occurrence in the state. The list includes 337 "regular" species, 29 “casual" species, 90 "accidental" species, and 5 extirpated or extinct species. I have included 462 species in the present list, with the capture and banding of the first example of the Pacific wren in Nebraska. I have also included in this book a number of other records that were not, or have not yet been, accepted by the NOU Records Committee. Recent Breeding Bird Surveys (Mollhoff, 2016) have shown that at least 215 species are breeding in or have bred in Nebraska since 2005, and the actual number might approach 225 species.

The taxonomy of the American Ornithologists' Union (AOU) as used in the AOU Check-list of North American Birds, 7 th edition and later supplements through 2017, is followed here. Major taxonomic changes in 2017 involved the shifting in sequence of many nonpasserine families as a result of accumulating new molecular evidence of basic avian relationships. As well, the AOU merged and was renamed the American Ornithological Society (AOS) in 2017.

I have followed the NOU species list and AOS sequence at of 2017 (Chesser et al., 2017) in this summary, although my terms of relative abundance and status often differ. Many of the state records of relatively rare species occurring since 2000 have not been individually mentioned in this present summary; rarity records through 2000 were summarized by Sharpe, Silcock, \& Jorgensen (2001) and since then have been documented in the state's "Official” Nebraska bird list, as sum- 
marized periodically in the Nebraska Bird Review. Except for the Nebraska counties map, all the drawings and maps in the book are my own.

The majority of Nebraska's bird species are declining, and one of the best lines of evidence on population trends is the annual North American Breeding Bird Surveys (Sauer et al., 2017), which began in 1966. Surveywide trend data from the most recent available summary (1966-2015) are used here. I have also included this information for nearly all the breeding Nebraska species but because of the small sample sizes involved, few if any of these state estimates reach the level of statistical significance. Trends of Nebraska's waterfowl populations are based on annual breeding and midwinter surveys of the US Fish and Wildlife Service and the Canadian Wildlife Service through 2017.

Arrival and departure migration data summarized here in most cases were based on my summary of $\mathrm{Ne}$ braska Bird Review data from the 1930 s to the late 1970 , and thus are now about a half-century old (Johnsgard, 1980a, 1980b). Because of climate change, the median spring arrivals given here should probably be adjusted up to about 10 to 15 days earlier, and the fall median departures up to about 15 to 30 days later, especially for waterbirds and shorebirds, whose movements are more dependent on ice-free water than changing photoperiods and day-to-day temperatures, as is more typical of passerines. The arrival dates for insectivores and flower-adapted birds, such as hummingbirds, have changed substantially less than those of water-dependent species, although departure dates of hummingbirds have seemingly been delayed by human birdfeeding activities.

Major changes in early winter (late December) distributions of about 200 species of Great Plains birds developing over four late twentieth-century decades as a likely result of global climate have been documented earlier (Johnsgard, 2007b, 2015c). Nearly all of those changes have resulted in more northerly December bird distributions, later times of final fall departures (Expected Late Dates, or ELDs), and earlier first spring arrivals (Expected Early Dates, or EEDs), or overwintering.

Nebraska's overwintering bird populations have increased as winters have ameliorated in recent decades, especially among water-dependent species. (Johnsgard, 2006). Until the early 1950 s only one species of waterfowl (mallard) had appeared on Lincoln's Audubon Christmas Bird Count records. By the early 1970 six duck and goose species had been seen, but by the late 1990s eight had been reported (Johnsgard, 1998b), and during the $2017-18$ count, 18 species of waterfowl were noted. During the 53-year period of Lincoln's Christmas Bird Counts up to 1997 an average of only 40 species was seen annually, while during the 2017-18 count an overall total of 80 bird species was reported, a probable result of both climate change and greatly increased birding activities. 
Lying near the center of the Great Plains of North America, Nebraska has a variety of geographic and ecologic influences that affect its bird fauna. Of its approximately 200 breeding species, the largest single component is arboreal, or adapted to living in trees, woodlands, and forests, while limnic (aquatic- and shorelineadapted) species make up the second largest component. Species primarily associated with grasslands compose a still smaller breeding component, and xeric-adapted forms associated with semidesert scrub are the least numerous of Nebraska's birds. Most arboreal species of birds, which compose about $45 \%$ of the state's total species, are eastern or northern in their geographic breeding affinities, while a small percentage are western or southern in origin. Of the limnicadapted forms, which make up about $32 \%$ of the state's total avifauna, many are either northern or widespread (pandemic) in breeding distributional affinities, and a considerable proportion of these are only migrants in the state (Johnsgard, 1987a).

Although natural grasslands made up about $90 \%$ of the native vegetation component in the state (tall-grass prairie about $34 \%$, mixed-grass prairie about $32 \%$, and shortgrass steppe about 35\%, the remaining $9 \%$ being woodlands and other or transitional community types), bird species especially associated with grasslands make up less than $10 \%$ of the state's approximately 350 regularly occurring bird species. The remaining 90\% of Nebraska's bird species are diverse in their ecological breeding requirements, such as being dependent on water, trees, shrubs, or even topography (Johnsgard 2001b, 2008a).

The surface topography of $\mathrm{Ne}$ braska is primarily that of a slightly inclined plane, sloping from west to east at an average gradient of about nine feet per mile. The state's elevations range from more than 5,00o feet in the Panhandle region to about 825 feet in the extreme southeast. Precipitation likewise increases from the northwest to the southeast, from about 15 to 33 inches of total annual precipitation. The two largest river valleys in the state are the Missouri Valley and the Platte Valley, which both tend to be quite broad and fairly shallow, while the Niobrara Valley in the northern part of the state tends to be deeper and narrower, the shorelines often lined with steep bluffs. Bluffs and escarpments are also typical of the Pine Ridge region of the northern Panhandle, the Wildcat Hills in Scotts Bluff and Banner counties, and the upper portions of the North Platte Valley (Fig. 1).

In its original state, probably about $90 \%$ of the land area of Nebraska was covered by native grasslands (Fig. 2). Major grassland components are the tall-grass bluestem prairie of the eastern third of the state, the mixed-grass prairie generally lying to the west of the tall-grass prairies, and the farwestern shortgrass steppe. Of the state's total land area of 77,510 square miles, about 19,000 square miles com- 
prise the Sandhills grasslands, which are generally considered to be part of the mixed-grass prairie. Minor or transitional communities include the sandsage prairie of southwestern Nebraska, the Kansas mixed-grass prairie of the southernmost counties of Nebraska, the shortgrass Dakota prairie of the Pine Ridge region, and the shortgrass steppe of the high plains in western Nebraska. Nebraska's terrestrial plant communities were described by Steinauer and Rolfsmeier (2003) and by Johnsgard (2001a). The state's wetland communities and their associated aquatic-based fauna were described by Johnsgard (2012g). The vascular flora of Nebraska was monographed by Kaul, Sutherland, and Rolfsmeier (2001).

About 30 to 35 species of North American birds are ecologically associated with native North American grasslands and represent a "guild" of species that has declined in population more greatly and consistently than any other group of ecologically definable avians (Johnsgard, 2001b). At least eight species of Nebraska birds have become extirpated or probably extirpated as an apparent result of human activities since settlement times, and many relatively ecologically specialized species have undergone considerable retraction of numbers and ranges, as wetlands have disappeared and natural vegetation has given way to agriculture, urbanization, and other disturbances.

In contrast, many generalist species, such as various "blackbirds" (including starlings and cowbirds) and crows, have benefited from these same changes. Some ecological changes, such as the increasing development of riparian woodlands along the Platte and other river systems crossing the plains have also facilitated east-to-west range expansion in forest-adapted birds. Reservoirs such as Lake McConaughy have attracted many new water-dependent species (especially gulls) to the state in recent years. The appearance of some other non-water-dependent species on the Nebraska list has been influenced by urbanization. Urbanization has favored edge-adapted ("backyard") species, scavengers, and human-adapted species. Thus, increased bird-feeding activities by the general public has resulted in an increase in the number and abundance of hummingbird species. 


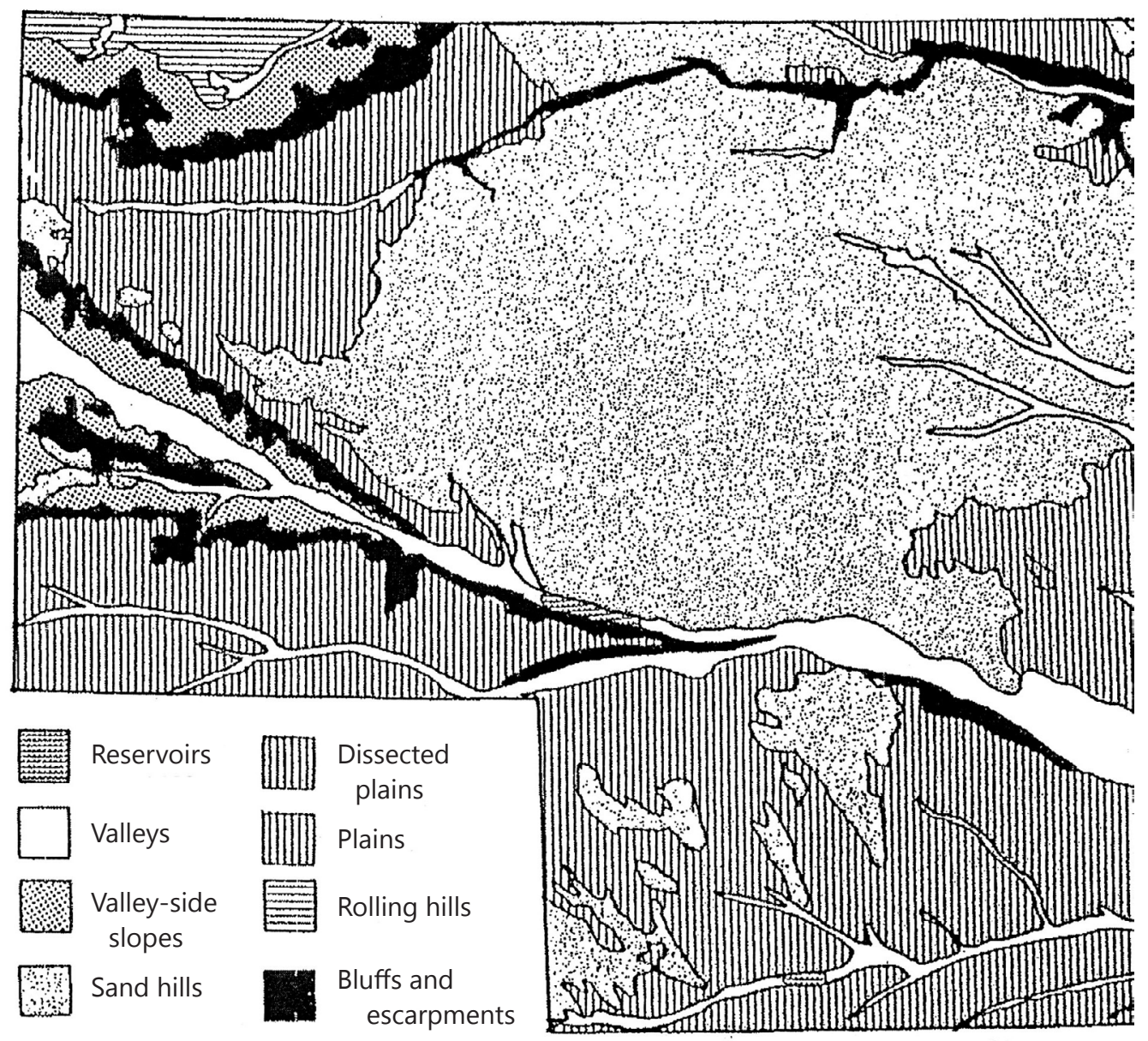

Figure 1. Landforms of Nebraska. After a map by the University of Nebraska Conservation and Survey Division. 


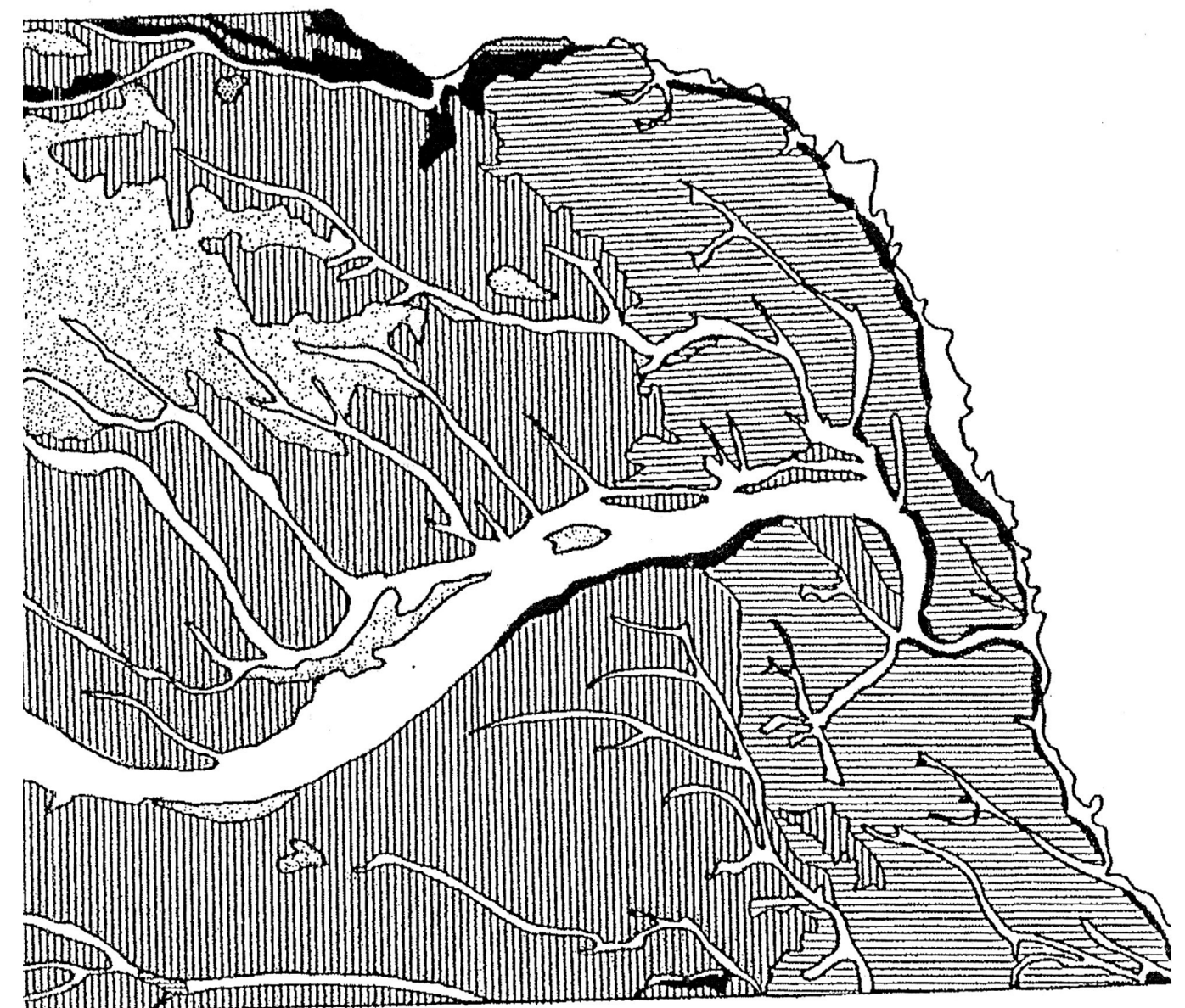




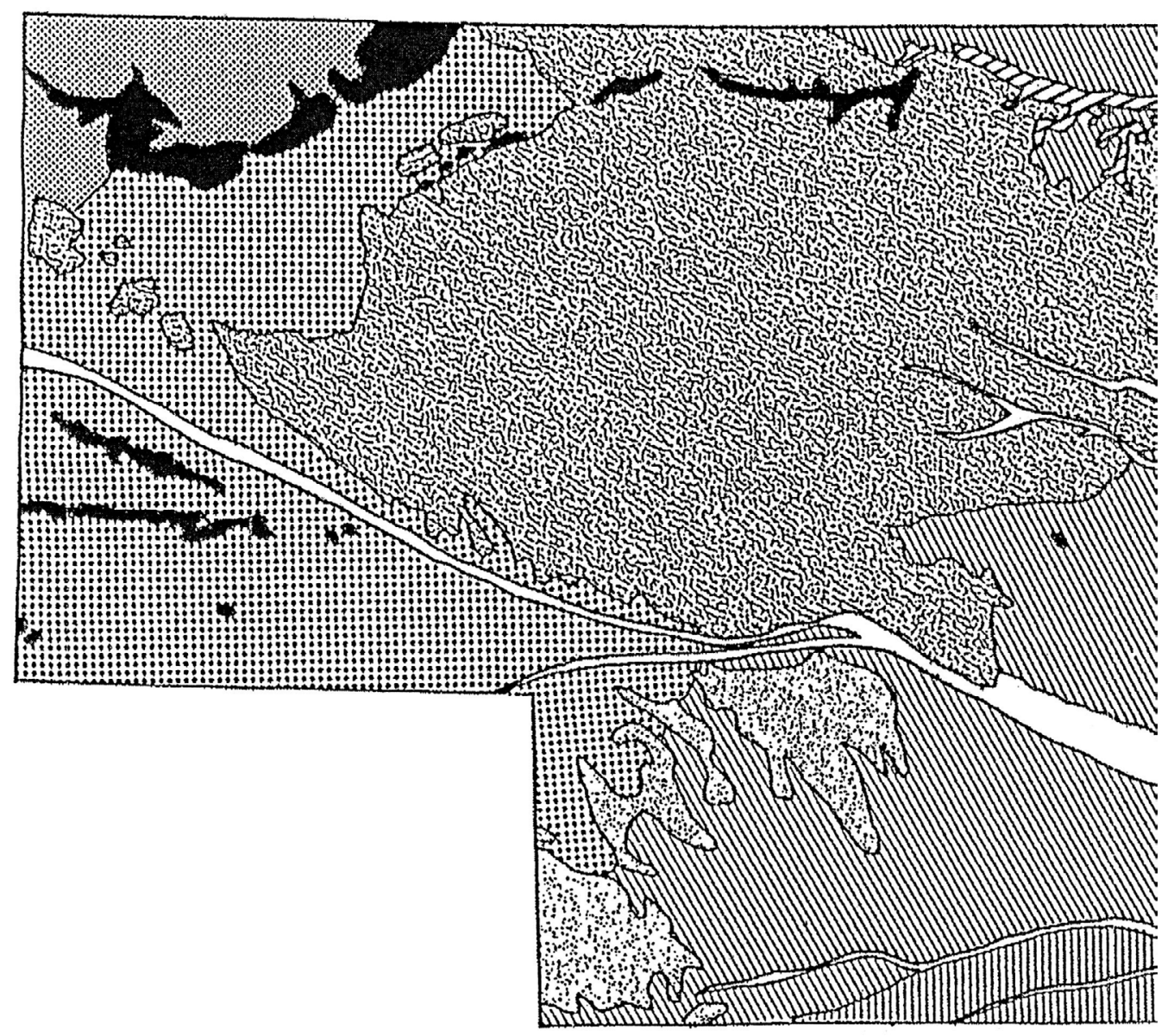

Grass-dominated communities

Mixed prairie
Tallgrass Bluestem prairie




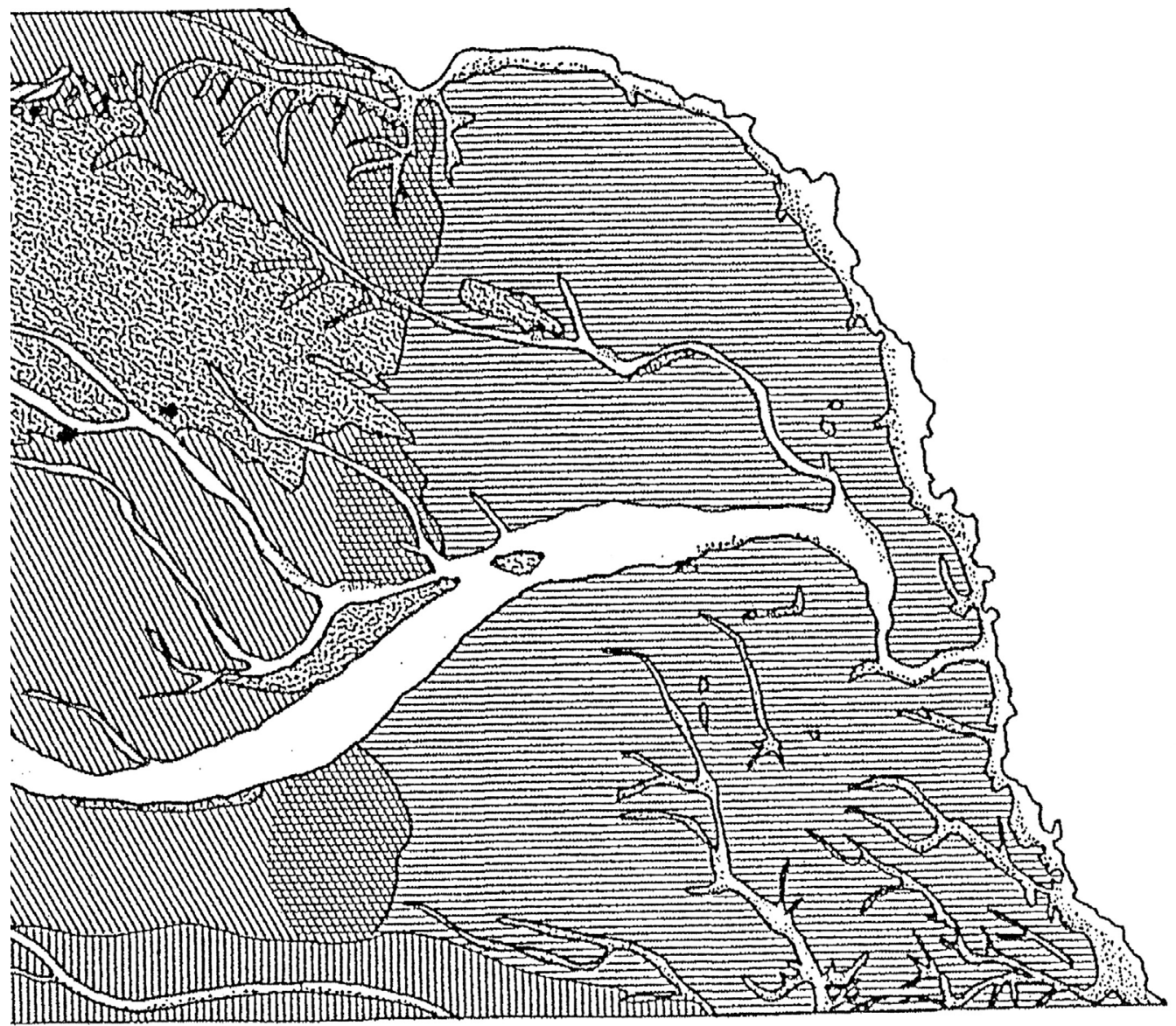

Communities dominated by deciduous or coniferous trees

Rocky Mountain forest

Q7D Rocky Mountain-deciduous transition zone

$\because \because \quad$ Eastern deciduous forest

Floodplain forest and prairie

Figure 2. Native vegetation of Nebraska. After a map by Robert Kaul. 


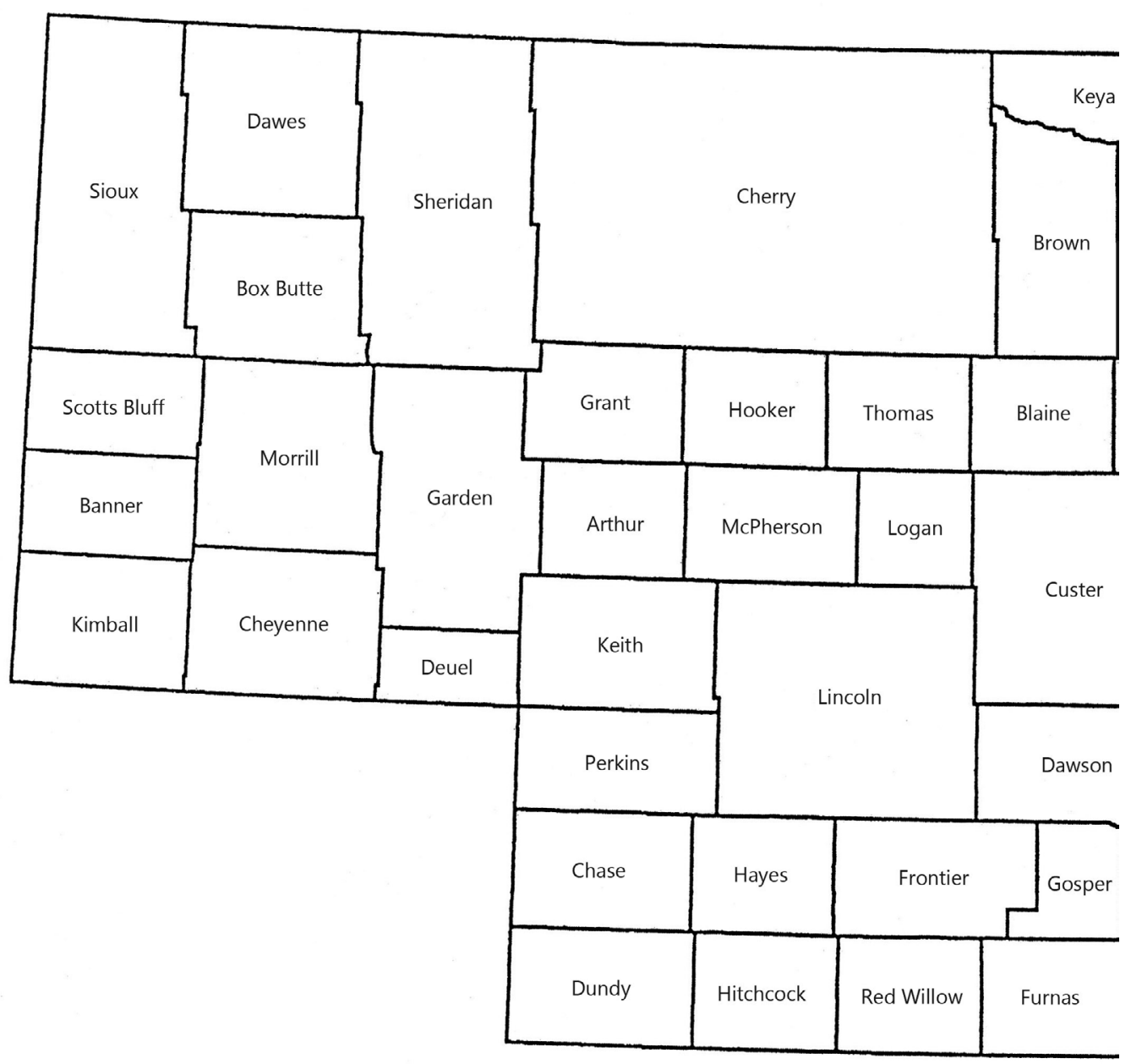

Figure 3. Nebraska counties 


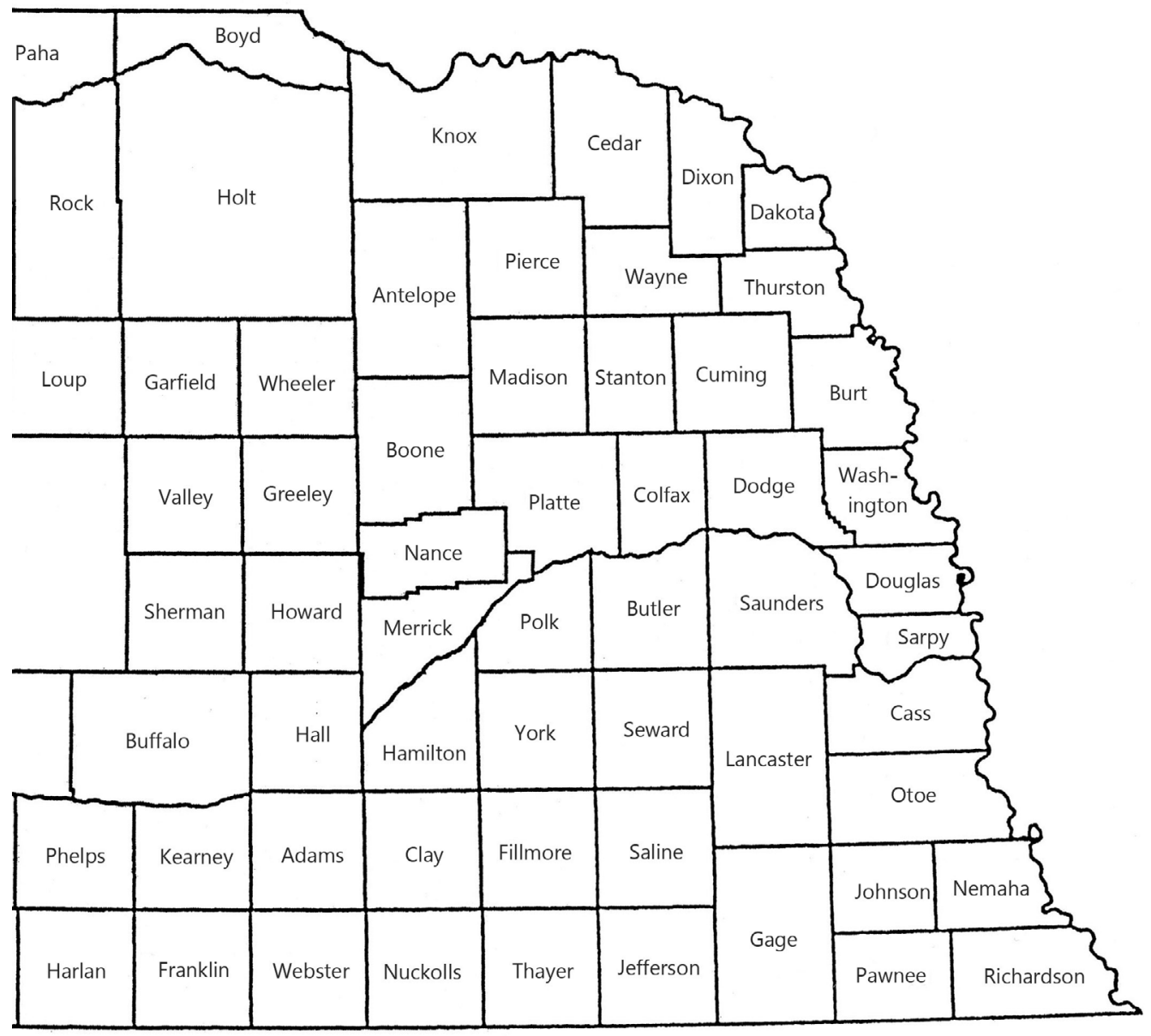




\section{Terms of Temporal Occurrence}

Permanent resident - Present throughout the year and presumably breeding.

Summer resident - Present during the summer, presumably breeding, but migrating out of the state for part of the year.

Migrant - Passing through the state in spring or fall or both, but normally not remaining through summer or winter. The term "straggler" is used for rare migrants, or individuals of regular migrant species that sometimes remain in the state beyond their normal period.

Vagrant - Refers to species normally resident or migratory in other regions, individuals of which sometimes stray well outside their range and are of accidental occurrence in the state.

Winter visitor - Species normally present in the area only between November 1 and May 1. The term "late winter visitor or spring migrant" refers to those species usually not appearing until mid-January and sometimes remaining until late May.

\section{Terms of Relative Abundance}

Abundant - Present in such numbers that large numbers are likely to be encountered daily during the proper season and in appropriate habitats.

Common - Present in such numbers that several are likely to be encountered daily during the proper season and in appropriate habitats.
Uncommon - A few are likely to be seen each year by visiting the appropriate habitats.

Occasional - Not observed every year but reported more than 50 times in the state.

Rare - Up to 50 state records for the species exist.

Extremely rare - Six to 25 state records for the species exist. "Very rare" is a comparable term but is not based on a precise count of records.

Accidental - Up to five state records for the species exist.

Hypothetical - Evidence of occurrence in the state is still inadequate.

Extirpated - The species rarely if ever now occurs in the state but once was more numerous.

Extinct - The species is no longer alive anywhere.

\section{Terms of Geographic or Ecological Distribution}

Arboreal - The species is associated with woodlands and forests.

Endemic - The species is essentially limited to a particular region or habitat.

Limnic - The species is associated with aquatic environments.

Montane - The species is associated with mountains.

Pandemic - The species has a wide distribution, sometimes throughout the entire continent.

Pelagic - The species is associated with open oceans.

Xeric - The species is associated with deserts or dry climates. 


\section{List of Nebraska Bird Species}

\section{Family Tinamidae (Tinamous)}

\section{(Elegant [Crested] Tinamou) \\ Eudromia elegans}

This species was unsuccessfully introduced into Nebraska. Birds of this species were released in Dundy County in 1970. There were no sightings after approximately five months following release (Nebraska Bird Review 39:39).

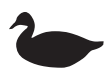

\section{Family Anatidae (Waterfowl)}

\section{Black-bellied Whistling-Duck \\ Dendrocygna autumnalis}

Extremely rare. A male black-bellied whistling-duck shot near Ong, Clay County, on October 29, 1989, was the first state record (Nebraska Bird Review 58:91), and two were later seen in Lancaster County in 1993 (Nebraska Bird Review 61:136). There were 19 total state records as of 2017, 16 of which have occurred since 2000 ( $\mathrm{Ne}$ braska Bird Review 82:58). Breeding Bird Surveys between 1966 and 2015 indicate that the species collectively underwent a survey-wide population increase (5.48\% annually) during that period, and the species' breeding range in the Gulf Coast region has expanded greatly.

\section{Emperor Goose}

Anser canagica

Accidental. An emperor goose specimen was found dead at Harvard Waterfowl Production Area during the spring of 1997 (Nebraska Bird Review 66:149, 153). Most extralimital records of this Alaskan and Asian species have occurred in the Pacific Northwest; the nearest breeding area is on coastal tundra in Alaska.

\section{Snow Goose}

\section{Anser caerulescens}

The snow goose is an abundant spring and fall migrant throughout Nebraska, less common westwardly and most abundant in the Missouri River valley, central Platte Valley, and Rainwater Basin (Vrtiska \& Sullivan, 2009). The bluish morph ("blue goose") and less common intermediate (heterozygotic) types compose about a third of the total population in eastern Nebraska but are much less frequent westward. Migrants are abundant throughout the Great Plains during spring and fall, particularly in the Missouri River valley, which supported a midcontinental population of about 5 million birds in the early 20oos. The nearest breeding area of this species is on coastal tundra in northern Manitoba.

Migration: Thirty-six initial spring sightings range from January 8 to March 28, with a median of March 9. Twenty-six final spring sightings are from March 6 to May 20, with a median of April 20. Forty initial fall sightings are from August 19 to December 16 , with a median of October 
4. Thirty-eight final fall sightings are from October 26 to December 31, with a median of December 2.

Habitats: Marshes, sloughs, riverbottom meadows, and croplands such as corn fields are used on migration. Lakes or reservoirs near croplands are also utilized.

Comments: Snow geese in the Great Plains have increased tremendously in the past few decades; the current Central Flyway population of about 10 million birds is more than the tundra breeding grounds can support (Johnsgard, 2010c, 2016b). This situation caused the US Fish and Wildlife Service to relax hunting seasons and expanded daily bag limits to something approaching "all you can stack in a pickup." The resulting carnage to snow geese, and the careless killing of and disruptions to many nontarget birds, has done almost nothing to stop the population growth in snow geese and Ross's geese. Snow and Ross's geese in Nebraska have also increasingly shifted their migration route somewhat farther west, from the Missouri River valley to the central Platte River valley, especially during spring. Peak numbers at DeSoto National Wildlife Refuge sometimes reached up to 800,000 birds until about two decades ago, but currently few snow geese stop there, and as many as 1.5 million to 2 million snow geese instead concentrate in March on large Rainwater Basin marshes, such as the Harvard and Funk Waterfowl Production Areas (Nebraska Bird Review 85:58). The estimated 2017 continental midcontinent population for white geese (snow and Ross's geese) was 3.47 million birds, with a ten- year upward trend of $4 \%$ annually (US Fish and Wildlife Service, 2017).

\section{Ross's Goose}

Anser rossii

Ross's goose is an increasingly common to abundant spring and fall migrant in the state. It is especially common each spring among snow goose flocks in the Rainwater Basin wetlands (Vrtiska \& Sullivan, 2009), at Plattsmouth Game Management Area in Cass County, and in many other eastern and Platte Valley counties, typically in the company of snow geese. Ross's geese composed an estimated $2 \%$ of the 1,200 snow and Ross's geese carcasses killed by a tornado passing near York on March 13, 1990 (NEBRASKAland 68(2): 34-41, 1991). A similar percentage was judged to be in a 2017 flock of 1,074,080 snow geese, or 21,482 birds (Nebraska Bird Review 85:6). Ross's geese currently (2018) probably make up about 3\% to $5 \%$ of Nebraska snow goose flocks, and up to $10 \%$ has been estimated (Nebraska Bird Review 84:158; Johnsgard, 2016b). The nearest breeding area of this species is on coastal tundra in northern Manitoba.

Migration: Six spring migration records are from March 10 to April 13, with a mean of March 29. Five fall records are from November 10 to December 22, with a mean of November 26. These small samples are less helpful than those that are much larger for snow geese, with which Ross's geese usually migrate.

Habitats: Ross's geese occupy the same habitats as snow geese.

Comments: These tiny geese are easily overlooked among the vast 
flocks of snow geese with which they associate. At least seven blue-morph Ross's geese or Ross's $\times$ snow goose hybrids have been reported in the state (Nebraska Bird Review 66:19, $82: 14,83: 58,85: 58)$. It is likely that these geese were hybrids, the genes probably entering the gene pool via hybridization with blue-morph snow geese, rather than Ross's goose mutants (Johnsgard, 2014). Two captiveraised hybrids support that position, these birds differing most obviously from typical Ross's geese by lacking caruncles along the basal sides of the bill, which is grayish blue rather than pale blue there, and in having definite if narrow black "grinning patches" along the mandibular edges.

Based on distances between the measurement extremes of the parental species, adult male hybrids are likely to have culmen lengths (dorsal bill profile distances) of 47-52 $\mathrm{mm}$, flattened wing lengths (the distance from the "wrist" to the tip of the folded wing's longest primary) of 411$427 \mathrm{~mm}$, and average fall weights of 3.3-4.75 pounds $\left(1.5^{-2.15} \mathrm{~kg}\right)$. Adult female hybrids are likely to have culmen lengths of 42-49 mm, flattened wing lengths of $381-426 \mathrm{~mm}$, and average fall weights of 2.75-4.25 pounds (1.25-1.9 kg) (various sources).

The estimated 2017 continental midcontinent population for combined snow and Ross's geese was 3.47 million birds, and an additional 624,000 Ross's geese were estimated (US Fish and Wildlife Service, 2017). Assuming Ross's geese composed at least $5 \%$ of the combined midcontinent flocks, there would have been a population of about 800,00o Ross's geese in 2017.

\section{Greater White-fronted Goose}

Anser albifrons

The greater white-fronted goose is a common spring and fall migrant throughout Nebraska, becoming abundant in the central Platte Valley and Rainwater Basin. Migrants occur throughout the Great Plains but are more common in western and central regions than toward the east. The nearest breeding area of this species is on coastal tundra in northern Nunavut.

Migration: Twenty-nine initial spring sightings are from February 12 to May 12, with a median of March 12. Seventeen final spring sightings are from March 23 to May 18, with a median of April 14. Nineteen initial fall sightings are from September 14 to November 21, with a median of October 23. Fifteen final fall sightings are from October 12 to December 29, with a median of November 6 .

Habitats: Migrants are associated with large marshes, shallow lakes, wide rivers with bars and islands, and adjacent agricultural grain fields. It breeds in high Arctic tundra, often near colonies of snow geese, but it is not a colonial nester.

Comments: This beautiful North American "gray" goose, often called "specklebelly" by hunters, concentrates in the Platte Valley in spring, with estimates during the late 1900 s of up to about $80 \%$ of the entire midcontinent population then concentrated within the state. More recently it has seemingly become much less common in spring in Nebraska than it was in the 196os, and national population surveys support this view. The estimated 2017 midcontinent population of greater white-fronted geese 
was 156 , ooo birds, with a preceding ten-year downward trend of 1\% annually (US Fish and Wildlife Service, 2017).

\section{Taiga Bean Goose}

Anser fabalis

Accidental. This rare Asian goose, the taiga bean goose, was photographed at DeSoto National Wildlife Refuge from December 29, 1984, to January 10, 1985 (Nebraska Bird Review 53:3). It was also reported April 4, 1998, at Funk Waterfowl Production Area (Brogie, 1999). This goose is a casual visitor to Alaska but is extremely rare elsewhere in North America. It is often considered conspecific with the more northerly breeding tundra bean goose (A. serrirostris) of Arctic Siberia, but the taiga been goose breeds in the boreal forest (taiga) zone.

\section{(Pink-footed Goose)}

\section{Anser brachyrhynchus}

Hypothetical. A pink-footed goose photographed at Harvard Waterfowl Production Area, January 30, 2006, was judged by the NOU rarities committee as unproven to have been from a wild bird (Nebraska Bird Review 75:91). However, very few if any pinkfooted geese are being kept in captivity by aviculturists in North America, and vagrants of the species have been seen recently in Maine, Pennsylvania, and especially Newfoundland, where it has been reported at least eight times. It breeds in eastern Greenland, Iceland, and Svalbard.

\section{Brant}

Branta bernicla

Extremely rare. Besides some early records for Buffalo and Hamilton counties, recent sightings of this small coastal goose are from Webster (1960), Nemaha (1959), Adams (1957), and Kearney counties (1998). The brant was considered a rare fall migrant at Lake McConaughy, with records by Roche (1994) from November and December (Brown, Dinsmore, \& Brown, 2012). There are records for both the eastern (bernicla) and western (nigricans) taxa, with at least four records for the latter (Nebraska Bird Review 79:49). As of 2015 there had been 15 Nebraska reports of this coastal tundra breeding goose ( $\mathrm{Ne}$ braska Bird Review 83:7). The nearest breeding area is in northern Manitoba and Nunavut.

\section{Cackling Goose}

Branta hutchinsii

The cackling goose is a common to abundant spring (mid-February to late March) and fall (early October to early December) migrant, especially in the central Platte Valley, with overwintering increasingly common in central and western regions. Swenk (Nebraska Bird Review 2:103-116, 1934) identified 17 of 404 Nebraska-shot Canada goose specimens as hutchinsii. Typical hutchinsii types are very common in the Rainwater Basin (Nebraska Bird Review 74:99-105), and their wintering regions include southwestern Nebraska and adjacent western Kansas (Johnsgard, 2016b) This tiny goose breeds in coastal tundra habitats from western Alaska to northeastern Canada (Nunavut) and has been increasing in population for several decades. Its great similarity to the smallest races of the Canada goose 
pose problems for species identification in the field, but the ratio of its culmen-to-wing length ratio seems to be diagnostic for identification of birds in the hand (Johnsgard, 2016b). The estimated 2017 Central Flyway and Arctic nesting population of cackling geese was 3.76 million birds, with a preceding ten-year downward trend of 1\% annually (US Fish and Wildlife Service, 2017).

\section{Canada Goose}

Branta canadensis

The Canada goose is a common to abundant migrant throughout Nebraska, with widespread breeding and local overwintering. Canada geese have been released widely, and breeding now occurs throughout the state. Overwintering is now normal in the Platte Valley (Vrtiska and Lyman, 2004) and in some cities, especially among birds of the larger races. These large geese include intergrades of $B$. $c$. maxima and B. c. moffitti, and possibly also of $B$. c. interior (Nebraska Bird Review 74:99-105).

Migration: Forty-five initial spring sightings are from January 4 to April 3, with a median of March 27. Fortyone final spring sightings are from March 19 to May 30, with a median of April 28. Fifty-four final fall sightings are from October 18 to December 31, with a median of December 10. Spring counts often number more than 100,000 statewide.

Habitats: Migrant birds are found on large marshes, lakes or reservoirs, and nearby grain fields. Breeding is typical on prairie marshes, or sometimes on larger lakes with islands or muskrat houses. Seven nests of this species were discovered during the second atlasing period of the Breeding Bird Atlas project, and nesting was confirmed in 142 survey blocks, as compared with confirmed nestings in 30 blocks during the first survey (Mollhoff, 2001, 2016).

Comments: These familiar geese have become widespread breeders in Nebraska in recent years, having adapted to small farm ponds and city park lagoons as well as Sandhills wetlands, largely as a result of captive rearing and release programs of the Nebraska Game and Parks Commission about a half-century ago. Smaller races that breed in Canada are also abundant migrants through the state, and up to 100,000 may winter in icefree locations. Separating Canadas from the newly recognized cackling goose in Nebraska under field conditions is often very difficult. Breeding Bird Surveys between 1966 and 2015 indicate that the species collectively underwent a survey-wide population increase ( $9.17 \%$ annually) during that period, with Nebraska showing an estimated and notably $13.58 \%$ rate of annual increase, based on 29 survey routes, the highest rate of increase for any Nebraska waterfowl species. The estimated 2017 western prairie and Great Plains population of Canada geese was 1.35 million birds, with a preceding ten-year upward trend of $4 \%$ annually (US Fish and Wildlife Service, 2017).

\section{Barnacle Goose}

Branta leucopsis

Accidental. An apparently wild barnacle goose was shot in Otoe County during November of 1968 (Nebraska 
Bird Review 37:2). A presumed escaped captive was also seen in 1998 (Nebraska Bird Review 66:34). Most North American sightings of this Icelandic-breeding goose have occurred east of Illinois, but it has been reported as far west as Colorado and New Mexico.

\section{Mute Swan}

Cygnus olor

This familiar introduced European species has recently (2017) been accepted to Nebraska's state list, owing to the increasing numbers of seemingly wild birds being reported ( $\mathrm{Ne}$ braska Bird Review 84:6). Many mute swan sightings have almost certainly been of escaped captives, and so far no breeding by certainly wild birds has been noted (Nebraska Bird Review 76:132, 77:49, 82:155). However, it is very likely that such will occur soon, if it has not already, since the feral Great Lakes population of mute swans has been substantially expanding and increasing, with recent records occurring west to eastern Iowa (Johnsgard, 2016a; Brogie, Silcock, \& Jorgensen, 2016). Breeding Bird Surveys between 1966 and 2015 indicate that the species collectively underwent a surveywide population increase $(1.79 \%$ annually) during that period.

\section{Trumpeter Swan}

\section{Cygnus buccinator}

The trumpeter swan is a rare spring and fall migrant in eastern Nebraska and a local summer resident in the Sandhills. Probable pair or familygroup migrants have also been observed in many western and southern counties. This species originally nested in the state but was extirpated and apparently absent until the late 1960 , when recolonization occurred as a result of releases made in South Dakota. Nesting has since occurred in many Sandhills lakes, mainly in Cherry and Grant counties but with breeding-season usage also reported from marshes in Sheridan, Garden, and Brown counties. By 1995 the Nebraska population totaled about 150 birds, and the northern Plains population has since continued to increase (Vrtiska \& Comeau, 2009). There were seven confirmed nestings during the 1984-89 atlasing period (Mollhoff, 2001). No nests of this species were described in detail during the second atlasing period of the Breeding Bird Atlas project, but nesting was confirmed in 15 survey blocks, as compared with confirmed nestings in 7 blocks during the first survey (Mollhoff, 2001). Of 32 nesting habitats, more than half were wetlands of more than 100 acres (Mollhoff, 2016).

Migration: Eight spring sightings are from January 24 to May 23, with a mean of March 28. Six fall sightings are from August 10 to November 7, with a mean of October 6. Major wintering areas are at Crescent Lake National Wildlife Refuge, Lake Ogallala, Calamus Reservoir, and DeSoto National Wildlife Refuge (Nebraska Bird Review 84:7, 85:6). Small numbers also often winter at Carter Lake, near Omaha.

Habitats: Migrants are found on lakes, large marshes, and impoundments. Breeding occurs on large shallow marshes or lakes having abundant submerged vegetation, emergent plants, and stable water levels. Wet- 
lands used during the breeding season average about 180 acres, with about $75 \%$ open water and having slight to (infrequently) medium salinity levels.

Comments: This is the heaviest of all Nebraska's birds, and perhaps the most regal. These swans prefer to nest on large Sandhills marshes having a substantial amount of freedom from human disturbance or other nearby pairs. The birds are only slightly migratory, sometimes moving south as far as Kansas during winter, but most are replaced by others from farther north. Birds seen in the easternmost parts of Nebraska probably are mostly associated with the increasingly large Minnesota breeding population, which now extends south into Iowa and which probably winter mostly in Missouri (Johnsgard, 2016e). During the most recent trumpeter swan survey of 2015, 63,00o adult and subadults were counted by the North American Trumpeter Swan Society, as compared with 2,600 that were counted during the first (1968) survey (US Fish and Wildlife Service, 2017).

\section{Tundra Swan}

\section{Cygnus columbianus}

The tundra swan is an uncommon or occasional spring and fall migrant in $\mathrm{Ne}$ braska, primarily in eastern and northeastern areas, but it has been observed as far west as Garden and Dawes counties, usually in company with trumpeter swans. It is a regular and common migrant in the northern portions of the Great Plains. The nearest breeding area of this species is on coastal tundra in northeastern Manitoba.

Migration: Twenty spring sightings range from January 1 to May 15, with a median of March 27. Eleven fall sightings are from October 21 to December 14, with a median of November 22.

Habitats: Shallow lakes, marshes, and adjacent flooded fields are used by migrants.

Comments: Previously known as the whistling swan, this species' new name reflects a merger with the Bewick's swan of the Old World, and "tundra" describes its breeding habitat very well. Few tundra swans pass through Nebraska while migrating from Canadian breeding areas. They either turn southeast after entering eastern North Dakota and head down the Minnesota River valley toward mid-Atlantic coast wintering grounds, with a few sometimes entering eastern Nebraska (eastern population), or they head southwest from western North Dakota toward wintering grounds in Utah and California (western population) (Johnsgard, 2016e). The estimated 2017 eastern population of tundra swans based on midwinter surveys was 119,300 birds, which was $5 \%$ above the previous year's total of 113 , ooo (US Fish and Wildlife Service, 2017).

\section{Wood Duck}

Aix sponsa

The wood duck is an uncommon spring and fall migrant and a summer resident in eastern Nebraska but is less common westwardly, becoming infrequent in the Panhandle and Sandhills. Breeding was originally limited to the Missouri River's forested valley and the lower portions of the Platte Valley, probably west to about Kearney. However, this species is significantly extending its range westward, and prob- 
able family groups have been seen as far west as Box Butte Reservoir; Garden, Dawes, and Scotts Bluff counties, and the North Platte River valley. Breeding mainly occurs in the eastern half of the Great Plains, and most migrants are also found in this region.

Migration: Sixty-nine initial spring sightings are from January 17 to June 7, with a median of March 28. Half of the sightings fall within the period March 13 to April 8. Thirty-five final fall sightings are from September 10 to December 31, with a median of October 21. Half of the records fall within the period October 3-30.

Habitats: Throughout the year this species is associated with tree-lined rivers, creeks, oxbows, and lakes, and it usually breeds near slow-moving rivers, sloughs, or ponds where large trees are found (Johnsgard, 2017a). No nests of this species were reported during the second atlasing period of the Breeding Bird Atlas project, but nesting was confirmed in 100 survey blocks (Mollhoff, 2016), as compared with confirmed nestings in 84 blocks during the first survey (Mollhoff, 2001). Stray mandarin ducks (Aix galericulata) sometimes appear among wood duck flocks and are presumed escapes from captivity (Nebraska Bird Review 81:54; personal observations).

Comments: Wood ducks have become much more widespread and common in Nebraska recently, both because of nest-box erection programs and also the increasing growth and maturation of riverine forests along major river systems. Breeding Bird Surveys between 1966 and 2015 indicate that the species collectively underwent a survey-wide population in- crease (1.63\% annually) during that period, with Nebraska showing an estimated $6.26 \%$ rate of annual increase, the second-highest rate of increase for any Nebraska waterfowl species.

\section{Garganey}

Spatula querquedula

Accidental. A male of this Eurasian species was seen on March 28, 1998, in Kearney County, and probably the same garganey was later seen in Hall County, March 29 to April 5, 1998 (Nebraska Bird Review 66:35, 149). This species is barely a member of the "blue-winged ducks" that include the shovelers and is now taxonomically recognized as Spatula; it is instead structurally and behaviorally transitional to the typical Anas assemblage (Johnsgard, 2017a).

\section{Blue-winged Teal}

Spatula discors

This species is an abundant spring and fall migrant and common summer resident throughout Nebraska. Migrant blue-winged teal occur throughout the Great Plains, and breeding is regular in all but the southernmost regions.

Migration: Sixty-eight initial spring sightings range from February 10 to June 1, with a median of April 2. Half of the sightings fall within the period March 28 to April 10. Eightyeight final fall sightings are from August 19 to December 31, with a median of October 10. Half of the records fall within the period September 24 to October 23.

Habitats: Migrants are found on generally shallow ponds, ditches, marshes, and the like and rarely occur 
in deep open water. Breeding is typically in marshes surrounded by native prairies and grassy sedge meadows.

Comments: This bird is the commonest migrant teal in the state, and one of the latest duck species to arrive in spring, owing to its long $\mathrm{mi-}$ gration from wintering grounds sometimes as far away as northern South America. It is also probably the most common breeding duck in Nebraska, but few remain long in the fall, the birds usually departing shortly after the first freezing weather. Breeding Bird Surveys between 1966 and 2015 indicate that the species collectively underwent a survey-wide population increase (0.49\% annually) during that period, with Nebraska showing an estimated $1.43 \%$ rate of annual increase. The estimated 2017 continental population of blue-winged teal based on the traditional US and Canada survey route was 7.89 million birds, which was $57 \%$ above the preceding longterm average of 5.03 million (US Fish and Wildlife Service, 2017).

\section{Cinnamon Teal}

Spatula cyanoptera

The cinnamon teal is an uncommon spring and fall migrant in the western half of Nebraska, becoming rarer eastwardly, but it has been observed as far east as Sarpy and Dakota counties, with about 40 eastern records as of 2013 (Nebraska Bird Review 81:55). It is probably a local summer resident but confusion with the blue-winged teal during that time makes the species' breeding status unclear. The birds are regularly present at Crescent Lake during the summer, and there is a fairly recent nesting record for Gar- den County (Mollhoff, 2001). Breeding has also been reported at Facus Springs (now the Chet and Jane Fleisbach Wildlife Management Area) in Morrill County. It has also bred in several other Great Plains states, especially toward the southwest.

Migration: Sixty-two initial spring sightings are from January 9 to June 6 , with a median of April 26. Half of the sightings fall within the period April 8 to May 10. Six fall records are from July 13 to November 14 , with a mean of September 19.

Habitats: This species occupies the same if slightly more alkaline habitats as does the blue-winged teal in $\mathrm{Ne}$ braska and usually is found in flocks of that species.

Comments: Persons wanting to see this beautiful duck should consider visiting Crescent Lake National Wildlife Refuge in June, when as many as six to eight males might be seen on a good day. Females are difficult to distinguish from female blue-winged teal but have somewhat longer bills and are generally more uniformly brownish, and tawny rather than white on the cheeks and throat. Breeding Bird Surveys between 1966 and 2015 indicate that the species collectively underwent a survey-wide population decline (2.97\% annually) during that period.

\section{Northern Shoveler}

Spatula clypeata

The northern shoveler is a common to abundant spring and fall migrant, and a common to uncommon summer resident in Nebraska. Breeding is most frequent in the Sandhills region and decreases southeastwardly. It is a mi- 
grant throughout the Great Plains and breeds locally except in the southern and southeastern portions.

Migration: Seventy initial spring sightings are from January 27 to June 6 , with a median of March 23. Half of the sightings fall within the period March 11-30. Sixty-two final fall sightings range from September 5 to December 31, with a median of November 4. Half of the records fall within the period October 20 to November 20.

Habitats: Migrants use aquatic habitats rich in zooplankton and phytoplankton, and during the nesting season the birds favor shallow prairie marshes rich in those food sources. Non-wooded shorelines are preferred over those that are wooded, and mudbottom ponds are also apparently preferentially used.

Comments: Although shovelers are generally avoided by hunters because of their reputed poor taste and the enlarged bill, the species' bill is a marvelously adapted structure, allowing the birds to strain planktonsized materials from a wetland's surface water by pumping it out the sides of the bill. In spring the males are one of the state's most attractively plumaged waterfowl. They arrive late, at about the time the blue-winged teals also appear, and males are soon actively engaged in aquatic head-pumping displays and noisy display flights. Breeding Bird Surveys between 1966 and 2015 indicate that the shoveler population collectively underwent a survey-wide population increase (2.0\% annually) during that period, whereas Nebraska had a somewhat questionable estimated $2.07 \%$ rate of annual decline, based on 20 survey routes. The estimated 2017 continental population of shovelers based on the traditional US and Canada survey route was 4.35 million birds, which was $69 \%$ above the preceding longterm average of 2.57 million (US Fish and Wildlife Service, 2017).

\section{Gadwall}

\section{Mareca strepera}

This species is a common to abundant spring and fall migrant, and a common summer resident in $\mathrm{Ne}$ braska, primarily breeding north of the North Platte River and especially in the Sandhills. It also nests south to the Rainwater Basin of Clay and adjacent counties. Breeding also occurs widely in the Dakotas and western Minnesota.

Migration: The range of 48 initial spring sightings is from January 3 to June 8, with a median of March 28. Half the records fall within the period March 6 to April 8. Fifty final fall sightings range from October 4 to December 31 , with a median of November 21. Half of the records fall within the period November 2 to December 2.

Habitats: Migrants are normally found in shallow marshes and sloughs, and sometimes on deeper waters such as lakes and reservoirs. Nesting occurs preferentially on shallow prairie marshes, especially those having grassy or weedy islands or surrounding weedy cover. Four nests of this species were discovered during the second atlasing period of the Breeding Bird Atlas project, and nesting was confirmed in one survey block (Mollhoff, 2016), as compared with confirmed nestings in 8 blocks dur- 
ing the first survey (Mollhoff, 2001).

Comments: The common name "gray duck" is often used by hunters and fits the bird well; it is often overlooked by birders whose eyes are first attracted to the more brilliantly plumaged duck species. Breeding Bird Surveys between 1966 and 2015 indicate that the species collectively underwent a survey-wide population increase (2.66\% annually) during that period, whereas Nebraska had an estimated $4.34 \%$ rate of annual decline, based on a small sample of nine survey routes. It is unfortunate that the gadwall has recently been shifted taxonomically into the weakly defined genus Mareca with the wigeons; many lines of evidence indicate that it is a typical Anas, and a near relative of the falcated duck (Anas falcata) (Johnsgard, 2017a). The estimated 2017 continental population of gadwalls based on the traditional US and Canada survey route was 2.77 million birds, which was $6 \%$ above the preceding long-term average of 2.62 million (US Fish and Wildlife Service, 2017).

\section{Eurasian Wigeon}

Mareca penelope

Rare spring Eurasian vagrant. Besides a single old specimen record from Cuming County (Bruner, Wolcott, \& Swenk, 1904), this species was reported in Adams County in March 1955 and Lincoln County in November 1966, and it has been observed at Valentine National Wildlife Refuge in Cherry County. It has also been reported from Cedar and Clay counties (Brogie, 1997) and Thayer County (Nebraska Bird Review 73:81). Most records are for March and April; the latest is May 2. Fall plumages are very difficult to distinguish from those of the American wigeon. In recent years reports suggest the species is a regular spring migrant, especially in the Rainwater Basin. As of 2011 there were at least 30 Nebraska spring records (Nebraska Bird Review 79:49). One probable hybrid Eurasian $\times$ American wigeon has been reported in $\mathrm{Ne}$ braska (Nebraska Bird Review 66:35).

\section{American Wigeon}

Mareca americana

The American wigeon is a common to locally abundant spring and fall $\mathrm{mi}$ grant throughout Nebraska, and a local and generally uncommon breeder that seems mostly confined to the northwestern parts of the Sandhills (south and east to Garden and Holt counties). It is a migrant through the Great Plains and often breeds in the Dakotas and Minnesota.

Migration: Sixty-seven initial spring sightings range from January 9 to May 28, with a median of March 22. Half of the sightings fall within the period March 6-30. Thirty-four final spring sightings are from March 27 to June 6, with a median of May 3. Fifty initial fall sightings are from August 28 to December 17, with a median of September 30. Fifty final fall sightings are from October 9 to December 31, with a median of November 18 .

Habitats: During migration these birds are sometimes found on large lakes or reservoirs, but they forage where submerged plants can easily be reached from the surface or around the shoreline in grassy meadows. Breeding is usually done on marshes or lakes with abundant aquatic food 
at or near the surface, and especially those with adjacent sedge meadows or brushy, partially wooded habitats nearby. No nests of this species were discovered during the second atlasing period of the Breeding Bird Atlas project, but nesting was confirmed in one Sheridan County survey block (Mollhoff, 2016), as compared with one confirmed nesting in a Cherry County block during the first survey (Mollhoff, 2001).

Comments: This species, which was once called the "baldpate" because of the male's white forehead in breeding plumage, can be easily recognized in flight by the brilliant white forewing patches. It often associates with gadwalls but is more inclined to feed on grassy vegetation along shorelines than are other surface-feeding ducks. Gadwalls and wigeon usually arrive about the same time as green-winged teal in spring, composing a "second wave" of birds that appear after mallards and pintails. Breeding Bird Surveys between 1966 and 2015 indicate that the species collectively underwent a survey-wide population decline (2.13\% annually) during that period. The estimated 2017 continental population of wigeon based on the traditional US and Canada survey route was 2.78 million birds, which was $6 \%$ above the preceding long-term average of 2.62 million (US Fish and Wildlife Service, 2017).

\section{Mallard}

\section{Anas platyrhynchos}

The mallard is an abundant migrant and a locally common summer resident throughout Nebraska. Wintering birds are common wherever open water occurs. Migrants occur throughout the Great Plains, and breeding occurs locally in all but the southernmost portions.

Migration: Forty-three initial spring sightings are from January 1 to May 29, with a median of March 12. Half of the records fall within the period March 2 to April 3. Sixty-four final fall sightings are from August 25 to December 31, with a median of November 27. Half of the sightings fall within the period November 21 to December 28.

Habitats: Breeding birds favor fairly shallow waters, either still or slowly flowing, and surrounding dry areas of nonforested vegetation. Migrants are often found on large marshes, lakes, or reservoirs, especially where nearby grain fields provide food. Thirty-eight nests of this species were discovered during the second atlasing period of the Breeding Bird Atlas project, and nesting was confirmed in 81 survey blocks (Mollhoff, 2016), as compared with confirmed nestings in 63 blocks during the first survey (Mollhoff, 2001).

Comments: The mallard is Nebraska's commonest duck. It is a hardy bird, usually overwintering in large numbers and breeding even in locations as unlikely as the heart of Lincoln and Omaha, wherever urban ponds and streams allow. Breeding Bird Surveys between 1966 and 2015 indicate that the mallard population collectively underwent a survey-wide population increase ( $0.3 \%$ annually) during that period, and Nebraska had an estimated $1.67 \%$ rate of annual increase, based on 49 survey routes. The estimated 2017 continental population 
of mallards based on the traditional US and Canada survey route was 11.8 million birds, which was 36\% above the long-term average of 7.9 million (US Fish and Wildlife Service, 2017).

\section{American Black Duck}

Anas rubripes

This mallard-like species is a rare migrant in the eastern half of Nebraska, becoming increasingly rare in the west. Breeding is regular in northeastern Minnesota and occasional in North Dakota. It is most commonly observed at the DeSoto National Wildlife Refuge, on the Washington County-Iowa boundary but has been observed west to at least Dawson, Keith, and Cherry counties.

Migration: Nine spring records range from March 1 to May 26, with a mean of March 26. There are fall records from August to December 22, and the species has been captured during winter banding operations in eastern Nebraska.

Habitats: Black ducks are usually found among flocks of mallards in $\mathrm{Ne}$ braska and occupy the same habitats during migration.

Comments: In Nebraska, black ducks are seen only infrequently among mallard flocks, and a substantial number of these birds are actually mallard $\times$ black duck hybrids. Such hybridization by mallards has threatened the black duck's gene pool over nearly all of the eastern United States, with "pure" black duck populations now restricted to Canada's Atlantic coast (Johnsgard, 1967, 2017a; Johnsgard and DiSilvestro, 1976). Breeding Bird Surveys between 1966 and 2015 indicate that the species collectively underwent a survey-wide population decline (1.51\% annually) during that period.

\section{Mottled Duck}

Anas fulvigula

Hypothetical. The "Mexican duck" ( $A$. platyrhynchos diazi) and the mottled duck (A. fulvigula) are both of questionable occurrence in Nebraska. A specimen attributed to diazi was collected in Cherry County in October 1921, and a possible mottled duck was taken in Rock County in October 1969 (Nebraska Bird Review 38:80). The 1921 specimen has since been proven to be a hybrid with the mallard (New Mexico Department of Game and Fish Bulletin 16, 1977). The mottled duck record is also suspect as to identity; mottled ducks are extremely hard to distinguish from female mallard $\times$ black duck hybrids (Johnsgard, 1967, 2017a). However, mottled ducks bred repeatedly in southern Kansas during the 1970s, and there are specimens from Barton and Woodman counties (Thompson et al., 2011). Breeding Bird Surveys between 1966 and 2015 indicate that the mottled duck (Florida and Gulf Coast races) collectively underwent a survey-wide population decline (3.13\% annually) during that period, and both races have been affected by hybridization with mallards.

\section{Northern Pintail}

Anas acuta

This species is an abundant spring and fall migrant and a common summer resident throughout Nebraska, breeding locally in suitable habitats. It frequently overwinters in considerable 
numbers where open water occurs.

Migration: Sixty initial spring sightings range from January 18 to May 29, with a median of March 12. Half of the records fall within the period February 27 to March 20. Flocks of from 73,000 to 200,00o birds have been noted between March 9 and 17 (Nebraska Bird Review 85:59). Fiftyseven final fall sightings range from September 16 to December 31, with a median of November 19. Half of the records fall within the period November 6 to December 18 .

Habitats: While on migration, nearly all aquatic habitats are used, ranging from flooded fields to large lakes and reservoirs. Breeding is also near water areas, ranging in type from small ponds to permanent marshes, but usually where the surrounding land is quite open and well drained. Thirteen nests of this species were discovered during the second atlasing period of the Breeding Bird Atlas project, and nesting was confirmed in four survey blocks (Mollhoff, 2016), as compared with confirmed nestings in 21 blocks during the first survey (Mollhoff, 2001).

Comments: Pintails are among the most graceful of all our waterfowl, and by early March usually rival mallards in abundance. They are also among the commonest breeding ducks in Nebraska, along with mallards and blue-winged teal. During spring their wonderful courtship flights are simply breathtaking to watch, and the males' accompanying fluty display whistles are among the sweetest sounds of nature. Breeding Bird Surveys between 1966 and 2015 indicate that the species collectively underwent a survey-wide population decline (2.4\% annually) during this period, with Nebraska routes showing an estimated $6.17 \%$ annual rate of decline, the highest rate of decline for any Nebraska waterfowl species. The estimated 2017 continental population of pintails based on the traditional US and Canada survey route was 2.89 million birds, which was $27 \%$ below the preceding long-term average of 3.97 million (US Fish and Wildlife Service, 2017).

\section{Green-winged Teal}

Anas crecca

This species is an abundant spring and fall migrant and an occasional summer resident. Breeding is largely limited to the northern half of the state and is concentrated in the western Sandhills. There is at least one breeding record from south of the Platte River, in the eastern Rainwater Basin (Nebraska Bird Review 76:138). Migrants occur throughout the Great Plains, and breeding is regular in the Dakotas, western Minnesota, and northwestern Iowa.

Migration: Fifty-eight initial spring sightings range from January 1 to June 4, with a median of March 20. Half of the records fall within the period March 12-30. Fifty-five final spring sightings are from April 4 to June 10, with a median of May 10. Forty-six initial fall sightings are from August 3 to October 18, with a median of September 12. Forty-nine final fall sightings are from September 20 to December 31, with a median of November 2 .

Habitats: Migrants are associated with almost all standing or slowly flowing aquatic habitats in Nebraska, 
and breeding normally occurs where ponds or sloughs are surrounded by a mixture of grassland, sedge meadows, and well-drained areas supporting shrubby or tall woody vegetation. No nests of this species were discovered during the second atlasing period of the Breeding Bird Atlas project, but nesting was confirmed in one Clay County survey block (Mollhoff, 2016), as compared with confirmed nestings in six blocks during the first survey (Mollhoff, 2001).

Comments: In spite of its small size, the green-winged teal is a very early spring migrant, appearing soon after the mallards and northern pintails make their appearance. Then the males' cricket-like display calls become quite apparent, and their animated courtship displays are a delight to watch. This teal is also a late fall migrant, remaining long after the blue-winged teal have departed, and arriving sooner in the spring. Breeding Bird Surveys between 1966 and 2015 indicate that the species collectively underwent a survey-wide population decline (0.41\% annually) during that period, with Nebraska showing an estimated $1.88 \%$ rate of annual decline. The estimated 2017 continental population of green-winged teal based on the traditional US and Canada survey route was 3.6 million birds, which was $70 \%$ above the preceding long-term average of 2.13 million (US Fish and Wildlife Service, 2017).

\section{Canvasback}

Aythya valisineria

This species is an uncommon to locally common spring and fall migrant statewide, and a local summer resi- dent in the western Sandhills (especially Valentine and Crescent Lake National Wildlife Refuges). Breeding also occurs in the Dakotas and western Minnesota, and migrants occur throughout the Great Plains.

Migration: Sixty-eight initial spring sightings are from February 12 to May 21, with a median of March 18. Half of the records fall within the period March 7-30. Thirty-nine final fall sightings are from October 12 to December 31, with a median of November 14. Half of the records fall within the period October 29 through November 23.

Habitats: On migration, this species uses marshes, rivers, and shallow lakes rich in submerged pond weeds and similar vegetation. Prairie marshes with abundant emergent vegetation and some areas of open water are favored for nesting. No nests of this species were discovered during the second atlasing period of the Breeding Bird Atlas project, but nesting was confirmed in three blocks in Sheridan and Rock County survey blocks (Mollhoff, 2016), as compared with confirmed nestings in six blocks during the first survey (Mollhoff, 2001).

Comments: Canvasbacks have traditionally been regarded as regal ducks; their long sloping bills and robust outlines set them apart from most other ducks, and they are reputed to be among the most edible of all waterfowl. They are larger than redheads and generally paler in both sexes, and they lack the high rounded head profile of that species. Breeding Bird Surveys between 1966 and 2015 indicate that the species collec- 
tively underwent a survey-wide population decline (0.2\% annually) during that period, with Nebraska showing an estimated $4.47 \%$ rate of annual increase. The estimated 2017 continental population of canvasbacks based on the traditional U.S. and Canada survey route was 733 , 00o birds, which was $25 \%$ above the preceding long-term average of 587,000 (US Fish and Wildlife Service, 2017).

\section{Redhead}

\section{Aythya americana}

This species is a common spring and fall migrant statewide and a locally common summer resident in the Sandhills west to Garden County. There is occasional breeding in the Rainwater Basin (Nebraska Bird Review 75:73). Breeding is regular in the Dakotas, Minnesota, and Northern Iowa, and migrants occur throughout the Great Plains.

Migration: Sixty initial spring sightings range from February 9 to May 25, with a median of March 13. Half of the sightings fall within the period March 1-20. Fifty-six final fall sightings are from October 9 to December 1, with a median of November 9. Half of the records fall within the period October 28 to November 19.

Habitats: Migrants are found on large prairie marshes, lakes, and reservoirs, especially where submerged vegetation is abundant. Nesting typically occurs on marshes at least an acre in size, having both open areas and stands of emergent vegetation. Two nests of this species were discovered during the second atlasing period of the Breeding Bird Atlas project, and nesting was confirmed in six survey blocks (Mollhoff, 2016), as compared with confirmed nestings in seven blocks during the first survey (Mollhoff, 2001).

Comments: Redheads are considerably more common than canvasbacks in Nebraska and can usually by seen during the summer at Crescent Lake and Valentine refuges. Neck-stretching and head-throw displays are common in spring, accompanied by soft cat-like meowing calls. Breeding Bird Surveys between 1966 and 2015 indicate that the species collectively underwent a survey-wide population increase (0.74\% annually) during that period, with Nebraska showing an estimated $1.63 \%$ rate of annual increase. The estimated 2017 continental population of redheads based on the traditional US and Canada survey route was 1.15 million birds, which was $55 \%$ above the preceding long-term average of 718,00o (US Fish and Wildlife Service, 2017).

\section{Ring-necked Duck}

Aythya collaris

This species is an uncommon to common spring and fall migrant almost statewide, becoming less common in the Panhandle. Nebraska is outside its regular breeding range, and there are no proven breeding records for the Sandhills. Local breeding occurs in the Dakotas, and breeding is regular in much of Minnesota.

Migration: Forty-two initial spring sightings are from February 12 to May 25, with a median of March 21. Half of the records fall within the period March 7 to March 30. Twenty-six final spring sightings are from March 24 to May 30, with a median of April 
21. Twenty-seven initial fall sightings are from September 17 to December 7, with a median of October 12. Twentythree final fall sightings are from October 27 to December 31, with a median of November 17.

Habitats: Migrants are found on large prairie marshes, lakes, and reservoirs, but prairie marshes are only secondary breeding habitats. Rather acidic swamps and bogs surrounded by shrubby covers are the primary breeding habitat.

Comments: This species, often called the "ring-billed duck," is closely related to the redhead rather than the scaups, as is obvious from its downy plumage. However, its breeding habitats are quite different from those of redheads, and it is now known to be only a migrant in Nebraska. Breeding Bird Surveys between 1966 and 2015 indicate that the species collectively underwent a survey-wide population increase $(1.77 \%$ annually) during that period.

\section{Tufted Duck}

Aythya fuligula

Accidental. A male was found at Lake Keystone/Ogallala, Keith County, November 3, 1999, and remained in the area until at least March 2000. Several more recent sightings have occurred there (Brown, Dinsmore, \& Brown, 2012). This Eurasian species is a close relative of the scaups, and many hybrids with the greater scaup have been described in Europe.

\section{Greater Scaup}

Aythya marila

This species is an occasional migrant and winter visitor in Nebraska, and is more common than the relatively few published records would suggest. It is probably regular during late fall, winter, and early spring on larger reservoirs and lakes. Although migrants might appear anywhere in the Great Plains, they are probably most common in the Missouri Valley impoundments.

Migration: Twenty-seven total spring records are from January 11 to May 18, with the largest number (12) for March, followed by April (8), and three each for February and May. There are fall records from October 27 to December 30.

Habitats: Migrants and wintering birds utilize lakes and reservoirs in the interior, but most birds winter coastally.

Comments: Males of the two scaup species are quite similar (and the females even more), but greater scaups have a greenish-glossed head (not purplish) and a much flatter crown profile, with no hint of a crest at the rear. The two species don't often associate because of their differing habitat preferences, and no definite hybrids are known, although they would be very difficult to recognize.

\section{Lesser Scaup}

Aythya affinis

This scaup is a common to abundant spring and fall migrant statewide, and an occasional summer resident in the Sandhills (probably Garden, Morrill, Cherry, and Brown counties). It is known to have nested at Crescent Lake National Wildlife Refuge but not at the Valentine refuge, and it overwinters locally where open water is present. It also breeds in the Dakotas and locally in Minnesota. Migrants occur throughout the Great Plains. 
Migration: Sixty-nine initial spring sightings are from February 12 to May 20, with a median of March 19. Half of the records fall within the period March 5 through March 25. Fortythree final spring records are from March 10 to June 6, with a median of May 11. Forty-five initial fall sightings are from July 20 to December 15 , with a median of October 18 . Thirty-one final fall sightings are from November 22 to December 31, with a median of December 14.

Habitats: Deeper marshes, reservoirs, borrow pits, and lakes are commonly used by migrating birds. Prairie marshes surrounded by partially wooded uplands are favored for breeding, especially those supporting large populations of amphipods ("scuds"). No nests of this species were discovered during the second atlasing period of the Breeding Bird Atlas project (Mollhoff, 2016).

Comments: This "bluebill" is a very common spring and fall migrant, and is perhaps the most abundant of the diving ducks in Nebraska. Males have bright blue bills in spring; as for male ruddy ducks, this blue coloration is caused by light refraction effects rather than blue pigmentation. Breeding Bird Surveys between 1966 and 2015 indicate that the species collectively underwent a survey-wide population decline (1.84\% annually) during that period. The estimated 2017 continental population of scaups (both species combined) based on the traditional US and Canada survey route was 4.3 million birds, which was $13 \%$ below the preceding long-term average of 5.02 million (US Fish and Wildlife Service, 2017).

\section{King Eider}

Somateria spectabilis

Accidental. This sea duck was photographed at DeSoto National Wildlife Refuge November 10-24, 1985 (Bray, Padelford, \& Silcock, 1986). It is an Arctic-breeding coastal species that normally winters coastally. The nearest breeding ground of king eiders is the coastal tundra in northern Manitoba and Nunavut.

\section{Common Eider}

Somateria mollissima

Accidental. A specimen remains of a female shot in December 1967 in Lincoln County; this bird was of the somewhat nonmigratory race sedentaria (Nebraska Bird Review 37:38). The common eider is an Arctic-breeding coastal species that breeds and winters as close as the Hudson Bay coast of Manitoba.

\section{Harlequin Duck}

Histrionicus histrionicus

Accidental, with three early records from the Omaha area (Bruner, Wolcott, \& Swenk, 1904). Only three documented records existed for the state as of 2001, plus four undocumented records (Nebraska Bird Review 69:164). There has since been at least one more reported sighting in 2017. Harlequin ducks are normally found no closer than Wyoming, where they locally breed on a few mountain streams in the northwestern corner of that state.

\section{Surf Scoter}

Melanitta perspicillata

This scoter is a rare migrant in $\mathrm{Ne}$ braska, occurring primarily in the 
fall. As of the early 2ooos, it had been seen repeatedly in Lancaster, DouglasSarpy, and Keith counties, and it is a rare spring, fall, and early winter migrant at Lake McConaughy (Brown, Dinsmore, \& Brown, 2012). Like the other scoters, most reports are of females or immature males that are often overlooked or confused with other species. As of 2010 there were seven documented spring records, as compared to three for black scoters ( $\mathrm{Ne}$ braska Bird Review 78:43). The nearest breeding of this species is in northern Manitoba.

Migration: Five spring records are from April 21 to May 15. Eight fall records are from October 7 to December 16, with a mean of November 6 . Reported at Lake McConaughy from April 22 to May 15, and October 8 to January 20 (Brown, Dinsmore, \& Brown, 2012).

Habitats: Lakes, reservoirs and larger rivers are used by migrants. Most wintering is done coastally; those appearing in Nebraska are largely female-like (females and males in first-year plumage).

Comments: About as rare as the harlequin duck, the birds seen in Nebraska mostly have the distinctive head pattern of first-year birds, with whitish spots in front of and behind the eye.

\section{White-winged Scoter}

Melanitta fusca

This species is an occasional spring and fall migrant, more common in the fall than spring. Most of the records are from counties bordering the Platte or Missouri Rivers. As of the early 200os, it had been recorded at least twice in Lincoln, Adams, Lancaster, and Douglas counties. It is also an uncommon spring, fall, and early winter migrant at Lake McConaughy (Brown, Dinsmore, \& Brown, 2012) and is probably an annual visitor to the state, especially along the Missouri River and on the larger reservoirs. As of 2011, there were 26 spring records (Nebraska Bird Review 80:50). The nearest breeding area of this species is on coastal tundra in central Manitoba.

Migration: Five total spring records are from March 31 to April 29, with a mean of April 7. Twenty-one fall records are from October 7 to December 10 , with a median of November 10. Half of the records fall within the period October 28 to November 22 . It has been reported at Lake McConaughy from November 1 to May 28 (Brown, Dinsmore, \& Brown, 2012).

Habitats: Lakes, reservoirs, and larger rivers are used by some migrants. Most birds migrate to winter in coastal areas; those appearing in Nebraska are largely immatures.

Comments: First-year birds of this largest of the scoters are similar to the surf scoter in female plumage but have large white patches on their inner (secondary) flight feathers that allow for positive identification. This is the species most often seen in $\mathrm{Ne}$ braska; it bred as close as northern North Dakota in the early twentieth century.

\section{Black Scoter}

\section{Melanitta americana}

This species is a rare or very rare migrant and is the rarest of the scoters in Nebraska. It has been seen in scat- 
tered locations throughout the state, primarily in fall and early winter, and is a rare fall and early winter migrant at Lake McConaughy (Brown, Dinsmore, \& Brown, 2012). The nearest breeding of this species is coastal tundra in northern Manitoba.

Migration: Two spring records are for March 25 and May 4. Seven fall records range from September 28 to December 10, with a mean of October 28. It has been reported at Lake McConaughy from October 12 to January 15 (Brown, Dinsmore, \& Brown, 2012).

Habitats: Lakes, reservoirs, and larger rivers are used by migrants. Most wintering is done coastally; those appearing in Nebraska are largely immatures.

Comments: This rare sea duck is usually seen in the female-like immature plumage while in Nebraska, when its two-tone brown head helps in identification. There were six fall reports in 2010 along with six for whitewinged scoters and five for surf scoters (Nebraska Bird Review 78:134).

\section{Long-tailed Duck}

\section{Clangula hyemalis}

This species is a rare fall and spring migrant statewide but is perhaps slightly more common eastwardly. As of the early 20oos, two or more records existed for at least Keith, Lancaster, Douglas, and Washington counties, including at least eight for Douglas County. It is more common now than before the formation of large reservoirs. As of 1933, less than a dozen definite records for the state existed (Nebraska Bird Review 1:11), but the species was seen almost every year during the 1970 s and is now regular during early winter at Lakes McConaughy and Ogallala, with up to nine reported at one time in early December. The nearest breeding area of this species is on coastal tundra in northern Manitoba.

Migration: Thirteen total spring records are from February 3 to April 19, with a median of March 29. Ten total fall records are from October (no date) to December 11, with a median of November 27. It has been reported at Lake McConaughy from November 3 to April 29 (Brown, Dinsmore, \& Brown, 2012).

Habitats: Lakes, reservoirs, and larger rivers are used by migrating birds; most wintering is done in coastal habitats.

Comments: Long-tailed ducks nest higher in the Arctic than almost any other duck and mostly occur in Nebraska as late fall and winter vagrants on deeper waters. They are probably the most abundant and widespread of all sea ducks.

\section{Bufflehead}

\section{Bucephala albeola}

This species is a common to uncommon migrant statewide. Occasionally stragglers remain in the state through the summer, and there is one breeding record for Brown County. Breeding occurs locally in North Dakota, and migration occurs throughout the Great Plains.

Migration: Fifty-three initial spring sightings are from February 21 to May 1, with a median of March 18. Half of the records fall within the period March 6 through March 24. Thirtyeight final spring sightings are from March 15 to May 29, with a median 
of April 21. Thirty-four initial fall sightings are from August 14 to December 16 , with a median of October 19. Thirty-one final fall sightings are from October 29 to December 31, with a median of November 24 .

Habitats: Lakes, reservoirs, and deeper marshes are used by migrating birds. No nests of this species were discovered during the second atlasing period of the Breeding Bird Atlas project, but an adult with four downy young were seen at Hagar Lake, Brown County, on June 24, 2000 (Mollhoff, 2016). Breeding Bird Surveys between 1966 and 2015 indicate that the species collectively underwent a survey-wide population increase (0.21\% annually) during that period.

Comments: Easily one of the most beautiful of Nebraska's ducks, these birds tend to appear on the same kinds of wetlands as goldeneyes and mergansers. The males sparkle like gigantic snowflakes on the water, and the tiny, drab females are almost invisible by contrast. Nesting occurs in the cavities made by flickers and other similar-sized woodpeckers.

\section{Common Goldeneye}

Bucephala clangula

This species is a common to uncommon spring and fall migrant statewide. It occasionally overwinters when open water is available. Breeding occurs in Minnesota and locally in North Dakota.

Migration: Thirty-five initial spring sightings range from January 1 to April 12, with a median of March 5 . Twenty-four final spring sightings are from March 9 to May 8, with a me- dian of March 30. Thirty-four initial fall sightings are from October 10 to December 31, with a median of November 21. Thirty-one final fall sightings are from November 22 to December 31, with a median of December 14 . It has been reported at Lake McConaughy from September 9 to June 13 (Brown, Dinsmore, \& Brown, 2012).

Habitats: Deeper marshes, rivers, lakes, and reservoirs are used during migration.

Comments: This beautiful diving duck appears in spring at about the same time as the common mergansers, and both species can often be seen engaging in excited courtship displays, performing head-throws, backward kicks, vertical neck-stretching, and other remarkable male posturing, as the drab females either ignore the males or perhaps threaten them with bill-pointing gestures. The white plumages of male goldeneyes and common mergansers fairly glisten in the sun, and when in flight both species exhibit large white wing-patches.

\section{Barrow's Goldeneye}

Bucephala islandica

This species is a rare winter and spring vagrant in Nebraska, mainly occurring westwardly but with records east to Douglas County. It is a rare to uncommon spring, fall, and early winter migrant at Lake McConaughy (Nebraska Bird Review 66:11; Brown, Dinsmore, \& Brown, 2012). As of the early 2000 it had been observed two or more times in Garden, Lincoln, and Douglas counties.

Migration: Eight spring records range from February 15 to April 2, with a mean of March 19. Three fall 
records are from November 26 to December 21. It has been reported at Lake McConaughy from November 14 to April 19 (Brown, Dinsmore, \& Brown, 2012).

Habitats: While on migration, this species uses the same habitats as the common goldeneye, but it is more prone to winter in coastal or brackish waters.

Comments: There is little chance of seeing this species in Nebraska, although it breeds in Wyoming's Teton Range and elsewhere, mostly west of the Continental Divide. A few hybrids with common goldeneyes have been recorded. Such hybrids, and especially female hybrids, are difficult to recognize, but the intermediate patterns of white on the face and lesser wing-coverts of adult males are distinctive.

\section{Hooded Merganser}

Lophodytes cucullatus

This species is an uncommon to occasional spring and fall migrant in eastern Nebraska, and an occasional to rare migrant in western parts of the state. Stragglers sometimes remain into summer, but there are at present very few records of breeding in Nebraska. However, apparently valid early records of nesting came from Lancaster, Gage, and Cuming counties (Bruner, Wolcott, \& Swenk, 1904). I observed a female and five newly fledged young at Twin Lakes, Seward County, in July 1995. Two other breeding records for eastern Nebraska also exist (Nebraska Bird Review 73:50). As of 2010 there were only three confirmed state breeding records ( $\mathrm{Ne}$ braska Bird Review 78:43). No nests of this species were discovered dur- ing the second atlasing period of the Breeding Bird Atlas project, but an adult with day-old young was seen on an Omaha pond in early May, and nesting was confirmed in three survey blocks (Mollhoff, 2016). It was not reported during the first survey period.

Migration: Seventy-four initial spring sightings range from January 16 to May 30, with a median of March 26. Half of the records fall within the period March 13 to March 28. Fourteen final spring records are from March 19 to May 30, with a median of April 25. Sixteen initial fall sightings are from September 14 to November 27, with a median of November 5 . Nineteen final fall sightings are from November 6 to December 17, with a median of November 22.

Habitats: Migrants are found on clear-water rivers, lakes, reservoirs, and deeper marshes. Breeding is usually on rivers, creeks, and oxbows bordered by woods and supporting good populations of fish (Johnsgard, 2016d).

Comments: This species seems to be increasing in Nebraska, as I rarely observed it in the 1960s and '70s, but it is now a regular spring migrant in eastern Nebraska. Perhaps it has benefited from nest-box erection programs for wood ducks, as it often will choose such places for laying its eggs. Breeding Bird Surveys between 1966 and 2015 indicate that the species collectively underwent a survey-wide population increase ( $3.89 \%$ annually) during that period.

\section{Common Merganser}

Mergus merganser

This species is a regular spring and fall migrant statewide, varying in 
abundance from very common to occasional. It overwinters commonly where open water persists; stragglers sometimes remain through the summer. Summering birds are regular in the Lake Alice area of Scotts Bluff County, and nesting has been suspected. Evidence of breeding in the state includes a brood sighted in Custer County in 1968 (Nebraska Bird Review 37:45) and one reported from the North Platte Valley west of Lake McConaughy (Nebraska Bird Review 62:105). It regularly breeds in Minnesota and migrates throughout the Great Plains.

Migration: Fifty initial spring sightings are from January 14 to April 25, with a median of March 9. Half of the records fall within the period March 3 through March 27. Thirtynine final spring sightings are from March 4 to May 30, with a median of April 6. Thirty-eight initial fall sightings are from September 18 to December 31, with a median of November 13 . Thirty-six final fall sightings are from November 20 to December 31, with a median of December 17. Up to 40,000 migrants have been seen on Harlan County Reservoir (Nebraska Bird Review 84:8).

Habitats: Migrants and wintering birds are found on rivers, lakes, reservoirs, and any other large water areas supporting fish populations. Most nesting is done on forest-lined lakes and ponds near rivers, but some occurs rarely in treeless areas among rock crevices or other natural cavities (Johnsgard, 2016d). No nests of this species were discovered during the second atlasing period of the Breeding Bird Atlas project, but adults with young were seen on three occasions on the Niobrara River in July 2007 (Mollhoff, 2016).

Comments: More nesting records of this splendid species are likely to accrue as time passes because summering birds are increasingly common in Nebraska. The birds need clear waters with a good fish population; hunters and fishermen tend to hate this and other "sawbill" species because of their fishy taste and appetites. However, the birds generally eat slow-swimming prey rather than trout and other game fish. Breeding Bird Surveys between 1966 and 2015 indicate that the species collectively underwent a survey-wide population decline (1.98\% annually) during that period.

\section{Red-breasted Merganser}

\section{Mergus serrator}

This species is an occasional to rare spring and fall migrant statewide, more common westwardly than in eastern Nebraska. It may overwinter rarely. The red-breasted merganser is a regular migrant throughout the Great Plains.

Migration: Sixty-one initial spring sightings are from January 15 to May 12, with a median of March 29. Half of the records fall within the period March 19 to April 7. Twenty-four final spring sightings are from February 14 to May 18, with a median of April 20. Sixteen total fall sightings are from September 21 to December 31, with a median of November 18 . Half of the records fall within the period November 4-27. It has been reported at Lake McConaughy from August 7 to June 7 (Brown, Dinsmore, \& 
Brown, 2012). The nearest breeding area of this species is on coastal tundra in southern Manitoba and northeastern Minnesota.

Habitats: Lakes, reservoirs, and large rivers are used by migrants; wintering more often occurs coastally.

Comments: The red-breasted merganser is less common in eastern $\mathrm{Ne}$ braska than the two other mergansers, which is too bad because it is a most attractive species. Like the common merganser, it is dependent upon fish in clear-water habitats.

\section{Ruddy Duck}

Oxyura jamaicensis

This species is a common spring and fall migrant statewide and an uncommon and very local summer resident in some of the deeper and more permanent marshes of the Sandhills and Rainwater Basin. It is considered a common breeder at both Valentine and Crescent Lake refuges, and it has bred in York and Lancaster counties (Nebraska Bird Review 83:107). It is a regular breeding species in the Dakotas and Minnesota and migrates throughout the Great Plains.

Migration: Sixty-seven initial spring sightings are from February 12 to June 9, with a median of April 3. Half of the records fall within the period March 14 to April 19. Fifty-nine final fall records are from August 30 to December 31, with a median of November 27. Half of the records fall within the period October 10 to November 27.

Habitats: Migrants may be found on lakes, reservoirs, larger marshes, and similar habitats that offer considerable open water and mud-bottom feeding areas. Breeding is on prairie marshes that have stable water levels and an abundance of emergent vegetation, along with some areas of open water. No nests of this species were discovered during the second atlasing period of the Breeding Bird Atlas project, but nesting was confirmed in one Garden County survey block (Mollhoff, 2016), as compared with confirmed nestings in eight blocks during the first survey (Mollhoff, 2001).

Comments: This wonderful little duck is nearly everybody's favorite; from its sky-blue bill to its long, spiky tail it advertises its uniqueness. From the time it finally arrives in spring and begins its bizarre displays through the summer breeding period, it is hard to imagine a more interesting bird to watch. Like other stiff-tailed ducks it feeds almost entirely on small fly larvae that live in the muddy bottoms of ponds, using its sensitive bill to locate its prey (Johnsgard \& Carbonell. 1996; Johnsgard, 2017c). Breeding Bird Surveys between 1966 and 2015 indicate that the species collectively underwent a survey-wide population increase (0.94\% annually) during that period, whereas Nebraska had a statistically unlikely estimate (based on eight survey routes) of a $0.81 \%$ rate of annual decline. 


\section{Family Odontophoridae (New World Quails)}

(Scaled Quail)

\section{Callipepla squamata}

This southwestern quail was unsuccessfully introduced into Nebraska. Scaled quail releases were made during the late 1950s, but there have been no observations since 1962 . The nearest breeding region is in southwestern Kansas and southeastern Colorado, and it also breeds in Oklahoma, Texas, and New Mexico.

\section{(California Quail)}

\section{Callipepla californica}

This western quail was unsuccessfully introduced into Nebraska. An attempt to establish Calfornia quail in 1939 was a failure. This species was also unsuccessfully introduced into South Dakota in 1961.

\section{Northern Bobwhite}

Colinus virginianus

This species is a permanent resident almost statewide, becoming rarer westwardly. It breeds commonly in eastern and southern Nebraska, extending into the Sandhills along river drainages, and reaching the Wyoming and Colorado borders along the North Platte and South Platte Rivers as well as the tributaries of the Republican River. The western range limits are highly variable, depending on yearly weather conditions. The northern range limits are in South Dakota and southern Minnesota.

Habitats: Throughout the year this species is normally found where there is a combination of grassy nesting cover, cultivated crops, and brushy cover or woodlands with a brushy understory. Nesting is typically done in open herbaceous cover consisting of rather short vegetation that does not obstruct easy entry and exit but is sufficient to provide concealment from above. No nests of this species were discovered during the second atlasing period of the Breeding Bird Atlas project, but nesting was confirmed in 14 survey blocks (Mollhoff, 2016). Confirmed nestings were reported from 60 blocks during the first survey period (Mollhoff, 2001).

Comments: The familiar "bobwhite" call of the male bobwhite is known to everybody and is more a signal of a male's availability than a territorial proclamation. All of the New World quails are monogamous, and in all the species the male remains with his mate to help protect and raise the brood. Family broods become the basis for fall coveys, which usually are made up of about the right number (six to ten birds) to compose an effective roosting ring at night. The group organizes itself into a tight circle with heads pointed outward, thereby sharing body heat and remaining alert in all directions. Breeding Bird Surveys between 1966 and 2015 indicate that the species collectively underwent a survey-wide population decline (3.48\% annually) during that period, and Nebraska underwent an estimated $0.56 \%$ rate of annual decline. 


\section{Family Phasianidae (Pheasants, Grouse, and Turkeys)}

(Chukar)

Alectoris chukar

Various attempts have been made to establish this Eurasian species in Nebraska, including the release of 700 birds in southern Scotts Bluff County in 1969. Chukar were observed in Lincoln, Banner, Sheridan, and Dawes counties until as late as the early or mid 1970s and in Sioux County in 1998. It is unlikely that a breeding population still persists in the state, but there have been persistent sighting reports from the Redington area.

\section{Gray Partridge}

Perdix perdix

This Eurasian species is an uncommon and local introduced resident in northern Nebraska, declining during recent years. Fairly common in South Dakota, it has been reported in Nebraska regularly since 1950 , most often in the northern tier of counties, west to Sioux and Scotts Bluff counties. It is currently centered in Knox, Cedar, and Dixon counties ( $\mathrm{Ne}$ braska Bird Review 77:51). Currently (2018) the population is very low, but a brood was seen in Cedar County in 2016 (Nebraska Bird Review 84:115). It is a regular breeder from southern South Dakota northward, and some of the Nebraska records may represent fall wanderers, but nesting has been reported near West Point (Nebraska Bird Review 48:88). During the 198489 atlasing period, there were four confirmed nestings, extending from Cherry County east to Cedar County (Mollhoff, 2001). In the more recent survey, there were no confirmed nestings and only two probable nestings (Mollhoff, 2016), but there were sightings for Boyd, Holt, Knox, Cedar, and Antelope counties, as compared with confirmed nestings in four blocks during the first survey (Mollhoff, 2001). Breeding Bird Surveys between 1966 and 2015 indicate that the species collectively underwent a survey-wide population decline (1.8\% annually) during that period.

(Japanese Quail)

Coturnix japonica

This Eurasian quail was unsuccessfully introduced into Nebraska in 1957. The migratory tendencies of Japanese quail make it an unsuitable game bird.

\section{Ring-necked Pheasant}

Phasianus colchicus

This species is an introduced permanent resident, now fairly common almost statewide but more common eastwardly. It is also resident in other Great Plains states, primarily the Dakotas and Kansas.

Habitats: Throughout the year a combination of small grain croplands and adjacent heavier covers such as weedy ditches, sloughs, wooded areas, or shelterbelts provide optimum habitat. Nesting is often done in roadside ditches, in alfalfa or sweet clover fields, or in heavy grass cover. Twenty-six nests of this species were discovered during the second atlasing period of the Breeding Bird Atlas project, and nesting was confirmed 
in 56 survey blocks (Mollhoff, 2016), as compared with confirmed nestings in 122 blocks during the first survey (Mollhoff, 2001).

Comments: The ring-necked pheasant perhaps represents the most successful of the many efforts to introduce exotic game birds into North America. These efforts began in the early 190os, and by midcentury the species was established over much of the country, especially in the grain belt of the northern plains, Evidently it fit into our avifauna without displacing our native grouse, although it gradually replaced prairie-chickens as the loss of prairie habitats caused the gradual disappearance of these native birds. Breeding Bird Surveys between 1966 and 2015 indicate that the species collectively underwent a survey-wide population decline (0.64\% annually) during that period, and Nebraska underwent a $1.78 \%$ rate of annual decline.

\section{Ruffed Grouse}

Bonasa umbellus

Extirpated from Nebraska. The ruffed grouse was previously a permanent resident of the Missouri River's forested valley. Releases during 1968 in Nemaha County were evidently unsuccessful, with no records since 1973 . Introductions into northeastern Kansas during the 1980s were also apparently failures (Thompson et al., 2011). The nearest breeding area is the Black Hills.

\section{Greater Sage-Grouse}

Centrocercus urophasianus

Probably extirpated from Nebraska. Apparently greater sage-grouse once bred in extreme northwestern Sioux
County (Rosche, 1982), but no specific nesting records exist. Displaying birds are sometimes seen in Sioux County, so rare nesting within Nebraska is still possible. It still breeds in adjacent South Dakota, Wyoming, and southwestern North Dakota (Johnsgard, 2002a). Breeding Bird Surveys between 1966 and 2015 indicate that the species collectively underwent a survey-wide population decline (3.43\% annually) during that period, and its should have been added to the list of nationally threatened species decades ago.

\section{Sharp-tailed Grouse}

Tympanuchus phasianellus

This species is a locally common permanent resident over much of $\mathrm{Ne}$ braska, primarily north of the Platte River, and with its eastern range limits approximating those of the Sandhills (Sisson, 1970, 1976). It was once much more widespread, possibly occurring throughout the entire state.

Habitats: Open grassland habitats, where trees are absent or nearly so, is the typical Nebraska habitat (Twedt, 1974; Johnsgard, 1973, 2002a, 2013c). Land with brushy cover over $5 \%$ to $30 \%$ of the area is used in more northerly areas, especially where winter snow accumulation is considerable. Sixty-one nests of this species were discovered during the second atlasing period of the Breeding Bird Atlas project, and nesting was confirmed in ten survey blocks (Mollhoff, 2016), as compared with confirmed nestings in 17 blocks during the first survey (Mollhoff, 2001).

Comments: Sharp-tailed grouse are still surprisingly widespread and 


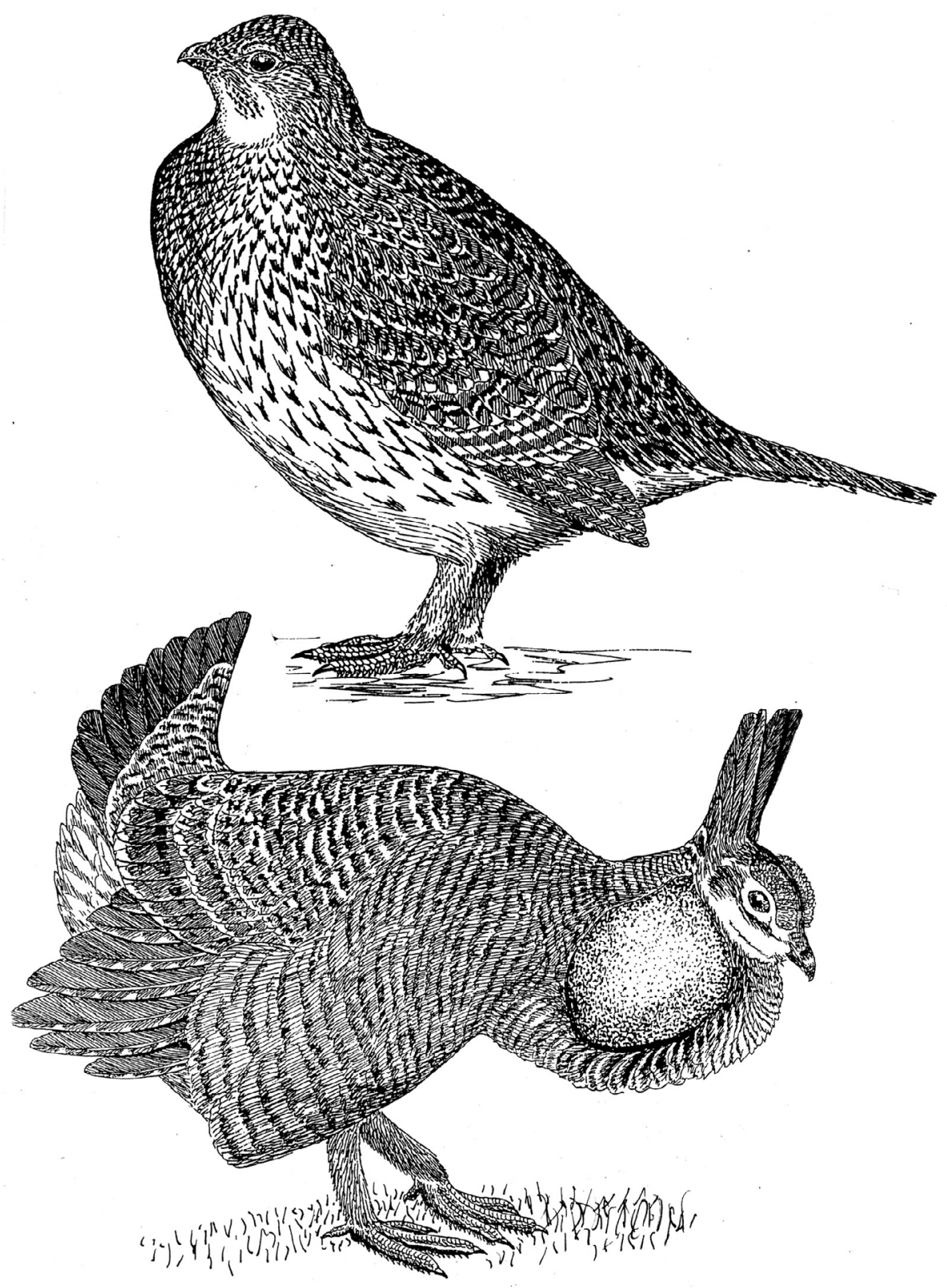

Figure 4. Adult males of sharp-tailed grouse (above) and greater prairie-chicken (below) 
common in Nebraska and, like prairiechickens, offer early risers a chance to witness the visual poetry of several males dancing in nearly perfect synchrony on their traditional leks, or display grounds. In some areas of the Sandhills, both species display on the same grounds, and hybrids occasionally result (Johnsgard \& Wood, 1968). The displays and vocalizations of the two species are quite different, but females sometimes are attracted to the "wrong" male for mating (Johnsgard, 1973, 2002a, 2007a, 2017b). Breeding Bird Surveys between 1966 and 2015 indicate that the species collectively underwent a survey-wide population decline (0.37\% annually) during that period, and Nebraska underwent an estimated $0.56 \%$ rate of annual decline.

\section{Greater Prairie-Chicken}

Tympanuchus cupido

This nationally declining species is a locally common to uncommon permanent resident, especially in the eastern half of the Sandhills, southwestern Nebraska, and a few southeastern counties. Greater prairie-chickens are rare in the Panhandle and absent from some Missouri Valley counties. The species' range is discontinuous and declining as native grasslands disappear, but the Nebraska populations are perhaps the best among all the states in which it still survives, and its population appeared to be stable as of 2018 (Johnsgard, 1973, 1983a, 200ob, 2002a, 2010a). Breeding Bird Surveys between 1966 and 2015 indicate that the species collectively underwent a survey-wide population increase (2.8\% annually) during that period, with Nebraska showing an estimated $6.79 \%$ rate of annual increase based on 25 survey routes, but the statistical reliability for both of these estimates is questionable.

Habitats: Greater prairie-chickens are primarily associated with native mixed-grass grasslands and places where native grasslands and grain croplands interdigitate. Nesting usually occurs in grassy open habitats, such as ungrazed meadows or hayfields, usually in rather dry sites, but sometimes nests are placed in brushy vegetation or in open woods or at the edge of woods. Two nests of this species were discovered during the second atlasing period of the Breeding Bird Atlas project, and nesting was confirmed in eight survey blocks (Mollhoff, 2016), as compared with confirmed nestings in six blocks during the first survey (Mollhoff, 2001).

Comments: Nebraska is one of the few states in which prairie-chickens are still sufficiently common as to be major game birds. The eastern edge of the Sandhills probably represents the prime prairie-chicken habitat; here a mixture of native grasses and grain crops such as corn provide both nesting cover and winter foods for these birds (Johnsgard, 1973, 1983a, 2002a, 2017b).

\section{Lesser Prairie-Chicken}

Tympanuchus pallidicinctus

Extirpated. Only three 1924 and 1925 specimens from Red Willow County are known to exist. The lesser prairiechicken is resident in southwestern Kansas, with nesting records as close as three counties removed from $\mathrm{Ne}$ braska (Thompson et al., 2001). 


\section{Wild Turkey}

Meleagris gallopavo

The wild turkey is native to Nebraska but was extirpated, reintroduced, and is now reestablished as a resident in most areas, especially in the Pine Ridge region and along all of the wooded river systems. It has also been reintroduced into the Dakotas, and indigenous populations exist from Kansas southward.

Habitats: Although various races differ greatly in habitats utilized, in most parts of Nebraska the birds are found in floodplain forests having a variety of hardwood trees, especially those bearing acorns or other large and edible seeds. In the Pine Ridge region, they are associated with pines, cedars, running water, and a fairly rugged topography. Nesting occurs in forested areas, with the nests well concealed, often placed under a log or at the base of a tree. Ten nests of this species were discovered during the second atlasing period of the Breeding Bird Atlas project, and nesting was confirmed in 116 survey blocks (Mollhoff, 2016), as compared with confirmed nestings in 55 blocks during the first survey (Mollhoff, 2001).

Comments: Wild turkeys scarcely differ from domestic "bronzed" turkeys in their general appearance, although their tail-tips are usually tan rather than white, but they are much more wary and slim bodied. Yet their calls and display postures are identical, and sometimes wild birds will mate with the domestic, producing feral individuals of varied wildness. Breeding Bird Surveys between 1966 and 2015 indicate that the species collectively underwent a survey-wide population increase ( $7.51 \%$ annually) during that period, and Nebraska underwent a scarcely believable $12.71 \%$ rate of estimated annual increase, based on 43 survey routes, the highest estimated rate of increase among all Nebraska's game bird species.

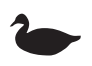

\section{Family Podicipedidae (Grebes)}

\section{Pied-billed Grebe}

Podilymbus podiceps

This species is a common spring and fall migrant and local summer resident throughout Nebraska. The piedbilled grebe breeds almost throughout the Great Plains, excepting the drier areas of the southwestern states.

Migration: A total of 116 initial spring sightings range from February 27 to June 10, with a median of April 5. Half of the sightings fall within the period March 24 to April 22. Eightyfour final fall sightings are from August 21 to December 6, with a median of November 6 . Half of the sightings fall within the period October 10 to November 16.

Habitats: Breeding occurs on small ponds, river impoundments, and lakes ranging from quite small to large but always those having extensive stands of heavy emergent vegetation and adjacent areas of open water. Two nests of this species were discovered during the second atlasing period of the Breeding Bird Atlas project, and nest- 
ing was confirmed in 20 survey blocks (Mollhoff, 2016), as compared with confirmed nestings in 23 blocks during the first survey (Mollhoff, 2001).

Comments: This is the commonest grebe in the state, and one that rarely strays far from reedy or weedy shorelines. It often dives by sinking vertically when alarmed, with at most its head remaining above water. Its bill is adapted for eating crustaceans and other invertebrates rather than fish. Other Nebraska grebes will be seen in flocks but never the pied-billed grebe. Breeding Bird Surveys between 1966 and 2015 indicate that the species collectively underwent a survey-wide population increase (0.68\% annually) during that period versus a statistically unreliable estimate (based on only eight survey routes) of a $2.67 \%$ annual decline in Nebraska.

\section{Horned Grebe}

\section{Podiceps auritus}

This species is an uncommon spring and fall migrant throughout Nebraska and an accidental resident. Horned grebes reportedly once bred in Cherry County, but the closest area of regular breeding now is in central South Dakota. It also breeds in North Dakota and northwestern Minnesota.

Migration: Sixty-two initial spring sightings range from February 20 to June 4, with a median of April 16. Twenty-four final spring sightings are from April 14 to May 22, with a median of May 6. Seventeen initial fall sightings are from September 5 to November 11, with a median of October 8. Seventeen final fall sightings are from October 9 to November 27, with a median of November 11.
Habitats: Rivers, lakes, and reservoirs are used while on migration. Breeding occurs on ponds and marshes ranging in size from less than an acre to several hundred acres, which may be seasonal or permanent. Submerged aquatic vegetation is typically abundant, but emergent growth may be rather sparse.

Comments: Slightly larger than the eared grebe, the horned grebe is much less common and lacks that species' black neck.

\section{Red-necked Grebe}

Podiceps grisegena

This species is an extremely rare spring and fall migrant in Nebraska. There have been sightings of this species in at least six counties, with most of the reports for Douglas-Sarpy and nearly all from counties bordering the Platte or Missouri Rivers. Its nearest breeding area is in Minnesota and North Dakota.

Migration: Seven spring records are from March 13 to May 17, with a mean of April 9, and eight fall records are from September 30 to December 21, with a mean of October 30.

Habitats: Rivers, lakes, and reservoirs are used while on migration.

Comments: The red-necked grebe is a large, robust species that seems to prefer rather large bodies of water and has a sharp bill well adapted to fish eating. Like the eared grebe, it also occurs widely in Europe (Johnsgard, 1987a).

\section{Eared Grebe}

Podiceps nigricollis

This species is an uncommon spring and fall migrant throughout Nebraska 
and is a fairly common summer resident, especially in the Sandhills, but locally also in the Rainwater Basin east to York County (Nebraska Bird Review 83:108).

Migration: A total of 105 initial spring sightings range from February 19 to June 5, with a median of April 22. Half of the sightings fall within the period of April 11 to May 5. Twenty-three final fall sightings are from August 23 to November 15, with a median of October 16. Half of the sightings fall within the period October 8-30.

Habitats: Rivers, lakes, and reservoirs are used during migration. Breeding occurs on ponds, marshes, and shallow river impoundments that are usually rich in submerged aquatic plants. Large, open ponds providing abundant feeding areas, but some sheltered locations with emergent aquatic plants for nesting sites also seem to be favored. One nest of this species was discovered during the second atlasing period of the Breeding Bird Atlas project, and nesting was confirmed in six survey blocks (Mollhoff, 2016), as compared with confirmed nestings in ten blocks during the first survey (Mollhoff, 2001).

Comments: This beautiful little grebe is a colonial nester, and one of the summer attractions of Crescent Lake National Wildlife Refuge during mid-June is watching families of eared grebes with several chicks on the backs of most adults. Breeding Bird Surveys between 1966 and 2015 indicate that the species collectively underwent a survey-wide population increase (1.11\% annually) during that period, and Nebraska had an estimated $0.22 \%$ rate of annual increase.

\section{Western Grebe}

Aechmophorus occidentalis

This species is a common spring and fall migrant in the western part of Nebraska, rarer eastwardly, and a summer resident in western areas. Breeding occurs primarily on the larger Sandhills marshes, including the Crescent Lake and Valentine refuges, which represent the southeastern limit of breeding of this species in the Great Plains. Many nonbreeders and a few breeders summer on Lake McConaughy.

Migration: Seventy-seven initial spring sightings range from March 10 to June 10, with a median of May 6 . Half of the sightings fall within the period April 19 to May 18. Forty-three final fall sightings are from September 10 to December 7, with a median of October 3. Half of the sightings fall within the period October 1-24.

Habitats: Rivers, lakes, and reservoirs are used while on migration. Breeding is on ponds and lakes that usually have large expanses of open water and on some marshes that are at least 50 acres in area. No nests of this species were discovered during the second atlasing period of the Breeding Bird Atlas project, but nesting was confirmed in three survey blocks (Mollhoff, 2016), as there were during the first survey (Mollhoff, 2001).

Comments: The western grebe is perhaps the most spectacular of all the North American grebes. During migration as many as 35,000 to 44 , 000 of these splendid birds aggre- 
gate on Lake McConaughy during late September, and 14,000 to 18 , ooo from mid-April to mid-May (Nebraska Bird Review 82:157, 85:60). Breeding is common on several large marshes at the Crescent Lake and Valentine wildlife refuges. The species' spectacular courtship displays are perhaps best seen during May. Breeding Bird Surveys between 1966 and 2015 indicate that the species (and Clark's grebe) collectively underwent a survey-wide population decline (2.02\% annually) during that period versus a statistically unreliable estimate (based on four survey routes) of a $4.61 \%$ annual increase in Nebraska.

\section{Clark's Grebe}

Aechmophorus clarkii

This species is an occasional and probably regular but very local breeder. The state's first record was of an adult found dead at Lake Keystone, Keith County, on June 1, 1986, and since then a considerable number of sightings have been reported in western Nebraska, including adults with young at the western end of Lake McConaughy in late July 1993 (Rosche, 1994). Groups of up to 16 birds have been reported there, and some have also been seen at Crescent Lake National Wildlife Refuge. In 1998 and 2002 nesting was noted at Willy Lake, Sheridan County, the only well-documented nesting location in the state apart from Lake McConaughy. Sightings have occurred east to Lancaster County.

Comments: Probably this poorly distinguished species is more common in Nebraska than generally appreciated, since Clark's grebe is very easily overlooked among flocks of western grebes. An apparent hybrid has also been seen (Nebraska Bird Review 65:161). Wintering birds were first seen in 1997-98 (Nebraska Bird Review 66:19).

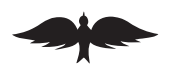

\section{Family Columbidae (Pigeons and Doves)}

\section{Rock Pigeon}

Columba livia

This introduced European species is a common permanent resident statewide, especially in towns and around farms. It is also a resident throughout the entire Great Plains and over most of North America.

Habitats: Rock pigeons are mostly associated with human habitations in cities, villages, and farms, but they also occur to a limited extent as feral populations around bluffs and cliffs in western Nebraska. Thirty nests of this species were discovered during the second atlasing period of the Breeding Bird Atlas project, and nesting was confirmed in 24 survey blocks (Mollhoff, 2016), as compared with confirmed nestings in 51 blocks during the first survey (Mollhoff, 2001). Breeding Bird Surveys between 1966 and 2015 indicate that the species collectively underwent a survey-wide population decline (1.22\% annually) during that period and an estimated $0.16 \%$ rate of annual decline in $\mathrm{Ne}$ braska. 


\section{Band-tailed Pigeon}

Patiogioenas fasciata

Accidental. One individual was reported in Morrill, Scotts Bluff County, October 15, 1996 (Nebraska Bird Review 64:116; Brogie, 1997). The species was also observed at Ceresco, Lancaster County, from November 2007 to March 2008. There is one other sight record from Scotts Bluff County (Nebraska Bird Review 76:7). The species' nearest breeding area is in western Colorado.

\section{Eurasian Collared-Dove}

Streptopelia decaocto

This introduced and rapidly increasing species has become common and widespread since it was first reported in 1997 (Nebraska Bird Review 65:168, 66:42). Nesting began in 1998 ( Nebraska Bird Review 66:43). By 1998 it had been seen at Kearney, Shelton, and Superior (Nebraska Bird Review 67:95), and by 2007 it had been reported from all Nebraska counties (Nebraska Bird Review 75:9).

Comments: Five nests of this species were discovered during the second atlasing period of the Breeding Bird Atlas project, and nesting was confirmed in 15 survey blocks (Mollhoff, 2016), as compared with no confirmed nestings during the first survey (Mollhoff, 2001). Breeding Bird Surveys between 1966 and 2015 indicate that the species collectively underwent a remarkably rapid surveywide population increase (29.18\% annually) during that period, and an amazing estimated annual increase rate of $40.66 \%$ in Nebraska. Both of these estimates are by far the high- est for any of Nebraska's birds and probably represent substantial overestimates.

\section{Passenger Pigeon}

Ectopistes migratorius

Extinct. This species was once a common migrant and summer resident in eastern parts of Nebraska (Johnsgard, 2003c) and elsewhere in the Great Plains, with the last records occurring at about the start of the twentieth century.

\section{Inca Dove}

Columbina inca

Extremely rare. Inca doves wintered in Kearney during December and January 1988-89 and were seen in Keya Paha County during late November 1989 (Nebraska Bird Review 58:93). The species was also reportedly observed at a Chadron bird feeder during the early fall of 1996. By 2009 eight records had accumulated for summer, fall, and winter (Nebraska Bird Review 77:102). There are many records of this species in Kansas, usually occurring in late fall or early winter. The species' nearest breeding area is in northern Texas.

\section{Common Ground-Dove}

Columbina passerina

Accidental. This dove was seen at Lincoln, Lancaster County, in November 1976 (American Birds 31:96) and at DeSoto National Wildlife Refugee on November 18, 1979 (Nebraska Bird Review 48:22). One was also seen November 26, 2004 (Nebraska Bird Review 73:81). The species' nearest breeding area is in central Texas. 


\section{White-winged Dove}

Zenaida asiatica

This slowly increasing southern species is a rare to occasional summer resident. It was photographed in Lincoln and Malcolm, Lancaster County, May 11-16, 1994 (Nebraska Bird Review 64:39), and seen at Scottsbluff on April 15-21, 1995 (Nebraska Bird Review 64:135). By 2005 there were at least 40 state records, mostly between April 15 and October 10 ( Nebraska Bird Review 73:10, 56, 142), and a probable nesting (Nebraska Bird Review 73:120). In recent years this dove has been reported several times per year, but breeding records are still few. Nesting probably occurred in 2005 and 2007 (Nebraska Bird Review $75: 78,78: 95$ ) but was not well documented until 2017 (Nebraska Bird Review 85:25). One nest of this species was discovered during the second atlasing period of the Breeding Bird Atlas project (Mollhoff, 2016). Overwintering has been reported a few times (Nebraska Bird Review 84:14). Breeding Bird Surveys between 1966 and 2015 indicate that the species collectively underwent a survey-wide population increase (0.93\% annually) during that period.

\section{Mourning Dove}

Zenaida macroura

This species is an abundant spring and fall migrant and summer resident statewide. Overwintering often occurs during mild winters and in sheltered locations. It also breeds and migrates throughout the entire Great Plains region.

Migration: Sixty-two initial spring sightings range from January 1 to May
29, with a median of March 26. Half of the records fall within the period March 9 to April 8. Ninety final fall sightings range from August 30 to December 31, with a median of November 1 . The wide spread of fall departure dates suggests that the species frequently overwinters in the state.

Habitats: A widely adaptable species, the mourning dove occurs in open woods and edge areas, in parks and cities, on grasslands far from trees, and in cultivated fields. Although nests are most often placed in trees, in treeless areas the birds regularly nest on the ground. Forty-two nests of this species were discovered during the second atlasing period of the Breeding Bird Atlas project, and nesting was confirmed in 233 survey blocks (Mollhoff, 2016), as compared with confirmed nestings in 213 blocks during the first survey (Mollhoff, 2001).

Comments: Mourning doves are probably the most abundant of nesting birds in Nebraska. They nest repeatedly through the long Nebraska summer, and may successfully raise several broods during that time. However, Breeding Bird Surveys between 1966 and 2015 indicate that the species collectively underwent a survey-wide population decline (0.29\% annually) during that period, and Nebraska had an estimated $0.22 \%$ rate of annual decline. It seems unlikely that the rapid increase in Eurasian collared-doves has impacted the mourning dove's apparently slightly declining population, as the two seemingly interact very little where they are in contact. 


\section{2 \\ Family Cuculidae (Cuckoos)}

\section{Yellow-billed Cuckoo}

Coccyzus americanus

This species is an increasingly rarer spring and fall migrant and summer resident statewide, uncommon in the east but less common westwardly, and increasingly rare in the Panhandle. It also breeds throughout the Plains states north to South Dakota and southern Minnesota.

Migration: The range of 170 initial spring sightings is from April 12 to June 10, with a median of May 23. Half of the records fall within the period May 15-29. The range of $101 \mathrm{fi}-$ nal fall sightings is from July 23 to October 14 , with a median of September 15. Half of the records fall within the period September 1-27.

Habitats: Migrating and breeding birds favor moderately dense thickets near watercourses, second-growth woodlands, deserted farmlands overgrown with shrubs and brush, and brushy orchards. Extremely dense woods are avoided. One nest of this species was discovered during the second atlasing period of the Breeding Bird Atlas project, and nesting was confirmed in 19 survey blocks (Mollhoff, 2016), as compared with confirmed nestings in 32 blocks during the first survey (Mollhoff, 2001).

Comments: The yellow-billed cuckoo is the so-called "rain crow" of Nebraska because the birds often call as the skies darken just prior to rain. Cuckoos are notable skulkers, which may predispose them to brood parasitism, although that is rare among Nebraska native cuckoo species. Breeding Bird Surveys between 1966 and 2015 indicate that the species collectively underwent a survey-wide population decline (1.45\% annually) during that period, and Nebraska a similar $1.83 \%$ rate of annual decline.

\section{Black-billed Cuckoo}

Coccyzus erythropthalmus

This species is a declining spring and fall migrant and summer resident almost statewide, uncommon in the northeast, rarer in the south and west, and nearly absent from parts of the Panhandle. The black-billed cuckoo also breeds throughout the Great Plains from North Dakota and Minnesota south to Oklahoma and migrates throughout.

Migration: The range of 163 initial spring sightings is from April 1 to June 10, with a median of May 24. Half of the records fall within the period May 16-30. The range of 60 final fall sightings is from July 28 to October 9, with a median of August 30. Half of the records fall within the period August 25 to September 9.

Habitats: Relatively dense wooded habitats are favored by this species, especially those that provide a variety of trees, bushes, and vines for possible nesting sites. No nests of this species were discovered during the second atlasing period of the Breeding Bird Atlas project, and nesting was confirmed in two survey blocks in Gage and Saunders counties (Moll- 
hoff, 2016), as compared with confirmed nestings in nine blocks during the first survey (Mollhoff, 2001).

Comments: This species is considerably less common than the yellowbilled cuckoo in Nebraska, and its call is more like that of a cuckoo clock. Both species feed largely on hairy caterpillars such as tent caterpillars, and their yearly abundance varies greatly, probably in relation to food supplies. Breeding Bird Surveys between 1966 and 2015 indicate a survey-wide population decline (1.62\% annually) during that period, and this decline is also evident in Nebraska, where the estimated rate of decline was 5.29\%. The black-billed cuckoo is now only very infrequently seen or heard.

\section{Groove-billed Ani}

\section{Crotophaga sulcirostris}

Accidental. There have been four sight records of this tropical cuckoo, including one seen in Antelope County during September and October 1952, one in Hall County during October 1975 , one in Cuming County in October 1976, and one seen at Beaver Lake, Cass County (Nebraska Bird Review $43: 49,45: 13,53: 78)$. It is considered accidental in South Dakota, is a casual visitant in Kansas, and is irregular in Oklahoma. The species' nearest breeding area is in southern Texas.

\section{Family Caprimulgidae (Nightjars)}

\section{Common Nighthawk}

Chordeiles minor

The common nighthawk is an abundant spring and fall migrant and summer resident statewide, particularly around cities. It is a regular migrant and breeder throughout the entire Great Plains region.

Migration: The range of 170 initial spring records is from April 16 to June 7, with a median of May 21. Half of the records fall within the period May 1628. The range of 137 final fall records is from July 21 to October 24 , with a median of September 18. Half of the records fall with the period September 8 to October 2 .

Habitats: During its stay in $\mathrm{Ne}$ braska, this species occurs widely in open habitats such as grasslands, sparse woods, and cities, perhaps being more common near humans than anywhere else, where the tops of flat buildings provide perfect nest locations. Nine nests of this species were discovered during the second atlasing period of the Breeding Bird Atlas project, and nesting was confirmed in seven survey blocks (Mollhoff, 2016), the same number of confirmed nesting blocks during the first survey (Mollhoff, 2001).

Comments: The common nighthawk is easily the most common of Nebraska's “nightjars," a group of insect-eating and seminocturnal birds mostly recognized (and usually named for) their distinctive vocalizations. The common nighthawk's 
familiar beep call can be heard over cities and towns from late May onward. Breeding Bird Surveys between 1966 and 2015 indicate that the species had a survey-wide population decline (1.93\% annually) during that period, whereas there was a surprising $1.12 \%$ estimated rate (based on 49 survey routes) of annual increase in Nebraska.

\section{Common Poorwill}

\section{Phalaenoptilus nuttallii}

This species is a common spring and fall migrant and summer resident in western Nebraska excluding the Sandhills, and occurs generally west of a line from Sheridan to Harlan counties. There have been scattered sightings of migrants in eastern counties, and a nesting in Lancaster County in 1976 (Nebraska Bird Review 39:70, 45:42). It breeds from in dry habitats from southwestern North Dakota southward to central Oklahoma.

Migration: Thirty-three initial spring records range from April 25 to June 9, with a median of May 6. Half of the records fall within the period May 1-16. Eighteen final fall records are from July 20 to November 1 , with a median of September 4. Half of the records fall within the period August 18 to September 16 .

Habitats: Although this species is most common in rather rocky habitats with scrubby cover or dry woodlands, it also locally extends into grasslands. However, the Sandhills area is evidently avoided by breeding birds. Three nests of this species were discovered during the second atlasing period of the Breeding Bird Atlas project, and nesting was confirmed in three Dundy, Sheridan, and Keya Paha County survey blocks (Mollhoff, 2016), as compared with confirmed nestings in two blocks (Morrill and Keya Paha counties) during the first survey (Mollhoff, 2001).

Comments: This rock- and canyonadapted bird is only rarely seen. Often it is flushed by headlights when cars travel down gravel roads at night in western Nebraska, and it is momentarily visible before disappearing into the darkness. Its poor-will call is a common sound in much of western Nebraska, but apparently only one nest has ever been located in the state. Breeding Bird Surveys between 1966 and 2015 indicate that the species collectively underwent a surveywide population decline (0.86\% annually) during that period.

\section{Chuck-will's-widow}

Antrostomus carolinensis

The chuck-will's-widow is a highly local but regular spring and fall migrant and presumed summer resident in southeastern Nebraska. It has been reported regularly from the Indian Cave area of Richardson and Nemaha counties north to Douglas County ( $\mathrm{Ne}$ braska Bird Review 35:50) and more recently to Dakota County. It has been heard as far north in the Missouri Valley as the Oahe Dam area in central South Dakota, and as far west in the Platte Valley as Kearney.

Migration: Fourteen spring records range from May 2 to June 9, with a median of June 3. No records after August 15 are available for Nebraska, but in Kansas fall records extend to September 16 (Thompson et al., 2011).

Habitats: Heavy woodlands near 

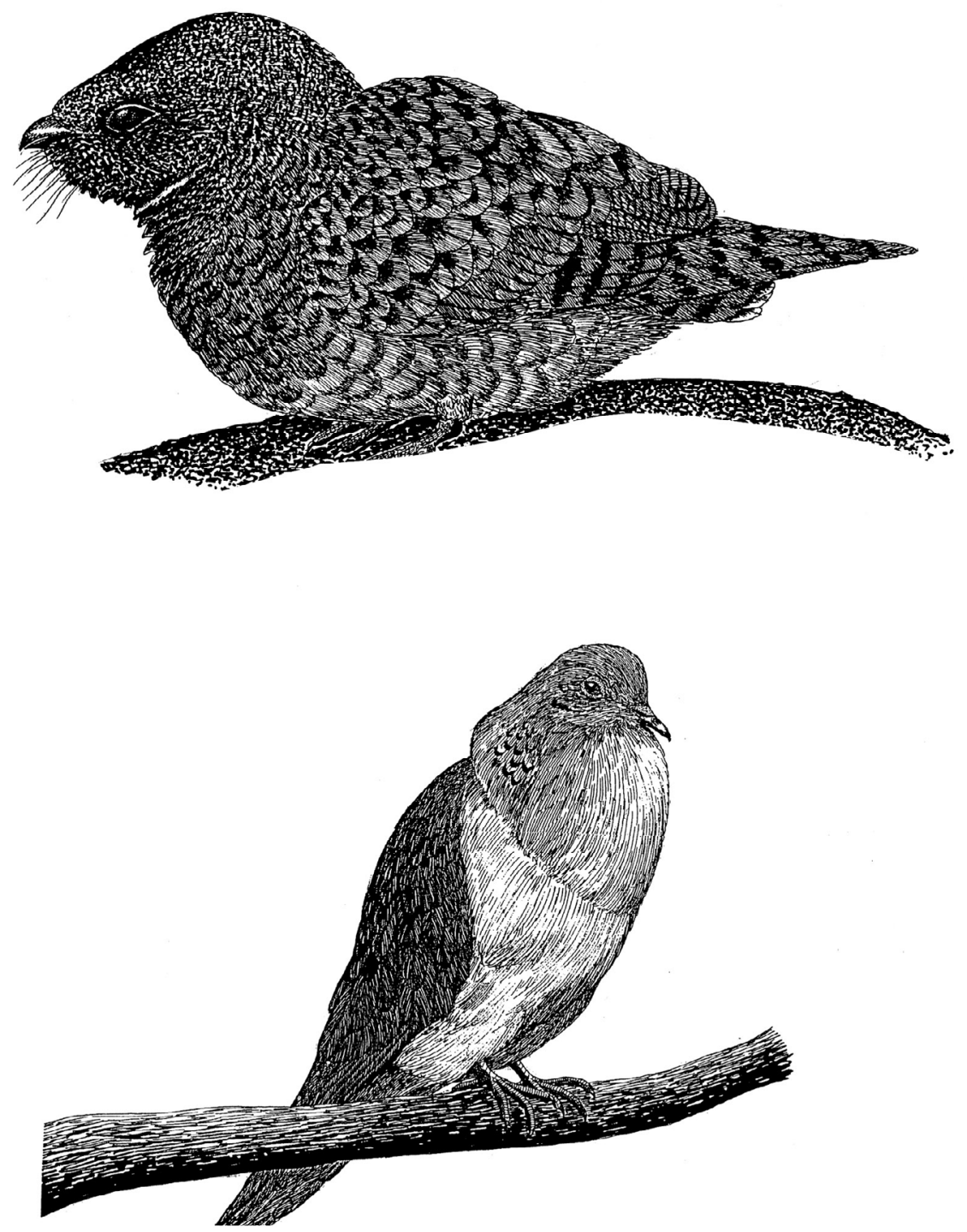

Figure 5. Adult common poor-will (above) and male mourning dove cooing (below) 
streams, frequently comprising mixed oaks and pines, are the favored habitat of this species. No nests of this species were discovered during the second atlasing period of the Breeding Bird Atlas project (Mollhoff, 2016).

Comments: This species is another caprimulgid that is named for its usual vocalization, and it is the largest member of its family that occurs in the state. Although its distinctive onomatopoeic call has been heard along the Missouri Valley all the way to South Dakota, only a single Nebraska nest of this highly elusive species has been located, in Saunders County. There were no confirmed nestings in the two state Breeding Bird Atlas studies (Mollhoff, 2001, 2016). Breeding Bird Surveys between 1966 and 2015 indicate that the species had a survey-wide population decline $(2.3 \%$ annually) during that period.

\section{Eastern Whip-poor-will}

Antrostomus vociferus

This species is a locally common spring and fall migrant and summer resident along the Missouri River's forested valley from the South Dakota line to the Missouri border, the lower Niobrara Valley west to eastern Cherry County(Nebraska Bird Review 83:115), and probably also in Pawnee County along the Big Nemaha River. It was also reported during 2003 in Sioux County (Nebraska Bird Review 71:119) and was judged to be of the arizonae taxon.

Migration: Thirty-four initial spring records range from April 14 to May 21, with a median of May 2. Half of the records fall within the period
April 25 to May 7. Fifteen final fall records range from July 31 to October 1 , with a median of September 2. Half of the records fall within the period $\mathrm{Au}$ gust 26 to September 7 .

Habitats: During the breeding season this species occupies open hardwood or mixed woodlands, especially younger stands in fairly dry habitats. Woodlands with scattered clearings also seem to be preferentially used. One nest of this species was discovered during the second atlasing period of the Breeding Bird Atlas project, and nesting was confirmed in one Dixon County survey block (Mollhoff, 2016). There was also one nesting confirmation (Dakota County) during the first survey (Mollhoff, 2001).

Comments: Like the chuck-will'swidow, the eastern whip-poor-will can usually be heard nightly along the forests of the Missouri Valley, but there are only two confirmed nesting records, for Pawnee and Dakota counties. Breeding Bird Surveys between 1966 and 2015 indicate that the species collectively underwent a survey-wide population decline (1.93\% annually) during that period, and Nebraska had an estimated $\mathbf{1 . 1 2} \%$ rate of annual increase. 


\section{Family Apodidae (Swifts)}

\section{Chimney Swift}

Chaetura pelagica

This species is an abundant spring and fall migrant and summer resident throughout most of Nebraska, but it is less common westwardly and probably only occasionally breeds west of a line from Dawes to Hitchcock counties. Its western limits now include Chadron, Harrison, Gering, and Alliance. The chimney swift breeds almost throughout the entire region of the Plains states but is rare or absent in extreme western areas.

Migration: The range of 129 initial spring records is from March 7 to June 6, with a median of April 27. Half of the records fall within the period April 20 to May 4. The range of $111 \mathrm{fi}-$ nal fall records is from July 22 to October 14 , with a median of October 7 . Half of the records fall within the period October 2-14.

Habitats: Like the common nighthawk, this species occurs in a wide variety of open habitats but is probably most common in cities, where chimneys and other similar human-made structures provide roosting and nesting sites. One nest of this species was discovered during the second atlasing period of the Breeding Bird Atlas project, and nesting was confirmed in 18 survey blocks (Mollhoff, 2016), as compared with confirmed nestings in 24 blocks during the first survey (Mollhoff, 2001).

Comments: Chimney swifts are now almost entirely city birds, depending on chimneys rather than large hollow trees for roosting and nesting. They have been seen circling over Cedar Point Biological Station, but there are no suitable chimneys there, and the birds move on. Chimney swifts evidently mate in flight, and some swifts are believed even to sleep in flight using unihemispheric sleep, that is, leaving one brain hemisphere active while the other rests. Their flight speeds have been exaggerated, probably because of their very rapid wing beats, but they have been timed at almost 40 miles per hour. Breeding Bird Surveys between 1966 and 2015 indicate that the species collectively underwent a survey-wide population decline (2.5\% annually) during that period, and a $2.03 \%$ rate of annual decline in Nebraska.

\section{White-throated Swift}

Aeronautes saxatalis

This species is a locally common spring and fall migrant and summer resident in the Pine Ridge region, extending east to northwestern Sheridan County, the vicinity of Scottsbluff, and the Wildcat Hills. Vagrants have been seen east to central Sheridan County.

Migration: Twenty-six initial spring sightings range from April 19 to June 10, with a median of May 18 . Half of the records fall within the period May 10 to June 1. Ten final fall sightings are from August 1 to September 22, with a median of August 29.

Habitats: Steep cliffs and deep canyons are the ideal habitat of this species, with nesting occurring in the inaccessible cracks and crevices of such locations. No nests of this species was discovered during the second 


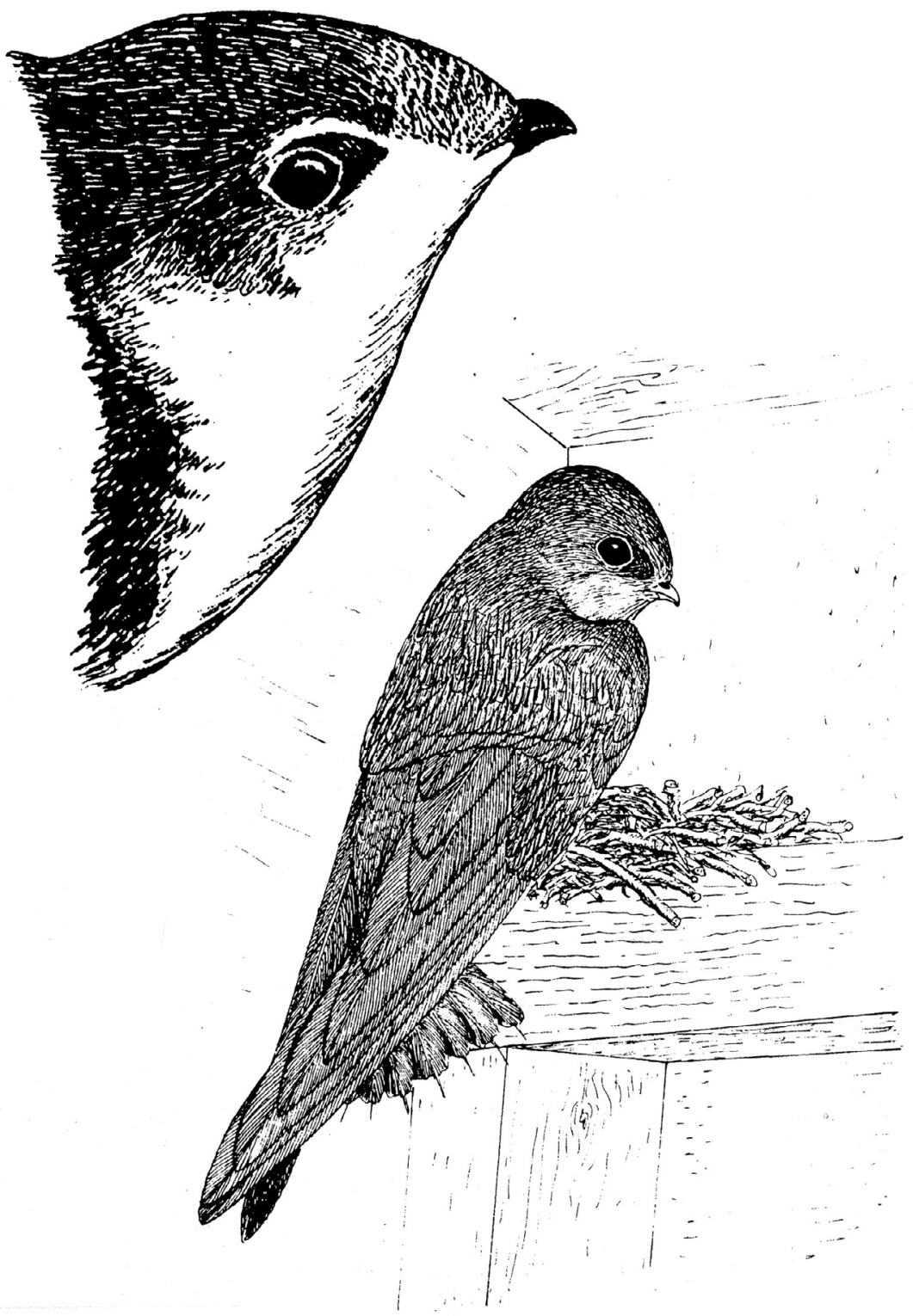

Figure 6. Adult white-throated swift (above) and chimney swift at nest (below) 
atlasing period of the Breeding Bird Atlas project, but nesting was confirmed in four Banner, Scotts Bluff, and Dawes County survey blocks (Mollhoff, 2016), as compared with a confirmed nesting in one Scotts Bluff County block during the first survey (Mollhoff, 2001).

Comments: Nests have been found at West Ash Creek Canyon, Dawes County (Nebraska Bird Review 73:17). Breeding Bird Surveys between 1966 and 2015 indicate that the species collectively underwent a survey-wide population decline (1.68\% annually) during that period.

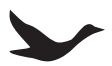

\section{Family Trochilidae (Hummingbirds)}

\section{Ruby-throated Hummingbird \\ Archilochus colubris}

This species is an uncommon to common spring and fall migrant and summer resident in eastern Nebraska, with nesting occurring at least along the Missouri River's forested valley and west probably rarely along the Platte River to at least Keith County (Nebraska Bird Review 76:60, 105). Vagrants appear farther west during migration, sometimes as far as Garden and Scotts Bluff counties. It breeds in the eastern half of the entire Plains states.

Migration: The range of 160 initial spring sightings is from April 7 to June 10, with a median of May 12. Half of the records fall within the period
May 5-17. Sixty-four final fall sightings are from July 30 to October 8, with a median of September 13. Half of the records fall within the period September 2-18.

Habitats: Migrants often appear in city gardens or other areas where nectar-bearing flowers occur, but breeding is done in woodlands, orchards, and parks where large trees as well as flowering herbs and shrubs are available. Five nests of this species were discovered during the second atlasing period of the Breeding Bird Atlas project, nesting was confirmed in two Dodge and Dixon County survey blocks, and ten probable nestings were reported from Jefferson County to Cedar County (Mollhoff, 2016), as compared with confirmed nestings in two blocks of Douglas and Washington counties during the first survey (Mollhoff, 2001).

Comments: Breeding Bird Surveys between 1966 and 2015 indicate that the species collectively underwent a survey-wide population increase (1.44\% annually) during that period. The increase in popularity of using hummingbird feeders has greatly increased the number of hummingbird reports, stretched out the extent of early spring and late fall records, and allowed for the documentation of several rare western hummingbird species in Nebraska.

\section{Black-chinned Hummingbird} Archilochus alexandri

Accidental. An adult female was photographed in Scottsbluff, May 7-8, 2012 (Nebraska Bird Review 80:596o; Delara and Smith, 2013). The other two records were July 28, 2013, 
near Ogallala, and September 13-16, 2013, at Shelton (Nebraska Bird Review 81:112, 147). The black-chinned hummingbird is a rare summer visitor and possible summer resident in Kansas (Thompson et al., 2011). The species' nearest known breeding area is in western Oklahoma.

\section{Anna's Hummingbird}

Calypte anna

Accidental. One record exists for this species: a bird was seen and photographed in an Omaha yard from November 19 to December 9, 2016 ( Nebraska Bird Review 84:162). The species' nearest breeding area is southern New Mexico.

\section{Costa's Hummingbird}

Calypte costae

Accidental. Three records exist for this species; the first was one present from about October 5 to November 17, 2001, at a Lexington feeder (Nebraska Bird Review 69:175, 71:97). As of 2010 there were three state records. The second was at Lake McConaughy from early September to October 23, 2013, and the was third was a bird at a Sarpy County feeder from September 10 to mid-October, 2010 (Nebraska Bird Review 81:147, 84:163). The species' nearest breeding area is in Arizona.

\section{Broad-tailed Hummingbird}

Selasphorus platycercus

This species is an occasional migrant in western Nebraska, mostly in fall, but with some summer records. Possible breeding has occurred in Scotts Bluff County (Nebraska Bird Review $75: 70$ ), but state breeding is still un- proven. Several sight records exist for Dawes and Scotts Bluff counties, and it has also been seen in Lincoln, Keith, Adams, and McPherson counties. As of 2016 there were four documented spring records, most from Dawes County (Nebraska Bird Review 82:60, 84:73). There were also about ten fall records for eastern Nebraska through 2011 (Nebraska Bird Review 80:96). The broad-tailed hummingbird is a common breeder in Wyoming and Colorado, a rare breeder in western South Dakota (Tallman, Swanson, \& Palmer, 2002), and a rare migrant in western Kansas (Thompson et al., 2011).

Migration: Fifteen initial fall records of this autumn migrant range from July 20 to September 13 , with a median of August 4. Sixteen final fall records are from August 3 to September 14, with a median of August 14. Half of the total fall records fall within the period July 29 to August 16.

Habitats: Migrants are normally associated with open plains, forest clearings, and mountain parklands but sometimes appear in gardens or at hummingbird feeders as well.

Comments: Broad-tailed hummingbirds are very common nesters in the mountains of Colorado and Wyoming; the birds seen in western Nebraska are probably vagrants from there.

\section{Rufous Hummingbird}

Selasphorus rufus

This species is an occasional fall migrant in western Nebraska, rare in the east. Most of the records are for Scotts Bluff County. As of 2010, there had been more than 20 records for eastern Nebraska (Nebraska Bird Review 
$78: 96)$. It is a rare regular migrant in western South Dakota and western to central Kansas, especially during fall. The nearest breeding area is in northwestern Wyoming.

Migration: Sixteen fall sightings of this species range from July 30 to September 14, with a median of August 12. Half of the records fall within a period August 9-17. There is at least one spring record (Nebraska Bird Review 81:64). Kansas records extend (surprisingly) to December 6 (Thompson et al., 2011).

Habitats: Migrants are associated with plains, foothills, and urban gardens.

Comments: Hummingbirds have greatly expanded their winter range in recent years, now commonly overwintering along the Gulf Coast states and even occasionally wandering east to the New England states. Probably this has resulted at least in part from the increase in hummingbird feeding activities, and more records of such rare hummingbirds can be expected. The species' nearest breeding area is in northwestern Wyoming.

\section{Calliope Hummingbird}

Selasphorus calliope

This tiny hummingbird is a rare migrant, mainly in western Nebraska. There is a specimen record for Lincoln County, obtained in April 1962 (Nebraska Bird Review 30:55), and the species had been seen in the same county in August 1960. A specimen was collected in Sioux County on June 23, 1994 (Nebraska Bird Review 64:135). There were 13 records through 2003, mostly for fall ( $\mathrm{Ne}$ braska Bird Review 71:157). The cal- liope hummingbird is a rare regular migrant in western South Dakota and western Kansas, especially during fall; Kansas records extend to October 19 (Thompson et al., 2011). The species' nearest breeding area is in northwestern Wyoming.

\section{, \\ Family Rallidae (Rails and Coots)}

\section{Yellow Rail}

Coturnicops noveboracensis

This species is a very rare spring and fall migrant in Nebraska. Most of the records are for eastern counties. There are at least two June records, suggesting possible breeding (Nebraska Bird Review 41:24), but the nearest area of known breeding is southern Minnesota. It also breeds in eastern North Dakota and perhaps in South Dakota, Kansas, and Iowa.

Migration: Eight total spring records are from April 26 to June 10, with a mean of May 6. The fall records are for late September-early October, include one at Peru Bottoms Wildlife Management Area, Nemaha County, and one at Omaha (Nebraska Bird Review 83:163-164). In Kansas it has been reported from as early as March 5 to as late as October 29 (Thompson et al., 2011).

Habitats: During migration, the yellow rail is likely to be found in marshes with extensive grassy or sedge vegetation. When it occurs in 
the same marshes with Virginia and sora rails, it tends to occupy the densest areas of sedges, while the other species are more often found in areas of cattails and bulrushes.

Comments: Yellow rails are among the most elusive of birds, and even the most avid birders often fail to add this species to their life lists. Most have to settle for hearing responses to playbacks of the species' calls.

\section{Black Rail}

\section{Laterallus jamaicensis}

This species is an apparently very rare spring and fall migrant and a possible breeder. Two specimen records exist from Nemaha County for September of 1873 , one bird was seen in the Omaha Market, and there was an early sight record for Cuming County (Bruner, Wolcott, \& Swenk, 1904). Recent records include one possibly seen at Lake 11 near Omaha, Douglas County, September 20, 1979; one reported on May 13, 1979, from Phelps County (Nebraska Bird Review 47:67), and one also reported present (based on questionable tape recordings) at Crescent Lake National Wildlife Refuge in late May 1991 and 1995 (Nebraska Bird Review 49:42, 63:73). As of 2016 only two Nebraska records (out of about 20 total reports) had been accepted by the NOU Records Committee. Using a call-playback technique, McGregor et al. (2016) elicited vocal responses from a black rail at Harvard Waterfowl Production Area on June 15, 2016. Nebraska is slightly north of the black rail's known Kansas breeding range, but possible Nebraska breedings have been suggested north and west to Crescent Lake National
Wildlife Refuge and Morrill County. Fall calling at Peru Bottoms Wildlife Management Area, Nemaha County, suggests possible territorial activity (Nebraska Bird Review 83:164). This species was also reported from Lancaster County in May 1980 (Nebraska Bird Review 48:88) and (based on a calling bird) from Verdigre, Knox County, November 1, 2002 (Nebraska Bird Review 71:138).

Migration: The few Nebraska records extend from May 13 to November 2. In Kansas it has been reported from as early as April 21 to as late as October 29 (Thompson et al., 2011).

Habitats: In the Great Plains this species occupies marshy meadows that are heavily overgrown with sedges and grasses. Like the yellow rail, it is much more likely to be heard than seen.

Comments: This species is even less frequently seen than the yellow rail, although some people have told stories of sitting still beside a dense marsh and seeing a black rail suddenly appear and nearly walk across their feet. Playback of recordings of black rail calls at the Crescent Lake refuge have suggested that a breeding population may occur there, but this remains to be proven, as does possible breeding in the Rainwater Basin.

\section{Clapper Rail}

Rallus longirostris

Accidental. A clapper rail was captured in a trap at Stapleton, Logan County, January 20, 1951, and an individual was also observed near Brule, May 9, 1954 (Brown, Dinsmore, \& Brown, 2012). The species' nearest breeding area is in coastal Texas. 


\section{King Rail}

Rallus elegans

The king rail is a rare summer resident in eastern Nebraska. An old nesting record exists for Douglas County. There are very few more recent records, but this rail probably breeds mainly and locally in the eastern Rainwater Basin. It possibly also nests in the Clear Creek marshes at the west end of Lake McConaughy, and in Sheridan and Morrill counties. Most recent regional sightings are from eastern North Dakota and southern Minnesota southward to eastern Texas. It has nested rarely in South Dakota and is an uncommon, local breeder in Kansas (Thompson et al., 2011).

Migration: Nine total spring records extend from April 2 to June 9, with a mean of May 6. Five fall records are from July 10 to September 11, with a mean of August 7. Kansas records extend to late December and suggest that occasional overwintering occurs there (Thompson et al., 2011).

Habitats: During the breeding season this species is associated with freshwater marshes, up to four feet deep, with abundant shoreline and emergent vegetation.

Comments: This large rail has been seen several times in the Lincoln area, but no recent recent nesting records have been established for Nebraska.

\section{Virginia Rail \\ Rallus limicola}

This species is an uncommon spring and fall migrant and summer resident almost statewide. It is less common in the Panhandle but is regular in southern Sioux and Dawes counties. It breeds widely in the Great Plains except in the drier western areas and also the southeastern portion, and it occurs throughout during migration.

Migration: Thirty-six initial spring sightings are from February 14 to June 1 , with a median of May 8 . Half of the records fall within the period April 29-May 16. Thirteen final fall sightings are from July 21 to October 13, with a median of September 16 .

Habitats: The primary breeding habitats are marshes with extensive stands of emergent vegetation such as taller grasses, bulrushes, and sedges. Nests are built over wet ground or in shallow water among emergent vegetation. One nest of this species was discovered during the second atlasing period of the Breeding Bird Atlas project, and nesting was confirmed in three survey blocks (Mollhoff, 2016), as compared with confirmed nestings in six blocks during the first survey (Mollhoff, 2001).

Comments: Virginia rails nest regularly across the state, especially in the Sandhills, but actual nesting records seem limited to Sioux, Sheridan, Garden, Arthur, Lincoln, Cherry, Hall, Holt, and Lancaster counties. Until Lake Ogallala was modified to allow for increased hydropower capabilities for Kingsley Dam in the 1980s, a veritable chorus of sora and Virginia rails could be heard regularly on summer evenings. Breeding Bird Surveys between 1966 and 2015 indicate that the species collectively underwent a survey-wide population increase (1.01\% annually) during that period.

\section{Sora}

Porzana carolina

This species is a common spring and 
fall migrant and locally common summer resident nearly statewide but is more local in the Panhandle.

Migration: Of 108 initial spring records, the range is from March 10 to June 3, and the median is May 6. Half of the records fall within the period April 30 to May 12. Twenty-five final fall sightings are from July 27 to November 27, with a median of September 30 .

Habitats: Habitats are apparently almost identical to those of the Virginia rail, namely marshlands with extensive stands of dense emergent vegetation, especially grasses and grassland plants. Nesting tends to occur in deeper water than is preferred by the Virginia rail, often in water 9-12 inches deep and well concealed in cattails, bulrushes, or sedges.

Comments: The sora is the commonest of the rails in Nebraska, but even so nesting records are rather few and far between (Nebraska Bird Review 80:40-42). During the first atlasing period there was only a single confirmed nesting, in Lincoln County (Mollhoff, 2001). One nest of this species was also discovered during the second atlasing period of the Breeding Bird Atlas project, and nesting was confirmed in two Saunders and Howard County survey blocks (Mollhoff, 2016), as compared with a confirmed nesting in one Lincoln County block during the first survey (Mollhoff, 2001). The eggs and nests of sora and Virginia rails are nearly identical. Breeding Bird Surveys between 1966 and 2015 indicate that the species collectively underwent a survey-wide population increase ( $0.43 \%$ annually) during that period, and a 3.89\% annual increase in Nebraska.

\section{Purple Gallinule}

Porphyrio martinica

Accidental. This gallinule was observed in Cuming County in the summer of 1884 or 1885 , and a second one was observed in Gage County on March 28, 1962 (Nebraska Bird Review 38:50). There are records from spring to early summer for at least ten Kansas counties (Thompson et al., 2011), and breeding occurs no closer than southeastern Oklahoma.

\section{Common Gallinule}

\section{Gallinula galeata}

This species is an occasional migrant in eastern Nebraska and a rare summer resident. There are a few old and scattered breeding records (Cherry, Lincoln, and Douglas counties), and more recent records in Lancaster, Seward, and Fillmore counties (Mollhoff, 2001, 2016). As of 2009 there had been about ten breeding records (Nebraska Bird Review 77:144).

Migration: Sixteen initial spring records are from March 23 to June 1, with a median of May 11. Half of the records fall within the period May 1-29. Three final fall sightings are from July 26 to September 29, with a mean of August 22. Kansas records extend to November 10 (Thompson et al., 2011).

Habitats: The favored summer habitat of the common gallinule consists of freshwater ponds and marshes having an abundance of emergent vegetation. Nests are usually placed above water or on land surrounded by water. 

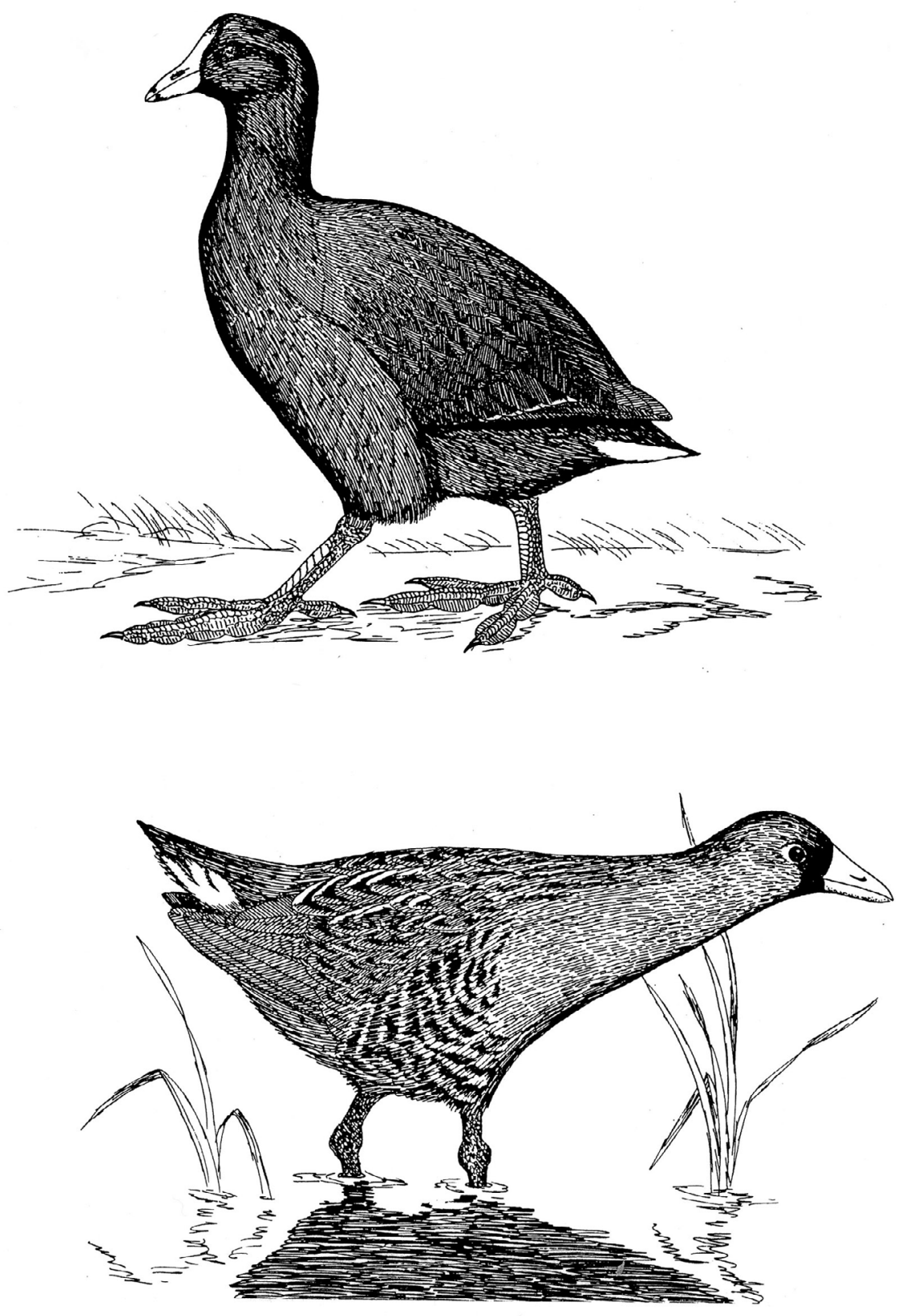

Figure 7. Adult American coot (above) and adult sora (below) 
No nests of this species were discovered during the second atlasing period of the Breeding Bird Atlas project, but nesting was confirmed in one Seward County survey block (Mollhoff, 2016), as compared with confirmed nestings in three blocks during the first survey (Mollhoff, 2001).

Comments: Common gallinules (called "common moorhens" in Britain) are moderately common birds, but they are nearly as elusive as rails in most locations. Yet in England, where they are fully protected, they are as fearless as coots and can be easily seen in park lagoons, even in the heart of London.

\section{American Coot}

\section{Fulica americana}

This species is a common to abundant spring and fall migrant and summer resident. It occurs throughout the state but is most abundant in the Sandhills marshes. Sometimes it overwinters where open water exists.

Migration: Seventy-four initial spring sightings are from February 4 to June 7 , with a median of March 29. Half of the records fall within the period March 19 to April 24. Eightytwo final fall records are from July 25 to December 31, with a median of November 2. Half of the records fall within the period October 14 to November 21.

Habitats: A wide variety of wetlands, ranging from small ponds or large lakes and reservoirs are used throughout the year, but those that are fairly shallow and rich in submerged aquatic plants are favored. Nesting usually occurs in emergent vegetation. Thirty-six nests of this species were discovered during the second atlasing period of the Breeding Bird Atlas project, and nesting was confirmed in 23 survey blocks (Mollhoff, 2016), as compared with confirmed nestings in 32 blocks during the first survey (Mollhoff, 2001).

Comments: Coots have a bad "image" problem-they tend to be "tame," and they dive with some difficulty (because their toes are not fully webbed) so they are often judged to be stupid. Hunters scoff at them as game birds because they take flight with some difficulty. During the 1950s the US Fish and Wildlife Service tried to popularize their hunting (and increase the sale of hunting permits) by increasing the daily kill limit and calling them "white-billed ducks," but this did nothing to enhance the coots' popularity. Yet, they are fascinating to watch as they establish and vigorously defend their territories with fights and threats, and industriously guard and feed their strange-looking chicks. Breeding Bird Surveys between 1966 and 2015 indicate that the species collectively underwent a survey-wide population increase (0.62\% annually) during that period, and Nebraska had an estimated $3.47 \%$ rate of annual decline. 


\section{Family Gruidae (Cranes)}

\section{Sandhill Crane}

Antigone canadensis

This species is an abundant spring migrant in the Platte Valley from Grand Island to Lewellen, becoming less numerous elsewhere but common west locally in the Clear Creek area of Lake McConaughy and around North Platte, Hershey, and Scottsbluff (Winters Creek).

Generally less abundant in the fall. Other than the Platte Valley, the only significant area of migrant concentration is near the Harlan County Reservoir, which the birds have increasingly used in early spring. Elsewhere in the Great Plains it is a regular but less common migrant. It is a widespread but local breeder. In recent years possibly breeding adults have been seen in at least 11 counties during the breeding season (Nebraska Bird Review 81:109, 82:16-17). Since 1996, breeding has occurred in the eastern Rainwater Basin on many occasions (Nebraska Bird Review 67:48; 71:113; 75:76; 76:101, 158; 77:54; Brown \& Johnsgard, 2013), as well as in Morrill County (Chet and Jane Fleisbach Wildlife Management Area) and Scotts Bluff County (Kiowa Wildlife Management Area) (Nebraska Bird Review 81:58).

Migration: Fifty-seven initial spring sightings are from January 8 to May 1, with a median of March 1 . Half of the records fall within the period February 10 to March 20. Thirty final spring sightings are from March 9 to June 1, with a median of April 7. Fiftyfive initial fall sightings are from September 2 to November 24, with a median of October 8. Half of the records fall within the period September 28 to October 22. Fifty-three final fall sightings are from October 1 to December 31, with a median of November 5 .

Habitats: Slowly flowing rivers, with relatively bare bars and islands for roosting, and adjacent wet meadows and croplands for foraging, are used by this species during migration. The Platte Valley is evidently the optimum spring habitat for this species in the entire Plains region. Spring concentrations there are unequaled anywhere in North America, usually peaking at about 500,ooo550,000 in late March. Scattered breeding now occurs in marshes almost statewide, but the birds are then so elusive their nests are only rarely found (Nebraska Bird Review $81: 58)$. No nests of this species were discovered during the second atlasing period of the Breeding Bird Atlas project, but nesting was confirmed in four Garden, Rock, and York County survey blocks (Mollhoff, 2016).

Comments: Sandhill cranes are the perfect harbinger of spring in $\mathrm{Ne}$ braska: they arrive with the break in winter weather (as soon as the Platte becomes nearly ice-free) and their departure coincides with the leafing out of our flowering trees and shrubs. Breeding Bird Surveys between 1966 and 2015 indicate that the species collectively underwent a survey-wide population increase ( $4.74 \%$ annually) during that period. 


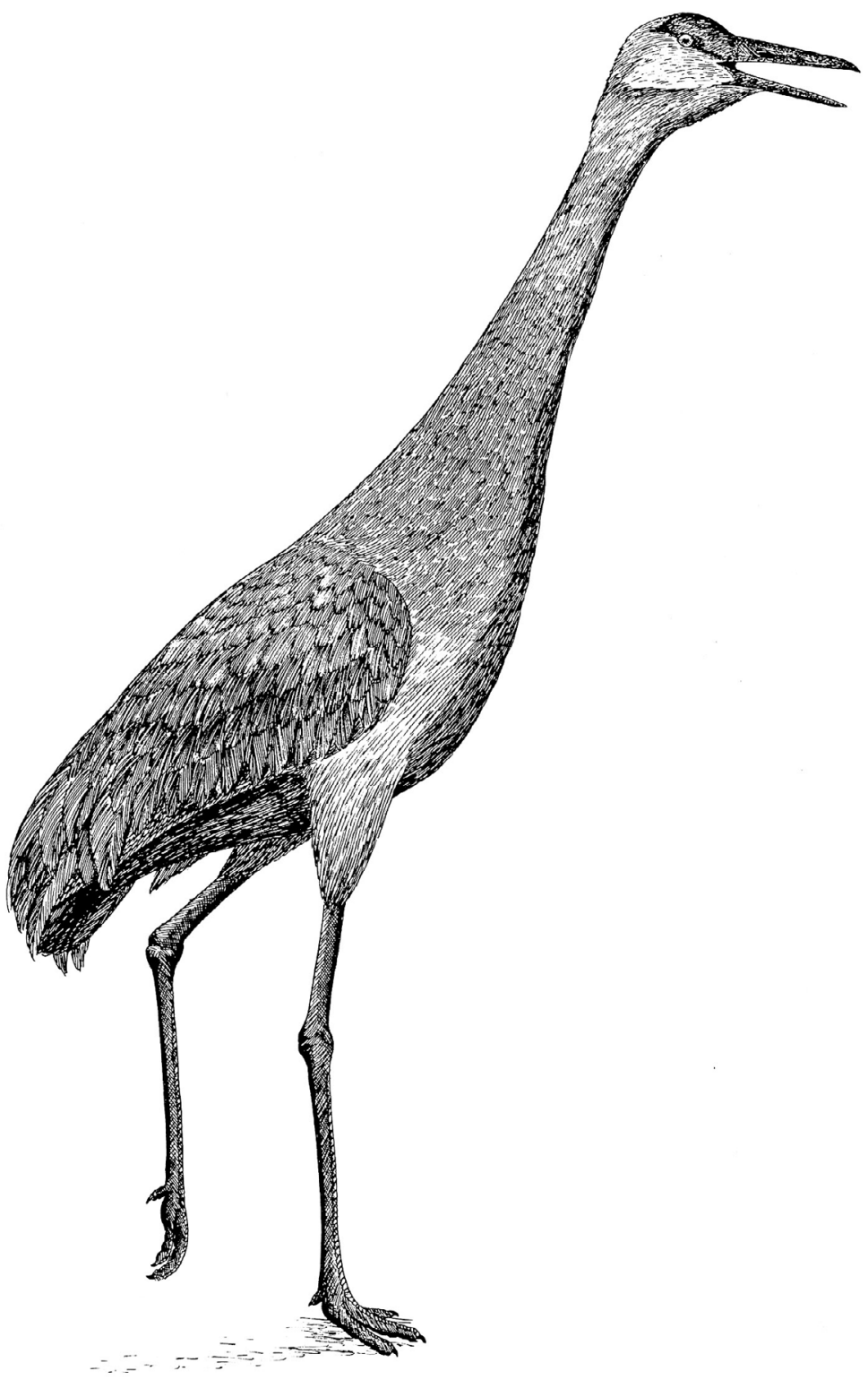

Figure 8. Adult sandhill crane, male uttering mild alarm ("guard") call 


\section{Common (Eurasian) Crane}

Grus grus

Extremely rare. Apparently two different individuals were observed in Lincoln County during 1972, and in 1974 one was seen in Kearney County on March 16 and 25. An adult was reported March 30-31, 1996, in Hall County (Nebraska Bird Review 64:8082; Brogie, 1997). One was also observed from March 6 until about March 14, 1999, in Kearney and Buffalo counties, and a probable male with a sandhill crane mate and two apparently hybrid offspring were seen in Hall County in mid-March 2000. A Eurasian crane was also observed near Lewellen, March 19, 2009, and elsewhere (Hershey, North Platte) that same month, and appeared near Hershey again March 18-24, 2010 (Brown, Dinsmore, \& Brown, 2012). As of 2011 there were 14 state records (Nebraska Bird Review 76:58, 77:54, $78: 47,79: 53)$. One was reported February 7,2017 , about 70 miles west of Kearney (Nebraska Bird Review 85:10).

\section{Whooping Crane}

\section{Grus americana}

This species is an occasional spring and fall migrant in Nebraska, more often present in spring than in fall. It has been observed in at least 26 counties but most commonly in Buffalo and Kearney counties. As of the early 20oos it had also been observed at least ten times each in Dawson, Hall, Lincoln, and Adams counties. More than $90 \%$ of the pre-1977 sightings occurred within 30 miles of the Platte River, and about 80\% have occurred between Lexington and Grand Island
(Johnsgard \& Redfield, 1977). There have been many recent sightings, with four confirmed and five probable in the fall of 1994 alone (Nebraska Bird Review 62:149-150) and 20 during the spring 1996 migration (Nebraska Bird Review 64:69). It is also rare to occasional in Oklahoma, Kansas, and the Dakotas; extremely rare in Colorado; and accidental in Minnesota.

Migration: An early summary of migration records for the whooping crane has already been published (Nebraska Bird Review 45:54-56), which indicates that the spring migration historically extended from early March to late May, with a peak during the period April 1-15. The earliest spring record is for February 10, 1995; many individual whooping cranes have followed early arriving sandhill cranes to the Platte Valley. The fall migration extends from midSeptember to early November, with a peak during the period October 11 to 25. Jorgensen and Brown (2017) provided data showing that this historic schedule is now outdated, owing to climate change, with spring arrival times occurring earlier and fall departure times later.

Habitats: While in Nebraska, the Platte Valley is the primary habitat, and a wide and slow-flowing river, with its numerous sandbars and islands, and adjacent wet meadows, grain fields, and marshlands, is evidently an important combination of habitat characteristics. The species migrates later in spring than does the sandhill crane, and thus does not normally associate with it. It uses marshy areas, playa "lagoons," and similar wetlands for foraging to a 
larger degree than does the sandhill crane, in conjunction with its greater dependence on aquatic invertebrates (Johnsgard, 2001b, 2015a).

Comments: Whooping cranes have stopped in Nebraska's Platte Valley more often than anywhere else along their entire migration route between wintering and breeding ranges. Unlike sandhill cranes' behavior, flock sizes are quite small, often composed of single families. In recent years a few cranes have arrived early with flocks of sandhill cranes; presumably these are immature birds. By the fall of 2017 the estimated population of the primary Wood Buffalo-Aransas flock was judged to be 431 birds, based on wintering birds arriving at Aransas National Wildlife Refuge.

\section{(Hooded Crane)}

\section{Grus monacha}

Hypothetical. A hooded crane was observed and photographed in Hall County for 17 days from March 25 to April 11, 2001. This rare east Asian species of crane was believed to have been a possible escape from captivity (Nebraska Bird Review 79:53), but an apparently wild hooded crane was also more recently seen and photographed in Tennessee and Indiana during January and February 2012.

\section{Family Charadriidae (Plovers)}

\section{Black-bellied Plover}

Pluvialis squatarola

This species is an uncommon spring and fall migrant in eastern Nebraska, becoming rarer westwardly. Blackbellied plovers are less common in fall than during spring but more common in both seasons than the golden plover. It migrates throughout most of the Great Plains region. The nearest breeding area is in northern Nunavut.

Migration: Sixty-six total spring sightings range from April 4 to June 9, with a median of May 16. Half of the records fall within the period May 12-23. Thirteen initial fall sightings are from July 27 to October 2, with a median of August 20. Thirteen final fall sightings are from August 27 to November 12, with a median of October 6 .

Habitats: Migrating birds use mudflats, shallow ponds, and plowed fields.

Comments: In contrast to most shorebirds, ploughed fields are a favorite habitat for migrant black-bellied plovers. In these locations the black and white plumage patterns seem adaptive. This species and the golden-plovers are almost unique among American shorebirds in having darker underparts than backs, which is contrary to the principle of countershading for maximum concealment.

\section{American Golden-Plover}

Pluvialis dominica

This species is an uncommon to occasional migrant in eastern Nebraska, 
becoming rarer westwardly. It is more common in spring than fall but present both seasons. It migrates throughout most of the Great Plains region. The nearest breeding area is in northern Manitoba.

Migration: Forty-nine total spring sightings are from April 6 to May 29, with a median of May 7. Half of the records fall within the period April 25 to May 14. Ten initial fall sightings are from September 2 to October 9, with a median of September 28. Ten final fall sightings are from September 8 to November 20, with a median of October 12.

Habitats: Migrants favor grass stubble, short pasturelands, and newly plowed fields. As many as 1,00o birds have been seen around Utica and Tamora in mid-April (Nebraska Bird Review 85:62).

Comments: In common with the previous species, the upperpart coloration of adults in breeding plumage is spangled with dark and light markings. When crouched on a nest these patterns merge almost perfectly with the wet tundra (golden-plovers) or dry tundra (black-bellied plover) habitats that are each species' preferred nest sites.

\section{Snowy Plover}

Charadrius nivosus

This species is a rare summer resident. There are two early specimen records from Lancaster County (Nebraska Bird Review 1:31). The snowy plover was also observed in Antelope County in 1955, Adams County in 1957, Lincoln County in 1964, Lancaster County in 1972, Phelps County in 1974, and Keith County in 1977. It has since been re- ported in Phelps County in May 1994 and 1995 (Nebraska Bird Review 62:99, 64:71) and in Fillmore and Clay counties in 1996 (Brogie, 1997). It has been a rare nester at Lake McConaughy since at least 2000 (Nebraska Bird Review 73:154-156; Brown, Dinsmore, \& Brown, 2012).

Migration: Six spring records for this species range from April 6 to May 17, with a mean of April 28. Five fall records are from August 7 to September 7, with a mean of August 21. Kansas fall records extend to October 18 (Thompson et al., 2011).

Habitats: Migrants are found on mudflats, alkaline flats, sandy shorelines, and in shallow ponds. Twentyfour nests of this species were discovered during the second atlasing period of the Breeding Bird Atlas project, and nesting was confirmed in four survey blocks (Mollhoff, 2016).

Comments: As for the piping plover, the pale gray back of the snowy plover matches the color of dry sand and makes the birds almost impossible to see when they are sitting on their eggs. It has been suggested that the black upper breast markings of these birds are examples of disruptive coloration, actually making them harder to see.

\section{Semipalmated Plover}

Charadrius semipalmatus

This species is an uncommon to occasional spring and fall migrant statewide but probably is more common eastwardly. It also migrates throughout the entire Plains region.

Migration: Eighty-two initial spring sightings are from March 24 to June 6 , with a median of May 12. Six- 
teen initial fall sightings are from July 25 to September 24, with a median of August 11. Sixteen final fall sightings are from July 30 to October 14, with a median of September 18.

Habitats: Migrants favor mudflats, shallow ponds, and the muddy banks of slowly flowing rivers.

Comments: Unlike the snowy and piping plovers, this species is a highArctic breeder, nesting on pebbly tundra sites. Its back is the color of wet sand, which helps to distinguish the species from the two just-mentioned species.

\section{Piping Plover}

Charadrius melodus

The piping plover is an occasional to rare spring and fall migrant, and a local rare summer resident. Older nesting records are numerous for the $\mathrm{Ni}$ obrara, North and South Platte, Loup, and Missouri Rivers, but most of the recent records are for the Platte (especially from Dawson County eastward), lower Niobrara and upper Missouri, Loup, and Middle Loup Rivers and at Lake McConaughy. Recent Breeding Bird Surveys indicate that 250-280 pairs breed in the state, most in the central Platte Valley, at Lake McConaughy, on spoil piles associated with gravel operations, and other humanaltered habitats (Brown, Jorgensen, \& Rehme, 2008). In 2005, 202 nests were found at Lake McConaughy, compared with 182 in 2004 and 117 in 2003 (Nebraska Bird Review 73:101). Counts in 2006 and 2011 revealed 723 (2006) and 330 birds in the state, many at Lake McConaughy (Nebraska Bird Review 79:88). It is classified as both nationally and state threatened.
Migration: Sixty-one initial spring sightings are from March 27 to June 1, with a median of May 3. Half of the records fall within the period April 21 to May 12. Five final fall sightings are from July 27 to September 5, with a mean of August 19. Fall Kansas records extend to October 22 (Thompson et al., 2011).

Habitats: Breeding birds are usually associated with sparsely vegetated shorelines of shallow lakes and impoundments, especially those having bare sand or salt-encrusted areas of gravel, sand, or pebbly mud. Clutches are laid in areas of pebbly gravel, the eggs often closely matching the color and stones of the surrounding area. Suitable areas include shorelines of natural wetlands as well as human-created habitats (Nebraska Bird Review 76:72-80). Double-brooding has been reported in Nebraska (Hunt et al., 2015). About 200 nests of this species were discovered as a result of intensive surveys by Mary Bomberger Brown and her assistants during the second atlasing period of the Breeding Bird Atlas project, and nesting was confirmed in 12 survey blocks (Mollhoff, 2016), as compared with confirmed nestings in 21 blocks during the first survey (Mollhoff, 2001). Brown and colleagues have surveyed and researched this species extensively (Brown \& Jorgensen, 2010; Brown, Jorgensen, \& Rehme, 2008).

Comments: The piping plover is one of the state's breeding birds that is considered nationally threatened. Changes in annual river flows of the Missouri and Platte Rivers have destroyed much of its historic breeding 
habitat, although sandpit operations have provided some new opportunities. The total northern Great Plains population comprised about 1,250 pairs in the mid-1990s, of which Nebraska's component represented about 20\%. In 2006 the Platte Valley population accounted for nearly $5 \%$ of the Interior race's entire population (Mary B. Brown, cited by Johnsgard, 2012e).

\section{Killdeer}

\section{Charadrius vociferus}

This species is a common to abundant spring and fall migrant and summer resident statewide. Killdeer overwinter infrequently in the state. It also breeds and migrates throughout the Great Plains.

Migration: The range of 86 initial spring sightings is from February 11 to May 27, with a median of March 13. Half of the records fall within the period March 8-19. The range of 110 final fall records is from August 18 to December 31, with a median of October 19. Half of the records fall within the period September 27 to November 10 .

Habitats: This highly adaptable species often occurs on open fields during migration but typically breeds near wetlands where there is exposed ground nearby. Killdeer seem to prefer gravelly, stony, or sandy areas for nesting, but they also nest in a wide variety of locations, sometimes even in garden plots and on building rooftops. Twenty-nine nests of this species were discovered during the second atlasing period of the Breeding Bird Atlas project, and nesting was confirmed in 145 survey blocks (Mollhoff, 2016), as compared with confirmed nestings in 157 blocks during the first survey (Mollhoff, 2001).

Comments: This is the most widespread and common plover in North America, often nesting well away from water and close to human population centers. Its conspicuous killdeer calls can be heard in Nebraska from mid-March onward, and its defensive "broken-wing" behavior is familiar to every rural schoolchild. Breeding Bird Surveys between 1966 and 2015 indicate that the species collectively underwent a survey-wide population decline (1.09\% annually) during that period, whereas Nebraska had an estimate (based on 51 survey routes) of a $0.8 \%$ rate of annual increase.

\section{Mountain Plover}

Charadrius montanus

This species is a rare spring and fall migrant and summer resident in extreme western Nebraska (Kimball grasslands and shortgrass prairies). A record of young seen in Kimball County in 1974 was the first known case of breeding in the state, and it was later found breeding there in 1990 and 1991. Breeding records exist for at least Kimball, Cheyenne, and Banner counties. In 200547 nests were located in Kimball County by Rocky Mountain Bird Observatory biologists, and one in Banner County, over 20,000 acres of dryland wheat fields (Nebraska Bird Review 73:101). In 2010 the Rocky Mountain Bird Observatory monitored 109 nests, which produced 30 broods (Nebraska Bird Review 78:93). The species is listed as state threatened. In Kansas there are 
breeding records for six counties and occurrence records for an additional 15 counties (Thompson et al., 2011).

Migration: Two initial spring sightings are for May 8 and May 15. There are no available fall records. In Kansas records extend from March 30 to November 6 (Thompson et al., 2011).

Habitats: Migrants or breeders in the Great Plains are usually found in short-grass plains habitats but sometimes also on sandy semiarid flats that support some brush or cactus. Nesting occurs in extremely exposed locations, often on bare ground. As a result of intensive studies by the Rocky Mountain Bird Observatory (e.g., Nebraska Bird Review 76:120-128), a total of 235 nests of this species were discovered by the Rocky Mountain Bird Observatory during the second atlasing period of the Breeding Bird Atlas project, and nesting was confirmed in three Dundy County survey blocks (Mollhoff, 2016). No nestings were found during the first survey (Mollhoff, 2001).

Comments: This characteristic species of the shortgrass plains benefits from grazing by bison or cattle, and its population has been seriously declining in recent years. Breeding Bird Surveys between 1966 and 2015 indicate that the species collectively underwent a survey-wide population decline (3.41\% annually) during that period.

\section{Family Recurvirostridae (Stilts and Avocets)}

\section{Black-necked Stilt \\ Himantopus mexicanus}

This species is a rare spring migrant. There was no evidence of breeding within the state until nesting began at Crescent Lake National Wildlife Refuge, Garden County, in 1985. Breeding has also occurred near Lakeside, Sheridan County, since at least 1985, and was documented in Dawes County in 1994, in Hall County in 1998, at Funk Waterfowl Production Area in 2003, and at Harvard Waterfowl Production Area and North Lake Basin (Seward County) in 2005. As of 2008 there had been five nestings in the eastern Rainwater Basin (Nebraska Bird Review 76:101, 159). There are also scattered nonbreeding records from other counties as far east as Antelope County, but no pattern of geographic consistency is evident.

Migration: Eight records extend from April 30 to August 8. Five of the records are for the month of May. Kansas records extend from March 21 to September 10 (Thompson et al., 2011).

Habitats: Black-necked stilts are generally associated with alkali ponds and marshes, often those used by avocets. Ten nests of this species were discovered during the second atlasing period of the Breeding Bird Atlas project, and nesting was confirmed in four survey blocks, three of which were in the Rainwater Basin (Mollhoff, 2016), as compared with confirmed nestings 
in two Sheridan and Garden County blocks during the first survey (Mollhoff, 2001).

Comments: This elegant, longlegged shorebird has been slowly increasing in Nebraska and elsewhere in the Great Plains. It seems to favor shallow, alkaline ponds such as those found in the western parts of Crescent Lake National Wildlife Refuge, where cinnamon teal and Wilson's phalaropes also congregate. Breeding Bird Surveys between 1966 and 2015 indicate that the species collectively underwent a survey-wide population increase (1.75\% annually) during that period.

\section{American Avocet}

\section{Recurvirostra americana}

This species is an uncommon spring and fall migrant in eastern and extreme western Nebraska. It is common in central parts of the state and a common summer resident in the Sandhills, and locally it also nests in the Rainwater Basin. The American avocet is a regular breeder in the western half of the Great Plains region, and migrants may appear throughout the region.

Migration: Eighty-two initial spring sightings range from April 2 to June 7 , with a median of April 28. Half of the records fall within the period April 20 to May 6. Thirty-eight final fall sightings are from July 25 to November 17, with a median of September 4 . Half of the records fall within the period August 25 to September 2.

Habitats: In Nebraska avocets are associated with shallow ponds or marshes with exposed and sparsely vegetated shorelines, often in association with fairly alkaline waters. Nests are placed in exposed locations on mudflats, sandbars, and islands with little or no surrounding cover. A total of 101 nests of this species were discovered during the second atlasing period of the Breeding Bird Atlas project, and nesting was confirmed in four survey blocks (Mollhoff, 2016), as compared with confirmed nestings in eight blocks during the first survey (Mollhoff, 2001).

Comments: The American avocet is one of the most beautiful of American shorebirds and can be easily seen at alkaline wetlands in the western parts of Crescent Lake National Wildlife Refuge. In the summer of 1995 more than 140 avocets were present there at Smith Lake, which was then being drained temporarily. Breeding Bird Surveys between 1966 and 2015 indicate that the species collectively underwent a survey-wide population decline ( $0.31 \%$ annually) during that period, and Nebraska had an estimated $0.30 \%$ rate of annual decline.

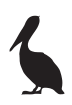




\section{Family Scolopacidae (Sandpipers, Snipes, and Phalaropes)}

\section{Upland Sandpiper}

Bartramia longicauda

This species is an uncommon spring and fall migrant and local summer resident in natural grasslands nearly statewide but is most common in the Sandhills. Elsewhere it nests in suitable habitats across the Great Plains, and migrants are regular throughout.

Migration: The range of 108 initial spring sightings is from March 9 to May 9, with a median of May 2. Half of the records fall within the period April 24 to May 10. Seventy-five final fall sightings are from July 21 to October 28, with a median of August 20. Half of the records fall within the period August 10-26.

Habitats: During summer, the upland sandpiper occurs on native prairies, especially mixed-grass and tall grass, on wet meadows, hayfields, retired croplands, and to a limited extent on fields planted to small grains. Ninety-seven nests of this species were discovered during the second atlasing period of the Breeding Bird Atlas project, and nesting was confirmed in 34 survey blocks (Mollhoff, 2016), as compared with confirmed nestings in 60 blocks during the first survey (Mollhoff, 2001).

Comments: One of the most typical and beautiful of the Sandhills breeders, the upland sandpiper provides a definition of grace when it lands on a fencepost and momentarily lifts both wings in a ballet-like movement, be- fore inserting them in its flank feathers and coming to rest. Its territorial song-flights are equally memorable. Once called the "upland plover," it is indeed rather plover-like in having a short bill and upland habitat preferences. Breeding Bird Surveys between 1966 and 2015 indicate that the species collectively underwent a surveywide population increase (0.04\% annually) during that period, and $\mathrm{Ne}-$ braska had an estimated $1.39 \%$ rate of annual increase.

\section{Whimbrel}

\section{Numenius phaeopus}

This species is a very rare or rare spring migrant. There were at least eleven sightings by the 1980 s, with the largest number from Lincoln County, but with other reports in York, Adams, Webster, and Lancaster counties. It is also an occasional to rare migrant elsewhere in the Great Plains; most fall migration probably occurs elsewhere. The nearest breeding area is coastal tundra in northern Manitoba.

Migration: Eleven spring records are from April 12 to May 27, with a median of May 10. There is one fall record (October 17) for Douglas County and a few other fall records. It has been reported in Kansas from April 3 to May 31, with most migration occurring from late April through mid-May. Fall migration records there are from July 12 to November 18 , with a peak during August (Thompson et al, 2011).

Habitats: Migrating whimbrels favor flooded grasslands, sandbars, and the shorelines of large impoundments.

Comments: There should be far more Nebraska records for this spe- 
cies than this summary would indicate. Whimbrels nest in Canadian tundra directly north of Nebraska, and some birds winter on the Gulf Coast, so a regular movement through $\mathrm{Ne}-$ braska seems likely.

\section{Eskimo Curlew}

Numenius borealis

The Eskimo curlew is almost certainly extinct; no documented records have accrued since the 1960 s. At one time it was a common to abundant spring and fall migrant in the state, but the last definite Nebraska record was on April 8, 1926, near Hastings. The species was once regular throughout the Great Plains from Texas to South Dakota. A Platte River sight record of April 16, 1986 (Nebraska Bird Review 55:78) was later withdrawn. The breeding grounds of this species were never located.

Migration: Ten spring records are from March 22 to about May 25, with a median of April 12. There are no specific fall records. Some birds possibly migrated through the state in October, although the bulk of the population migrated to the Atlantic coast and then flew south, with an extremely long and dangerous overseas transit from coastal United States to northeastern South America (Johnsgard, 1980c).

Habitats: While in Nebraska this species settled in large flocks on newly plowed fields and dry, burnedoff prairies, where they foraged on grasshoppers and other insects. They evidently concentrated in York, Fillmore, and Hamilton counties, in flocks of up to several hundred birds. As the native prairies disappeared, they increasingly used wheat fields and tame meadows.

Comments: Some believe that a few Eskimo curlews may yet survive, but there have been no verified sightings in the past few decades, and thus that fond wish is almost certainly a futile one.

\section{Long-billed Curlew}

Numenius americanus

This species is a common migrant and summer resident in western Nebraska, particularly in the Sandhills and High Plains regions. The eastern breeding limits reach at least Garfield and Holt counties, perhaps to the eastern edge of the Sandhills. Breeding also occurs in the western Dakotas, Colorado, New Mexico, Texas, and Oklahoma.

Migration: Eighty-three initial spring sightings range from March 7 to June 7, with a median of April 11. Half of the records fall within the period April 5-21. Twenty-eight final fall sightings are from July 22 to September 21, with a median of August 18. Half of the records fall within the period August 5-September 1. Probably many Nebraska breeders winter on the Gulf Coast of Texas and in northeastern Mexico, judging from the movements of a few radio-tracked birds.

Habitats: In Nebraska, this species is associated with Sandhills grasslands, short-grass plains, and other grassy environments offering extensive foraging and nesting opportunities. Nests often occur in prairie vegetation on upland slopes that are close to moist meadows for foraging. Two nests of this species were discovered during the second atlasing period of the Breeding Bird Atlas project, and 
nesting was confirmed in 18 survey blocks (Mollhoff, 2016), as compared with confirmed nestings in 35 blocks during the first survey (Mollhoff, 2001). Sandhills nesting might occur east to Brown, Rock, and Holt counties (Nebraska Bird Review 84:119).

Comments: It seems probable that the Nebraska Sandhills represent one of the last major breeding strongholds of this species in the Great Plains. The author once counted more than 50 curlews in a single wet meadow in Crescent Lake National Wildlife Refuge during July, at a time when flocks were starting to gather prior to fall migration. The Nebraska population has been estimated (probably much too optimistically) at about 24,00o (Nebraska Bird Review 79:89). Breeding Bird Surveys between 1966 and 2015 indicate that the species collectively underwent a survey-wide population increase (0.17\% annually) during that period, whereas Nebraska had a statistically questionable estimate (based on 19 survey routes) of a $3.04 \%$ rate of annual decline.

\section{Hudsonian Godwit}

\section{Limosa haemastica}

This species is an uncommon spring migrant in eastern Nebraska, becoming rare or absent in the west. There are no fall records for Nebraska or South Dakota, and few for Oklahoma and Kansas. It probably regularly migrates through the eastern half of the Great Plains during spring. The nearest breeding area is coastal tundra in northern Manitoba.

Migration: Sixty-nine initial spring records are from April 12 to May 27, with a median of May 2. Half of the records fall within the period April 22 to May 12. Ten final spring sightings are from May 6-25, with a median of May 15. In Kansas most of the relatively few fall records are from August 19 to September 26, with extremes of July 15 and August 2. Fall migrants in central Canada migrate first to James Bay and then east to the Atlantic coast before heading toward South America (Thompson et al., 2011).

Habitats: This godwit is associated with marshy ponds, wet grasslands, and flooded fields while on migration.

Comments: This is another beautiful shorebird that breeds in Arctic tundra and then upon arrival at its nesting grounds becomes a bush- and tree-perching bird, so that it can advertise its territory and look out for possible threats. Its rich rufous underpart coloration during spring easily separates it from the marbled godwit.

\section{Marbled Godwit}

\section{Limosa fedoa}

This species is an uncommon to locally common spring migrant throughout Nebraska, but there are far fewer records in fall. There are a few twentyfirst-century breeding records for the western and northern Sandhills and Sheridan County (Nebraska Bird Review 73:102, 76:102). It is a regular breeder in the Dakotas and western Minnesota, and is a migrant throughout the Great Plains. Marbled godwits are common during winter along the Gulf coast of Texas.

Migration: The range of 117 initial spring sightings is from April 5 to May 26, with a median of April 29. Half of the records fall within the period from April 22 to May 10. Eleven final spring 
sightings are from April 19 to May 23, with a median of May 7. Eleven total fall records are from July 20 to October 24, with a median of September 9.

Habitats: Migrating birds commonly use extensive mudflats, wet fields, sandbars, and the shorelines of impoundments. No nests of this species were discovered during the second atlasing period of the Breeding Bird Atlas project, but nesting was confirmed in two Dawes and Morrill County survey blocks (Mollhoff, 2016).

Comments: The name "godwit" comes from a traditional English name, meaning "a good thing (to eat)." That may be, but a godwit is a better thing to see and hear; this is the largest of all godwits and certainly one of the most attractive. Breeding Bird Surveys between 1966 and 2015 indicate that the species collectively underwent a survey-wide population decline (0.41\% annually) during that period.

\section{Ruddy Turnstone}

Arenaria interpres

This species is an occasional to rare spring migrant in eastern Nebraska but is very rarely seen as far west as Cherry and Garden counties. The largest number of sightings are for Adams and Lancaster counties, especially the latter. It is rarely reported during the fall, with a total of only 12 fall observations (Nebraska Bird Review 73:140). Migrants are most common in the eastern portions of the Great Plains, especially east of the Missouri River. The nearest breeding area is the coastal tundra of northern Nunavut.

Migration: Twenty-three total spring records are from April 19 to May 27, with a mean of May 18; half of the records fall within the period May 14-25, with a median of May 18. There are two fall records, September 10 and 17 (Rosche, 1982).

Habitats: Migrating birds use mudflats, shallow ponds, and plowed fields. Large concentrations of 100 or more birds sometimes appear briefly in mid-May among the fields and wetlands near Tamora, Seward County (Nebraska Bird Review 82:56).

Comments: Turnstones get their vernacular name from their tendency to flick over rocks and pebbles with their sharp bills in order to find small invertebrates that may be hiding below. Few turnstones are seen in $\mathrm{Ne}$ braska, but they are exciting finds whenever they can be found.

\section{Red Knot}

\section{Calidris canutus}

This species is an extremely rare spring and fall migrant. Most of the records are for Lancaster and Douglas-Sarpy counties, but scattered sightings are recorded elsewhere in eastern Nebraska. It is also a rare migrant in other locations in the Great Plains, mainly in the eastern portions. The nearest breeding area is in coastal tundra of northern Nunavut.

Migration: A total of six spring records range from May 7 to May 19, with a mean of May 14. Six fall records are from August 27 to October (no date), with a mean of September 12. Kansas records extend from April 9 to June 3 in spring and from July 24 to October 16 in fall (Thompson et al., 2011).

Habitats: Migrating knots use mudflats and sandbars. During spring on the Atlantic coast it feeds heavily on 
the eggs of horseshoe crabs during their brief spawning period.

Comments: The red knot is a rather robust little shorebird; its reddish underparts in spring is the basis for its common Atlantic coast name of "robin snipe." It is a high-Arctic nester, and its short bill would seem better adapted for surface foraging than for mud probing.

\section{Ruff}

\section{Philomachus pugnax}

Extremely rare. At least seven state records for this Eurasian species include one observed near Axtell, Kearney County, September 1991 (Nebraska Bird Review 64:31) plus later records in Phelps County, April 19, 1994 (Nebraska Bird Review 62:99), in Antelope County, April 10, 1998, (Nebraska Bird Review 66:41), in York County, September 27, 1998 (Brogie, 1999), at Branched Oak Lake, Lancaster County, May 4, 2002 (Nebraska Bird Review 70:60), and in Clay County, March 26, 2005 (Nebraska Bird Review 73:55). There are records from nine Kansas counties (Thompson et al., 2011).

\section{Sharp-tailed Sandpiper}

\section{Calidris acuminata}

Accidental, with four sight records. The first record of this Eurasian species was of a juvenile in Butler County, October 12, 1986 (Nebraska Bird Review 54:70), and the second was a bird seen in Sheridan County, September 6, 1996 (Nebraska Bird Review 62:114). By 2010 there were four state records (Nebraska Bird Review 78:138).

\section{Stilt Sandpiper}

Calidris himantopus

This species is a common or uncommon spring and fall migrant almost statewide but is less abundant westwardly. It is a regular migrant throughout the entire Plains states.

Migration: Ninety-nine initial spring sightings are from April 3 to May 29, with a median of May 11. Half of the records fall within the period May 9-19. Sixteen final spring sightings are from May 7 to May 30, with a median of May 17. Eleven initial fall sightings are from July 21 to September 19, with a median of August 11. Nine final fall sightings are from September 3 to October 21, with a median of September 20.

Habitats: Muddy flats, shallow mud-bottom ponds, and flooded fields are used by migrants; the birds feed in belly-deep water and are more likely than many other shorebirds to be in sheltered areas than on exposed shorelines.

Comments: The stilt sandpiper is a fairly frequently encountered shorebird in Nebraska. Jorgensen (2004) found this species to be the fifth most abundant spring migrant shorebird in the eastern Rainwater Basin.

\section{Curlew Sandpiper}

Calidris ferruginea

Accidental. There is one record of this Eurasian species, a bird at Funk Waterfowl Production Area, Phelps County, July 19 and 21, 1997 ( Nebraska Bird Review 66:3, 154). There are seven Kansas records, six of them in the fall (Thompson et al., 2011) 


\section{Sanderling}

Calidris alba

This species is a rare to occasional spring and fall migrant in Nebraska, mostly in eastern and central parts of the state. It is rarer in the west but has been observed as far west as Scotts Bluff County. It is a regular migrant throughout the eastern half of the entire Plains states. The nearest breeding area is coastal tundra in northern Nunavut.

Migration: Fifty-six initial spring sightings are from March 26 to June 2, with a median of May 6. Half of the records fall within the period April 25 to May 15. Thirteen final spring sightings are from April 26 to June 10, with a median of May 13. Seventeen initial fall sightings are from July 27 to October 2, with a median of August 20. Twelve final fall sightings are from August 12 to October 19, with a median of October 4. Sanderlings and white-rumped sandpipers are among the shorebirds with some of the longest migrations of all birds, breeding in the high Arctic and wintering south to Tierra del Fuego (Johnsgard, 2012g, 2013g).

Habitats: Migrants are associated with sandy shorelines, sand flats, saltencrusted flats, and less frequently muddy shorelines.

Comments: When the sanderlings pass through Nebraska they mostly seem to be in the pale winter plumage, during which time their darker anterior wing-coverts become conspicuous field-marks. On their Arctic nesting grounds they have a rufous cast on the upperparts.

\section{Dunlin}

Calidris alpina

This species is an occasional spring migrant in eastern Nebraska, rare in western parts of the state. Apparently rare during fall migration in all areas. It has been observed as far west as Cherry and Garden counties but is extremely rare in these areas. It is a migrant throughout the eastern half of the entire Plains states. The nearest breeding area is coastal tundra in northern Manitoba.

Migration: Forty-eight spring sightings range from April 6 to June 2, with a median of May 13. Half of the records fall within the period May 9-21. Eleven fall records are from August 15 to November 20, with a median of September 11.

Habitats: Migrants use mudflats, shallow ponds, and open stretches of muddy shorelines, often mingling with other small sandpipers.

Comments: Like the black-bellied plovers and golden-plovers, dunlins in breeding plumage have conspicuous black bellies, a most unexpected feature for a tundra nester. Perhaps this area is displayed during territorial flights or otherwise has special signal value.

\section{Baird's Sandpiper}

Calidris bairdii

This species is a common spring and fall migrant statewide and probably the most abundant of the "peeps" in Nebraska, especially in western portions of the state. It is a migrant throughout the entire Plains states. The nearest breeding area is coastal tundra in northern Nunavut. 
Migration: The range of 125 initial spring sightings is from March 12 to May 24, with a median of April 21. Half of the records fall within the period April 6 to May 4. Fifty-four final spring sightings are from April 7 to May 29, with a median of May 13. Thirty-two initial fall sightings are from July 20 to October 1, with median of August 12. Twenty-seven final fall sightings are from August 3 to December 5 , with a median of October 6 .

Habitats: Migrants use mudflats, shallow ponds, sandbars, and dried areas such as overgrazed pastures, salt plains, and similar open habitats while on migration.

Comments: Jorgensen (2004) found this species to be the sixth most abundant spring migrant shorebird in the eastern Rainwater Basin. Baird's sandpipers have a rather distinctive ochretinted back pattern that is more scalloped than linear in appearance.

\section{Least Sandpiper}

Calidris minutilla

This species is a common spring and fall migrant statewide but is becoming less common westwardly. The nearest breeding area is coastal tundra in northern Manitoba.

Migration: This species is a migrant throughout the entire Plains states. The range of 102 initial spring sightings is from March 8 to May 29, with a median of May 2. Half of the records fall with the period April 20 to May 10. Forty-one final spring sightings are from April 27 to June 2, with a median of May 12. Twenty-three final fall sightings are from July 20 to September 9, with a median of August 2. Twenty-three final fall sightings are from July 28 to November 11, with a median of September 18.

Habitats: Mudflats, shallow ponds, marsh edges, and flooded meadows are used by migrants, which frequently gather in small groups foraging in shallow puddles or wet grasslands well away from the larger "peeps."

Comments: This is one of the commonest of the small "peep" sandpipers in Nebraska and is identifiable by its olive-yellow legs and small size.

\section{White-rumped Sandpiper}

Calidris fuscicollis

This species is an abundant spring migrant, especially in central $\mathrm{Ne}$ braska. It is more common in eastern Nebraska than in western areas. The nearest breeding area is coastal tundra in northern Nunavut. Few birds migrate through the state in fall because they fly to the Atlantic coast to proceed farther south.

Migration: The range of 100 initial spring sightings is from March 28 to June 1, with a median of April 29. Half of the records fall within the period May 1-16. Seventeen final spring sightings are from May 8 to May 25. Eleven total fall sightings are from July 20 to October 4 , with a median of August 12.

Habitats: Migrants feed in shallow ponds, flooded pasturelands, flat shorelines, and muddy creeks, often with Baird's sandpipers, but they are less likely to forage in dry areas than is that species.

Comments: At least in western $\mathrm{Ne}-$ braska this is a very common spring migrant, which in flight can be easily recognized by its white rump. Jor- 
gensen (2004) found it to be the most abundant spring migrant shorebird in the eastern Rainwater Basin.

\section{Buff-breasted Sandpiper}

Tryngites subruficollis

This species is an uncommon spring and fall migrant in eastern Nebraska. It is highly local but has been reported several times in York, Seward, and Lancaster counties. It is apparently very rare in western Nebraska but has been reported from Scotts Bluff and Sheridan counties. Jorgensen (2004) found this species to be a regular migrant in the eastern Rainwater Basin, especially in Seward County (near Freeman Lake and North Lake Basin) and Fillmore County (Miller's Pond, two miles south of Shickley). The nearest breeding area is coastal tundra in northern Nunavut.

Migration: Twelve total spring sightings are from May 1 to May 20, with a median of May 10. Eleven fall sightings are from August 17 to September 26, with a median of September 7. Kansas records extend from April to June 13 in spring and from July 19 to November 11 in fall (Thompson et al., 2011).

Habitats: Migrants are usually found on recently plowed fields, mowed or burned grasslands, meadows, heavily grazed pastures, and other rather dry habitats. Jorgensen (2004) observed the use of agricultural fields, hayfields, and wetlands; saw maximum numbers during the second and third weeks of May; and judged that Nebraska is probably the species' most important spring staging area, the state supporting a large percentage of the world population in May.

\section{Pectoral Sandpiper}

Calidris melanotos

This species is a common to abundant spring and fall migrant almost statewide, becoming less common to rare westwardly. The nearest breeding area is lowland tundra in northern Nunavut.

Migration: The range of 102 initial spring sightings is from March 4 to June 6, with a median of April 28 and half of the records falling within the period April 15 to May 8. Thirty-nine final spring sightings are from April 5 to May 25, with a median of May 13. Twenty-eight fall sightings are from August 3 to November 20, with a median of October 4.

Habitats: Jorgensen (2004) found this species to be the most abundant fall migrant shorebird in the eastern Rainwater Basin. Migrating birds use a variety of habitats, including muddy shorelines, creeks, flooded grasslands, and shallow marshy areas where the emergent vegetation is not too thick.

Comments: Larger than the typical "peeps," the pectoral sandpiper often feeds among them, where its greater size and sharply cut-off breast pattern is usually quite apparent.

\section{Semipalmated Sandpiper}

Calidris pusilla

This species is a common to abundant spring and fall migrant but is uncommon in western Nebraska. The nearest breeding area is lowland tundra in northern Manitoba.

Migration: Eighty-nine initial spring sightings are from March 21 to June 10, with a median of April 28. Half of the records fall within the period April 20 to May 10. Thirty-nine 
final spring sightings are from April 28 to June 1 , with a median of May 15 . Twenty-three initial fall sightings are from July 20 to September 8, with a median of August 5. Twenty-three final fall sightings are from July 28 to October 16, with a median of September 18 .

Habitats: Migrating semipalmated sandpipers use mudflats, shallow ponds, exposed sandbars, and open shorelines as well, but they rarely move into dry fields with Baird's sandpipers or wet grasslands with least sandpipers.

Comments: Jorgensen (2004) found this species to be the third most abundant spring migrant shorebird in the eastern Rainwater Basin. The largest concentrations of this species in central North America pass through central Kansas (Thompson et al., 2011).

\section{Western Sandpiper}

\section{Calidris mauri}

This species is a rare spring and uncommon fall migrant in eastern $\mathrm{Ne}$ braska, becoming more common westwardly. The species' status in the state is still only poorly known, but the spring migration closely follows the Pacific coastline and is more common statewide during fall. The nearest breeding area is coastal tundra in northern Alaska.

Migration: Forty-one initial spring sightings are from April 7 to June 10, with a median of May 8 . Half of the records fall within the period April 28 to May 15. Ten final spring sightings are from May 3 to May 23, with a median of May 13. Fourteen initial fall records are from July 20 to September 19, with a median of August 12. Eleven final fall sightings are from August 26 to October 2, with a median of September 1.

Habitats: Mudflats, shallow ponds, and open shorelines are used by migrants, which avoid dry areas and prefer to forage while wading in shallow water, usually foraging at a slightly greater depth than do semipalmated sandpipers.

Comments: Western sandpipers are much like semipalmated sandpipers in appearance but are more rufous above (especially in spring) and have a longer bill that droops slightly at the tip.

\section{Short-billed Dowitcher}

\section{Limnodromus griseus}

This species is probably a rare migrant in eastern Nebraska, but field identification problems make the distribution almost impossible to judge. Studies of the dowitchers in $\mathrm{Ne}$ braska (Nebraska Bird Review 8:63$74,64: 74-78$ ) suggest that the shortbilled dowitcher is fairly rare in the state, as is also the case in Kansas (Thompson et al., 2011). Most recent sight records (e.g., Jorgensen, 2004) are from eastern counties. The nearest breeding area is lowland tundra in northern Manitoba.

Migration: Seven total spring sightings attributed to this species are from April 20 to May 18, with a median of May 14. Expected early departures are April 25-27, and expected late departures May 30-June 2 ( $\mathrm{Ne}$ braska Bird Review 85:63). Fourteen fall sightings are from early August to September 10, with most records between August 19 and September 10.

Habitats: Migrants use muddy flats and mud-bottom ponds probably iden- 
tical to those of the long-billed dowitcher, at least in Nebraska. They are often seen with black-bellied plovers.

Comments: Rather little is known of this species' occurrence in Nebraska; in spring it is less rufous below than is the long-billed dowitcher, and its usual call is a three-note whistle.

\section{Long-billed Dowitcher}

\section{Limnodromus scolopaceus}

This species is a common spring and fall migrant statewide. The nearest breeding area is lowland tundra in northern Northwest Territories.

Migration: This species is a regular migrant throughout the entire Great Plains region. Thirty-five initial spring sightings range from April 12 to May 23, with a median of May 1. Half of the records fall within the period April 20 to May 11. Thirteen final spring sightings are from May 4 to June 1, with a median of May 11. Eleven initial fall sightings are from July 20 to October 7 , with a median of August 8. Thirteen final fall sightings are from August 1 to December 3 , with a median of October 14. Of 1,500 birds banded in central Kansas, one was later shot in Mexico and another was killed in northeastern Russia (Thompson et al., 2011).

Habitats: Long-billed dowitchers are associated with muddy flats and mud-bottom ponds in Nebraska; foraging is done by probing in the shallow water of ponds or flooded grasslands.

Comments: Nearly all dowitchers seen in Nebraska seem to be of this species, which is distinguished by its rich rufous underparts and usually a single keek note upon takeoff. Jorgensen (2004) found this species to be the fourth most abundant spring migrant shorebird in the eastern Rainwater Basin and the second most abundant during the fall.

\section{American Woodcock}

\section{Scolopax minor}

This species is an uncommon to occasional spring and fall migrant in eastern Nebraska and an uncommon and local summer resident in the eastern third of the state. Besides some possible early nestings, there is a 1972 breeding record for Sarpy County, and a 1978 nesting in Hamilton County (Nebraska Bird Review 47:59). During the first breeding bird atlasing period 1984-89, there were confirmed nestings in Holt, Cedar, Stanton, and Burt counties (Mollhoff, 2001), and one in Seward County during the second period (Mollhoff, 2016). Possible nestings along the Niobrara River have been reported west to Keya Paha County. Displaying birds have been regularly observed along the Platte River west to Kearney. Woodcocks have also been observed west in the Rainwater Basin as far as Clay and Adams counties. Breeding is regular in Minnesota, and scattered breeding records exist for the areas directly south of Minnesota as well as for eastern South Dakota west to the Missouri River and eastern Kansas.

Migration: Thirteen total spring sightings range from March 12 to June 1, with a median of April 10. Thirteen total fall sightings are from September 12 to November 14, with a median of October 15. Kansas records extend from late February to late November, with some local overwintering (Thompson et al., 2011). 
Habitats: In Nebraska migrating woodcocks are generally associated with floodplain forests where the trees are rather scattered and the land is poorly drained, so that earthworms can be readily obtained by probing in the moist soil. No nests of this species were discovered during the second atlasing period of the Breeding Bird Atlas project, but a week-old chick was observed in Seward County (Mollhoff, 2016), as compared with confirmed nestings in five blocks during the first survey (Mollhoff, 2001).

Comments: Seemingly woodcocks have become more frequent nesters in Nebraska recently-or at least there are now many more sightings of displaying territorial males, nests, or chicks. The evening song-flight of males is an ethereal experience and recently has been reported regularly from the hike-bike trail bridge near Fort Kearney as well as many locations near Lincoln and Omaha. Moist ground and a ready supply of earthworms are major habitat needs. Breeding Bird Surveys between 1966 and 2015 indicate that the species collectively underwent a survey-wide population decline (0.66\% annually) during that period.

\section{Wilson's Snipe}

Gallinago delicata

This species is a common spring and fall migrant, and a local summer resident, especially in the Sandhills. Stragglers uncommonly overwinter in the state as well. It has bred in Garden, Rock, Cherry, Garfield, Howard, and Lancaster counties. It is regular during summer at the Clear Creek marshes, Garden County, and in the
Pine Creek drainage north of Smith Lake in Sheridan County, so nesting there is also quite likely, and in many Sandhills marshes. Regular nesting probably occurs from North Dakota and Minnesota southward to South Dakota, and migrants occur throughout the Great Plains.

Migration: Eighty-one initial spring sightings range from January 1 to May 29, with a median of April 13. Half of the records fall within the period April 4-21. Twenty-three final spring records are from April 12 to May 28, with a median of April 29. Thirtyseven initial fall records are from July 21 to December 21, with a median of September 18. Forty-two final fall records are from July 27 to December 31, with a median of November 12 . The data suggest that Nebraska overwintering is rather rare in this species, as is also true in Kansas (Thompson et al., 2011).

Habitats: Migrating birds are associated with marshes, sloughs and other wetlands that support areas of mudflats or mucky organic soil where foraging by probing is readily performed. Marshes rich in shoreline and emergent vegetation and are preferred over more open ones. Two nests of this species were discovered during the second atlasing period of the Breeding Bird Atlas project, and nesting was confirmed in three survey blocks (Mollhoff, 2016), as compared with confirmed nestings in five blocks during the first survey (Mollhoff, 2001).

Comments: Snipes are rarely seen until they suddenly take off in a low, twisting flight, usually uttering a raspy scaip note. The strange "win- 
nowing" noises resembling a whirling propeller made by vibrating the tail feathers of territorial birds flying high overhead can be heard in various parts of the state and probably indicate nesting, but very few actual nests or chicks have been found. Breeding Bird Surveys between 1966 and 2015 indicate that the species collectively underwent a survey-wide population increase (0.25\% annually) during that period, and Nebraska had an estimated $6.23 \%$ rate of annual increase.

\section{Spotted Sandpiper}

Actitis macularia

This species is a common spring and fall migrant and summer resident statewide. Local nesting occurs throughout the Great Plains except in the southern areas, and migrants occur throughout.

Migration: The range of 105 initial spring records is from March 3 to June 5 , with a median of May 4. Half of the records fall within the period April 26 to May 3. Sixty-two final fall records are from July 26 to October 26, with a median of September 9. Half of the records fall within the period August 27 to September 22.

Habitats: Throughout its stay in Nebraska, this species is associated with wetlands having exposed or sparsely vegetated shorelines or islands, and water ranging from fairly rapidly flowing streams to nonflowing. The shoreline features are apparently more important for this species than are the flowing or nonflowing characteristics of the water. No nests of this species were discovered during the second atlasing period of the Breeding Bird Atlas project, although young were observed, and nesting was confirmed in 11 survey blocks (Mollhoff, 2016), as compared with confirmed nestings in 12 blocks during the first survey (Mollhoff, 2001).

Comments: This little sandpiper can be seen along most of Nebraska's waterways, where its teeter to totter behavior and distinctive flight, with strongly down-curved wing actions, make it easily recognizable. It is also the only Nebraska shorebird with spotted underparts, at least in breeding plumage. Breeding Bird Surveys between 1966 and 2015 indicate that the species collectively underwent a survey-wide population decline (1.08\% annually) during that period, whereas Nebraska had a statistically unreliable estimate (based on only eight survey routes) of a $0.05 \%$ rate of annual increase.

\section{Solitary Sandpiper}

Tringa solitaria

This species is a common to occasional spring and fall migrant statewide, being most abundant eastwardly and probably least common in treeless areas. This species' status and distribution in Nebraska has been analyzed in some detail (Nebraska Bird Review 10:15-22). The nearest breeding areas are wooded wetlands of central Manitoba.

Migration: This species migrates throughout the Great Plains. Eightyeight initial spring sightings are from March 17 to June 7, with a median of May 4. Half of the records fall within the period April 28 to May 11. Twentynine final spring sightings are from May 6 to June 10, with a median of May 13. Thirty-six initial fall sightings 
are from July 20 to September 9, with a median of August 9. Thirty-five final fall sightings are from August 5 to November 26, with a median of September 1.

Habitats: Migrants use wooded ponds, streams, and flooded meadows.

Comments: This is indeed a "solitary sandpiper," since it typically forages alone rather than in groups of its own species or even near other shorebirds. Often it can be found along small creeks in the Sandhills that are lined with bushes or trees.

\section{Lesser Yellowlegs}

Tringa flavipes

This species is a common spring and fall migrant statewide, and usually is somewhat more abundant than the greater yellowlegs. The nearest breeding areas are wooded or tundra wetlands of central Manitoba.

Migration: This shorebird is a migrant throughout the entire Great Plains region. The range of 124 initial spring sightings is from March 13 to May 29, with a median of April 14. Half of the records fall within the period April 10 to June 1, with a median of May 13. Thirty-five initial fall sightings are from July 20 to September 22, with a median of August 15. Half of the records fall within the period $\mathrm{Au}$ gust 8 to September 5 . Forty-two final fall sightings are from August 20 to November 23, with a median of October 5 .

Habitats: Migrants use ponds, marshes, creeks, mudflats, and flooded meadows. There is no apparent ecological separation of migrating greater and lesser yellowlegs.

Comments: Both species of yellow- legs are tundra nesters, and it is always a shock for persons used to seeing these birds only on wintering or migration sites to find them perching in Arctic bushes and low trees, from which they scan for possible predators or other danger and utter territorial calls. In eastern Nebraska the lesser yellowlegs is nearly ten times more common than the greater.

\section{Willet}

\section{Tringa semipalmata}

This species is an uncommon to locally common spring and fall migrant statewide and a locally common summer resident in the Sandhills. The Sandhills apparently represent the species' southern limits of breeding in the Great Plains. It also breeds in both Dakotas and is a migrant throughout the entire Plains states.

Migration: The range of 104 initial spring sightings is from March 18 to June 10, with a median of April 27. Half of the records fall within the period April 19 to May 5. Sixteen final fall sights are from August 10 to November 9, with a median of August 24. Half of the records fall within the period August 19 to September 1.

Habitats: A rather wide variety of wetland habitats are used by breeding willets, including streams, ponds, and marshes or shallow lakes, provided that prairie vegetation is located nearby. Less often hayfields or croplands may be used for nesting. Thirteen nests of this species were discovered during the second atlasing period of the Breeding Bird Atlas project, and nesting was confirmed in seven survey blocks (Mollhoff, 2016), as compared with confirmed nestings 
in eight blocks during the first survey (Mollhoff, 2001).

Comments: It is always a surprise to persons unfamiliar with willets when these rather dull-looking birds take flight and suddenly expose their stunning white wing markings; the willet's older generic name Catoptrophorus means "bearing a mirror." Breeding Bird Surveys between 1966 and 2015 indicate that the species collectively underwent a survey-wide population decline ( $0.48 \%$ annually) during that period, whereas Nebraska had a statistically unreliable estimate (based on seven survey routes) of a $1.08 \%$ rate of annual increase.

\section{Greater Yellowlegs}

Tringa melanoleuca

This species is a common spring and fall migrant statewide. It is also a migrant throughout the entire Plains states. The nearest breeding areas are wooded or tundra wetlands of central Manitoba.

Migration: The range of 115 initial spring sightings is from March 13 to June 10, with a median of April 13. Half of the records fall within the period April 2-14. The range of 55 final spring sightings is from April 11 to May 30, with a median of May 5 . Thirty-eight initial fall sightings are from July 20 to October 16 , with a median of August 18. Half of the records fall within the period August 4 to September 3. Thirty-eight final fall sightings are from August 14 to November 16, with a median of October 7 .

Habitats: Migrants use ponds, marshes, creeks, mudflats, and flooded meadows.

Comments: Less common than the lesser yellowlegs, this species has a considerably longer and more robust bill, and when taking flight it usually utters three or four short notes rather than the two-noted call typical of lesser yellowlegs. The greater yellowlegs is notably less common in $\mathrm{Ne}$ braska than is the lesser.

\section{Wilson's Phalarope}

Phalaropus tricolor

This species is a common to abundant spring and fall migrant, and a common summer resident, breeding over much of Nebraska, especially in the Sandhills and Rainwater Basin. Breeding also occurs from North Dakota south to central Kansas (at least Barton, Stafford, and Lincoln counties), and migrants appear throughout the region.

Migration: A range of 115 initial spring sightings is from April 6 to June 6, with a median of May 2. Half of the records fall within the period April 25 to May 10. Thirty-eight final fall sightings are from July 26 to October 20 , with a median of September 8 . Half of the records fall within the period August 19 to September 12.

Habitats: Breeding occurs in wet meadows near aquatic habitats ranging from flooded ditches to ponds and marshes or shallow lakes, especially with somewhat alkaline waters. Migrants forage in open water, capturing surface invertebrates while swimming in tight circles, which produces a vortex that draws invertebrates up from below. Eighty-nine nests of this species were discovered during the second atlasing period of the Breeding Bird Atlas project, and nesting was confirmed in five survey blocks (Moll- 


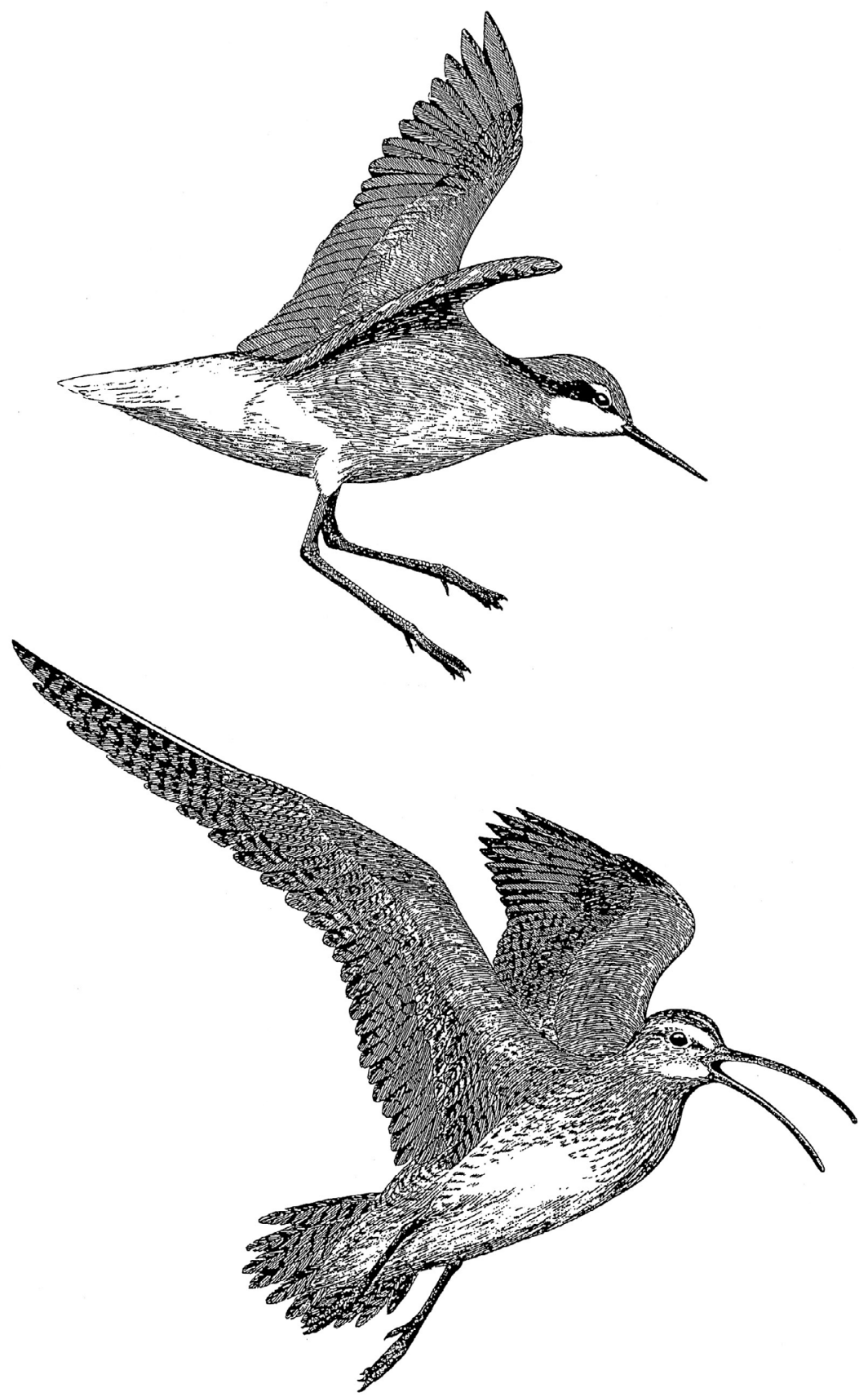

Figure 9. Males of Wilson's phalarope (above) and long-billed curlew (below) 
hoff, 2016), as compared with confirmed nestings in seven blocks during the first survey (Mollhoff, 2001).

Comments: Phalaropes are notable in that they exhibit "sex reversal" traits in which females are larger and more colorful. Females also have transferred incubation and brood-rearing chores to males, and to varying degrees are polyandrous. This species breeds commonly in saline Sandhills wetlands such as Border Lake, a highly alkaline lake at the western edge of Crescent Lake National Wildlife Refuge (Bomberger, 1984). Jorgensen (2004) found it to be the second most abundant spring migrant shorebird in the eastern Rainwater Basin; nesting there has occurred several times since 2000 ( $\mathrm{Ne}$ braska Bird Review 75:77). Recent genetic evidence indicates that phalaropes are close relatives of the Tringa sandpipers rather than being only peripherally related to typical shorebirds. Breeding Bird Surveys between 1966 and 2015 indicate that the species collectively underwent a surveywide population decline (0.48\% annually) during that period and a $0.61 \%$ annual decline in Nebraska.

\section{Red-necked Phalarope}

Phalaropus lobatus

This species is an uncommon to rare spring migrant in northern and western Nebraska, becoming less common in southeastern parts of the state. It is less common during fall in all areas. The nearest breeding area is lowland tundra of central Manitoba.

Migration: Migrants regularly appear in the northern portions of the Great Plains region, and are occa- sional as far south as the Oklahoma Panhandle. Forty-two initial spring sightings range from April 19 to May 27, with a median of May 14. Half of the records fall within the period May 8-19. Seven final spring sightings are from May 9-25, with a mean of May 19. Ten initial fall sightings are from July 20 to September 21, with a median of August 10. Eleven final fall sightings are from August 20 to October 14, with a median of September 27 .

Habitats: Migrants use the same habitats as do Wilson's phalaropes, namely open water areas of marshes and shallow lakes, where the invertebrate life is abundant and can be captured by surface foraging.

Comments: Once called the "northern phalarope," this is an Arctic-nesting bird that is seen in Nebraska only while on migration. In nonbreeding plumage it closely resembles the Wilson's phalarope but is somewhat darker dorsally. The species is rare in Kansas and uncommon in South Dakota.

\section{Red Phalarope}

Phalaropus fulicarius

Extremely rare. The first specimen of this Arctic-nesting phalarope was collected in Cherry County (Nebraska Bird Review 2:38). Since then, there have been at least nine fall records, mostly of young birds (Nebraska Bird Review 70:14). The species is casual in Kansas and accidental in South Dakota. 


\section{Family Stercorariidae (Jaegers)}

\section{Pomarine Jaeger}

Stercorarius pomarinus

Extremely rare, but probably the most frequently seen jaeger in Nebraska. There are early records for Dakota County in 1869, Fremont County in 1873, and Lincoln County in 1895 (Bruner, Wolcott, \& Swenk, 1904). One bird was observed in Lancaster County in September 1973. There were also sightings of a single bird at Conestoga Lake, Lancaster County, on December 15-17, 1991 (Nebraska Bird Review 54:31), one at Lewis and Clark Lake, Knox County, on June 30, 1990 (Brogie, 1997), and another at Pawnee Lake, Lancaster County, November 15-19, 1997 (Nebraska Bird Review 65:167). It is a rare summer and fall migrant at Lake McConaughy (Brown, Dinsmore, \& Brown, 2012). Twelve state records had accumulated through 2005 (Nebraska Bird Review 73:141), and several more have since been reported. The species is a casual vagrant in Kansas and accidental in South Dakota. Breeding occurs on lowland tundra of northern Nunavut.

\section{Parasitic Jaeger}

Stercorarius parasiticus

Extremely rare. The jaeger was considered a rare or accidental fall vagrant at Lake McConaughy by Brown, Dinsmore, \& Brown (2012). There is a specimen record from Lancaster County in 1898, and a second bird was obtained in Sheridan County in August of 1968 (Nebraska Bird Review 36:76, 37:31), which was first believed a great skua, Catharacta skua (Nebraska Bird Review 36:4). It was also reported from Lake McConaughy on October 5, 1997 (Nebraska Bird Review 65:167). One in Dawes County on September 2, 2013, was Nebraska's fifth documented record (Nebraska Bird Review 81:144). The species is a casual fall migrant in Kansas and accidental in South Dakota. Breeding occurs on lowland tundra of northern Manitoba.

\section{Long-tailed Jaeger}

Stercorarius longicaudus

Extremely rare. A specimen record exists from Lancaster County in 1952, and there are three more recent records, mostly of immatures (Nebraska Bird Review 69:170). It was considered a rare summer and fall migrant at Lake McConaughy by Brown, Dinsmore, \& Brown (2012). As of 2013 there were eight reports, most in fall (Nebraska Bird Review 77:110-111, $78: 139,81: 141)$. The species is a casual vagrant in Kansas and accidental in South Dakota. Breeding occurs on lowland tundra of southern Nunavut. 


\section{Family Alcidae (Auks)}

78:139). The species is rare in both Kansas and South Dakota. Breeding occurs on coastal cliffs of northern Baffin Island.

\section{Sabine's Gull}

Xema sabini

This species is a rare fall Arctic vagrant. Two old specimen records are from Lancaster and Gage counties from September 1899. It was also seen in Omaha during April 1928, in Lincoln County in October 1966, and in Garden County during October 1978. Sabine's gull was seen at Gavin's Point from October 26 to November 3 , 1996. Three more records were obtained during September 1996 in Lincoln and Keith counties (Nebraska Bird Review 65:42-43, 167-168; Brogie, 1997). There were at least nine state records for the species in Nebraska by 1996. In 1997 about 24 to 30 or more birds were seen between September 8 and October 12 at various locations (Nebraska Bird Review 65:167-168), and the species was also reported at Gavin's Point Dam on October 3, 1998 (Brogie, 1999). There had been only one spring record as of 2009 (Nebraska Bird Review 77:56). Breeding occurs on the coastline of northern Nunavut.

Habitats: Large rivers, lakes, and reservoirs are used in the interior by this normally coastal migrant.

Comments: Unlike some of the rare gulls of Nebraska, this bird's yellowtipped bill and the white triangular patch on its upper wing bounded by all-black wingtips easily identifies this species. 


\section{Bonaparte's Gull}

Chroicocephalus philadelphia

This boreal gull is an uncommon spring and fall migrant in eastern Nebraska, becoming rarer westwardly. Breeding occurs in the coniferous forests of central Manitoba.

Migration: Thirty-six total spring sightings are from April 3 to May 27, with a median of April 23. Half of the records fall within the period April 12 to May 9. Twenty fall sightings are from August 18 to November 21, with a median of October 26 .

Habitats: Migrants are associated with rivers, marshes, and lakes, especially large lakes.

Comments: Bonaparte's gull rather surprisingly often nests on the branches of low conifers, rather than on the ground. Its white outer wing patches makes it easily separable from Franklin's gull, with which it sometimes associates while on migration.

\section{Black-headed Gull}

Chroicocephalus ridibundus

Accidental. One individual of this Icelandic and Eurasian gull species was observed at Walgren Lake, Sheridan County, August 12, 1979 (Rosche, 1982). It was also reported December 19-21, 2003, at Lake McConaughy (Brown, Dinsmore, \& Brown, 2012). There are Kansas records from eight counties (Thompson et al., 2011).

\section{Little Gull}

Hydrocoloeus minutus

Extremely rare. One individual of this Eurasian gull species was seen at Wehrspan Lake on April 26, 1995 (Nebraska Bird Review 64:134) and at
Pawnee Lake, Lancaster County, October 3, 1996 (Brogie, 1997). It was also seen at North Platte National Wildlife Refuge on September 6, 1997, and Summit Reservoir on October 19, 1997 (Nebraska Bird Review 65:167). Through 2005 there have been 16 records (Nebraska Bird Review 73:141). It has been recorded April to December at Lake McConaughy (Brown, Dinsmore, \& Brown, 2012).

\section{Ross's Gull}

Rhodostethia rosea

Accidental. Single birds of this high Arctic gull were observed at Sutherland Reservoir, Lincoln County, December 17-23, 1992 (Nebraska Bird Review 61:88-90) and at Gavins Point Dam and Branched Oak Lake, November and December 2010 (Nebraska Bird Review 79:13, 104).

\section{Laughing Gull}

\section{Leucophaeus atricilla}

An extremely rare Atlantic and Gulf Coast migrant. Besides two old records of this gull from Douglas and Hall counties, this species was later reported from Keith County in 1947, 1950, 1952, and 1992, Platte County in 1953, Lancaster County in 1977, and Lincoln County in 1992. By 2011 there were about 20 state records ( $\mathrm{Ne}$ braska Bird Review 78:139, 79:56). It is a rare late spring and summer migrant at Lake McConaughy (Brown, Dinsmore, \& Brown, 2012).

Migration: Five spring records are from April 5 to May 21, with a mean of April 22. The species has been observed in June and July, and three fall records are from December 5 to 22 . As of 2013 there were six documented 
spring records and a state total of 20 , all but two occurring between April and October (Nebraska Bird Review $81: 145)$. Kansas records are numerous and extend from April 4 to January 29 (Thompson et al., 2011).

Habitats: Normally associated with coastal habitats while wintering and on migration, vagrants are likely to be seen near large impoundments in the interior.

Comments: This rare species closely resembles the common Franklin's gull but lacks any white near the wingtips. It seems to be increasingly reported in the Midwest.

\section{Franklin's Gull}

\section{Leucophaeus pipixcan}

This species is an abundant spring and fall migrant, and a very rare or accidental summer resident in Nebraska, with the only known breeding records from Garden County (Nebraska Bird Review 34:63, 35:32). Stragglers sometimes are present during the summer in the Sandhills area. Breeding is regular in the Dakotas, and migrants appear throughout the entire region.

Migration: Eighty-nine initial spring sightings range from March 6 to June 8, with a median of April 10. Half of the records fall within the period March 27 to April 21. Fifty-eight final spring sightings are from April 2 to June 2, with a median of May 14. Fifty-two initial fall sightings are from July 20 to October 24 , with a median of September 7. Fifty-eight final fall sightings are from August 17 to December 20, with a median of October 17. Half of the records are for the period October 3 to November 2 .
Habitats: Flocks of spring migrants are often found on plowed fields, sometimes closely following moving agricultural equipment in large flocks. Breeding occurs on large prairie marshes that have extensive areas of semi-open emergent vegetation for nesting. One of the species' largest nesting colonies is on the Sand Lake National Wildlife Refuge in South Dakota.

Comments: The Franklin's gull is a "seagull" with a nesting area that is a thousand miles from the sea, and is actually associated with prairie marshes for nesting. During migration it occurs in large flocks, and breeding also is performed in colonies. Breeding Bird Surveys between 1966 and 2015 indicate that the species collectively underwent a survey-wide population decline (2.95\% annually) during that period.

\section{Mew Gull}

\section{Larus canus}

This subarctic gull is a rare fall and winter vagrant. It is a rare winter and spring migrant at Lake McConaughy and was reported there from December 14 to May 11 (Brown, Dinsmore, \& Brown, 2012; Nebraska Bird Review 66:42). Up to five adults were seen at Branched Oak Lake, Lancaster County, December 1-3, 1996. As of 1998 there were at least 11 state records, nearly all from Lake McConaughy (Brogie, 1999). By 2010 there were 24 state records, and as of 2016 there were about 36 records (Nebraska Bird Review 78:139, 79:13, 83:11, 84:13). The nearest breeding occurs in the boreal wetlands of northern Saskatchewan. 


\section{Ring-billed Gull}

Larus delawarensis

This species is a common to abundant spring and fall migrant statewide, with stragglers sometimes remaining through the summer months. Nesting occurs in North Dakota and locally in South Dakota, and migrants are regular throughout the entire region.

Migration: Eighty initial spring sightings range from January 3 to May 15, with a median of March 16 . Half of the records fall within the period March 5-26. Fifty final spring sightings are from March 12 to June 7, with a median of May 12. Forty-eight initial fall sightings are from July 20 to November 15, with a median of September 12. Fifty-seven final fall sightings are from August 25 to December 21, with a median of November 28 .

Habitats: Migrants use a wide variety of lakes, reservoirs, rivers, marshes, and other water areas.

Comments: The ring-billed gull is by far the most common white-headed gull in Nebraska.

\section{California Gull}

\section{Larus californicus}

This species is a rare migrant or winter vagrant in most of Nebraska but is reportedly regular and uncommon in northwestern Nebraska (Rosche, 1982). Other than in the northern Panhandle, it has been observed in Garden, Lincoln, Lancaster, and Douglas counties. The species breeds in North and South Dakota, and migrants appear in western Nebraska from the Dakotas and other breeding areas farther west.

Migration: Seven spring records are from March 19 to April 26, with a mean of March 28. There is at least one June record. Ten late summer and fall records are from July 18 to November 10 . Nine winter records extend from December 13 to February 15.

Habitats: Migrants use lakes, large marshes, and similar habitats.

Comments: California gulls closely resemble herring gulls but have yellowish green or grayish green legs and are somewhat smaller. When seen beside a herring gull their darker upperparts are also apparent.

\section{Herring Gull}

Larus argentatus

This species is an uncommon spring and fall migrant throughout $\mathrm{Ne}$ braska, becoming rarer westwardly. Stragglers are sometimes seen during the summer months. Migrants are regular everywhere in the Great Plains region. The nearest breeding habitat is the larger wetlands of central Manitoba.

Migration: Forty-seven initial spring records range from January 13 to May 13, with a median of March 18. Half of the records fall within the period March 2 to April 1. Twenty-seven final spring sightings are from March 5 to May 28, with a median of April 21. Twenty-four initial fall sightings are from July 21 to November 24, with a median of October 26. Eighteen final fall sightings are from August 29 to December 21, with a median of November 28.

Habitats: Migrating birds are widely distributed over rivers, lakes, reservoirs, and other water areas.

Comments: This is the largest of Nebraska's gulls and the state's most common large gull. 


\section{Iceland Gull}

\section{Larus glaucoides}

This species (collectively) is a rare to uncommon winter migrant. As of 2009 there were at least 22 Nebraska records of the typical Iceland gull (L. g. glaucoides), half occurring in winter (Nebraska Bird Review 7:27). There is an early Saline County record in January 1907, but more recent February and March reports are from Keith County in 1994, 1996, and 1998, and at Branched Oak Lake, Lancaster County, in December 1996 and 2000 (Nebraska Bird Review 64:39; Brogie, 1997, 1999; American Birds 55:319). It is a rare winter and spring migrant at Lake McConaughy, having been reported from December 12 to April 29 (Brown, Dinsmore, \& Brown, 2012).

The "Kumlien's gull” (kumlieni), a racial variant of the Iceland gull, includes the eastern North American population of Iceland gulls that breeds on the Arctic shorelines of southeastern Baffin Island and northern Hudson Bay, and that are phenotypically slightly darker than the typical Iceland gulls (glaucoides) that breed on Greenland. The Kumlien's gull has been reported at least 30 times in Nebraska, including 13 winter and 9 spring records (Nebraska Bird Review 83:12, 84:13, 85:65).

The “Thayer's gull” (thayeri) breeds on the central Canadian Arctic islands, east to central Baffin Island. It is very similar to the Kumlien's gull, but its plumage is slightly darker, and it was designated as a recognized species in 1973. However, in 2017 thayeri was deemed an invalid species by the AOU, and birds of this phenotype have since been regarded as a North American subspecies of the Iceland gull (Larus glaucoides thayeri) (Nebraska Bird Review 85:64). Thayer's gulls have long been considered rare overwintering migrants in Nebraska, with most sightings from November through January. At least 20 were reported at Lake McConaughy during the winter of 199798 (Nebraska Bird Review 66:13) and were considered to be a regular uncommon spring, fall, and winter migrant at Lake McConaughy by Brown, Dinsmore, and Brown (2012). Thayer's gulls have also been reported from Lake North, Platte County, December 4, 1981, and at Gavin's Point Dam, November 24-30, 1985 (Bray et al., 1986). They were later reported again from Gavin's Point Dam, and at Cunningham Lake during November 1995 (Nebraska Bird Review 63:103). As of 1996 there were at least 22 reports of this form, and several additional sightings were reported in December 1996 (Nebraska Bird Review 64:53, 65:210; Brogie, 1997). In Kansas, Thayer's gulls have been reported from 24 counties, as compared with records from 5 counties for the Iceland gull (Thompson et al., 2011).

\section{Lesser Black-backed Gull}

\section{Larus fuscus}

This Icelandic and Eurasian species is an extremely rare fall, winter, and early spring migrant. First observed at Pawnee Lake, Lancaster County, February 16 and 24, 1992 (Nebraska Bird Review 64:32), it was also seen twice at Kingsley Dam in February and March 1994 (Nebraska Bird Re- 
view 64:39) and at Branched Oak Lake on March 12, 1995 (Nebraska Bird Review 64:135). Several were seen at Lake McConaughy during the winter of 1997-98 (Nebraska Bird Review 66:14; Brogie, 1999). It is now considered a rare spring, fall, and winter migrant at Lake McConaughy (Brown, Dinsmore, \& Brown, 2012). As of 1996 there were at least 11 accepted records (Nebraska Bird Review 64:53). Most of the reported sightings of this species through 2011 have been from February to April (Nebraska Bird Review 80:57), but as of 2015 there were nine January records (Nebraska Bird Review 83:12).

(Slaty-backed Gull)

Larus shistasagus

Hypothetical. This northeastern Asian gull was reported January 22, 200o, at Harlan County Reservoir (Nebraska Bird Review 68:19) and in Sarpy County, December 21, 2006 (Nebraska Bird Review 75:8). There are only a few interior North American reports-from Saskatchewan, South Dakota, Missouri, and Arkansas.

\section{Glaucous-winged Gull}

Larus glaucescens

Accidental. This Alaska-breeding gull was first observed and photographed on April 12, 1995, at Lake McConaughy (Nebraska Bird Review 64:3-4), and more recent sightings include December 13, 2000 (Brown, Dinsmore, \& Brown, 2012) and February 16March 23, 2013 (Nebraska Bird Review 81:58). With a total of five reported sightings by 2016, the third documented and sighting was an individual at Lake Ogallala on April 23, 2016
(Nebraska Bird Review 84:71). There are also three sight records from Kansas (Thompson et al., 2011).

\section{Glaucous Gull}

Larus hyperboreus

This Arctic-breeding and trans-Canadian gull is a rare overwintering migrant and has been most often reported in the west, especially at Lake McConaughy. It is a spring, fall, and winter migrant at Lake McConaughy, reported from October 16 to April 6 (Brown, Dinsmore, \& Brown, 2012). In addition to an early specimen from the Omaha area, there are at least four sight records for Lancaster County, and additional sightings from Douglas, Dawes, Harlan, Keith, Garden, Lincoln, and Scotts Bluff counties. Several were seen at Lake McConaughy during the winter of 1997-98 (Nebraska Bird Review 66:14), and one was possibly sighted in Adams County. It has also been reported from the Dakotas, is rare in Kansas, and is regular in Oklahoma during winter.

Migration: Ten total spring records range from January 24 to April 29, with a median of March 24. Five fall records occurred December 3-27.

Habitats: Migrants normally use rivers, lakes, and coastal shorelines.

\section{Great Black-backed Gull}

\section{Larus marinus}

This Atlantic coast gull is a rare migrant. It was considered a year-round migrant at Lake McConaughy by Brown, Dinsmore, and Brown (2012). About 40 state records have accrued for this species through 2015 (Nebraska Bird Review 85:65). There is an old record for May 1871 from the vicinity of Dakota 
City, Dakota County. More recently it was sighted in Hamilton County in April 1952, and at Kingsley Dam, Keith County, March 14, 1994 (Nebraska Bird Review 64:39). It was also seen at Wagon Train Lake, Lancaster County, April 3, 1996, and there were five sightings (perhaps of the same bird) at Lake McConaughy between January 20 and August 4, 1996 (Brogie, 1997). It was also seen at Gavin's Point Dam on November 12, 1997.

\section{Least Tern}

Sternula antillarum

This species is an uncommon spring and fall migrant in eastern Nebraska. It is a highly local and rare summer resident in the state's major river valleys: along the Platte River from its mouth to Keith County, the Niobrara River from its mouth to about the eastern edge of Cherry County, the Missouri River from Dixon County to the South Dakota border. It also breeds locally along the Elkhorn River. It is common around the shorelines of Lake McConaughy (Nebraska Bird Review 59:133-150; Brown, Dinsmore, \& Brown, 2012). The interior race athalassos is classified as both federally and state endangered, and it breeds locally in the other Plains states from North Dakota southward.

Migration: Eighty-seven initial spring sightings range from March 8 to June 10, with a median of May 23. Half of the records fall within the period May 16-30. Twenty-six final fall sightings are from July 20 to October 6, with a median of August 14 .

Habitats: Associated with rivers, lakes, and impoundments on migration; least tern nesting is mostly done on river sandbars or islands. These terns sometimes also nest on barren shorelines of large impoundments, gravel beaches, or even on newly cleared land. Nests are typically grouped in colonies on a sand or gravel substrate. In 2008, 215 nests were found along the Missouri River in Dixon County (Nebraska Bird Review 76:103). Sixty-three nests of this species were discovered during the second atlasing period of the Breeding Bird Atlas project (Mollhoff, 2016), and nesting was confirmed in 16 survey blocks, as compared with confirmed nestings in 24 blocks during the first survey (Mollhoff, 2001).

\section{Caspian Tern}

Hydroprogne caspia

This species is an uncommon spring and fall migrant in eastern Nebraska, especially along the Missouri River, but it is regularly reported as far west as Sheridan, Garden, Keith, and Lincoln counties. It is a local migrant in eastern and northern areas, mostly along the Missouri River. A few nonbreeding birds often summer in the Lake McConaughy area (Brown, Dinsmore, \& Brown, 2012).

Migration: Twenty-seven total spring sightings are from March 23 to May 28, with a median of May 10. Half of the records fall within the period May 3-17. Twenty-four fall records are from July 20 to October 14 , with a median of September 19. Half of the records fall within the period September 4-25.

Habitats: Migrants use larger rivers, deep marshes, lakes, and reservoirs. The nearest breeding areas are in the Dakotas. 


\section{Black Tern}

\section{Chlidonias niger}

This species is an uncommon spring and fall migrant statewide, and a local summer resident, primarily in the Sandhills but locally elsewhere as well. It breeds from North Dakota and Minnesota southward to Kansas and is a migrant throughout the entire region.

Migration: The range of 130 initial spring sightings is from April 9 to June 5, with a median of May 12. Half of the records fall within the period May 6-18. Sixty-six final fall sightings are from July 21 to October 5, with a median of September 2. Half of the records fall within the period August 19 to September 11 . The more precise nature of this species' migration compared to that of the other terns and gulls is no doubt a reflection of its insectivorous diet.

Habitats: Migrants are found over a variety of aquatic habitats and sometimes also forage well away from water over adjoining grasslands. Breeding occurs on small to large marsh areas that have a combination of open water and stands of emergent vegetation. Twelve nests in a Grant County colony of this species were discovered during the second atlasing period of the Breeding Bird Atlas project, and nesting was confirmed in eight survey blocks (Mollhoff, 2016), as compared with confirmed nestings in six blocks during the first survey (Mollhoff, 2001).

Comments: Breeding Bird Surveys between 1966 and 2015 indicate that the species collectively underwent a survey-wide population decline (1.37\% annually) during that period, and Nebraska had an estimated 5.74\% rate of annual decline.

\section{Common Tern}

Sterna hirundo

This species is an uncommon to rare spring and fall migrant in eastern Nebraska, becoming rarer westwardly. Frequent confusion with the Forster's tern makes the state status of this species somewhat uncertain, but it is relatively common only in eastern Nebraska. Breeding occurs in the Dakotas and Minnesota, and migrants are most common in the northeastern portions of the Great Plains region.

Migration: Sixty-five initial spring sightings are from March 18 to June 7 , with a median of May 5. Half of the records fall within the period April 24 to May 15. Fourteen final spring sightings are from April 25 to June 6, with a median of May 11. Eleven initial fall sightings are from August 9 to October 14, with a median of September 2 .

Habitats: Migrants use lakes, reservoirs, and rivers, and less often are found near smaller marshes and ponds.

\section{Arctic Tern}

Sterna paradisaea

Accidental. An adult of this Arcticbreeding tern was found September 20, 2000, at Lake Minatare ( $\mathrm{Ne}$ braska Bird Review 68:158), and one was seen at Lake Ogallala, December 21, 2003 (Nebraska Bird Review 72:61; Brown, Dinsmore, \& Brown, 2012).

\section{Forster's Tern}

Sterna forsteri

This species is a common spring and fall migrant statewide and a rather lo- 
calized summer resident in the Sandhills, especially in Garden, Cherry, and Grant counties. It probably also breeds in some Sheridan County marshes. Breeding is regular in Minnesota and the Dakotas, and migrants appear throughout the entire Plains states.

Migration: Fifty-eight initial spring sightings are from April 11 to June 8, with a median of April 28. Half of the records fall within the period April 19 to May 5. Twenty-one final spring sightings are from April 24 to June 6 , with a median of May 17 . Thirteen initial fall records are from July 21 to September 22, with a median of August 1. Twenty final fall sightings are from August 1 to October 8, with a median of September 11.

Habitats: Associated with lakes, rivers, and marshes while on migration. Breeding occurs in large marshes having extensive areas of emergent vegetation or muskrat houses for nesting sites. Small marshes seem to be avoided for nesting. Six nests of this species were discovered during the second atlasing period of the Breeding Bird Atlas project, and nesting was confirmed in five survey blocks (Mollhoff, 2016), as compared with confirmed nestings in four blocks during the first survey (Mollhoff, 2001). Breeding Bird Surveys between 1966 and 2015 indicate that the species collectively underwent a survey-wide population decline (1.60\% annually) during that period, and a 0.94\% annual decline in Nebraska.

\section{Royal Tern}

Thalasseus maximus

Accidental. A single state specimen record exists from North Lake, York County (Nebraska Bird Review 75:108, 76:39-45). The nearest breeding area of this species is the Gulf Coast.

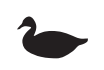

\section{Family Gaviidae (Loons)}

\section{Red-throated Loon \\ Gavia stellata}

This Arctic-breeding species is an extremely rare spring and fall migrant. There have been at least 14 sightings of this species in the state, mostly in the fall. Several are for Douglas and Lancaster counties, but it has also been observed at least once each in Buffalo, Frontier, Keith, Sarpy, and Washington counties. As of 2013 there were five spring reports (Nebraska Bird Review 61:59). It is casual in Kansas and accidental in South Dakota.

Migration: Five spring records are from April 17 to May 7, with a mean of April 28, and eight fall records are from October 31 to December 2, with a mean of November 17. There is also one June record.

Habitats: Larger rivers, lakes, and reservoirs are used while on migration.

Comments: This is the smallest of the loons, and the only one lacking black-and-white back patterning when in breeding plumage. It is also the only loon that can take off from small ponds, which are common on its low tundra nesting grounds. 


\section{Pacific Loon}

Gavia pacifica

Extremely rare, this Arctic-breeding loon was considered a rare fall, winter, and spring migrant at Lake McConaughy by Brown, Dinsmore, and Brown (2012). Besides a 1900 record in Frontier County (Bruner, Wolcott, \& Swenk, 1904), one was observed in November 1961 in Sarpy County ( $\mathrm{Ne}$ braska Bird Review 40:40). Other records up to 1985 are listed by Bray et al. (1986), and through 1996 by Brogie (1997). There were at least 14 mostly fall records for this species by 1997 ; as of 2010 there were only four spring records (Nebraska Bird Review 78:43).

\section{Common Loon}

Gavia immer

This species is an uncommon spring and fall migrant throughout Nebraska. It has been observed in at least 33 counties, having been recorded ten or more times in Douglas, Lincoln, and Lancaster counties and at least five times in Scotts Bluff and Keith counties. Most of the sightings have occurred in the eastern half of the state. It also migrates through other Plains states, becoming rarer southwestwardly, and it breeds in Minnesota and North Dakota.

Migration: Excepting two January records, 55 initial spring sightings range from March 18 to May 27, with a median of May 7. Fourteen final spring sightings are from April 12 to May 28, with a median of May 16. Twenty-five initial fall sightings are from July 20 to November 2, with a median of October 24. Seventeen fi- nal fall sightings are from October 25 to December 7 with a median of November 2. Of a total of 135 records, the largest number (37) are for April, followed by May (35), November (26), and October (15).

Habitats: Larger rivers, lakes, and reservoirs are used while on migration.

Comments: This is much the most common species of loon seen in the state, and the plumage patterns seen here vary greatly but usually are of the winter or immature type. Calling occurs only rarely while the birds are in Nebraska and nearly all observations are of single individuals.

\section{Yellow-billed Loon}

Gavia adamsii

Accidental. An adult of this Arcticbreeding species was photographed on Branched Oak Lake, Lancaster County, in November 1996 (Brogie, 1997). An immature was seen on Lake McConaughy August 8 to October 20, 1998 (Brogie, 1999); one was at Lake McConaughy in September 2003 (Nebraska Bird Review 72:61); one was also seen in Rock County on November 29, 2009 (Nebraska Bird Review 77:142). As of 2009 there had been four state records, all during fall.

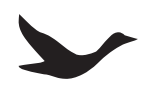




\section{Family Ciconiidae (Wood Storks)}

\section{Wood Stork}

Mycteria americana

Accidental. Although there is an early sight record (Sarpy County, 1925), the only wood stork specimen known was one from Hamilton County, obtained in the 1880s (Bruner, Wolcott, \& Swenk, 1904). Wood storks have also been seen in at least ten Kansas counties (Thompson et al., 2011). The nearest breeding area of this tropical species is the Texas Gulf coast.

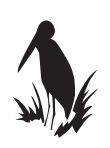

\section{Family Phaethontidae (Tropicbirds)}

(White-tailed Tropicbird)

Phaethon lepturus

Hypothetical. A questionable sight record for this tropical pelagic species exists for Lincoln County (Nebraska Bird Review 41:59, 79). There are no other regional records.

\section{Family Fregatidae (Frigatebirds)}

\section{(Magnificent Frigatebird)}

Fregata magnificens

Hypothetical. There is a sight record by Lawrence Bruner for this tropical pelagic species in Cuming County, in the spring of 1884. A frigatebird of uncertain species was seen in Knox County, September 7-8, 2007 ( $N e$ braska Bird Review 75:103). Specimens have been obtained in Kansas and Oklahoma.

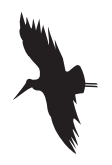

\section{Family Sulidae (Gannets and Boobies)}

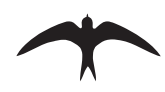

\begin{abstract}
Brown Booby
Sula leucogaster

Accidental. There are two records of this tropical pelagic species. The first was an adult photographed near LaPlatte, Sarpy County, June 28-30, 2014. The second was an adult at Harlan County Reservoir in June 2017; it was present for most of the month (Nebraska Bird Review 85:25).
\end{abstract}

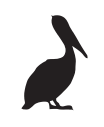




\section{Family Phalacrocoracidae (Cormorants)}

\section{Neotropic Cormorant}

Phalacrocorax brasilianus

Extremely rare. The first specimen of this southern cormorant was obtained October 2, 1982, at Sutherland Reservoir (Nebraska Bird Review 51:18). Since then, it has been photographed at Hackberry Lake, Cherry County, September 4, 1993 (Nebraska Bird Review 64:31), and seen at Valentine National Wildlife Refuge, Cherry County, July 19, 1995 (Nebraska Bird Review 63:71) and at Chambers, Holt County, May 20-30, 1996 (Nebraska Bird Review 64:44). It has also been reported several times between 1998 and 2017, totaling 21 reports by 2017 (Nebraska Bird Review 66:33, 67:72, 68:108, 78:135, 79:122, 81:107, 85:65). This species is evidently slowly expanding its range north into the central Great Plains. The nearest known nesting occurred in Kansas in 2007, and it has been reported from at least 15 Kansas counties (Thompson et al., 2011).

\section{Double-crested Cormorant}

Phalacrocorax auritus

This species is an uncommon spring and fall migrant throughout Nebraska, becoming more common westwardly. It is a summer resident in several locations in the western half of the state, east to Cherry County and the vicinity of North Platte. It also breeds locally in Minnesota and the Dakotas.

Migration: Of 102 initial spring sightings, the range is March 14 to May 29, with a median of April 12.
Half of the records fall during the period April 14-25. Thirty-nine final spring records range from April 17 to June 2, with a median of May 1. Thirty-one initial fall sightings are from August 7 to October 20, with a median of September 21. Thirty-one final fall sightings are from September 17 to December 14, with a median of October 23.

Habitats: Migrating birds use deeper marshes, lakes, rivers, and reservoirs. Breeding occurs on islands, trees, or cliffs near water, and within about ten miles of an adequate fish supply. Six nests of this species were discovered during the second atlasing period of the Breeding Bird Atlas project, and nesting was confirmed in six survey blocks (Mollhoff, 2016), as compared with confirmed nestings in eight blocks during the first survey (Mollhoff, 2001). Breeding occurs in the northern and western Sandhills, Lake McConaughy, and the Rainwater Basin (Nebraska Bird Review 83:108).

Comments: During the past few decades this cormorant has increased in North America, benefiting from fish farms in the south and better protection on its nesting grounds. Nesting may occur in partly submerged bushes or trees, or on nesting platforms set out for Canada geese, as well as on sandy or gravelly islands. Breeding Bird Surveys between 1966 and 2015 indicate that the species collectively underwent a survey-wide population increase (3.76\% annually) during that period versus a statistically unreliable estimate (based on 13 survey routes) of a $0.76 \%$ annual rate of increase in Nebraska. 


\section{d}

Family Anhingidae (Anhingas)

\section{Anhinga}

Anhinga anhinga

Accidental. This tropical relative of cormorants was first reported in Buffalo County in September 1913. It was also reported in Hamilton County in May 1955, in Greeley County in April 1975, on the Platte River in October 1976, from Sarpy County in April 1978, and at Indian Cave State Park in 2005 (Nebraska Bird Review 73:50). A recent record was from Saline County, May 18, 2017 (Nebraska Bird Review 85:65).

Migration: The few available records for this species range from April 27 to October (no date). There are also records for May and September. Kansas records include eight counties, and extend from April to September (Thompson et al., 2011).

Habitats: Anhingas are normally associated with lagoons, lakes, rivers, and swamps with quiet or sluggishly flowing fresh water that is clear and supports fish.

Comments: This is a tropical fisheating species that stalks its prey underwater, spearing it in a heron-like manner while wholly submerged. The nearest breeding area of this species is southeastern Oklahoma.

\section{Family Pelecanidae (Pelicans)}

\section{American White Pelican \\ Pelecanus erythroryhnchos}

This species is a common migrant throughout Nebraska, especially in central and western counties. Nonbreeders commonly occur through the summer on Harlan County Reservoir and Lake McConaughy. There are no successful breedings in the state, but several nesting attempts have been made at Valentine National Wildlife Refuge (Mollhoff, 2016). It breeds locally in Minnesota and the Dakotas.

Migration: Eighty-four initial spring sightings range from February 21 to May 22 with a median of April 28. Half of the records fall within the period May 10-24. Thirty final spring sightings are from April 12 to June 1, with a median of April 28. Twentyeight initial fall sightings range from August 5 to November 21, with a median of September 24. Twenty-eight final fall sightings are from September 16 to November 10, with a median of October 16.

Habitats: Migrating and nonbreeding birds use larger marshes, lakes, and reservoirs.

Comments: The nearest breeding site for this species is at LaCreek National Wildlife Refuge near Martin, South Dakota. Probably many of the birds seen in Nebraska are nonbreeders spending their summers away 
from the crowded breeding colonies, or are migrants going to and from LaCreek National Wildlife Refuge or other sites farther north. A colony at Chase Lake National Wildlife Refuge, North Dakota, is one of the largest in North America (Johnsgard, 1993), with up to about 30,000 birds in recent years. Breeding Bird Surveys between 1966 and 2015 indicate that the species collectively underwent a significant rate of population increase (4.82\% annually) during that period.

\section{Brown Pelican}

Pelecanus occidentalis

Extremely rare. Vagrants of this species have been seen in Nebraska on various occasions. Swenk (1934) summarized five early records, and since then the species was reported in Lincoln County in 1937, in Cherry and Keya Paha counties in 1955, and in Custer County in 1977. There are records for Dodge and Dakota counties (Nebraska Bird Review 59:150), DeSoto National Wildlife Refuge, Harlan County Reservoir (Nebraska Bird Review 73:81), and Lake Babcock (Nebraska Bird Review 77:52, 162). One bird was found at Sutherland Reservoir wintering with white pelicans, the state's first winter record and making nine total state records ( $\mathrm{Ne}$ braska Bird Review 83:10). Kansas records include 16 counties (Thompson et al., 2011).

Migration: The few available records for this species range from April 10 to October 23, plus a wintering bird present from December 26 to February 26.

Habitats: Brown pelicans are normally associated with coastal beaches and shorelines.
Comments: Unlike the white pelicans of the world, the brown pelican dives from the air for its prey and is almost entirely limited to coastal waters (Johnsgard, 1993). The nearest breeding area of this species is the Texas Gulf coast.

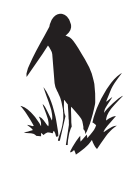

\section{Family Ardeidae (Herons and Egrets)}

\section{American Bittern}

Botaurus lentiginosus

This species is a common spring and fall migrant throughout Nebraska, and a locally common summer resident. It breeds throughout the state in suitable habitats, with the Sandhills marshes providing optimum habitat. It also breeds widely elsewhere in the Great Plains, except in the drier southwestern regions.

Migration: The range of 109 initial spring sightings is from March 26 to June 10, with a median of May 3. Half of the records fall within the period April 23 to May 11. Forty-four final fall sightings are from July 14 to December 17, with a median of October 6 . Half of the sightings fall within the period October 1 to 27 .

Habitats: Normally this species is found in marshes, swamps, and bogs that have heavy emergent vegetation or adjacent wet swales or tall grassy meadows. One nest of this species was discovered during the second atlas- 

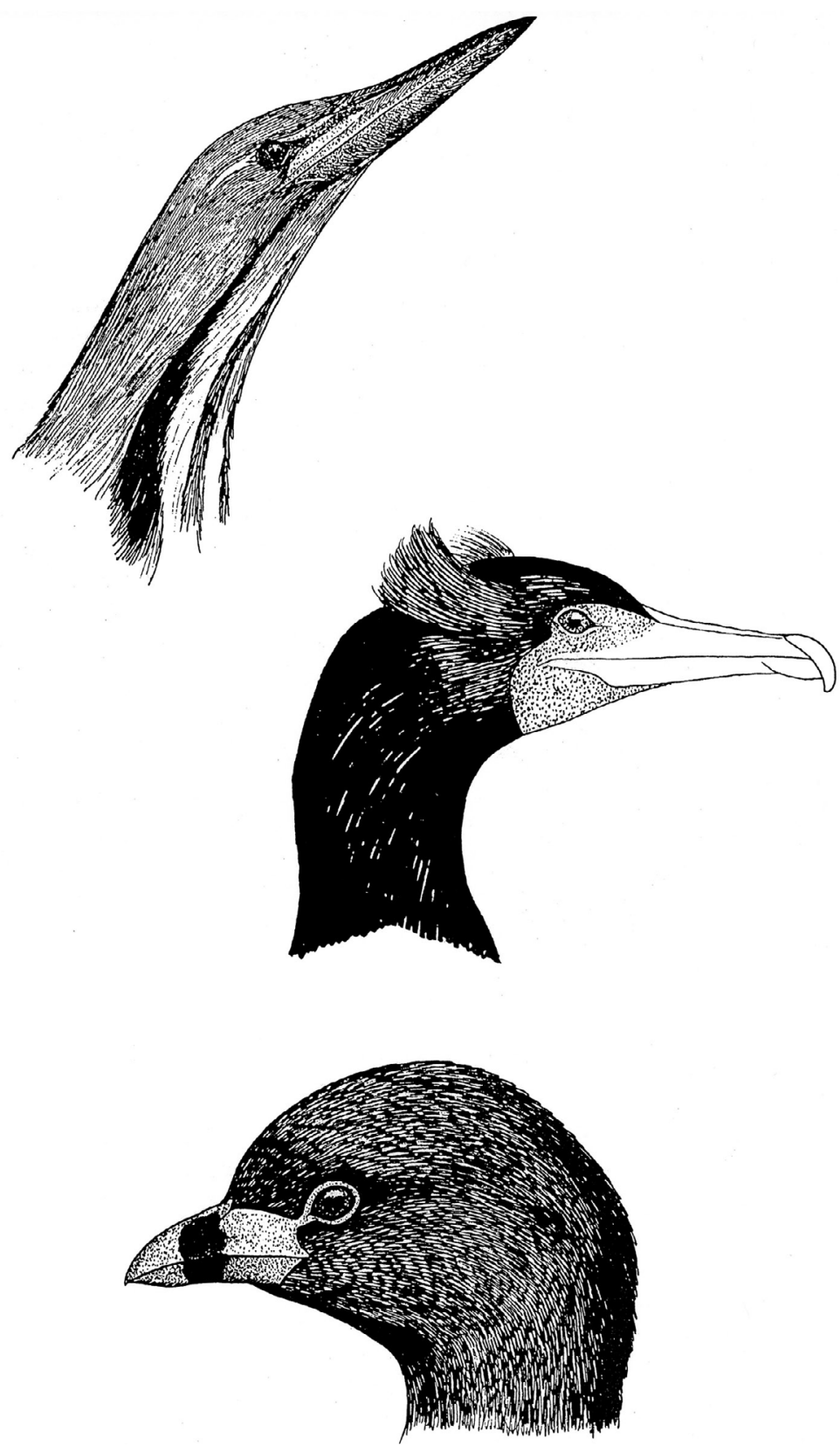

Figure 10. Wetland birds: Adults of American bittern (top), double-crested cormorant (middle), and pied-billed grebe (bottom) 
ing period of the Breeding Bird Atlas project, and nesting was confirmed in two survey blocks (Mollhoff, 2016), as compared with confirmed nestings in three blocks during the first survey (Mollhoff, 2001).

Comments: This strange heron, often obscenely called "shitepoke" by Nebraskans, usually goes unseen by casual observers, who fail to notice it standing erect and motionless among cattails and reeds. Its booming courtship call is responsible for its alternative vernacular name, "thunderpump." In the presence of a female, a displaying male gradually exposes two otherwise hidden fanlike clusters of airy white feathers over his contrasting back feathers; this happens during a very rarely observed courtship ceremony (Johnsgard, 1979c; 2016a). Similar egret-like display behavior has been seen in a closely related European species. Breeding Bird Surveys between 1966 and 2015 indicate that the species collectively underwent a survey-wide population decline (0.52\% annually) during that period, and Nebraska had an estimated $0.39 \%$ rate of annual decline.

\section{Least Bittern}

\section{Ixobrychus exilis}

This species is an uncommon spring and fall migrant and a seemingly rare summer resident. It breeds locally in the eastern half of the state, mainly in the Rainwater Basin, the Sandhills wetlands, and southeastern Nebraska. Perhaps it has its western nesting limits in Garden County, where it has been observed during summer at the Ash Hollow marshes and Crescent Lake National Wildlife Refuge. It breeds elsewhere in the Great Plains, except the drier western portions.

Migration: Thirty-nine initial spring sightings range from March 30 to June 4 , with a median of May 15. Half of the records fall within the period May 4-24. Ten final fall sightings are from July 28 to September 19, with a median of August 17.

Habitats: In Nebraska this species is usually found in freshwater or slightly brackish marshes or lake edges having extensive stands of emergent vegetation, and with scattered bushes or similar woody growth. Two nests of this species were discovered during the second atlasing period of the Breeding Bird Atlas project, and nesting was confirmed in three survey blocks (Mollhoff, 2016), and three blocks were also confirmed during the first survey (Mollhoff, 2001).

Comments: This is the smallest of the American herons and is a miniature relative of the American bittern. The least bittern builds a distinctive nest in marshy vegetation of plant materials that it arranges like the spokes of a wheel. Breeding Bird Surveys between 1966 and 2015 indicate that the species collectively underwent a survey-wide population increase $(0.17 \%$ annually) during that period.

\section{Great Blue Heron}

Ardea herodias

This species is a common migrant and a local summer resident that breeds in colonies in various locations throughout Nebraska, especially along major rivers and in the Sandhills. It also breeds locally elsewhere throughout the Great Plains.

Migration: The range of 87 initial 
spring sightings is from January 6 to June 6, with a median of April 2. Half of the records fall within the period March 26 to April 30. Of 103 final fall sightings, the range is August 8 to December 30, and the median is October 13. Half of the records fall within the period September 23 to November 7 .

Habitats: Migrants are found around all water areas that support a fish population and have shallows for foraging. Nesting usually occurs among groves of tall trees but sometimes also has been reported on the ground, on rock ledges, among bulrushes, or on other elevated situations. Cottonwood groves, up to a few miles distant from any water, seem to be favored nesting locations in $\mathrm{Ne}$ braska. Two nests of this species were examined during the second atlasing period of the Breeding Bird Atlas project, and nesting was confirmed in 44 survey blocks (Mollhoff, 2016), as compared with confirmed nestings in 18 blocks during the first survey (Mollhoff, 2001).

Comments: Commonly but incorrectly called "cranes" by Nebraskans, great blue herons differ from cranes in many ways, including their treenesting behavior, their flight profile (flying with kinked necks rather than outstretched necks), and their largely fish-dependent diet. They are beautiful and graceful birds and often nest colonially in areas where fish are plentiful. Breeding Bird Surveys between 1966 and 2015 indicate that the species collectively underwent a survey-wide population increase (0.44\% annually) during that period, and a 2.38\% annual decline in Nebraska.

\section{Great Egret}

Ardea alba

This species is an occasional spring and fall migrant, and a summer visitor or breeder. It is most common in eastern counties but has been observed as far west as Box Butte and Garden counties. Great egrets attempted to nest in Sarpy County in 1960 (Nebraska Bird Review 28:55), and another nesting by about seven birds occurred in that county in 2008 (Nebraska Bird Review 76:98), providing the first documented state breeding records of this species (Mollhoff, 2016). It is a regular breeder in Oklahoma, Iowa, and southern Minnesota, and an occasional nester (seven counties) in eastern and central Kansas.

Migration: Sixty-two initial or only spring records are from March 26 to June 1, with a median of April 29. Half of the records fall within the period April 16 to May 10. Ten final spring sightings are from April 6 to June 8, with a median of May 9. Twenty-one total fall records are from August 2 to October 21, with a median of September 1. Of 95 total records, the largest number (34) are for May, followed by April (30), August (10), and September (8).

Habitats: Great egrets are associated with streams, swamps, and lake borders, and are usually found near trees during the nesting season.

Comments: The range of several egrets seems to have expanded in recent years, and that is certainly the case with the great egret. There are influxes of the birds into Nebraska just prior to breeding (birds perhaps headed toward Minnesota and western Iowa) and again following the 
breeding season. Breeding Bird Surveys between 1966 and 2015 indicate that the species collectively underwent a survey-wide population increase (2.4\% annually) during that period.

\section{Snowy Egret}

Egretta thula

This species is a rare vagrant or summer visitor throughout Nebraska. Most of the records are for counties bordering the Platte or Missouri Rivers, including Scotts Bluff, Lincoln, Platte, Douglas-Sarpy, and Lancaster counties. In 1989 a nest was found in Garden County (Mollhoff, 2001, 2016). There are also breeding accounts from at least Lancaster, Scotts Bluff, and Hall counties, the last of which was considered confirmed although no nest was found. It regularly breeds in Oklahoma and South Dakota, and has also bred in Kansas (in six central and western counties) and southeastern Wyoming.

Migration: Twenty-four total spring records are from April 13 to June 10, with a median of May 7 . Ten total fall records are from July 30 to October 1, with a median of August 17. Of 34 total records, the largest number are for May (17) followed by April (6) and August (4).

Habitats: Nonbreeding birds occur over a wide array of aquatic habitats that support fish. During the breeding season fairly sheltered habitats with shrubby or low tree growth are favored. Nesting often occurs among other heron species. One nesting was confirmed in Hall County during the first Breeding Bird Survey (Mollhoff, 2001).
Comments: This beautiful little egret can be easily recognized by its "golden slippers" and its all-black bill. In the spring it exhibits red facial skin and beautiful filmy white "aigrette" plumes that once were the high-fashion rage and nearly spelled the species' doom before federal protection was enacted in the early 19oos. Breeding Bird Surveys between 1966 and 2015 indicate that the species collectively underwent a survey-wide population increase (0.65\% annually) during that period.

\section{Little Blue Heron}

\section{Egretta caerulea}

This species is an occasional to uncommon spring and rare fall vagrant, primarily in the eastern half of Nebraska. There are records from at least 18 counties, but the largest numbers of sightings are for Adams, Platte, Lancaster, and Douglas-Sarpy. Groups of up to 15 have been seen near Nebraska City. It breeds locally in Oklahoma and Kansas (records in eight counties), is a rare breeder in South Dakota, and is an accidental breeder in North Dakota.

Migration: A total of 55 spring records range from April 4 to June 1, with a median of May 8. Fifteen fall records are from July 23 to October 20, with a median of August 19. Of 80 total records, the largest number (37) are for May, followed by April (16), June (8), and July (7).

Habitats: Migrants are associated with freshwater marshes, swamps, and upland meadows.

Comments: The white juvenile plumage of this species makes it unique among North American her- 
ons. It is generally believed that the white plumage in egrets and herons renders them less visible to potential underwater prey than does the plumage of dark-colored birds. Breeding Bird Surveys between 1966 and 2015 indicate that the species collectively underwent a survey-wide population decline (1.57\% annually) during that period.

\section{Tricolored Heron}

\section{Egretta tricolor}

Accidental. There are at least five state records for this heron, including one shot in Kearney County in November of 1918, another collected in Clay County in August 1918, a sight record from Clay County in August 1971 (Nebraska Bird Review 41:14), and another in Hitchcock County in 2001 (Nebraska Bird Review 71:98). Kansas records include at least 15 counties, with breedings in two; state records extend from April 16 to October 2 (Thompson et al., 2011). The nearest regular breeding area of this species is the Texas Gulf coast, although some breedings have occurred in Oklahoma.

\section{Reddish Egret}

Egretta rufescens

Accidental. One photographic record of this egret exists for Lake McConaughy, September to October 2000 (Nebraska Bird Review 68:146). A second reddish egret was seen at Funk Waterfowl Production Area on June 12, 2008 (Nebraska Bird Review 76:99, 77:83). There were two Kansas records as of 2011 (Thompson et al. 2011) and another in 2017. The nearest breeding area of this species is the Texas Gulf coast.

\section{Cattle Egret}

Bubulcus ibis

This Old World species is an occasional spring and fall vagrant, being first reported in Nebraska in 1965 and observed with increasing frequency since then. It has been seen as far west as Dawes County but most records are for Lancaster, Otoe, and Douglas-Sarpy. Nesting has been documented for Keith County (Nebraska Bird Review 63:89), Cherry County (Mollhoff, 2001), and Garden and McPherson counties (Mollhoff, 2016). Two nests were found during the second atlasing years, but a colony at Valentine National Wildlife Refuge that had begun in 1982 had grown to about 100 breeding pairs by 2011 (Mollhoff, 2016), as compared with a confirmed nesting in one Cherry County block during the first survey (Mollhoff, 2001). It has been reported in all the other Plains states, with nesting records in Kansas for five counties.

Migration: Twenty-one total spring records range from April 12 to June 3 with a median of May 9. Eleven total fall records are from July 23 to October 20, with a median of August 29. Of 32 total records, the largest number (11) are for May, followed by April (8) and August (5).

Habitats: Migrants are associated with upland meadows and pastures.

Comments: Since this species found its way to America from Africa via the West Indies, it has spread widely. Feeding on insects disturbed by foraging cattle on the American plains is seemingly little different from feeding around the feet of zebras and wildebeest on the savannas of East Africa. Breeding Bird Surveys between 1966 
and 2015 indicate that cattle egret collectively underwent a significant North American population decline (1.38\% annually) during that period, whereas Nebraska had a statistically unreliable estimate (based on eight survey routes) of a $9.25 \%$ rate of annual increase.

\section{Green Heron}

\section{Butorides virescens}

This species is a common migrant and a summer resident that breeds over most of Nebraska except in the Panhandle and western Sandhills. It also breeds locally in other Plains states, primarily in the eastern portions.

Migration: The range of 93 initial spring sightings is from March 10 to June 7, with a median of April 27. Half of the records fall within the period April 15 to May 6. The range of 50 final fall sightings is from July 23 to November 9, with a median of September 18. Half of the records fall within the period September 4-25.

Habitats: Migrating birds occur almost anywhere small minnow-sized fish can be captured. Breeding usually occurs near trees, but some nesting is in marshlands well away from tree cover. Eleven nests of this species were discovered during the second atlasing period of the Breeding Bird Atlas project, and nesting was confirmed in four survey blocks (Mollhoff, 2016), as compared with confirmed nestings in eight blocks during the first survey (Mollhoff, 2001).

Comments: This widespread little heron is notable for the fact that it has been seen catching small minnows, disabling them, and then releasing them to serve as bait for attracting larger fish. At various times it has also been called the "green-backed heron" and "little green heron," in part because of naming problems among some Latin American populations of uncertain taxonomic rank. Breeding Bird Surveys between 1966 and 2015 indicate that the species collectively underwent a survey-wide population decline (1.77\% annually) during that period, and Nebraska had an estimated $0.01 \%$ rate of annual decline.

\section{Black-crowned Night-Heron}

Nycticorax nycticorax

This species is a common migrant throughout Nebraska, breeding locally in suitable habitats throughout most of the state except perhaps the driest portions of western Nebraska. It also breeds widely elsewhere in the Plains states, excepting the drier areas.

Migration: Eighty initial spring sightings range from March 29 to June 9, with a median of April 25. Half of the records fall within the period April 18 to May 10. Fifty-four final fall sightings are from July 22 to November 15, with a median of September 6 . Half of the records fall within the period August 18 to September 29.

Habitats: The black-crowned nightheron is a highly adaptable species, found in a wide array of aquatic habitats, with nesting occurring in swamps, marshes, and sometimes even city parks or orchards where water is nearby. Thirty nests of this species were discovered in a colony of night-herons at Smith Lake, Crescent Lake National Wildlife Refuge, in 2007 during the second atlasing pe- 
riod of the Breeding Bird Atlas project. Nesting was confirmed in five survey blocks (Mollhoff, 2016), and there also were confirmed nestings in five blocks during the first survey (Mollhoff, 2001).

Comments: The night-herons are called thus because of their large eyes and associated abilities to forage late into the evening hours when it is almost dark. This species is a fairly common breeder at the Crescent Lake and Valentine refuges, and it is a startling sight to have one of these herons suddenly take flight from just a few feet away while you are walking through heavy marsh vegetation. Breeding Bird Surveys between 1966 and 2015 indicate that the species collectively underwent a survey-wide population decline ( $0.84 \%$ annually) during that period, whereas Nebraska had a statistically unreliable estimate (based on eight survey routes) of a $1.0 \%$ rate of annual decline.

\section{Yellow-crowned Night-Heron}

Nyctanassa violacea

This species is an uncommon spring and fall migrant and occasional summer visitor in Nebraska, mainly in the eastern half of the state. There is a record of unsuccessful breeding in Sarpy County in 1963 (Nebraska Bird Review 32:9), and fledglings have been seen in or near Lincoln. Breeding is regular in Oklahoma, local in Kansas (with nesting records from at least 15 counties), and rare in Missouri.

Migration: Forty-three total spring sightings range from April 2 to June 10, with a median of May 6. Half of the records fall within the period April 29 to May 14. Twelve total fall records are from August 1 to October 24, with a median of September 5 .

Habitats: Nonbreeding birds occupy a wide range of aquatic habitats, but in Nebraska the birds are often found along tree-lined rivers, sometimes in company with other herons, and I once saw an adult in the Sandhills.

Comments: This beautiful nightheron mostly nests to the south of Nebraska but occasionally finds its way into this state. Young birds closely resemble those of black-crowned nightherons but are darker on the back and wing-coverts. Unlike the blackcrowned species, which nests above water in marshy wetlands, this species often nests in bushes or trees, and sometimes even within cities. This helps explain my astonishment in once seeing a fledgling in the southern part of Lincoln, an experience that I was later afraid to tell others about in fear they would question my sanity, and I never bothered to report the sighting. Breeding Bird Surveys between 1966 and 2015 indicate that the species collectively underwent a survey-wide population decline (0.75\% annually) during that period. 


\section{Family Threskiornithidae (Ibises and Spoonbills)}

\section{White Ibis}

Eudocimus albus

Accidental. One white ibis was observed over a period of several days in Rock County in August 1963 ( Nebraska Bird Review 32:12). The species was also reported July 5, 1999, at Kissinger Basin Wildlife Management Area (Nebraska Bird Review 67:88) and was seen at Funk Waterfowl Production Area, August 9, 2001 (Nebraska Bird Review 69:162, 71:98). More than a dozen Kansas records include at least seven counties and extend from May 2 to September 28 (Thompson et al., 2011). The nearest regular breeding area of this species is the Texas Gulf coast, although breedings have occurred north to southeastern Oklahoma.

\section{Glossy Ibis}

\section{Plegadis falcinellus}

Rare migrant and summer breeder. More than 50 spring records had been noted for this range-expanding species through 2001. It was not until 2015 that nesting was first discovered at Harvard Waterfowl Production Area, Clay County (Jorgensen \& Silcock, 2015; Nebraska Bird Review 83:109). By then 73 reports of the glossy ibis had accrued from 19 counties, of which 23 were accepted by the NOU Records Committee. Records extend from April to August, with the majority from the Rainwater Basin. Apparent hybrids with the following species had also been seen on at least seven occasions by 2015, nearly all from the Rainwater Basin. Breeding Bird Surveys between 1966 and 2015 indicate that the species collectively underwent a survey-wide population increase ( $4.24 \%$ annually) during that period.

\section{White-faced Ibis}

Plegadis chihi

This species is an uncommon spring migrant and summer breeder in central and western Nebraska. Early breedings occurred in Clay County (1916) and later (1984) in Cherry County (Mollhoff, 2001). Six state nesting records had accrued by 2003 , and many recent nestings have occurred in the Rainwater Basin (Clay County), as well as in Garden and Grant counties (Nebraska Bird Review 83:162; Mollhoff, 2016).

Migration: Thirty-two total records range from April 9 to October 14. The largest number (14) of the sightings are for May, followed by April (9), and there are two or more records each for June, August, September, and October. Spring migration numbers have reached as high as $150-400$ in some locations, such as 200 at North Platte sewage lagoon, and 150 at Crescent Lake National Wildlife Refuge ( $\mathrm{Ne}$ braska Bird Review 85:66).

Habitats: Nonbreeding birds may occur in almost any wet or moist habitat, including marshes, flooded fields, wet meadows, and other areas having shallow water suitable for foraging. Nesting usually occurs in shallow marshes having extensive emergent vegetation. Sixty-seven nests of this species were discovered during the second atlasing period of the Breed- 
ing Bird Atlas project, and nesting was confirmed in four survey blocks (Mollhoff, 2016), as compared with a confirmed nesting in one Cherry County block during the first survey (Mollhoff, 2001).

Comments: This somewhat exotic-looking bird has become regular at the Crescent Lake refuge; I have seen groups of dozens of white-faced ibises there in recent years, and they are abundant in the western Sandhills wetlands. This species is difficult to distinguish from the glossy ibis, and they sometimes hybridize. Breeding Bird Surveys between 1966 and 2015 indicate that the species collectively underwent a survey-wide population increase (2.4\% annually) during that period, and Nebraska had a remarkable but unlikely estimate (based on five survey routes) of a $14.66 \%$ rate of annual increase.

\section{Roseate Spoonbill}

Platalea ajaja

Accidental. A Nebraska specimen record exists from Buffalo County, obtained in June 1932. There is also a sight record of two seen near Hastings, Clay County, in August 1966 ( Nebraska Bird Review 34:77), and a single individual seen near Nebraska City on August 5 and 14, 1997 (Nebraska Bird Review 65:162). Kansas records include at least eight counties and extend from April to August 30; they date mostly since 2000 , possibly a reflection of dispersal from rapidly growing Gulf Coast colonies (Thompson et al., 2011). The nearest breeding area of this species is the Texas Gulf coast.

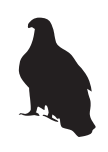

\section{Family Cathartidae (New World Vultures)}

\section{Black Vulture}

Coragyps atratus

Accidental. There is an old specimen record from Franklin County in 1916, and more recent sightings in January 1950 (Keith County), April 1951 (Logan County), April 1955 (Keya Paha County), and March 1963 (Hamilton County). One was rescued in Lincoln by Raptor Recovery on about September 24, 2017. Kansas records include at least ten counties (Thompson et al., 2011). The nearest regular breeding area of this species is eastern Oklahoma, although breeding has also occurred in Kansas.

\section{Turkey Vulture}

Cathartes aura

This species is an uncommon to common spring and fall migrant statewide, and a common but still inadequately documented summer resident. It is a local breeder along some of the major river systems (Republican, Missouri, and Niobrara) and in the Pine Ridge region, but there are relatively few early published records (Nebraska Bird Review 39:19, 64:47). Mollhoff (2000, 2016) reported only six confirmed nestings, from Fillmore County west to Sheridan County, during the early Breeding Bird Atlasing years, and only seven in the second 
survey, from Richardson County west to Scotts Bluff County (Mollhoff, 2001, 2016). Raptor Recovery has raised several chicks rescued from various locations. This vulture is a local but regular breeder in all of the Plains states, and a migrant throughout.

Migration: Ninety initial spring sightings are from January 12 to June 10, with a median of April 14. Half of the records fall within the period April 1-24. Nineteen final spring sightings are from April 11 to June 10, with a median of May 18. Eleven initial fall sightings are from July 20 to September 25, with a median of September 6. Thirty-five final fall sightings are from August 6 to December 30, with a median of September 26. Half of the records fall within the period September 16 to October 4 .

Habitats: Migrants or nonbreeders are found widely over open plains, sandhills, or other areas that offer visual foraging. At the northern end of its range the species is mostly associated with brushy woodlands adjoining open grasslands or croplands during the breeding season. Cliffs, crevices, abandoned buildings, or other cavities are needed for nesting sites. Seven nests of this species were discovered during the second atlasing period of the Breeding Bird Atlas project. Although there were 377 "possible" nestings, nesting was confirmed in only five survey blocks (Mollhoff, 2016), as compared with confirmed nestings in seven blocks during the first survey (Mollhoff, 2001).

Comments: Once associated largely with the remote plains of the American West, the turkey vulture has become yet another urbanized spe- cies. For example, more than 60 now (2018) roost nightly during summer among tall trees in the heart of Lincoln. They disperse out into the country during the day to scavenge for carrion along roadsides, and often nest in abandoned barns or farmhouses. The same situation now (2018) occurs in many outstate towns, including some smaller Sandhills towns such as Mullen. Breeding Bird Surveys between 1966 and 2015 indicate that the species collectively underwent a survey-wide population increase $(2.25 \%$ annually) during that period, and $\mathrm{Ne}$ braska had a high statistically but slightly questionable estimate (based on 40 survey routes) of a $10.23 \%$ rate of annual increase.

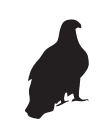

\section{Family Pandionidae (Ospreys)}

\section{Osprey}

Pandion haliaetus

This species is an uncommon to occasional spring and fall migrant statewide, and a recently developing local nesting species in western Nebraska. Nestings have occurred since 2008 in the Panhandle near Scottsbluff and Keystone Dam (Nebraska Bird Review 76:57, 80:91).

Migration: The range of 102 initial spring sightings is from January 1 to May 25, with a median of April 21. Half of the records fall within the period April 12 to May 1. Twenty-one final spring sightings are from April 7 
to May 27, with a median of May 5 . Twenty-two initial fall sightings are from August 28 to November 30, with a median of September 15. Half of the records fall within the period September 14-24. Seventeen final fall sightings are from September 17 to December 26, with a median of October 9 .

Habitats: While on migration this species occurs along rivers, lakes, and reservoirs that support fishes and have fairly clear water for foraging. Nests in Scotts Bluff County from 2008 to 2011 were the first confirmed breedings of ospreys in Nebraska in more than a century (Mollhoff, 2016). By 2016 there had been several successful nestings in Keith County and two successful nestings in Scotts Bluff County (Nebraska Bird Review 80:134, 84:116).

Comments: It is pleasing to know that ospreys are once again nesting in Nebraska, considering the many new reservoirs that have been formed in recent decades and their resulting increased food resources. A program of hacking young birds (a release method) in South Dakota has probably helped facilitate the onset of $\mathrm{Ne}$ braska nesting. The birds are now regular spring and fall migrants at Lake McConaughy and many other reservoirs and rivers in the state. Breeding Bird Surveys between 1966 and 2015 indicate that the species had a surveywide population increase $(2.81 \%$ annually) during that period.

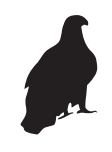

\section{Family Accipitridae (Hawks and Eagles)}

\section{Swallow-tailed Kite}

Elanoides forficatus

Accidental. This kite previously bred in eastern Nebraska-in Greenwood (Cass County), Rockport (Douglas or Washington counties), and Calhoun (Washington County), according to Bruner, Wolcott, and Swenk (1904)but disappeared sometime after 1900. A reputed 1960 sighting for Douglas County was later retracted, but a bird photographed at Kearney on July 25, 2016, was Nebraska's second accepted modern record (Nebraska Bird Review 84:117). The nearest breeding area of this species is in eastern Texas.

\section{White-tailed Kite}

Elanus leucurus

Accidental. This species was reported from Sarpy County, August-September 1983, and from Polk County, May 6, 1995 (Nebraska Bird Review 51:91, 63:60). Four state records accrued by 2004 (Nebraska Bird Review 73:52). The fifth and sixth state records were from southeastern Lincoln County in the summers of 2007 and 2008 ( Nebraska Bird Review 77:99). The nearest breeding area of this species is in eastern Texas.

\section{Mississippi Kite}

Ictinia mississippiensis

Rare. In addition to some old records for Adams and Douglas counties, there were three sightings between 1975 and 1977 in Douglas and Sarpy counties, and earlier ones in Lincoln, Lancaster, Antelope, Adams, and Web- 
ster counties. Since 1991, breeding attempts have occurred regularly in the city of Ogallala (Nebraska Bird Review 63:88-89) and more recently in Red Cloud (Nebraska Bird Review 73:52), Benkleman (Nebraska Bird Review 78:136), Imperial (Nebraska Bird Review 80:91), and North Platte ( $\mathrm{Ne}$ braska Bird Review 82:158). Possible breedings have also occurred in Kearney and Omaha (Nebraska Bird Review 84:117). No nests of this species were discovered during the second atlasing period of the Breeding Bird Atlas project, but nesting was confirmed in one Dundy County survey block (Mollhoff, 2016).

Migration: Eight total spring records are from April 15 to May 30, with a mean of May 15. Four fall records are for September 9 (2 records), 11, and 19. Kansas fall records extend to late October.

Habitats: Associated with scrub and open woodlands near water. The Ogallala nestings have been in a large tree in a residential area. Parks and golf courses are also used for nesting by these insectivorous hawks. By 2013 nesting in North Platte had occurred at three sites (Nebraska Bird Review 81:141).

Comments: Breeding by this attractive kite began in Ogallala and has slowly spread over western Nebraska. The breeding range in Kansas has slowly advanced northward to include several north-central counties, so additional nesting locations in Nebraska should be expected. Breeding Bird Surveys between 1966 and 2015 indicate that the species collectively underwent a survey-wide population increase (0.55\% annually) during that period.

\section{Bald Eagle}

Haliaeetus leucocephalus

This species is an uncommon spring and fall migrant and locally common winter resident in Nebraska, especially along the major rivers and reservoir areas, such as Lewis and Clark Lake, Lake McConaughy, Johnson Lake, and Harlan County Reservoir. Although it once bred regularly in eastern Nebraska, the first known modern-era nesting attempt was in 1973 in Cedar County (Nebraska Bird Review 41:76). Recently nesting efforts have occurred every year, often along the Platte River or other larger bodies of water. By 1998 nesting efforts were known from Douglas, Sherman, Garden, Gage, Nemaha, Pawnee, and Boyd counties. By 2005, 35 nests were occupied, mostly along larger rivers. Between 1991 and 2009, 49 young fledged from 440 nests with known outcomes (Nebraska Bird Review 78:121-126, 79:121-126), and since then most Nebraska counties have hosted nests. A 2016 Nebraska Game and Parks Commission survey revealed 162 active nests, with sites recorded in 72 of the state's 93 counties, mostly along wooded rivers and in the Sandhills. Rivers with the largest numbers of active nests were the lower Platte (18), Elkhorn (15), Niobrara (12), central Platte (11), and North Loup (10).

Migration: Sixty-five initial fall sightings range from September 16 to December 31, with a median of November 29. Half of the records fall within the period November 16 to December 16. Eighty-eight final spring sightings are from January 8 to May 12, with a median of March 19. Half 
of the records fall within the period March 17 to April 2. During winter bald eagles appear at lakes, reservoirs, or larger rivers throughout the Great Plains, especially after fish kills; up to 800 or more have gathered at Calamus Reservoir in March ( $\mathrm{Ne}$ braska Bird Review 85:66).

Habitats: Bald eagles in Nebraska utilize ice-free areas of larger treelined rivers and reservoirs during winter periods. Perching is usually done in tall cottonwoods near water. Twenty-four nests of this species were discovered during the second atlasing period of the Breeding Bird Atlas project, and nesting was confirmed in 26 survey blocks (Mollhoff, 2016), as compared with a confirmed nesting in one Grant County block during the first survey (Mollhoff, 2001).

Comments: Bald eagle winter populations have greatly increased in recent years; now an average of more than 1,00o birds winter within the state. Lake McConaughy is especially favored, but Johnson and Harlan County Reservoirs, the J-2 hydroplant near Lexington, the central Platte River, and the Republican and Missouri Rivers are also important concentration areas. Usually about $25-30 \%$ of these birds are immatures, suggesting that favorable reproduction is occurring. Breeding Bird Surveys between 1966 and 2015 indicate that the species collectively underwent a surveywide population increase $(5.18 \%$ annually) during that period.

\section{Northern Harrier}

\section{Circus hudsonicus}

This species is a common migrant and permanent resident through- out Nebraska. Although in cold winters most birds may leave the state, in most areas and years the species can be regarded as a resident. It is probably most common as a breeder in the Sandhills and the Rainwater Basin. It breeds locally almost throughout the Plains states and is a regular throughout during migration.

Migration: Thirty-nine initial spring sightings range from January 1 to June 2, with a median of March 13. The wide spread of the records suggest it is a resident over much of the state. Thirty-six final fall records are from September 14 to December 31, with a median of December 9 .

Habitats: This species occurs in open habitats such as native grasslands, prairie marshes, and wet meadows. Nesting is done in grassy or woody vegetation ranging from upland grasses and shrubs to emergent vegetation in water more than two feet deep. Three nests of this species were discovered during the second atlasing period of the Breeding Bird Atlas project, and nesting was confirmed in six survey blocks (Mollhoff, 2016), as compared with confirmed nestings in ten blocks during the first survey (Mollhoff, 2001).

Comments: Northern harriers are graceful predators that are usually seen sweeping low over marshes and fields, showing white rump patches in both sexes. Adult males are otherwise silvery gray with black wingtips, while females and young males are mostly chocolate brown. Breeding Bird Surveys between 1966 and 2015 indicate that the species collectively underwent a survey-wide population decline (1.21\% annually) during 
that period, and Nebraska had an estimated $1.17 \%$ rate of annual decline.

\section{Sharp-shinned Hawk}

Accipiter striatus

This species is an uncommon to occasional winter visitor and spring migrant throughout Nebraska. Although the only recent breeding records are for the northwest (Sioux County) and the Niobrara Valley (Brown County), the species may also nest in the Missouri River's forested valley. It probably nests locally in the Dakotas and Minnesota, has nested in Kansas and Oklahoma, and migrates throughout the Great Plains.

Migration: A total of 142 initial spring records range from January 1 to June 1, with a median of March 29. Half the records fall within the two periods January 1-9 and March 17 to April 27, indicating that this species is probably a winter visitor and early spring migrant. Forty-one initial fall records are from July 26 to December 30, with a median of September 16 . Half of the records fall within the period September 3-19. Thirty-five final fall sightings are from August 20 to December 31, with a median of November 10 .

Habitats: Throughout the year this species is associated with fairly dense forests, especially mixed woods with some coniferous trees. The species often preys on small birds such as sparrows but also takes robins and even small chickens. Sharpshins often wait in hiding around bird feeders, and a rapid evacuation of the area will follow the hawk's sudden appearance.

Comments: This is the smallest of the accipiter hawks, a group noted for their rounded wings, long tails, and swift flight abilities. Breeding Bird Surveys between 1966 and 2015 indicate that the species collectively underwent a survey-wide population increase (0.92\% annually) during that period. There was a confirmed nesting in one Brown County survey block during the first Breeding Bird Atlas survey, but none in the second (Mollhoff, 2016).

\section{Cooper's Hawk}

Accipiter cooperii

This species is an uncommon winter visitor and spring migrant throughout Nebraska, and a local permanent resident. It is a rare to uncommon nester in the forests of eastern Nebraska, and there are recent breeding records for the Pine Ridge region and the North Platte and western Republican valleys. It is a local but probably regular breeder in suitable habitats throughout the Plains states, especially in eastern and southeastern regions.

Migration: A total of 164 initial spring sightings range from January 1 to June 10, with a median of March 16. Half of the records fall within the two periods January 1-9 and March 13 to April 26. Thirty-four initial fall records are from August 7 to December 27, with a median of September 16. Half of the records fall within the period September 4 to October 1. Thirty-five final fall sightings are from September 8 to December 31, with a median of October 30 . These dates suggest that the species is both a winter visitor and local permanent resident statewide. Cooper's hawks 
have consistently outnumbered sharpshinned hawks in statewide Christmas Counts since 2013, suggesting that the Cooper's hawk is increasing in Nebraska, as indicated by recent Breeding Bird Surveys. By comparison, during Lincoln's Christmas Counts from 1946 to 1997 the sharp-shinned hawk outnumbered the Cooper's hawk by a ratio of more than three to one (Johnsgard, 1998).

Habitats: Throughout the year this species is associated with mature forests, especially hardwood forests. Nestings were confirmed in Hitchcock and Frontier counties during the first breeding bird atlasing period of 1984-89 (Mollhoff, 2001). A dozen nests of this species were discovered during the second atlasing period of the Breeding Bird Atlas project, and nesting was confirmed in 11 survey blocks (Mollhoff, 2016), as compared with confirmed nestings in two blocks during the first survey (Mollhoff, 2001).

Comments: A larger relative of the sharp-shinned hawk, the Cooper's preys on bigger birds and mammals, and is even more fearless in its attacks, taking birds up to the size of grouse, and mammals as large as skunks and opossums. The two accipiter species are best distinguished by size, the Cooper's nearly crow-sized, although large female sharpshins might approach small male Cooper's hawks in body mass. Breeding Bird Surveys between 1966 and 2015 indicate that the species collectively underwent a survey-wide population increase (2.24\% annually) during that period, and Nebraska had an incredi- bly (and impossibly) high $14.38 \%$ estimated rate of annual increase. Much of this increase might be the result of the birds becoming urbanized nesters; Lincoln now (2018) has several nesting pairs annually.

\section{Northern Goshawk}

\section{Accipiter gentilis}

This species is an occasional winter visitor and spring migrant nearly statewide. The species is probably less common now than earlier, but there have been periodic observations from Box Butte, Cherry, Custer, Saunders, and Lancaster counties. During the winter of $2015-16$, there were five reports from eastern and central $\mathrm{Ne}$ braska (Nebraska Bird Review 84:10). The goshawk's only breeding regions in the Great Plains are the Black Hills and northern Minnesota, but it is a migrant throughout.

Migration: Forty-eight spring records range from January 1 to June 1, with a median of March 15. Half of the records fall within the two periods January 1-11 and April 14 to May 16 , suggesting this species is both a winter visitor and late spring migrant. Twenty-two total fall records are from September 16 to December 31, with half of the records occurring within the two periods September 21 to October 17 and December 25-31. Perhaps these apparent timing differences reflect later fall and earlier spring arrivals of adult birds.

Habitats: Throughout the year this species is rarely found far from wooded to heavily forested areas.

Comments: The Latin name of the goshawk may suggest it is "gentle," 
but the name refers to the royal appearance of the bird. The common name goshawk refers to the species' ability to attack and kill geese and various animals up to the size of woodchucks, and domestic fowl weighing up to about five pounds.

\section{Harris's Hawk}

Parabuteo unicinctus

Accidental. The first evidence of this species' occurrence in the state was a specimen collected at Elkhorn, Douglas County, on October 28, 1922, which is now in the Hastings Museum (Nebraska Bird Review 45:52). The species was also observed in Scotts Bluff County on January 13 and 27, 1995 (Nebraska Bird Review 64:134), and a road-killed bird was found in Lancaster County on October 26, 2012 (Nebraska Bird Review 80:134-135). One was seen on November 5, 2017 , and then for a few days near Niobrara, Knox County. There are Kansas records for six counties, including one breeding record (Thompson et al., 2011). The nearest regular breeding area of this species is in western Texas.

\section{Red-shouldered Hawk}

\section{Buteo lineatus}

This species is an uncommon to occasional spring and fall migrant in eastern counties and a rare permanent resident in southeastern and western Nebraska. It has been observed west to Scotts Bluff County and reported rarely in the Pine Ridge region, but known breeding is mostly limited to the Missouri Valley. It apparently bred in Douglas County in 1958 and again in 1964 (Nebraska Bird Re- view 47:38) and in Fontenelle Forest in 1995. Fontenelle Forest and Indian Cave State Park are likely potential breeding sites. In 2009 a nesting attempt was made at Pawnee Lake, Lancaster County (Nebraska Bird Review 77:99, 143), and a probable breeding occurred in Jefferson County in 2016 (Nebraska Bird Review 84:85). A recent western breeding occurred in North Platte and possibly also near Wright's Gap, Scotts Bluff County (Nebraska Bird Review 82:159). It also breeds in eastern Kansas (at least 13 counties) and eastern Oklahoma.

Migration: Forty-nine initial spring sightings are from January 1 to June 10. Eleven final fall sightings are from September 25 to December 27, with a median of November 16 , with no clear indication of migratory tendencies.

Habitats: In Nebraska this species is found in relatively moist woodlands, especially floodplain forests, with adjacent open country for foraging. One nest of this species was discovered during the second atlasing period of the Breeding Bird Atlas project, and nesting was confirmed in one Lancaster County survey block (Mollhoff, 2016).

Comments: This rarely seen hawk has apparently increased in the Midwest in recent decades, probably at least in part because of forest regeneration trends. Eastern Nebraska represents the western edge of its historic Great Plains breeding range, although there is also a Pacific coast population. Breeding Bird Surveys between 1966 and 2015 indicate that the species collectively underwent a survey-wide population increase $(2.7 \%$ annually) during that period. 


\section{Broad-winged Hawk}

Buteo platypterus

This species is an uncommon spring and fall migrant in eastern Nebraska, and an occasional summer resident in the Missouri's forested valley and the Panhandle. Nesting has occurred in eastern Nebraska, but there are few recent records. Breeding has occurred since 2008 in North Platte (Nebraska Bird Review 76:100, 80:92). One nest of this species was discovered during the second atlasing period of the Breeding Bird Atlas project, and nesting was confirmed in two survey blocks of Sarpy and Lincoln counties (Mollhoff, 2016). It still breeds locally in Minnesota, Kansas (in at least three counties), and Oklahoma, and has bred in South Dakota. Wintering occurs in South America.

Migration: Excluding a single January record, the range of 82 initial spring sightings is from March 4 to June 6, with a median of April 26. Half of the records fall within the period April 17 to May 1. Nineteen final spring sightings are from April 12 to June 8, with a median of May 15 . Eleven initial fall sightings are from August 8 to October 3, with a median of September 12. Sixteen final fall sightings are from August 25 to November 19, with a median of October 5. Most broad-winged hawks winter in South America.

Habitats: Associated with mature deciduous forests, especially those near water, during the breeding season. Migrant birds are sometimes seen in flocks over open country.

Comments: Like the red-shouldered hawk, this little woodland-nesting buteo has regionally declined in popu- lation and shows little sign of recovery. It is a highly migratory species and, like the Swainson's hawk, is perhaps exposed to pesticides on its wintering grounds. Breeding Bird Surveys between 1966 and 2015 indicate that the species had a survey-wide population increase (1.02\% annually) during that period.

\section{Swainson's Hawk}

\section{Buteo swainsoni}

This species is a common to uncommon spring and fall migrant and summer resident almost statewide, becoming less common eastwardly, and with the eastern limits of regular breeding probably west of a line from Gage to Burt counties. Largest numbers occur during the fall migration period in late September, but wintering occurs in southern South America. It also breeds elsewhere in the Plains states excepting the easternmost regions and migrates throughout the region.

Migration: Ninety-three initial spring sightings are from January 1 to June 8, with a median of April 18. Half of the records fall within the period April 3 to May 3. Sixty-five final fall sightings are from August 4 to December 27, with a median of September 26. Half of the records fall within the period September 14 to October 1.

Habitats: While this species occurs in Nebraska it is associated with open country, especially high plains and sandhills with only scattered trees available for nesting sites. Sixteen nests of this species were discovered during the second atlasing period of the Breeding Bird Atlas project, and nesting was confirmed in 40 survey blocks (Mollhoff, 2016), as com- 
pared with confirmed nestings in 36 blocks during the first survey (Mollhoff, 2001).

Comments: This is a plainsadapted, largely insect-eating hawk that is still quite common in western Nebraska, although mass poisoning by pesticides on wintering regions in South America has done great damage to populations. West of Kearney many of the buteos seen from roadsides are likely to be Swainson's hawks, whereas east of Grand Island redtailed hawks increasingly compose the majority. Breeding Bird Surveys between 1966 and 2015 indicate that the species collectively underwent a survey-wide population increase (0.72\% annually) during that period, and $\mathrm{Ne}$ braska had an estimated $1.64 \%$ rate of annual increase. However, in the area around Cedar Point Biological Station of Keith County, where in the 1980 s a person could sometimes find a half dozen Swainson's hawk nests within a 20-mile radius of the station, it is rare now to find a single nest. A small percentage of Nebraska's Swainson's hawks are melanistic.

\section{Zone-tailed Hawk}

Buteo albonotatus

Accidental. A single bird of this species was photographed near Cedar Point Biological Station, Keith County, April 25, 2007 (Nebraska Bird Review 76:118). The nearest breeding area of this species is in central Texas.

\section{Red-tailed Hawk}

Buteo jamaicensis

This species is an uncommon summer or permanent resident statewide, but it is more common eastwardly and a common spring and fall migrant. It is a breeder and migrant throughout the Great Plains.

Migration: Thirty-two initial spring sightings range from January 1 to May 21, with a median of March 22 and a nearly random temporal distribution, suggesting that the species is essentially a permanent resident. Twentythree final fall sightings are from September 29 to December 31, with a median of November 26.

Habitats: A combination of extensive open habitat for visual hunting and scattered clumps or groves of tall trees for nesting provide the yearround needs for this species. Twelve nests of this species were discovered during the second atlasing period of the Breeding Bird Atlas project, and nesting was confirmed in 127 survey blocks (Mollhoff, 2016), as compared with confirmed nestings in 43 blocks during the first survey (Mollhoff, 2001).

Comments: The red-tailed hawk is the most familiar of Nebraska's buteo hawks. It is present all year, but migrants also move through the state during September to October and again in March and April. Nesting is done in tall hardwoods near the edges of woodlands, and the birds are highly effective predators of rodents, rabbits, and snakes such as bullsnakes. Not all red-tailed hawks have rusty tails; first-year birds have barred brown tails, and the melanistic Harlan's race often has a grayish tail with little or no rufous tinting. The leucistic (semialbinistic) Krider's hawks often have pinkish tails, but some pale red-tails are thought to be leucistic versions of the Harlan's hawk. Typical Harlan's 
hawks are fairly frequent (about 2\% to $5 \%$ of the population) during winter in Nebraska. So too are a few Krider's hawks, a supposedly Great Plains endemic but more probably an occasional leucistic variant. Krider's hawk phenotypes might sometimes nest in western Nebraska, as I have twice seen leucistic birds at Crescent Lake National Wildlife Refuge during May. Breeding Bird Surveys between 1966 and 2015 indicate that the species has undergone a survey-wide population increase (1.7\% annually) during that period, and a $3.58 \%$ rate of annual increase in Nebraska.

\section{Ferruginous Hawk}

\section{Buteo regalis}

This species was an uncommon to occasional permanent resident in western Nebraska. It is apparently migratory and is a summer visitant only in northwestern Nebraska but is a permanent resident or winter visitor elsewhere. Regular breeding occurs west of a line from Dundy to Keya Paha counties, and there are also late twentieth-century records of breeding from Banner, Cherry, Chase, Furnas, and Lincoln counties. Elsewhere in the Great Plains it nests widely in the drier and short-grass plains region and may be seen on migration somewhat farther east.

Migration: Seventy initial spring sightings range from January 1 to May 25, with a median of March 1 . The wide spread of the records (half falling between January 17 and April 12) suggest that the species is essentially resident in Nebraska. Twenty final fall records are likewise widely spread between August 26 and December 31.
Habitats: While in Nebraska, this species is normally found in grassland habitats having scattered trees, buttes, or bluffs for nesting sites. A remarkably high total of 36 nests of this species were reported by Rocky Mountain Bird Observatory biologists during the second atlasing period of the Breeding Bird Atlas project, and nesting was confirmed in four survey blocks in Sioux, Box Butte, and Grant counties (Mollhoff, 2016). There likewise were confirmed nestings in four blocks in Lincoln, Cherry, Chase, and Furnas counties during the first survey (Mollhoff, 2001).

Comments: This majestic buteo is almost eagle-sized (but about half the weight), and like the golden eagle is able to prey very effectively on prairie dogs and rabbits. It has a very broad gape, causing it to have a somewhat froglike appearance when its beak is opened. At times its pale rusty tail may cause confusion with pale-morph red-tailed hawks, but the rusty thighs and white "panels" in its outer wing feathers help with identification. Breeding Bird Surveys between 1966 and 2015 indicate that the species collectively underwent a surveywide population increase (0.61\% annually) during that period. However, Nebraska had a statistically unreliable estimate (based on 12 survey routes) of a $1.16 \%$ rate of annual decline, which has been the general trend of grassland-dependent birds.

\section{Rough-legged Hawk}

Buteo lagopus

This Arctic-nesting species is an uncommon migrant and winter visitor statewide, becoming more common 
westwardly. It also occurs throughout the entire plains region.

Migration: Eighty-five initial fall records range from September 30 to December 30, with a median of November 2. Half of the records fall within the period October 9 to November 22. A total of 73 final spring sightings range from January 8 to May 20, with a median of March 26. Half of the records fall within the period March 10 to April 12.

Habitats: Open prairies, plains, and other grassland habitats are used while on migration and during wintering in the Great Plains.

Comments: This is a common winter buteo in Nebraska, for only then does it move south from Arctic breeding grounds and share the plains with red-tailed and ferruginous hawks. They then are much more common than ferruginous hawks but usually are outnumbered by red-tails five- to ten-fold. Like the ferruginous hawk, its tarsi are fully feathered (hence the name "rough-legged"), but the species is somewhat smaller and is adapted to preying on lemming-sized rodents. A small percentage of Nebraska's roughlegged hawks are melanistic.

\section{Golden Eagle}

Aquila chrysaetos

This North American and Eurasian eagle is an uncommon migrant and winter resident throughout $\mathrm{Ne}$ braska, becoming more common westwardly, and is a permanent resident in western Nebraska, especially the Pine Ridge region. There are late twentieth-century breeding observations from at least Sioux, Dawes,
Sheridan, Box Butte, Scotts Bluff, Banner, Morrill, Garden, Cheyenne, and Lincoln counties, according to $\mathrm{Ne}$ braska Game and Parks Commission records. It also breeds in the western portions of the Dakotas and from Colorado southward, and during winter sometimes appears farther east.

Migration: This species is evidently a resident in western Nebraska and a winter visitor elsewhere, and thus the records are not susceptible to ready statewide analysis. Late winter sightings seem to follow closely the temporal pattern of the bald eagle's movements.

Habitats: Throughout most of the year this species is associated with arid, open country, often with buttes, mountains, or canyons that offer remote nesting sites and large areas of grassland vegetation for foraging. In winter it is sometimes found near rivers or reservoirs but not nearly to the extent that is true of the bald eagle. Nineteen nests of this species were discovered during the second atlasing period of the Breeding Bird Atlas project, and nesting was confirmed in eight survey blocks (Mollhoff, 2016) in Sioux, Dawes, Banner, Chase, Cheyenne, and Garden counties as compared with confirmed nestings in two blocks in Banner and Cheyenne counties during the first survey (Mollhoff, 2001).

Comments: Breeding Bird Surveys of golden eagles in Nebraska suggest that they are widely distributed in western counties, with no special areas of concentration. This is not surprising because jackrabbits and cottontails are probably important parts of their diet, but there is no attrac- 
tion to localized sources of fish. Good places to look for nesting birds include the Pine Ridge region and southern Panhandle. Breeding Bird Surveys between 1966 and 2015 indicate that the species collectively underwent a survey-wide population decline (0.11\% annually) during that period, whereas Nebraska had a statistically unreliable estimate (based on four survey routes) of a $0.03 \%$ rate of annual increase.

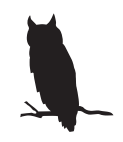

\section{Family Tytonidae (Barn Owls)}

\section{Barn Owl}

Tyto alba

This widespread (nearly worldwide) species is an uncommon permanent resident statewide but probably is more common in the southern counties. It also breeds throughout the Plains states north to South Dakota.

Habitats: Open to semi-open habitats, where small rodents are abundant and where hollow trees, old buildings, or caves are available to provide roosting and nesting sites, are favored by barn owls. Rats are particularly favored as prey species, but many other rodents are also consumed. Fifteen nests of this species were discovered during the second atlasing period of the Breeding Bird Atlas project, and nesting was confirmed in 19 survey blocks as compared with confirmed nestings in 20 blocks during the first survey (Mollhoff, 2001). Most confirmed nestings were south of the Platte River (Mollhoff, 2016).

Comments: Barn owls are rodent catchers without peer, and the presence of a pair at a farm may account for the disappearance of several thousand mice or rats per year. They are thus highly valuable birds, although farmers often seem unaware of their presence or, if so, may actually try to kill them. Near Cedar Point Biological Station in Keith County, the nesting birds concentrate on pocket mice and kangaroo rats for prey but in turn are preyed upon by great horned owls. Breeding Bird Surveys between 1966 and 2015 indicate that the species collectively underwent a survey-wide population increase (2.02\% annually) during that period.

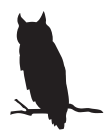

\section{Family Strigidae (Typical Owls)}

\section{(Flammulated Owl)}

\section{Otus flammeolus}

Hypothetical. An owl identified as possibly being of this species on the basis of its calls was heard in Chadron State Park, Dawes County, in June 1978 (Nebraska Bird Review 46:70). The nearest known breeding area is in Wyoming's Sierra Madre Mountains (Faulkner, 2012). 


\section{Eastern Screech-Owl}

\section{Megascops asio}

This species is a common permanent resident in wooded areas throughout the state but is rare or absent from the treeless regions. Even in eastern Nebraska the rufous plumage morph is rare. There are no Nebraska records of Megascops kennicottii, and none in eastern Wyoming or South Dakota.

Habitats: This widespread and adaptable species is probably the most common Nebraska owl and occurs in a variety of wooded habitats, including farmyards, cities, orchards, and other human-made habitats, as well as in forests and woodlands. It is probably more common in cities than in heavy woodlands, where it is preyed upon by larger owls. Three nests of this species were discovered during the second atlasing period of the Breeding Bird Atlas project, and nesting was confirmed in 18 survey blocks (Mollhoff, 2016), as compared with confirmed nestings in 32 blocks during the first survey (Mollhoff, 2001).

Comments: Screech-owls often go unnoticed in places where they are common. The whinny-like call these birds utter is not very owl-like, and they hide during daylight hours in tree cavities. In eastern Nebraska about $90 \%$ of the birds are gray morphs, and farther west the rufous morph is even rarer. Breeding Bird Surveys between 1966 and 2015 indicate the species collectively underwent a survey-wide population decline $(1.27 \%$ annually) during that period, whereas Nebraska had a statistically unreliable (based on five survey routes) estimated $6.09 \%$ rate of annual increase.

\section{Great Horned Owl}

\section{Bubo virginianus}

This species is an uncommon permanent resident statewide but probably is most common in the heavily wooded major river valleys and the Pine Ridge region. It also breeds and migrates throughout the entire Plains states. It is probably the second most common owl in the state.

Habitats: This highly adaptable owl occurs in a variety of habitat types ranging from dense forests to city parks and farm woodlands, and extends into nonwooded environments in rocky canyons and gullies. Eleven nests of this species were discovered during the second atlasing period of the Breeding Bird Atlas project, and nesting was confirmed in 57 survey blocks (Mollhoff, 2016), as compared with confirmed nestings in 86 blocks during the first survey (Mollhoff, 2001).

Comments: This is Nebraska's largest and most powerful owl, and it is able and likely to attack skunks, feral cats, and sometimes even very small dogs. It is not safe to climb up to a nest of these birds without protective headgear; their talons are long and the birds have a vise-like grip. Breeding Bird Surveys between 1966 and 2015 indicate that the species collectively underwent a survey-wide population decline (0.81\% annually) during that period, and Nebraska had an estimated $0.69 \%$ rate of annual decline.

\section{Snowy Owl}

\section{Bubo scandiacus}

This nearly snow-white species is an occasional winter visitor, not present 
every winter but occurring almost anywhere in the state. It is progressively more common to the north of Nebraska during winter.

Migration: The range in 18 initial fall sightings is from November 6 to December 29, with a median of December 4. Twenty-three final spring sightings are from January 3 to April 30, with a median of February 5.

Habitats: Wintering birds are usually associated with open fields, plains, marshes, and grassy lowlands. They often perch on haystacks or other somewhat elevated sites.

Comments: Only during occasional winters do snowy owls enter Nebraska in any numbers; this probably occurs when a population surplus of lemmings is present during the breeding season, and so many owlets are produced that these juveniles are likely to starve during their first winter of life unless they drift south into milder climates where prey might be more abundant. More than 200 were reported in Nebraska during the invasion of 201112 (Nebraska Bird Review 80: 7276). The birds are highly conspicuous where snow is absent from the landscape, and many snowy owls are shot by scofflaws. Females and first-year males are more freckled with brown feathers than are older males.

\section{Northern Hawk Owl}

Surnia ulula

Accidental. The state's only hawk owl record is a specimen obtained in Lancaster County during November 1891 (Bruner, Wolcott, \& Swenk, 1904). It was also reported from Sheridan County, 1912. The nearest breeding area of this species is in Manitoba.

\section{Burrowing Owl}

Athene cunicularia

This iconic plains species is a common to uncommon spring and fall migrant and summer resident in western and central Nebraska, becoming rare eastwardly. It has not been known to breed east of Platte County since the 1980s. Rock, Loup, and Kearney counties were the eastern limits of confirmed breeding during the second Breeding Bird Atlas survey of the early 200os (Mollhoff, 2016). No nests of this species were examined during the second atlasing period of the Breeding Bird Atlas project, but nesting was confirmed in 38 survey blocks (Mollhoff, 2016), as compared with confirmed nestings in 37 blocks during the first survey (Mollhoff, 2001).

Migration: The range of 119 initial spring sightings is from March 10 to June 10, with a median of April 24. Half of the records fall within the period April 13 to May 9. Forty-three final fall sightings are from July 21 to November 9, with a median of September 16. Half of the records fall within the period August 30 to September 30 .

Habitats: This species is normally associated with heavily grazed grasslands, especially those that support colonies of large burrowing rodents such as prairie dogs. Normally colonial, scattered nestings may also occur by individual pairs where suitable excavations are available.

Comments: Largely because of probably unconstitutional state laws requiring the control of prairie dogs on private lands, the numbers of both prairie dogs and burrowing owls have plummeted in recent decades, and 

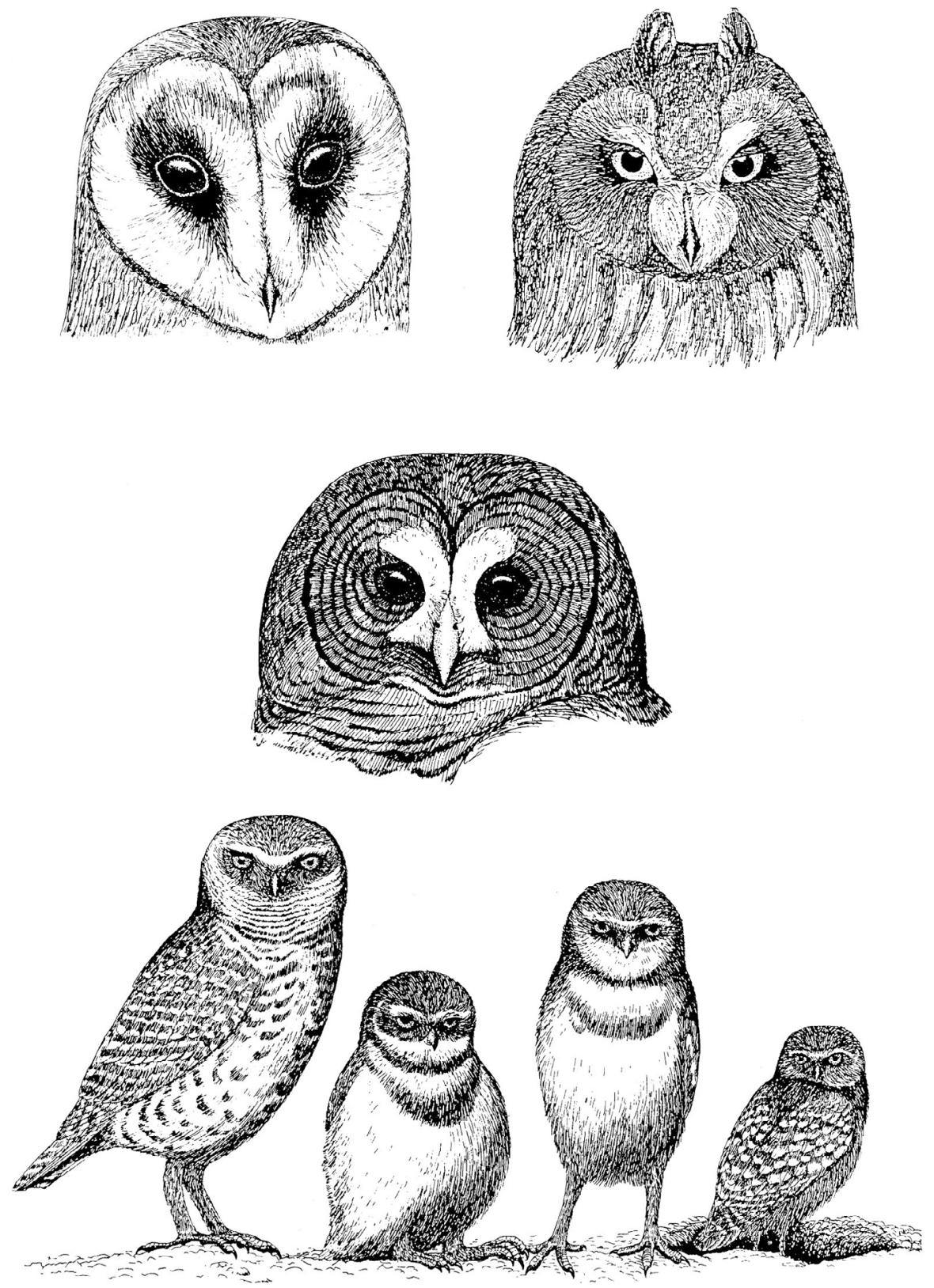

Figure 11. Adults of barn owl (top left), short-eared owl (top right), and barred owl (middle); also burrowing owl, adults and two owlets (bottom) 
there are few places left where these fascinating little owls can be readily observed. Unlike most owls, these birds are daytime feeders, and they also are mostly insect eaters, at least while they are in Nebraska. Breeding Bird Surveys between 1966 and 2015 indicate that the species collectively underwent a survey-wide population decline (0.98\% annually) during that period, and Nebraska had an estimated $0.85 \%$ rate of annual increase. Clay County may be the easternmost current breeding area in the state (Nebraska Bird Review 84:121).

\section{Barred Owl}

\section{Strix varia}

This woodland species is an uncommon permanent resident in southeastern Nebraska, becoming rarer westwardly, and is absent from the western half of the state. The current western breeding limits of this species in the Platte Valley are at about Nance and Merrick counties, and probably around Fairbury in the Republican River valley. It has been seen west to Harlan County in the Republican Valley, to Hall County in the Platte Valley, to central York County along the west fork of the Big Blue River, and to Seward County on the main stem of the Big Blue River (Nebraska Bird Review $85: 13,68)$. It is a rare straggler in eastern Colorado, and a vagrant in Wyoming (five records) (Faulkner, 2012).

Habitats: Throughout the year this species is found in dense river-bottom woods, which in Nebraska are typically hardwoods. However, coniferous forests are also used when available and seem to be preferred. Five nests of this species were discovered during the second atlasing period of the Breeding Bird Atlas project, and nesting was confirmed in four survey blocks (Mollhoff, 2016), as compared with confirmed nestings in two blocks during the first survey (Mollhoff, 2001).

Comments: The dark brown eyes of the barred owl mark it as a highly nocturnal species; those that hunt during the day and in twilight have yellow eyes. It is also one of the most vocal of owls, and can be easily called up by imitation or playback of its calls. Breeding Bird Surveys between 1966 and 2015 indicate that the species collectively underwent a surveywide population increase (1.63\% annually) during that period.

\section{Great Gray Owl}

Strix nebulosa

Accidental. In addition to a specimen record from Douglas County from December 1893, a bird was shot during January 1978 in Dixon County, and another was taken in the vicinity of Long Pine, Brown County, in 1977 ( $N e$ braska Bird Review 47:63). It was also observed in Douglas County in April 1948 and Lincoln County in January 1950. The nearest breeding area is in northwestern Wyoming, although it is probable that the Nebraska records are from birds coming out of southern Canada.

\section{Long-eared Owl}

Asio otus

This species is a permanent resident in wooded areas such as major river valleys throughout the state, being uncommon in the east and becoming rarer westwardly. The population is 
probably supplemented from migrants from farther north during winter. It also breeds and migrates throughout the other Plains states.

Migration: Twenty-four spring sightings range from January 2 to May 14 , with a median of March 9. Nineteen fall sightings are from July 21 to December 31, with a median of November 24. These limited data suggest that the species is a summer resident and a late fall and early spring migrant, with frequent overwintering.

Habitats: Throughout the year this species is associated with wooded areas, including riverbottom forests, parks, orchards and woodlots. Both coniferous and hardwood forests are utilized, with the former apparently preferred. Three nests of this species were discovered during the second atlasing period of the Breeding Bird Atlas project, and nesting was confirmed in two Hitchcock and Sheridan survey blocks (Mollhoff, 2016), as compared with confirmed nestings in five blocks during the first survey (Mollhoff, 2001).

Comments: This secretive owl is mainly a bird of mature forests in the east, but we found two newly fledged young perched in a dense clump of junipers at Cedar Point Biological Station, Keith County, in 1995. Like the barred owl it is quite a vocal bird, but it is hard to find during daytime hours as it hides quietly in dense wooded vegetation.

\section{Short-eared Owl}

Asio flammeus

This prairie owl is a permanent resident throughout Nebraska, being more common in the summer in the
Sandhills and other natural grasslands. During winter the population is apparently supplemented by migrants from farther north. It is probably least common in the Pine Ridge region. The short-eared owl also breeds in the other Plains states south to at least southern Kansas, and it occurs farther south during migration.

Migration: Thirty-five spring sightings range from January 8 to June 6 , with a median of March 12. Twentynine fall sightings are from July 20 to December 31, with a median of November 30. The data are very similar to those of the long-eared owl, suggesting that the species is a summer resident and a late fall and early spring migrant, with frequent overwintering.

Habitats: Throughout the year this species is found in open, grass-dominated environments, and in Nebraska the Sandhills prairie and other natural grasslands are favored habitats. Nesting usually occurs in grassy cover, with several pairs often nesting fairly close to one another in a loose colonial situation. No nests of this species were discovered during the second atlasing period of the Breeding Bird Atlas project (Mollhoff, 2016), as compared with a confirmed nesting in one Banner County block during the first survey (Mollhoff, 2001).

Comments: Like the northern harrier, this species is a prairie breeder. Breeding Bird Surveys between 1966 and 2015 indicate that the species collectively underwent a survey-wide population decline (0.89\% annually) during that period, and an annual decline of $4.08 \%$ in Nebraska. 


\section{Boreal Owl}

Aegolius funereus

Accidental. There are two early Lancaster County records for this species from October 1907 and December 1892, a Clay County record for 1916 , and a record from Webster County in December 1963 (Nebraska Bird Review 32:13). The nearest known nesting area is in northern Wyoming's Bighorn Mountains, where it is apparently rare (Canterbury, Johnsgard, \& Downing, 2013).

\section{Northern Saw-whet Owl}

Aegolius acadicus

This coniferous forest species is an uncommon to rare winter visitor in Nebraska, and a rare breeder in the Panhandle. There was early evidence of breeding at Chadron State Park (Nebraska Bird Review 77:147). Calling by a territorial male was heard yearly at Fort Robinson for many years during the 1980 s and again in 1997 near Ash Creek Canyon, northeastern Dawes County. A newly fledged juvenile was found as a road kill in Antelope County in late May 2002 (Nebraska Bird Review 70:63). Nesting was finally proven by the occupation of a nest box in the Wildcat Hills, Scotts Bluff County, in March 2014 (Mollhoff, 2014); in 2015 a nest box in Dawes County produced six young (Nebraska Bird Review 83:13, 28). The species is also known to nest in the Black Hills of South Dakota.

Migration: Ten fall records are from July 29 to December 22, with a median of November 8. Seven spring records are from January 1 to May 16 , with a median of February 20. These and other limited data suggest that the species is primarily a winter visitor. In northwestern Nebraska it is reportedly a rare summer resident, arriving as early as April 18 (Rosche, 1982). Mist-netting by Daniel Kim at the Crane Trust, Hall County, captured 40 owls over several winters $(\mathrm{Ne}$ braska Bird Review 73:67-70; Brown \& Johnsgard, 2013).

Habitats: Although normally associated with rather dense woods, especially cedar groves in Nebraska, this species sometimes appears in unexpected locations during migration. In the Black Hills of South Dakota, it breeds in pine and spruce forests, and probably the same is true in the Wildcat Hills and Pine Ridge region.

Comments: Most saw-whet owls in Nebraska are obviously migrants, but it is probable that a viable breeding population exists in the Wildcat Hills, Pine Ridge region, or Niobrara Valley (Nebraska Bird Review 82:10).

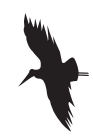

\section{Family Alcedinidae (Kingfishers)}

\section{Belted Kingfisher}

Megacerle alcyon

This waterside species is a common spring and fall migrant and summer resident statewide in suitable habitats and a rare winter resident where open water persists. It also breeds and migrates throughout the entire Plains states. 
Migration: Forty-three initial spring sightings range from January 2 to May 10, with a median of March 20. Half of the records fall within the period February 14 to April 10. Fortyseven final fall sightings are from July 26 to December 31, with a median of November 15 . The concentration of fall records toward the end of the year (nearly half occurring in December) suggest that the species overwinters rarely.

Habitats: Throughout the year this species occurs near water areas supporting populations of fish, amphibians, and similar aquatic life. Nests are excavated from nearly vertical earth exposures in bluffs, road cuts, eroded stream banks, and the like. No nests of this species were investigated during the second atlasing period of the Breeding Bird Atlas project, but nesting was confirmed in 23 survey blocks (Mollhoff, 2016), as compared with confirmed nestings in 32 blocks during the first survey (Mollhoff, 2001).

Comments: The belted kingfisher is Nebraska's only representative of this large and diverse family of mostly fish-eating birds, although the smallest kingfishers are largely insectivorous and the largest ones are omnivorous. Only the female has chestnut underparts, making the sexes easy to identify. Breeding Bird Surveys between 1966 and 2015 indicate that the species collectively underwent a survey-wide population decline $1.35 \%$ annually) during that period, and $\mathrm{Ne}$ braska had an estimated $0.77 \%$ rate of annual decline.

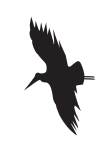

\section{Family Picidae (Woodpeckers)}

\section{Lewis's Woodpecker}

Melanerpes lewis

This open woodland species is a migrant and rare summer resident in the Pine Ridge region. Recently it was found to be a rare breeder, with one Sheridan County record (Mollhoff, 2001), three Dawes County records (Nebraska Bird Review 72:155, 73:17), and a few more recent possible or confirmed nesting records (Mollhoff, 2016). During fall, winter, and spring it sometimes wanders, occasionally reaching as far east as Brown, Buffalo, and Adams counties. It has also been reported in Kansas (16 counties) and has bred in Cimarron County, Oklahoma.

Migration: Too few records prevent judgement of this rare species' migration, but 15 records range from January 20 to September 23, with the largest number of sightings in May. Most Kansas records are from April 23 to June 6, but the range is from April 10 to November 7 (Thompson et al., 2011). Like the red-headed woodpecker, Lewis's woodpecker is somewhat dependent on aerial insects and is probably relatively migration prone. Like three-toed woodpeckers, this species is likely to move into recently burned coniferous woodlands, where it feeds on bark beetles and nests for a few years. 
Habitats: The edges of pine forests and streamside cottonwood groves that have considerable dead growth are favored Black Hills habitats, and probably similar habitats are used in the Pine Ridge region. No nests of this species were investigated during the second atlasing period of the Breeding Bird Atlas project, but nesting was confirmed in two Sioux and Dawes County survey blocks (Mollhoff, 2016), as compared with a confirmed nesting in one Dawes County block during the first survey (Mollhoff, 2001).

Comments: Burned-over areas of coniferous forest are favorite places for Lewis's woodpecker, as well as for the three-toed and black-backed woodpeckers, since insect-foraging opportunities are probably improved in such situations. Thus the burned portions of the Pine Ridge region forests, such as around Fort Robinson, are a good place to look for this unusual woodpecker. Breeding Bird Surveys between 1966 and 2015 indicate the species collectively underwent a survey-wide population decline (3.42\% annually) during that period.

\section{Red-headed Woodpecker}

Melanerpes erythrocephalus

This familiar open-country woodpecker is a common spring and fall migrant and summer resident nearly statewide but is more common eastwardly. It extends west into Colorado along the Platte Valley and reaches the Wyoming border in the Pine Ridge region. It is distinctly migratory and only very rarely overwinters in the state, but a few overwinter in Kansas (Thompson et al., 2011). Breeding oc- curs virtually throughout the entire Plains states.

Migration: Ninety-eight initial spring sightings are from January 2 to June 9, with a median of May 7 . Half of the records fall within the period April 28 to May 17. The range of 106 final fall sightings is from August 8 to December 31. Half of the records fall within the period September 8 to October 3. Less than $10 \%$ of the fall records are for December, suggesting that this species rarely overwinters. Presumably its relatively high dependence on aerial insects accounts for this species' migration tendencies, as compared with most other Nebraska woodpeckers.

Habitats: While in Nebraska this colorful species occurs in fairly open forests, woodlots, urban parks, and wooded housing areas. It occupies somewhat more open areas than does the red-bellied woodpecker and is more widespread than that species. No nest cavities of this species were investigated during the second atlasing period of the Breeding Bird Atlas project, but nesting was confirmed in 132 survey blocks (Mollhoff, 2016), as compared with confirmed nestings in 151 blocks during the first survey (Mollhoff, 2001).

Comments: This is probably the most migratory of Nebraska's woodpeckers, and it is also one that is adept at catching insects in flight as well as probing for them in the ground. At times it will even eat acorns or berries, a trait better developed in a near relative, the acorn woodpecker. Breeding Bird Surveys between 1966 and 2015 indicate that the species collectively underwent a survey-wide population 
decline (2.35\% annually) during that period, and Nebraska had an estimated $1.31 \%$ annual rate of decline.

\section{Acorn Woodpecker}

Melanerpes formicivorous

Accidental. This species was photographed at a feeder in Chambers, Holt County, May 18-22, 1996 (Nebraska Bird Review 64:55; Brogie, 1997). It was also reported from Blair on October 7, 2012, and from Hayes County, June 15-16, 2013 (Nebraska Bird Review 81:112-113). The nearest regular breeding area of this species is in New Mexico.

\section{Red-bellied Woodpecker}

Melanerpes carolinus

This species is a common permanent resident in eastern Nebraska, extending westward along the major river systems at least to the Valentine area of Cherry County in the Niobrara Valley, to Scotts Bluff County in the Platte Valley, and to Dundy County in the Republican Valley. Of 99 Panhandle records, 86 were from the North Platte Valley and 50 were within Scotts Bluff County (Nebraska Bird Review 85:13).

Habitats: Throughout the year this species occupies somewhat open stands of coniferous or hardwood forests, often riverbottom forests. It also frequents orchards, gardens, and similar urban or suburban areas. No nest cavities of this species were investigated during the second atlasing period of the Breeding Bird Atlas project, but nesting was confirmed in 42 survey blocks (Mollhoff, 2016), as compared with confirmed nestings in 23 blocks during the first survey (Mollhoff, 2001).
Comments: The name "red-bellied woodpecker" is not very appropriate; "zebra-backed" would have been a much better descriptive choice. In any case, these are highly attractive woodpeckers and a welcome sight whenever they are seen. Breeding Bird Surveys between 1966 and 2015 indicate that the species collectively underwent a survey-wide population increase (1.02\% annually) during that period, and a $5.12 \%$ estimated rate of annual increase in Nebraska.

\section{Williamson's Sapsucker}

Sphyrapicus thyroideus

Accidental. There are about five state records for this species, including one for Adams County in March 1939, one for Douglas County in February 1945, and one for Hall County in May 1959 (Nebraska Bird Review 7:27, 13:61, 27:52). A female was photographed near North Platte on November 13, 2017. A Nebraska State Museum specimen was obtained May 13, 1989, in Omaha. This species is also accidental in South Dakota, Kansas, and Oklahoma. The nearest breeding area is in south-central Wyoming and adjacent north-central Colorado.

\section{Yellow-bellied Sapsucker}

Sphyrapicus varius

This sap-eating species is an uncommon spring and fall migrant in eastern Nebraska, becoming rarer westwardly. An occasional to uncommon winter visitor perhaps statewide. Probably more birds winter in southern Nebraska than in the northern part of the state, where the species may be entirely migratory. It breeds in eastern North Dakota and Minnesota. 
Migration: Thirty-four initial fall sightings are from September 1 to December 30, with a median of October 3. Twenty-five final fall sightings are from October 9 to December 31, with a median of December 18. Sixteen initial spring sightings are from January 1 to May 28, with a median of March 14. Fourteen final spring sightings are from January 9 to May 21, with a median of March 23. These data would suggest that this species is a very late fall migrant, frequently overwintering in the state and remaining for a rather variable period in spring.

Habitats: While in Nebraska this species is associated with various woodlands, especially those having poplars or aspens, which are favored foraging trees. However, it also drills in birches, maples, cottonwoods, apple trees, and junipers but only infrequently in such hardwoods as oaks and hackberries.

Comments: Yellow-bellied sapsuckers are among the few woodpeckers that would rather drink the sap of trees than capture insects, and they are very efficient at drilling equally spaced holes in poplars and birches to extract such fluids. Sapsuckerdrilled trees often attract other species too, such as hummingbirds and flying squirrels. At least in eastern Nebraska these birds seem to be increasing. Breeding Bird Surveys between 1966 and 2015 indicate that the species collectively underwent a survey-wide population increase $(1.1 \%$ annually) during that period.

\section{Red-naped Sapsucker}

Sphyrapicus nuchalis

This coniferous forest species is a rare fall migrant in the Panhandle. Three known specimen records exist for Sioux County (Bray, Padelford, \& Silcock, 1986). It is an uncommon resident of the Black Hills and probably occasionally strays to northwestern Nebraska. As of 2008 there were eight documented fall reports, the most easterly of which was from Lake Ogallala, Keith County (Nebraska Bird Review 76:146).

\section{Downy Woodpecker}

Picoides pubescens

This species is a common permanent resident statewide that occupies essentially the same habitats as the hairy woodpecker but is probably somewhat more common than that species. It breeds virtually throughout the Plains states.

Habitats: Throughout the year this species lives in dense or open forests but also is found in cities in parks, gardens, and the like. Besides foraging in smaller trees and along the smaller branches of large trees, it also sometimes visits shrubs and tall weeds. No nest cavities of this species were investigated during the second atlasing period of the Breeding Bird Atlas project, but nesting was confirmed in 70 survey blocks (Mollhoff, 2016), as compared with confirmed nestings in 51 blocks during the first survey (Mollhoff, 2001).

Comments: Downy woodpeckers are probably the commonest of $\mathrm{Ne}$ braska's woodpeckers, and the nesting holes they drill provide potential nesting sites for many other cavitydependent birds, such as bluebirds, tree swallows, chickadees, and nuthatches. In locations where it com- 
petes with hairy woodpeckers, the downies concentrate their foraging on smaller branches and twigs, or even on shrubs or weeds that are able to support their weight. Woodpeckers probably help protect many tree species from boring beetle infestations, and so fully deserve our protection. Breeding Bird Surveys between 1966 and 2015 indicate that the species collectively underwent a surveywide population increase (0.03\% annually) during that period, and $\mathrm{Ne}$ braska had an estimated $0.27 \%$ rate of annual increase.

\section{Hairy Woodpecker}

\section{Picoides villosus}

This species is a common permanent resident statewide in suitable wooded habitats. Censuses and Christmas Counts in eastern Nebraska suggest that the downy woodpecker is about eight times more common than the hairy, while records from the Nebraska breeding bird atlasing project suggest that the hairy woodpecker is less than half as common as the downy woodpecker in Nebraska (Mollhoff, 2001).

Habitats: Throughout the year this species prefers fairly extensive areas of coniferous or deciduous forest, or streamside groves of trees. Although sometimes seen in urban areas, the species more commonly remains in mature forests, especially hardwood forests, where it forages on the trunks and larger branches. It breeds virtually throughout the entire Great Plains. No nest cavities of this species were examined during the second atlasing period of the Breeding Bird Atlas project, but nesting was confirmed in 20 survey blocks (Mollhoff, 2016), as compared with confirmed nestings in 17 blocks during the first survey (Mollhoff, 2001).

Comments: Hairy woodpeckers have substantially longer and more robust beaks than do downy woodpeckers, therefore they can drill deeper into wood. They also excavate somewhat larger nest cavities, which eventually are used by other species. Its distribution in the state may be more closely tied to the larger river valleys, where large trees are more abundant. Breeding Bird Surveys between 1966 and 2015 indicate the species collectively underwent a survey-wide population increase (0.81\% annually) during that period, and Nebraska had an estimated $1.93 \%$ rate of annual decline.

\section{American Three-toed Woodpecker}

Picoides dorsalis

This species is accidental in $\mathrm{Ne}$ braska. Just a single specimen record exists, from Scotts Bluff County on June 15,1916 . There have been two additional, less-convincing sightings (Bray, Padelford, \& Silcock, 1986), plus a 1994 sighting (Nebraska Bird Review 62:111). It is a rare permanent resident of the Black Hills and is likely to increase in northern Nebraska as more pines die from bark beetles and occasional drought.

\section{Black-backed Woodpecker \\ Picoides arcticus}

Accidental. There are three early records of this forest-dwelling species from Nebraska, including two from Douglas County and one from Dakota County. Additionally, the species was reported in Custer County in August 
1970 (Nebraska Bird Review 25:46). It is an uncommon permanent resident of the Black Hills but unreported elsewhere in the Plains states. Both this and the American three-toed woodpecker may become more common as dead pines become increasingly common in the Pine Ridge region.

\section{Northern Flicker}

\section{Colaptes auratus}

This species is a common semipermanent resident statewide that overwinters occasionally. In eastern Nebraska the population is predominantly of the yellow-shafted race or hybrids, with typical red-shafted types found only in extreme western Nebraska. Probably most if not all of the Nebraska population is influenced by hybridization (Short, 1965; Mollhoff, 2001). Collectively, the species breeds in and migrates through the entire Plains states.

Habitats: Throughout the year this species occupies diverse habitats, including relatively open woodlands, orchards, woodlots, and urban environments. Dense forests are apparently avoided, and much foraging is done by probing in the ground. Ten nest cavities of this species were examined during the second atlasing period of the Breeding Bird Atlas project, and nesting was confirmed in 120 survey blocks (Mollhoff, 2016) as compared with confirmed nestings in 94 blocks during the first survey (Mollhoff, 2001).

Comments: To a greater degree than other Nebraska woodpeckers, this is an ant-eating species, and because of that flickers often forage in fields well away from woodlands. Al- though essentially sedentary, some movement out of the state may occur during most winters. Breeding Bird Surveys between 1966 and 2015 indicate that the species collectively underwent a survey-wide population decline (1.33\% annually) during that period, and an annual decline of 2.01\% in Nebraska.

\section{Pileated Woodpecker}

Dryocopus pileatus

This spectacular species is a rare local resident in eastern Nebraska. Once an uncommon permanent resident in extreme eastern counties, it was probably extirpated prior to 1900 . There have been numerous recent sightings in Washington, Richardson, Gage, Otoe, Franklin, Sarpy, and Douglas counties, indicating a reinvasion of southeastern Nebraska. By 2013 the species was probably present in small numbers north to Thurston County (Nebraska Bird Review 81:64). A pair was seen tending a nest hole during April and May 1999 in Fontenelle Forest and has since bred there most years since. As many as two active nests have been found at Fontenelle Forest in some years, and it has bred in Indian Cave State Park in recent decades (Nebraska Bird Review 75:79). More recent sightings elsewhere include Schramn State Park and Boyer Chute National Wildlife Refuge ( $N e$ braska Bird Review 80:60, 85:67), DeSoto Bend National Wildlife Refuge (Nebraska Bird Review 82:10), and north of Beatrice (Nebraska Bird Review 85:13). Scattered records in Jefferson, Saunders, and Knox counties might represent young wandering birds (Nebraska Bird Review 83:14). 
Habitats: This species is generally limited to mature forests, often riverbottom forests, that have a mixture of tall living trees and dead stubs. Trees that are at least 15 inches in diameter are required for nesting birds. Three nest cavities of this species were examined during the second atlasing period of the Breeding Bird Atlas project, and nesting was confirmed in one Sarpy County survey block (Mollhoff, 2016).

Comments: It is fortunate that Nebraska is slowly developing a breeding population of pileated woodpeckers, for they are the largest and most memorable of America's woodpeckers. Breeding Bird Surveys between 1966 and 2015 indicate that the species collectively underwent a surveywide population increase $(1.41 \%$ annually) during that period.

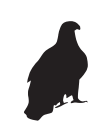

\section{Family Falconidae (Falcons)}

\section{Crested Caracara}

Caracara cheriway

Accidental. One was reported from Seward County, August 20-21, 2011 (Nebraska Bird Review 79:125). In the spring of 2013 an emaciated adult, blind in one eye, was found near Genoa (Nebraska Bird Review 80:142-143). It was brought to Nebraska Raptor Recovery near Lincoln and later sent to Texas for release (Fly Free 30(1):1, 2013). The nearest breeding area of this species is in eastern Texas.

\section{American Kestrel}

\section{Falco sparverius}

This tiny falcon is a common permanent resident statewide. Kestrels are less common in winter (mainly males) and more abundant during spring and fall, so substantial migration must occur. The species occurs throughout the Plains states as a migrant or breeder.

Migration: Twenty-nine spring records and 22 fall records are widely scattered, suggesting that the species is largely residential in Nebraska.

Habitats: Open country with elevated perching sites, such as telephone lines or scattered trees, are used throughout the year. Nesting is usually done in tree hollows (nest boxes are also often used) near large areas of grasslands or croplands. No nest cavities of this species were examined during the second atlasing period of the Breeding Bird Atlas project, but nesting was confirmed in 69 survey blocks (Mollhoff, 2016) as compared with confirmed nestings in 50 blocks during the first survey (Mollhoff, 2001).

Comments: The American kestrel, once called the "sparrow hawk," is one of the most attractive of all our raptors. The smaller males are bright rufous with bluish gray wings and a rusty tail, whereas the female is nearly all barred or striped with rufous and brown. They are hole nesters, often choosing old woodpecker cavities but also artificial cavities. During summer they feed largely on grasshoppers and other large insects, but they turn to small mammals and other prey in cold weather. Breeding Bird Surveys between 1966 and 2015 indicate that the species collectively 
underwent a survey-wide population decline (1.39\% annually) during that period, whereas Nebraska had a statistically rather weak estimate (based on 48 survey routes) of a $0.25 \%$ rate of annual increase.

\section{Merlin}

Falco columbarius

This bird-eating falcon is an uncommon migrant and winter visitor statewide, and an extremely rare summer resident in the Pine Ridge region (Sioux and Dawes counties). There are nesting records for Sioux County in 1975 and 1978 (Nebraska Bird Review 47:39), and one during the first atlasing period (Mollhoff, 2001). Nesting occurs in western South Dakota, Minnesota, and rarely in North Dakota. Migrants may appear anywhere in the Plains states.

Migration: Ninety-nine initial spring sightings range from January 1 to June 6, with a median of March 19. Half of the records fall within the two periods January 1-20 and March 30 to April 24, suggesting that the species is primarily a winter visitor and spring migrant. Forty-eight fall records extend from August 16 to December 31, with a median of October 23. The largest number (21) of fall records are for December, followed by September (15) and October (7).

Habitats: Open country with elevated perches, such as telephone lines or scattered trees, are used throughout the year, and nesting is typically in scattered trees or groves near large areas of grasslands, croplands, or badlands. No nest cavities of this species were examined during the second atlasing period of the Breeding Bird At- las project (Mollhoff, 2016) as compared with a confirmed nesting in one Sioux County block during the first survey (Mollhoff, 2001).

Comments: This little falcon is slightly larger than the American kestrel and is largely a hunter of small birds, such as horned larks and small shorebirds. The males are mostly bluish gray above, whereas females are various tones of brown and buffy. It is likely that nesting occurs more frequently in Nebraska than the few available records suggest; there have been no nesting reports since 1990. Breeding Bird Surveys between 1966 and 2015 indicate the species collectively underwent a survey-wide population increase (2.8\% annually) during that period.

\section{Gyrfalcon}

Falco rusticolus

This stunning falcon is a rare winter visitor from the Canadian high Arctic. A single specimen was obtained in Johnson County in 1885 , and another was captured in Kearney County in 1974. Additionally there are sight records from Cuming County (1880s), Keith County (1947, 2001), Dawes County (1965), Lincoln County (1975), Kearney County (1977), Garden County (1979), Adams County (1980), Buffalo County (2011), and Boyd County (2015). Falconers have captured several during the winter in the Sandhills in recent years, such as two in Cherry County in 1983 (Brogie, 1997). The gyrfalcom is a rare or accidental winter migrant in the Lake McConaughy region (Brown, Dinsmore, \& Brown, 2012).

Migration: Nine total records for 
this species range from November 27 to April 3. There are three records for January, two for December, and one each for November, February, March, and April. Most of the 6o-plus reports as of 2013 have occurred in January (Nebraska Bird Review 81:66). I saw one in flight near Grand Island on December 31, 2011, while I was traveling with friends on I-80, but my claiming to have identified a gyrfalcon from a car going $75 \mathrm{mph}$ would probably not have convinced most people.

Habitats: Open plains and prairies are used during migration and while wintering.

Comments: This is the bird most prized by falconers for their sport; gyrfalcons have been trained to kill birds as large as bustards and will readily attack pheasants or large waterfowl. The species exhibits an array of color morphs, ranging from nearly pure white to dusky gray. The lightercolored birds are typically nesters in the highest latitudes.

\section{Peregrine Falcon}

Falco peregrinus

This nearly worldwide falcon is a rare to occasional migrant and winter visitor statewide and a reintroduced local breeder. It apparently once bred in the Panhandle (Bruner, Wolcott, \& Swenk, 1904); since the early 20oos, a recovery program in Omaha and Lincoln has produced several successful nestings in both locations (Johnsgard, 2010b).

Migration: A total of 97 initial spring sightings range from January 1 to May 17, with a median of March 20. Half of the records fall within the two periods January 1-20 and April
21-May 11, suggesting that the species is a winter visitor and spring migrant. Twenty total fall records extend from July 26 to December 26, with a median of September 22. The largest number of fall records (8) is for September, but the sample is too small to suggest a peak period. In Kansas the fall migration peaks in September (Thompson et al., 2011).

Habitats: During migration this species is most likely to be found in open, grassland habitats, but it sometimes enters cities while hunting pigeons. During dives ("stoops") toward fleeing prey it may reach speeds in excess of 200 miles per hour. Two nest sites of this species were monitored during the second atlasing period of the Breeding Bird Atlas project (Mollhoff, 2016).

Comments: Until the successful release program undertaken in Omaha, peregrines were believed to have been extirpated from the state as breeders. However, thanks to this and other similar programs, the sight of peregrines is no longer a rarity, and a few successful attempts at nesting have now occurred near the dome of the state capitol building. These cityadapted birds have even learned to hunt by night, using the lights that illuminate the capitol to capture night-flying prey such as nighthawks. Breeding Bird Surveys between 1966 and 2015 indicate that the species collectively underwent a survey-wide population increase ( $2.77 \%$ annually) during that period.

\section{Prairie Falcon}

Falco mexicanus

This species is an occasional to rare 
permanent resident in western $\mathrm{Ne}$ braska, mainly in the Pine Ridge region and the Wildcat Hills, and a rare migrant and winter visitor in eastern Nebraska. It is a rare and local breeder in the western Panhandle, with nesting records for at least Dawes, Sheridan, Sioux, Scotts Bluff, and Banner counties.

Migration: A total of 135 initial spring sightings range from January 1 to May 22, with a median of January 30. Half of the records fall within the period January 1-30, suggesting that the species is primarily a resident and winter visitor with no obvious secondary peak of spring migration. Fortyfive fall records extend from July 21 to December 31, with a median of November 13 and no obvious fall peak in records, but a progressively increasing number of monthly records exists from July to December.

Habitats: This species is associated with large expanses of open grasslands or sagebrush scrub, with nearby cliffs, bluffs, or rocky outcrops for nesting. Two nests of this species were reported during the second atlasing period of the Breeding Bird Atlas project, and nesting was confirmed in three survey blocks of Scotts Bluff and Sioux counties (Mollhoff, 2016), as compared with confirmed nestings in seven blocks during the first survey (Mollhoff, 2001).

Comments: The prairie falcon resembles a paler version of the peregrine falcon and is a species more likely to specialize on prairie dogs and ground squirrels than on birds. It attacks such prey at high speed and from a nearly ground-level altitude rather than from a high-altitude stooping dive, but it is equally deadly. Like the peregrine, it prefers to nest on steep cliffs, and seeing a female diving on birds such as ravens that stray too close to its nest is a lesson in highspeed acrobatics. Breeding Bird Surveys between 1966 and 2015 indicate that the species collectively underwent a survey-wide population increase (1.05\% annually) during that period, and Nebraska had an estimated 3.33\% rate of annual increase.

\section{,}

\section{Family Psittacidae (Parrots)}

(Monk Parakeet)

Myopsitta monarchus

Hypothetical. Individuals of this introduced South American parrot were observed in the Omaha area in 1972-73 and 1998, in Kearney in 1975, and in Lincoln in 1975-76. Probably they represent escaped cage birds rather than origination from the feral populations in Florida and some of the New England states.

\section{Carolina Parakeet}

Conuropsis carolinensis

Extinct. This once super-abundant parakeet was formerly a common resident in the Missouri River valley of Nebraska (Nebraska Bird Review 2:5559; Johnsgard, 2003d) and elsewhere in the Plains states, but it went extinct in the early 1900 as a result of uncontrolled hunting. The last Kansas record was in 1904 (Thompson et al., 2011). 


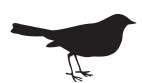

\section{Family Tyrannidae (New World Flycatchers)}

\section{Olive-sided Flycatcher}

Contopus cooperi

This western and boreal species is an uncommon to occasional spring and fall migrant in eastern Nebraska, at least west to Lancaster County. Farther west the species is less common, but it probably migrates statewide. It breeds in northern Minnesota and migrates throughout the Plains states.

Migration: Sixty-eight initial spring sightings range from April 3 to June 4 , with a median of May 18. Half of the records fall within the period May 10-26. Sixteen final spring sightings are from May 10 to June 8 , with a median of May 24. Thirteen initial fall sightings are from August 24 to September 9, with a median of September 2. Twelve final fall sightings are from September 1-29, with a median of September 20.

Habitats: Migrants are found in wooded areas in which there are trees with prominent dead upper branches. They also sometimes perch on telephone wires in open country.

Comments: This flycatcher is rather easily identified by its olivegray flanks, which look something like an unbuttoned vest. Its song is an easily remembered Quick, three beers or Look, three deer. The birds somewhat resemble oversized wood-pewees and are only slightly smaller than kingbirds.

\section{Western Wood-Pewee}

Contopus sordidulus

This species is a common spring and fall migrant and summer resident in western and northwestern Nebraska; the breeding range includes Sioux, Dawes, and Scotts Bluff counties and probably extends east to at least Garden County. Singing has been heard east to Brown and Keya Paha counties in the Niobrara Valley (Nebraska Bird Review 71:119, 76:195), and both western and eastern species occur in Keith County along the North Platte Valley (Nebraska Bird Review 76:105). Hybridization with $C$. virens possibly occurs in areas of contact with C. cooperi (Short, 1961).

Migration: Sixty-four initial spring sightings range from March 20 to June 10, with a median of May 21. Half of the records fall within the period May 13-26. Thirty-three final fall sightings are from July 8 to October 9, with a median of September 4. Half of the records fall within the period August 22-September 12.

Habitats: In the Black Hills, and probably in the Pine Ridge region, this species is mostly associated with open, mature pine forests. Generally the birds use habitats dominated by conifers, but they also use mixed woodlands and generally occupy drier regions than do eastern wood-pewees. Eight nests of this species were reported during the second atlasing period of the Breeding Bird Atlas project, and nesting was confirmed in nine survey blocks (Mollhoff, 2016), as compared with confirmed nestings in five blocks during the first survey (Mollhoff, 2001). 
Comments: Although the two wood-pewees differ in the color of their lower mandibles, and the western has slightly darker plumage, it is probably easier to recognize this species by its raspier pee-err vocalization. Breeding Bird Surveys between 1966 and 2015 indicate that the species collectively underwent a surveywide population decline (1.37\% annually) during that period.

\section{Eastern Wood-Pewee}

Contopus virens

This species is a common spring and fall migrant and summer resident in eastern Nebraska, extending west locally at least as far as Dawes, Cherry, Keith, Deuel, and Dundy counties along river systems. Breeding in the Sandhills is apparently infrequent. It breeds widely through the eastern portions of the Plains states and occurs almost throughout as a migrant.

Migration: Seventy-seven initial spring sightings range from March 20 to June 10 , with a median of May 10. Half of the records fall within the period May 3-21. Sixty-one final fall sightings are from July 29 to October 12 , with a median of September 10. Half of the records fall within the period August 31 to September 18.

Habitats: While in Nebraska this species is generally associated with deciduous forests, including floodplain and riverine bluff forests, but also woodlots, orchards, and suburban areas with tree plantings. No nests of this species were reported during the second atlasing period of the Breeding Bird Atlas project, but nesting was confirmed in ten survey blocks (Mollhoff, 2016) as compared with con- firmed nestings in eight blocks during the first survey (Mollhoff, 2001).

Comments: Over most of Nebraska, the wood-pewees seen are most likely to be the eastern species, whose song is a distinctive pee-a-wee. However, in the Panhandle and western Niobrara Valley be on the alert for possible western wood-pewees or hybrids. Breeding Bird Surveys between 1966 and 2015 indicate that the species collectively underwent a survey-wide population decline ( $1.4 \%$ annually) during that period, versus a statistically weak estimate (based on 22 survey routes) of a $3.35 \%$ rate of annual increase in Nebraska.

\section{Yellow-bellied Flycatcher}

Empidonax flaviventris

This species is an uncommon spring and fall migrant in eastern Nebraska, rarely occurring as far west as Cherry County. There were possible nestings of this species in Sarpy County and Lancaster County in 1978, records that subsequently were questioned (Nebraska Bird Review 46:86, 72:155).

Migration: Twenty-six total spring sightings range from April 16 to June 7 , with a median of May 16 . Half of the records fall within the period May 10-20. Fifteen total fall sightings range from August 8 to October 5 , with a median of September 4 . Half of the records fall within the period September 1-14.

Habitats: The yellow-bellied flycatcher is associated with secondgrowth woodlands while on migration and is normally limited to alder and willow thickets in boreal forest during the breeding season.

Comments: This eastern species of 
Empidonax is distinctly yellowish below. Its song is a chelek that is more liquid than the least flycatcher's distinctly enunciated che-bek.

\section{Acadian Flycatcher}

\section{Empidonax virescens}

This Empidonax (or "empid") is an uncommon spring and fall migrant in eastern Nebraska and a probable summer resident in the forested valley of the Missouri River (Nebraska Bird Review 62:11, 63:77, 80:61). It also breeds in western Iowa and southward through eastern Kansas and Oklahoma.

Migration: Fifty-five initial spring sightings range from April 17 to June 9, with a median of May 15. Half of the records fall within the period May 8-21. Fourteen final fall sightings range from July 28 to October 1 , with a median of August 28.

Habitats: During the summer, this species is found in shady and humid riverbottom forests, forested swamps, and wooded uplands. No nests of this species were reported during the second atlasing period of the Breeding Bird Atlas project (Mollhoff, 2016).

Comments: The Acadian flycatcher is one of the many difficult empidonaces (the generic name means "king of the flies"); this species is rather greenish toned and has a sharp peetsa song.

\section{Alder Flycatcher}

\section{Empidonax alnorum}

This empid is a regular but uncommon migrant in eastern and central Nebraska, at least in spring. The small proportion of sightings attributed to this species since it was sep- arated from $E$. traillii suggest that it must be quite infrequent by comparison. It probably is a regular migrant through the eastern portions of all the Plains states, with banding indicating that some Nebraska migrants may migrate as far as north-central Alaska. The nearest known breeding area is in North Dakota, but it has been thought to possibly breed in southeastern South Dakota, so it should be looked for in northeastern Nebraska.

Migration: Eight initial spring sightings attributed to this species range from May 8 to May 29, with a mean of May 21. Six final spring sightings are from May 24 to June 18, with a mean of June 7. Six fall sightings range from July 20 to September 16 , with a mean of August 19.

Habitats: Migrants probably use the same habitats as does the willow flycatcher, namely shrubbery and small trees near openings of grassland or water. While breeding it generally occupies the more northerly and easterly forested areas, compared with the more open and arid habitats of the willow flycatcher.

Comments: This empid is too little known in Nebraska to say much about it. However, 92 of 203 “Traill's flycatchers” banded by Dr. William Scharf in western Nebraska during the 1990s were identified by him as alders. Thus, the species may be a much more regular migrant through Nebraska than is yet appreciated.

\section{Willow Flycatcher}

\section{Empidonax traillii}

This empid is a common spring and fall migrant and uncommon to rare summer resident in eastern Nebraska. 
Breeding extends west at least to Cherry, Thomas, and Keith counties in the Sandhills and to Sheridan County in the Panhandle. It also breeds in the other Plains states from North Dakota to Oklahoma. Only four confirmed Nebraska breedings occurred during the atlasing years 1984-89 (Mollhoff, 2001).

Migration: Seventy-eight initial spring sightings range from April 17 to June 10, with a median of May 15 . Half of the records fall within the period May 9-25. Sixteen final fall sightings range from July 26 to September 21, with a median of September 2 . Half of the records fall within the period August 29 to September 7.

Habitats: In Nebraska this species inhabits edge habitats such as thickets or groves of small trees and shrubs surrounded by grasslands, and the edges of gallery forests along rivers. Three nests of this species were reported during the second atlasing period of the Breeding Bird Atlas project, and nesting was confirmed in eight survey blocks (Mollhoff, 2016), as compared with confirmed nestings in three blocks during the first survey (Mollhoff, 2001).

Comments: Probably this is the most common and widespread of $\mathrm{Ne}$ braska's empidonaces, although in appearance it is extremely similar to the alder flycatcher. Breeding Bird Surveys between 1966 and 2015 indicate that the willow flycatcher underwent a survey-wide population decline (1.48\% annually) during that period, whereas there was a statistically weak estimate (based on 12 survey routes) of a $3.03 \%$ annual increase in Nebraska.

\section{Least Flycatcher}

Empidonax minimus

This empid is a common spring and fall migrant statewide, and apparently an extremely rare summer resident. Besides some early reports of breeding in Douglas and Dakota counties, territorial birds have also been reported in Brown and Dawes counties. Thus, northern Nebraska very possibly constitutes part of the breeding range, but there were no confirmed breedings during the atlasing years (Mollhoff, 2001, 2016).

Migration: The range of 100 initial spring sightings is from April 7 to June 9, with a median of May 8. Half of the records fall within the period May 3-11. Sixteen final spring sightings are from May 3 to June 3, with a median of May 14. Twenty-four fall sightings range from July 29 to October 1 , with a median of September 5 . Half of the records fall within the period August 30 to September 12.

Habitats: While in Nebraska this species occupies floodplain forests in grassland regions, scattered grovelands, shelterbelts, and urban parks or gardens. No nests of this species were reported during the first or second atlasing periods of the Breeding Bird Atlas project, although nesting is possible in northeastern Nebraska near the South Dakota border and in Pine Ridge canyons (Mollhoff, 2001, 2016).

Comments: This is the smallest of the Empidonax species, but in the field this difference is not apparent. Breeding Bird Surveys between 1966 and 2015 indicate that the species collectively underwent a survey-wide population decline (1.8\% annually) during that period. 


\section{Hammond's Flycatcher}

Empidonax hammondii

This empid is a rare but regular fall migrant in western Nebraska, with 30 fall records as of 2013 (Nebraska Bird Review 81:151). The first specimen identified as this species was collected in Dawes County in 1911. Observed and photographed in Adams County on September 2, 1995 (Nebraska Bird Review 64:135). The nearest breeding area of this species is in eastern Wyoming.

\section{Gray Flycatcher}

Empidonax wrightii

Very rare. A few sight records of this empid exist for Oliver Reservoir, including May 17, 1999, and several August and September sightings in 2002 (Nebraska Bird Review 70:152). Five fall records are from August 24 to October 5. In 2016 the second spring record was of a male singing at Oliver Reservoir on May 22 (Nebraska Bird Review 84:75). The nearest breeding area of this species is in central Wyoming.

\section{Dusky Flycatcher}

Empidonax oberholseri

Rare. By 2013 at least 32 fall records had accumulated for this elusive western empid, mostly in Kimball and Scotts Bluff counties (Nebraska Bird Review 68:118, 162; 71:158; 81:152). In 2016 the seventh spring record was reported at Exit 1 of I-29 (Nebraska Bird Review 84:75). One was banded at the Wildcat Hills Nature Center in September 2015 (Nebraska Bird Review 83:184). About ten spring records extend from May 9 to June 15, including three 2017 records ( $N e$ - braska Bird Review 85:70). The nearest breeding areas of this species are in northeastern Wyoming and the Black Hills.

\section{Cordilleran Flycatcher}

Empidonax occidentalis

This empid is a local migrant and summer resident in western $\mathrm{Ne}$ braska, known to have a nesting area in Sioux County (Nebraska Bird Review 43:18) in Sowbelly Canyon and in nearby Monroe Canyon. Now it is known to extend eastward into Dawes County, breeding in East Ash Canyon (Nebraska Bird Review 76:106, 84:75), and in Sheridan County (Mollhoff, 2016). It was also observed in Scotts Bluff, Garden, and McPherson counties, with a 2003 nesting in the Wildcat Hills (Nebraska Bird Review 71:120).

Migration: Five fall records are all in the period August 9 to September 10 (Nebraska Bird Review 65:167). As of 2013 there were more than 20 spring records (Nebraska Bird Review 81:66).

Habitats: While breeding this species is associated with forested canyons and mountain slopes, but on migration it may occur in deciduous trees along streambeds, oak-lined gullies, and other wooded habitats. Seven nests of this species were reported during the second atlasing period of the Breeding Bird Atlas project, and nesting was confirmed in nine survey blocks (Mollhoff, 2016), as compared with no confirmed nestings during the first survey (Mollhoff, 2001).

Comments: This empid has one of the most localized breeding ranges of any of Nebraska's birds, being largely 
limited to a few small canyons in northwestern Nebraska. It used to be called the "western flycatcher" but has been "split" into a Pacific-slope form and this interior-breeding species. Breeding Bird Surveys between 1966 and 2015 indicate that this species (including the Pacific-slope form, now considered a distinct species) collectively underwent a survey-wide population decline (0.30\% annually) during that period.

\section{Eastern Phoebe}

\section{Sayornis phoebe}

This familiar woodland species is a common spring and fall migrant and summer resident in woodlands of eastern Nebraska and extending west locally to Sioux, Thomas, Lincoln, Garden, and Dundee counties along the major river valleys. It also breeds throughout the eastern portions of the other Plains states, west to eastern Colorado and northeastern New Mexico.

Migration: The range of 169 initial spring sightings is from March 20 to June 10, with a median of April 16. Half of the records fall within the period March 28 to April 29. Sixtyseven final fall sightings range from August 4 to October 25, with a median of September 26. Half of the records fall within the period September 5 to October 6 .

Habitats: During summer, this species is usually found near water in woodlands or partially wooded areas, including farmsteads. Farm buildings, wooden bridges, and other locations providing artificial or natural ledges protected from above are used for nest sites. Fifty-seven nests of this species were reported during the second atlasing period of the Breeding Bird Atlas project, and nesting was confirmed in 184 survey blocks (Mollhoff, 2016), as compared with confirmed nestings in 106 blocks during the first survey (Mollhoff, 2001).

Comments: Eastern phoebes are the earliest of the flycatchers to arrive in eastern Nebraska, where they soon take up residence under bridges and in farm outbuildings. They typically return to the same nest site in successive years. One site on a window sill of my family's Minnesota lake cabin was used every year for at least five years, even though it had to be temporarily moved about five feet one summer to allow for repainting of the sills, while the birds were still tending nestlings. Breeding Bird Surveys between 1966 and 2015 indicate that the species collectively underwent a survey-wide population increase $(0.22 \%$ annually) during that period, and $\mathrm{Ne}$ braska had an estimated $2.99 \%$ rate of annual increase.

\section{Say's Phoebe}

Sayornis saya

This western species is a common spring and fall migrant and summer resident in western Nebraska, extending east locally to at least Cedar, Wayne, Cuming, Greeley, York, and Clay counties. Vagrants may be seen all the way to the Missouri River. It also breeds throughout the western portions of the other Plains states, from North Dakota to Texas.

Migration: The range of 129 initial spring sightings is from March 20 to June 10, with a median of April 16. Half of the records fall within the 
period April 5-24. Fifty-two final fall sightings range from July 29 to October 29, with a median of September 14. Half of the records fall within the period September 8-20.

Habitats: In Nebraska this species is found in fairly open and dry habitats, including rocky canyons, badlands, and ranchlands. The species is independent of surface water, but in common with the eastern phoebe, it often nests under bridges or on the horizontal ledges of other manmade structures. Twenty nests of this species were reported during the second atlasing period of the Breeding Bird Atlas project, and nesting was confirmed in 38 survey blocks (Mollhoff, 2016), as compared with confirmed nestings in 28 blocks during the first survey (Mollhoff, 2001).

Comments: In Keith County near Cedar Point Biological Station both the eastern and Say's phoebes occur, but they do not appear to interact and rarely nest in the same immediate area. Breeding Bird Surveys between 1966 and 2015 indicate that the species collectively underwent a survey-wide population increase (2.45\% annually) during that period, and an estimated 3.2\% rate of annual increase in Nebraska.

\section{Vermilion Flycatcher}

Pyrocephalus rubinus

Accidental, with a sight record for Douglas County in November 1954, a specimen from Lincoln County in December 1954, and a carcass probably of this species found in Lincoln County in November 196o (Nebraska Bird Review 23:28, 29:23). There was also a sight record for Lincoln County in May 1976 (American Birds 30:861). One was photographed in Lancaster County on May 16, 1995 (Nebraska Bird Review 64:135), and another was photographed on October 25, 2017, in Phelps County.

Habitats: During the summer this species is usually found in trees or shrubs along roadsides or in open forested riverbottoms.

Comments: This amazingly brightplumaged species is a distinct change from the many dull-plumaged flycatchers, and one can only wonder what sorts of selective pressures drove the species to evolve such a brilliant male plumage. The nearest breeding area of the vermilion flycatcher is in northeastern New Mexico.

\section{Ash-throated Flycatcher}

Myiarchus cinerascens

This species is an extremely rare summer resident that was first found breeding in Kimball County in 2007 (Nebraska Bird Review 75:40; 76:43$37,161)$. It was also observed there in 2009, and in Scotts Bluff County in July 2009 (Nebraska Bird Review 77:105). There is also a 1957 sight record for Dawes County (Bray, Padelford, \& Silcock, 1986) and another for Sowbelly Canyon, July 20, 2000 ( Nebraska Bird Review 68:118).

\section{Great Crested Flycatcher}

Myiarchus crinitus

This species is a common spring and fall migrant and summer resident in eastern Nebraska, mainly along the larger river valleys but also extending west locally to Sioux County in the Niobrara Valley; to Garden, Keith, and Deuel counties along the North 
Platte and South Platte; and to Dundy County in the Republican Valley.

Migration: The range of 130 initial spring sightings is from March 30 to June 9, with a median of April 30. Half of the records fall within the period May 2-15. Sixty-six final fall sightings are from July 22 to October 3, with a median of September 6. Half of the records fall within the period August 30 to September 12.

Habitats: During the breeding season, this species occurs in rather extensive hardwood forests, including riverbottom forests, and especially those with fairly open canopies. Unlike most flycatchers, nesting is in cavities such as woodpecker holes. Although nest building and parental behavior was observed, no nests of this species were examined during the second atlasing period of the Breeding Bird Atlas project, and nesting was confirmed in 23 survey blocks (Mollhoff, 2016), as compared with confirmed nestings in 20 blocks during the first survey (Mollhoff, 2001).

Comments: This eastern deciduous forest species is notable for its rufous wing and tail markings, and its loud wheep calls. Breeding Bird Surveys between 1966 and 2015 indicate that the species collectively underwent a survey-wide population decline (0.03\% annually) during that period, whereas Nebraska had a statistically questionable estimate (based on 27 survey routes) of a $1.85 \%$ rate of annual increase.

\section{Cassin's Kingbird}

Tyrannus vociferans

This species is a spring and fall migrant and regular summer resident of the western Panhandle, ranging from rare to uncommon. The species breeds locally in Nebraska, at least in the southwestern Panhandle, in the Wildcat Hills, and also from about Crawford westward in the north (Mollhoff, 2001). It has long been regularly seen south of Reddington, but there were no proven breedings there until 2003.

Migration: Eight initial spring sightings range from April 27 to May 30, with a mean of May 2. Twelve last fall sightings range from August 22 to September 28, with a median of September 17.

Habitats: To a greater degree than the western kingbird, this species is associated with dry, open country such as plains and semideserts, with only scattered tall trees. However, it overlaps widely with this species and probably competes locally with it. Seven nests of Cassin's kingbird were reported during the second atlasing period of the Breeding Bird Atlas project, and nesting was confirmed in six survey blocks (Mollhoff, 2016) as compared with a confirmed nesting in one Sheridan County block during the first survey (Mollhoff, 2001).

Comments: Few breeding records have been obtained in Nebraska for this western kingbird look-alike. Nests have been found in Dawes, Sheridan, Kimball, and Cheyenne counties, and east to a canyon south of Reddington, Morrill County (Nebraska Bird Review 73:18). This species lacks the white outer tail feather markings of the western and has a more conspicuous dark ear-patch. Its usual call is a loud chi-bek. Breeding Bird Surveys between 1966 and 2015 indicate that the species collectively underwent 
a survey-wide population increase (o.19\% annually) during that period.

\section{Western Kingbird}

Tyrannus verticalis

This species is a common spring and fall migrant and summer resident almost statewide, becoming less common eastwardly. It is more common than the eastern kingbird in much of western Nebraska but less common in the state's eastern third. It is a breeder and migrant throughout the entire Plains states.

Migration: The range of 117 initial spring sightings is from April 30 to May 26, with a median of May 5 . Half of the records fall within the period May 1-10. The range of 125 final fall sightings is from July 26 to October 10 , with a median of September 3 . Half of the records fall within the period August 24 to September 10.

Habitats: While in Nebraska this species seems to occupy much the same habitats as does the eastern kingbird, including a variety of edge habitats such as shelterbelts, orchards, woodland margins, and tree-lined residential districts, but it is more tolerant of drier environments. Twenty nests of this species were reported during the second atlasing period of the Breeding Bird Atlas project, and nesting was confirmed in 138 survey blocks (Mollhoff, 2016), as compared with confirmed nestings in 126 blocks during the first survey (Mollhoff, 2001).

Comments: In western Nebraska around Cedar Point Biological Station, these noisy birds nest almost anywhere that medium to tall trees occur near open foraging areas. There they often outnumber eastern kingbirds and tend to favor somewhat drier and more open habitats. Breeding Bird Surveys between 1966 and 2015 indicate that the species collectively underwent a survey-wide population increase (0.06\% annually) during that period, whereas Nebraska had an estimated $1.42 \%$ rate of annual decline.

\section{Eastern Kingbird}

Tyrannus tyrannus

This species is a common spring and fall migrant and summer resident statewide, generally considerably more common that the western kingbird in eastern Nebraska, becoming relatively less common westwardly. It is a breeder and migrant throughout the entire Plains states.

Migration: Seventy-three initial spring sightings range from March 24 to May 29, with a median of May 3. Half of the records fall within the period May 1-7. The range of $126 \mathrm{fi}-$ nal fall sightings is from August 4 to October 14, with a median of September 9. Half of the records fall within the period September 1-16.

Habitats: While in Nebraska this species occupies open areas having scattered trees or tall shrubs and forest edges or hedgerows. It frequently occurs in cities, foraging out over streets or intersections, and perching on favored vantage points, such as street lights or telephone lines. Twenty-six nests of this species were reported during the second atlasing period of the Breeding Bird Atlas project, and nesting was confirmed in 152 survey blocks (Mollhoff, 2016), as compared with confirmed nestings in 158 blocks during the first survey (Mollhoff, 2001). 
Comments: The kingbirds are named for their rather imperial behavior, and the generic name Tyrannus is a further indication of their tyrannical nature. Other songbird species, such as orioles, often nest close to kingbird nests to gain their protection. The birds have hidden goldenreddish crown patches, although these are exposed only rarely during hostile or sexual encounters. Breeding Bird Surveys between 1966 and 2015 indicate that the species collectively underwent a survey-wide population decline (1.28\% annually) during that period, and Nebraska had an estimated $0.76 \%$ rate of annual decline.

\section{Scissor-tailed Flycatcher}

Tyrannus forficatus

This species is a rare spring and fall migrant and summer resident in southern Nebraska, with definite breeding records by 2005 from Adams, Cass, Clay, Gage, Lancaster, and Logan counties. By 2013 there had been at least 20 state nesting records (Nebraska Bird Review 81:114). Vagrants have been seen elsewhere in the state, and rarely have also been seen as vagrants north to South Dakota. It is a regular breeder from Kansas southward and is casual into South Dakota. It is a regular breeder from Kansas and extreme southeastern Colorado southward.

Migration: Seventeen initial spring sightings range from April 19 to June 10, with a median of May 2. Half of the records fall within the period April 29 to May 3. Eight final fall sightings are from July 23 to October 5, with a mean of September 14 .

Habitats: During the summer this species is found in open to semi-open habitats with a scattering of trees or other elevated perching sites, and in woodlands with edges or openings for foraging. Nesting usually is in isolated trees or tall structures such as utility poles or windmills rather than in groves or heavy cover. Seven nests of this species were reported during the second atlasing period of the Breeding Bird Atlas project, and nesting was confirmed in two survey blocks (Mollhoff, 2016), as compared with one confirmed nesting in a Cass County block during the first survey (Mollhoff, 2001).

Comments: Although this beautiful species is fairly common in southern Kansas, it only occasionally nests in Nebraska. However, its Kansas range is slowly advancing northward, so perhaps in the future it will become a regular breeder across southern $\mathrm{Ne}$ braska. Breeding Bird Surveys between 1966 and 2015 indicate that the species collectively underwent a survey-wide population decline (0.78\% annually) during that period.

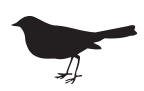

\section{Family Laniidae (Shrikes)}

\section{Loggerhead Shrike}

Lanius ludovicianus

This species is an uncommon spring and fall migrant and summer resident statewide. A few birds overwinter in some years, but apparently the popu- 
lation is essentially migratory. Breeding occurs throughout the Great Plains in suitable habitats.

Migration: The range of 95 initial spring sightings is from January 2 to May 28, with a median of April 4. Half of the records fall within the period March 17 to April 21. Ninety-eight final fall sightings are from July 26 to December 30, with a median of September 19. Half of the records occur from August 26 to October 1.

Habitats: Outside the breeding season these birds occupy the same open country that northern shrikes utilize, and during the nesting period they are also associated with open habitat with scattered or clustered shrubs or small trees. Twenty-six nests of this species were reported during the second atlasing period of the Breeding Bird Atlas project, and nesting was confirmed in 63 survey blocks (Mollhoff, 2016), as compared with confirmed nestings in 61 blocks during the first survey (Mollhoff, 2001).

Comments: The Nebraska Sandhills seem to represent perfect habitat for loggerhead shrikes; scattered Russian olive trees are favorite nesting sites, and the open country provides for excellent viewing of the surroundings. Shrikes are often called "butcher birds," as they frequently impale their prey on barbed wire or the thorns of trees to store them temporarily. Breeding Bird Surveys between 1966 and 2015 indicate that the species collectively underwent a surveywide population decline $(2.78 \%$ annually) during that period, and an estimated $3.23 \%$ rate of annual decline in Nebraska. The Nebraska Sand- hills population now seems to have become part of the species' national decline pattern.

\section{Northern Shrike}

Lanius borealis

This species is an uncommon to locally common winter resident statewide, but perhaps it is more common in the western regions than in the east. It also occurs throughout the Great Plains as a migrant or winter visitor.

Migration: The range of 44 initial fall sightings is from August 28 to December 26, with a median of November 9 . Half of the records fall within the period October 23 to November 28. Twenty-four final spring sightings range from January 7 to April 24, with a median of March 11 . Half of the records fall within the period February 23 to March 25.

Habitats: Migrants and wintering birds are found on open plains or prairies having scattered trees or telephone posts for perches.

Comments: The larger size, somewhat barred breast, and more contrasting black ear-stripe all help to identify this species, and it rarely overlaps in seasonal occurrence with the loggerhead shrike. Both are surprisingly effective predators, sometimes killing birds as large as warblers and sparrows.

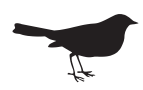




\section{Family Vireonidae (Vireos)}

\begin{abstract}
Black-capped Vireo
Vireo atricapilla

Extirpated. There are two definite early records for black-capped vireo: a sight record for Sarpy County in 1894 and a specimen from Sarpy County in 1921. Oklahoma is the nearest region of current breeding of this endangered species. Once nesting in the Red Hills of southern Kansas, it has no recent known occurrences in the state (Thompson et al., 2011).
\end{abstract}

\section{White-eyed Vireo}

Vireo griseus

This species is an uncommon to occasional spring and fall migrant in eastern Nebraska and a local summer resident in the lower part of the Missouri River's forested valley, with a northern limit at least as far as Sarpy County. Reported west to Keith and Sioux counties. Breeding also occurs from eastern Kansas south through eastern Oklahoma to Texas. It is casual in South Dakota.

Migration: Forty-four initial spring sightings range from April 19 to June 5 , with a median of May 10. Half of the records fall within the period May 3-15. Fourteen final fall sightings are from August 2 to September 22, with a median of September 6 .

Habitats: During the breeding season, this species occupies the dense understory of wooded bottomlands and thickets near streams. There were no reported nesting activities during the two Breeding Bird atlas surveys (Mollhoff, 2001, 2016).

Comments: White-eyed vireos are well named; they are the only native vireos with pale white eyes, which are exaggerated by a white eye-ring. Breeding Bird Surveys between 1966 and 2015 indicate that the species had a survey-wide population increase (o.62\% annually) during that period.

\section{Bell's Vireo}

Vireo bellii

This species is a common spring and fall migrant and summer resident in eastern Nebraska, becoming rarer westwardly, and breeding locally to Dawes County in the Pine Ridge region, to Cherry County in the Niobrara Valley, to Morrill County and probably Scotts Bluff County in the North Platte River valley, and to the Colorado border in the valleys of the South Platte and Republican Rivers. Breeding also occurs north to western North Dakota and south to Oklahoma and the Texas Panhandle.

Migration: The range of 114 initial spring sightings is from March 30 to June 10, with a median of May 13. Half of the records fall within the period May 6-20. Sixty-four final fall sightings range from July 24 to October 20 , with a median of September 8. Half of the records fall within the period $\mathrm{Au}$ gust 25 to September 17.

Habitats: In Nebraska this prairieadapted vireo is widespread in thickets near streams or rivers and in second-growth scrub, forest edges, and brush patches. Ten nests of this species were reported during the second atlasing period of the Breeding Bird 
Atlas project, and nesting was confirmed in 14 survey blocks (Mollhoff, 2016), as compared with confirmed nestings in 20 blocks during the first survey (Mollhoff, 2001).

Comments: Like many vireos, this species is more easily heard than seen; it often sings from thick brush near the ground. Breeding Bird Surveys between 1966 and 2015 indicate that the species collectively underwent a survey-wide population increase (0.63\% annually) during that period, and an estimated $4.5 \%$ annual rate of increase in Nebraska.

\section{Yellow-throated Vireo}

\section{Vireo flavifrons}

This species is an uncommon spring and fall migrant in eastern counties and an uncommon summer resident in the forested valley of the Missouri River from South Dakota to Kansas, and west along various tributaries to at least Jefferson and Lancaster counties. Breeding also occurs widely in the eastern parts of the Great Plains, from central North Dakota southward through eastern Oklahoma, and migrants are somewhat more widespread.

Migration: Eighty initial spring sightings range from March 24 to June 3, with a median of May 7. Half of the records fall within the period April 30 to May 13. Twenty-seven final fall sightings range from July 21 to October 26 , with a median of September 9 . Half of the records fall within the period August 30 to September 16.

Habitats: Migrants and breeding birds are associated with mature, moist deciduous forests, especially riverbottom forests and shady slopes, and infrequently with wooded residential areas. There were three confirmed breedings of this species during the first atlasing periods, and all were along the Missouri River in Dakota, Sarpy, and Otoe counties (Mollhoff, 2001). Four nests of this species were reported during the second atlasing period of the Breeding Bird Atlas project, and nesting was confirmed in Lancaster and Otoe counties (Mollhoff, 2016) as compared with confirmed nestings in three blocks of Thurston, Sarpy, and Otoe counties during the first survey (Mollhoff, 2001).

Comments: Breeding Bird Surveys between 1966 and 2015 indicate that the species had a survey-wide population increase (0.98\% annually) in that period.

\section{Cassin's Vireo}

Vireo cassinii

This western species is a regular fall migrant in western Nebraska. Until the taxonomic splitting of this form from the blue-headed vireo (formerly constituting the solitary vireo), there was little information on this species in Nebraska. Besides two specimen records, there have been many fall sightings in the Panhandle between August 24 and September 21. Perhaps this represents a somewhat earlier migration than that typical of the blue-headed vireo (Nebraska Bird Review 65:173). It was also reported May 16-17, 1998. Many of the records are from Oliver Reservoir. As of 2016 there were still only four spring records, from May 14 to June 1 ( $N e$ braska Bird Review 84:76). The nearest breeding area of this species is in western Montana. 


\section{Blue-headed Vireo}

Vireo solitarius

This boreal and eastern species is an uncommon spring and fall migrant in eastern Nebraska. It breeds in Minnesota, and migrants occur throughout the Plains states.

Migration: Seventy-seven initial spring sightings (for the originally constituted solitary vireo) range from April 18 to June 10, with a median of May 9. Half of the records fall within the period May 3-16. Fourteen final spring sightings range from May 7 to June 7 , with a median of May 18. Eighteen initial fall sightings range from July 22 to October 6 , with a median of September 11. Half of the records fall within the period September 3-16. Twenty final fall sightings are from September 22 to November 3, with a median of October 1 . It is possible that this form migrates through Nebraska somewhat later in fall than does the plumbeous vireo (Nebraska Bird Review 65:173).

Habitats: Migrating birds occupy riverbottom cottonwood forests and other deciduous wooded habitats, where the birds usually forage among the larger branches. It breeds in swampy coniferous forests.

Comments: This once-called "solitary vireo" is notable for its very conspicuous white eye-ring; I liked to think it needed large eyeglasses as a result of too much "solitary" reading. Its song consists of repeated two- to six-note phrases. Breeding Bird Surveys between 1966 and 2015 indicate that the species had a survey-wide population increase ( $2.86 \%$ annually) during that period.

\section{Plumbeous Vireo}

Vireo plumbeus

This western species is a rare breeder in the Pine Ridge region, especially in the canyons of Sioux, Dawes, and Sheridan County. It also breeds in South Dakota's Black Hills.

Migration: Little Nebraska migration data exists for this rather recently recognized species (see Condor 97:903-919). The few available fall dates are for September. Rosche (1982) gives the dates of the Pine Ridge nesting population of the "solitary vireo" as May 21 to September 17. In Kansas a few spring dates are from May 3 to 12 , and the fall dates are from September 3 to 30 (Thompson et al., 2011).

Habitats: While breeding, pine forests and scrubby oak woodlands are favored habitats in the Black Hills and Colorado. One nest of this species was reported during the second atlasing period of the Breeding Bird Atlas project, and nesting was confirmed in three survey blocks of Sioux and Dawes counties (Mollhoff, 2016); nesting was also confirmed in three blocks of Sioux and Dawes counties during the first survey (Mollhoff, 2001).

Comments: Breeding Bird Surveys between 1966 and 2015 indicate that the species collectively underwent a survey-wide population decline (2.44\% annually) during that period.

\section{Philadelphia Vireo}

Vireo philadelphicus

This species is an uncommon spring and fall migrant in eastern Nebraska, west to at least Garden County. Breeding occurs in northern Minnesota and 
adjacent North Dakota, and migrants are widespread in the eastern half of the Plains states region.

Migration: Fifty-two initial spring sightings range from April 23 to June 4 , with a median of May 13. Half of the records fall within the period May 5-19. Eleven final spring sightings are from May 10 to June 10, with a median of May 24. Thirteen initial fall sightings range from July 30 to September 25, with a median of August 25. Twelve final fall sightings are from September 1 to October 21, with a median of September 21.

Habitats: Migrants are associated with open second-growth woodlands, old burned-over wooded areas and clearings, and streamside or lakeside thickets.

Comments: Like the red-eyed vireo, this species lacks wing-bars and has a striped head. Its song is also similar; both species sing extended songs consisting of short sing-song phrases separated by brief pauses.

\section{Warbling Vireo}

Vireo gilvus

This species is a common spring and fall migrant statewide, and a common summer resident almost throughout the state, extending west to the Pine Ridge region, throughout the Sandhills in suitable habitats, and to the Colorado and Wyoming borders in probably all the adjoining counties.

Migration: The range of 112 initial spring sightings is from April 30 to June 10 , with a median of May 8 . Half of the records fall within the period May 1-14. Seventy-nine final fall sightings range from July 26 to October 4 , with a median of September 9 .
Half of the records fall within the period August 30 to September 16.

Habitats: During the summer this species occurs in open stands of deciduous trees, including streamside vegetation, groves, scrubby hillsides, and residential areas. Tall streamside trees such as cottonwoods are favored nesting sites. No nests of this species were reported during the second atlasing period of the Breeding Bird Atlas project, although nesting was confirmed in 24 survey blocks (Mollhoff, 2016), as compared with confirmed nestings in 30 blocks during the first survey (Mollhoff, 2001).

Comments: Usually foraging high in the treetop canopies of tall hardwood trees, the warbling vireo made my students hate to try to identify this species-until I told them that its song is easily learned if they simply remember it is saying in a syncopated manner, Let's go down to the corner and buy us a beer! From then on they rarely misidentified this bird. Breeding Bird Surveys between 1966 and 2015 indicate that the species collectively underwent a surveywide population increase (0.85\% annually) during that period, and an estimated $1.2 \%$ annual rate of increase in Nebraska.

\section{Red-eyed Vireo}

Vireo olivaceus

This species is a common spring and fall migrant statewide, and a common summer resident in wooded regions of eastern Nebraska, locally extending west to at least Sioux (White River), Sheridan (Niobrara River), Thomas (Bessey Unit, Nebraska National Forest), Scotts Bluff (North Platte River), 
Keith (South Platte River), and Hitchcock (Republican River) counties.

Migration: The range of 129 initial spring sightings is from March 20 to June 10, with a median of May 14. Half of the records fall within the period May 9-22. Eighty final fall sightings range from July 23 to October 20, with a median of September 7. Half of the records fall within the period August 25 to September 5 .

Habitats: While in Nebraska these birds are usually found in deciduous forests, especially those with rather open canopies and fairly large trees. One nest of this species was reported during the second atlasing period of the Breeding Bird Atlas project, and nesting was confirmed in 24 survey blocks (Mollhoff, 2016), as compared with confirmed nestings in 11 blocks during the first survey (Mollhoff, 2001).

Comments: The red-eyed vireo is one of the commonest breeding vireos in eastern Nebraska. As with many vireos, its song consists of short phrases that alternately end on ascending and descending notes, as if the bird were asking a question and then immediately answering it, as in, You got any eggs? I didn't get any eggs. Breeding Bird Surveys between 1966 and 2015 indicate that the species collectively underwent a surveywide population increase $(0.75 \%$ annually) during that period, and an estimated $3.17 \%$ rate of annual increase in Nebraska.

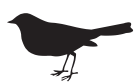

\section{Family Corvidae (Crows, Jays, and Magpies)}

\section{Gray Jay \\ Perisoreus canadensis}

This species is an extremely rare winter visitor or vagrant. There are early records from Belmont (presumably Dawes County) and Monroe Canyon (Dawes County). It has also been reported from Sioux, Cuming, and Douglas counties, usually during winter and spring months. These birds presumably originate from the Black Hills, where the species breeds commonly.

Migration: This species has been observed from November 12 to April (no date), but almost no specific dates are available.

Habitats: Associated throughout the year with coniferous or mixed forests.

Comments: Like other jays this is an inquisitive and bold bird, often acting as a "camp robber" at protected sites such as parks, stealing bits of food that it is able to carry off and perhaps cache for later consumption.

\section{Pinyon Jay}

Gymnorhinus cyanocephalus

This species is an uncommon to rare permanent resident of the Pine Ridge region (Sioux, Scotts Bluff, and probably Sheridan and Morrill counties). Vagrants may appear elsewhere in the state during winter months. Breeding was not documented in the state (in the Pine Ridge region) until 1999.

Migration: The pinyon jay is probably a permanent resident in north- 
western Nebraska. Vagrants sometimes appear in other parts of the state during late winter or spring.

Habitats: In the Black Hills, and probably also in the Pine Ridge region, this species is found in pine forests where the soil is fairly dry and the trees are small and scattered. No nests of this species were reported during the second atlasing period of the Breeding Bird Atlas project, although nesting was confirmed in four survey blocks of Sioux, Dawes, and Morrill counties (Mollhoff, 2016), as compared with confirmed nestings in two Sioux and Scotts Bluff County blocks during the first survey (Mollhoff, 2001).

Comments: The pinyon jay is another of the attractive members of the corvid family, which calls with raucous notes and tends to cache food. Breeding Bird Surveys between 1966 and 2015 indicate that the species collectively underwent a survey-wide population decline (3.69\% annually) during that period.

\section{Steller's Jay}

Cyanocitta stelleri

This Rocky Mountain species is a rare vagrant. It has most often been seen in western parts of the state, but in addition to sightings in Scotts Bluff and Sioux counties, it has been seen in at least Keith, Lincoln, Logan, and Lancaster counties as well. It is also a vagrant in South Dakota, Oklahoma, and Kansas. As of 2012 there were about 30 state records (Nebraska Bird Review 80:145). The nearest breeding area of this species is in eastern Wyoming.

Migration: This species has been observed from October 6 to April 30, with a few records each for November, December, January, and April.

Habitats: Throughout most of the year this species is associated with montane coniferous or mixed forests and woodlands, but sometimes flocks or individuals move to city edges and feeding stations during the fall and winter.

Comments: Steller's jays are bold and brassy birds of the American West. In a few regions they overlap with blue jays and have been known to hybridize with them rarely.

\section{Blue Jay}

Cyanocitta cristata

This species is a common permanent resident statewide, although somewhat less common in western $\mathrm{Ne}$ braska than in eastern parts of the state. It is also a resident almost throughout the Plains states, except the extreme southwestern portions.

Habitats: Throughout the year this species is widely distributed in forests, parks, suburbs, cities, and almost anywhere a combination of trees and grasslands occur. It is somewhat more adapted to city life than is the Steller's jay. Nesting was confirmed in 56 survey blocks during the second atlasing period of the Breeding Bird Atlas project (Mollhoff, 2016), as compared with confirmed nestings in 80 blocks during the first survey (Mollhoff, 2001).

Comments: This familiar bird of cities and countryside is a noisy and sometimes annoying bird, as it will often steal eggs from the nests of smaller songbirds. However, its thief call warns all within range of possible danger, and it also effectively 
mimics the alarm calls of red-shouldered and red-tailed hawks. Breeding Bird Surveys between 1966 and 2015 indicate that the species collectively underwent a survey-wide population decline (0.66\% annually) during that period, and an estimated $1.29 \%$ rate of annual decline in Nebraska. This reduction is probably the result of West Nile disease during the early 2000 .

\section{(Western Scrub-Jay)}

\section{Aphelocoma woodhouseii}

Hypothetical. Some early questionable references to this species exist from western Nebraska, but these have been generally discounted. A sight report of came from Bull Canyon, Banner County, very close to the Wyoming border (Nebraska Bird Review 48:89). The western scrub-jay is resident in eastern Colorado, New Mexico, and adjacent Oklahoma, and has wandered to central Kansas.

\section{Clark's Nutcracker}

Nucifraga columbiana

This species is a vagrant and an extremely rare breeder in Nebraska, with most records from the Pine Ridge region, but it has been reported as far east as Douglas and Cass counties. It bred in Sowbelly Canyon near Harrison in 1987, which was the only confirmed breeding during early atlasing years (Mollhoff, 2001). No nests of this species were reported during the second atlasing period of the Breeding Bird Atlas project, but there was one probable breeding in Sioux County (Mollhoff, 2016). By 2005 there were three state breeding records (Nebraska Bird Review 73:58), but the nearest regular breeding area of this species is in eastern Wyoming. Migration: This species is an irregular vagrant, with records extending from September 4 to November 9, and from March 2 to June 25, with the largest number of records for September.

Habitats: Throughout the year this species is normally associated with montane coniferous forests, but wintering birds might appear almost anywhere.

Comments: The learning and memory abilities of these birds, which often cache hundreds or even thousands of seeds for months, and then are able to locate them accurately, is simply amazing. Although rare in Nebraska, they are typical birds in the high mountains of Colorado, where they depend on the cached seeds of limber and whitebark pines for winter survival. Breeding Bird Surveys between 1966 and 2015 indicate that the species collectively underwent a surveywide population decline (0.26\% annually) during that period.

\section{Black-billed Magpie}

Pica hudsonia

This species is an increasingly uncommon to rare permanent resident in western Nebraska and is now largely limited to the Panhandle region. It breeds widely in the Plains states, from North Dakota south to Kansas and extreme northern New Mexico.

Habitats: Throughout the year the species normally frequents wooded canyons and riverbottom forests and forest edges but ranges out into more arid environments wherever there are thickets of shrubs or small trees that provide nest sites. During the second 
atlasing period of the Breeding Bird Atlas project nesting was confirmed in 26 survey blocks, but the species was found in only $8 \%$ of the 443 blocks studied during the first atlas surveys, far fewer than the 34\% found during the first survey (Nebraska Bird Review 81:79-86; Mollhoff, 2016).

Comments: Magpies are widespread and highly adaptable birds that histocially seem to have been rather rigidly limited to regions west of Grand Island. Their large stick nests, usually placed in low trees, are a certain indicator of breeding pairs in the area. Breeding Bird Surveys between 1966 and 2015 indicate that the species collectively underwent a survey-wide population decline (0.49\% annually) during that period, and a frightening 9.43\% rate of annual decline in Nebraska, following a West Nile outbreak that started in 2002. By 2016 the species' only remaining stronghold in the state had become limited to the region from the Panhandle east to about Keith and Lincoln counties (Nebraska Bird Review 84:76).

\section{American Crow}

Corvus brachyrhynchos

This species is a common to abundant spring and fall migrant statewide, and a common summer resident. Numbers are greatly increased in winter by migrants from farther north, so the species is present throughout the year. Breeding occurs over most of the Plains states excepting the southwestern portions, and the species is a migrant throughout.

Habitats: Throughout the year this species occurs in a wide variety of forests, wooded riverbottoms, suburban areas, orchards, parks, and woodlots. During the second atlasing period of the Breeding Bird Atlas project, nesting was confirmed in 41 survey blocks. The species was found in $64 \%$ of the 443 blocks studied during the first atlas surveys, compared with $65 \%$ of 557 blocks in the second survey (Mollhoff, 2016), suggesting a now-stable population that has recovered from the West Nile pandemic of the early 2000 .

Comments: The ubiquitous crow has in recent decades become more adapted to cities, where it gains some safety from great horned owls and perhaps large hawks. Breeding Bird Surveys between 1966 and 2015 indicate that the species collectively underwent a survey-wide population decline (0.15\% annually) during that period, and an estimated $0.84 \%$ rate of annual decline in Nebraska.

\section{Fish Crow}

\section{Corvus ossifragus}

Accidental. This southeastern species was observed on several occasions from May 29 to August 8, 2009, along the lower Platte and Missouri Rivers (Nebraska Bird Review 77:60, 155-159). The nearest breeding area of the fish crow is in eastern Missouri.

\section{Chihuahuan Raven}

\section{Corvus cryptoleucus}

This southwestern species was previously an uncommon or local resident in Adams and Kearney counties; now perhaps it is extirpated. There is an old nesting record for Dundy County (Nebraska Bird Review 45:16) and a possible nest of this species (or per- 
haps that of an American crow) from the Grand Island region for the same period (Nebraska Bird Review 44:3839). There have been scattered reports of vagrants elsewhere in the state, but the current status of this species in the state remains very doubtful. Regular breeding occurs from southwestern Kansas and eastern Colorado southward, where it is a permanent resident.

Migration: Too few dates are available for an analysis. Six spring sightings range from January 1 to June 6 , with no obvious clustering of dates.

Habitats: The usual breeding habitat consists of open and arid grasslands, with scattered trees, telephone poles, or windmills for nest sites. It is generally not associated with river valleys or heavily forested areas.

Comments: This species once was called the "white-necked raven," but the white bases of the neck feathers are rarely visible. It is only slightly larger than the American crow and has a slightly higher-pitched voice.

\section{Common Raven}

Corvus corax

Extirpated, or nearly so. Ravens previously occurred and probably bred in western parts of the state but were extirpated before 1900, probably not log after the last of the bison herds had been eliminated and their carcasses were no longer available. Recent sightings attributed to this species include two for Scotts Bluff County and one each for Adams and Douglas counties, all between March 31 and May 26. Similarities to the Chihuahuan raven make such sightings suspect, but the species does occur in the eastern plains of Colorado during winter months. Other recent sightings have been made in the Sandhills region (Nebraska Bird Review 75:111) and at North Platte (Nebraska Bird Review 85:14).

Habitats: This species is associated with open plains, canyons, and forests throughout the year.

Comments: Perhaps the common raven will one day return as a breeder to western Nebraska, but the egg- and chick-eating tendencies of these birds make them a threat to many other species, and so its absence is not a great loss. In recent years there have been several probable state sightings of ravens but no hard evidence. Breeding Bird Surveys between 1966 and 2015 indicate that the species collectively underwent a survey-wide population increase ( $2.4 \%$ annually) during that period.

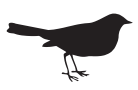

\section{Family Alaudidae (Larks)}

\section{Horned Lark}

Eremophila alpestris

This widespread, open-country species is a common to abundant spring and fall migrant and summer resident statewide, and a common winter visitor as well. Several subspecies are present in the state at various times of the year. It breeds in or migrates through the entire Great Plains. 
Habitats: A variety of low-stature open habitats are used by this species throughout the year, but in Nebraska it is mostly found in natural grasslands and cultivated fields. The sparse grasslands of the Sandhills are probably a nearly optimum habitat. Three nests of this species were reported during the second atlasing period of the Breeding Bird Atlas project, and nesting was confirmed in 132 survey blocks (Mollhoff, 2016), as compared with confirmed nestings in 102 blocks during the first survey (Mollhoff, 2001).

Comments: Probably few if any other species of songbird is as common as the horned lark in the Nebraska Sandhills, although the coloration of the birds matches their substrate so well that they are usually overlooked until they fly, when their mostly black tails become apparent. Breeding Bird Surveys between 1966 and 2015 indicate that the species collectively underwent a survey-wide population decline (2.46\% annually) during that period, and an estimated $0.47 \%$ rate of annual decline in Nebraska.

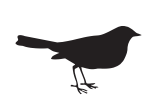

\section{Family Hirundinidae (Swallows)}

\section{Purple Martin}

Progne subis

This species is a common spring and fall migrant and summer resident throughout most of Nebraska, with the western limits being generally east of a line from eastern Cherry County through Dundy County. The range may still be expanding west, but Ogallala, Lewellen, and Crescent Lake represent the species' approximate current western limits. It breeds in the eastern parts of the Plains states, from North Dakota south to Texas.

Migration: The range of 143 initial spring sightings is from March 8 to June 5, with a median of April 10. Half of the records fall within the period March 27 to April 15. The range of 101 final fall sightings is from July 22 to October 15, with a median of August 30. Half of the records fall within the period August 20 to September 15.

Habitats: The purple martin is widespread in urban, suburban, and rural habitats, usually fairly near water and always where suitable nesting cavities are available. Typically these are in birdhouses, but the birds sometimes also nest in clusters of gourds or even in unused woodpecker holes or crevices in old buildings. No nests of this species were examined during the second atlasing period of the Breeding Bird Atlas project, although nesting was confirmed in 26 survey blocks west to Garden County (Mollhoff, 2016), as compared with confirmed nestings in 21 blocks during the first survey (Mollhoff, 2001).

Comments: Purple martins are sociable nesters that readily accept martin houses, although it is necessary to keep house sparrows from confiscating such locations before the martins arrive in mid-April. The houses must also be placed fairly high, in obstacle-free locations, if they are to be used by the birds. Breeding Bird Sur- 
veys between 1966 and 2015 indicate that the species collectively underwent a survey-wide population decline (0.91\% annually) during that period, and an estimated $2.94 \%$ annual rate of decline in Nebraska.

\section{Tree Swallow}

\section{Tachycineta bicolor}

This species is a common spring and fall migrant in eastern Nebraska, and a common summer resident in the forested valley of the Missouri River, extending locally westward as far as Dawes County in the Niobrara Valley, the Wyoming border in the North Platte Valley, and Colorado in the Republican Valley. It also breeds in the Dakotas, Minnesota, Iowa, and Missouri and migrates throughout the Plains states.

Migration: The range of 86 initial spring sightings is from March 20 to June 8, with a median of April 29. Half of the records fall within the period April 14 to May 11. Twenty-eight final fall sightings are from July 25 to October 27, with a median of September 17. Half of the records fall within the period August 26 to October 7.

Habitats: During summer this species occurs in open woodlands, usually fairly close to water. Woodpecker holes in dead trees, especially aspens and willows, are favorite nesting sites. Forty-five nests of this species were reported during the second atlasing period of the Breeding Bird Atlas project, and nesting was confirmed in 128 survey blocks (Mollhoff, 2016), as compared with confirmed nestings in 25 blocks during the first survey (Mollhoff, 2001).

Comments: Tree swallows have benefited from the bluebird nest-box program in Nebraska and elsewhere, and have expanded their breeding range in the state accordingly. Their nests are always lined with feathers, unlike those of bluebirds, and the swallows are as much of a delight to have on one's property as are bluebirds. Breeding Bird Surveys between 1966 and 2015 indicate that the species collectively underwent a surveywide population decline $(1.38 \%$ annually) during that period, versus an estimated and highly questionable (based on 32 survey routes) $11.76 \%$ annual rate of increase in Nebraska.

\section{Violet-green Swallow}

\section{Tachycineta thalassina}

This species is a local but common spring and fall migrant and summer resident in western Nebraska, including the Pine Ridge region, the Wildcat Hills, and the Scottsbluff region, with confirmed breedings during the atlasing years in Sioux, Dawes, Scotts Bluff, and Morrill counties (Mollhoff, 2016). Vagrants have appeared east to Perkins and Cuming counties during migration. It also breeds in western South Dakota and has bred at least once in western Kansas.

Migration: Thirty-eight initial spring sightings range from April 17 to June 10, with a median of May 13. Half of the records fall within the period May 5-19. Four final fall sightings are from August 20 to September 5, with a mean of August 27.

Habitats: During summer, this species is found in open forests such as ponderosa pine forests or poplar woodlands, but sometimes also urban areas, where it occasionally nests 
in birdhouses. Old woodpecker holes are the usual nesting sites in forested areas. No nests of this species were examined during the second atlasing period of the Breeding Bird Atlas project, although nesting was confirmed in seven survey blocks of Sioux, Dawes, Scotts Bluff, and Morrill counties (Mollhoff, 2016), as compared with confirmed nestings in two Scotts Bluff County blocks during the first survey (Mollhoff, 2001).

Comments: Violet-green swallows are close relatives of tree swallows but perhaps are even more attractive. The "racing stripe" white markings on their upper tail-coverts seem to be a perfect decorative touch to their plumage and allow for easy identification. Breeding Bird Surveys between 1966 and 2015 indicate that the species collectively underwent a surveywide population decline $(0.66 \%$ annually) during that period.

\section{Northern Rough-winged Swallow}

Stelgidopteryx serripennis

This species is a common spring and fall migrant and summer resident throughout Nebraska. It breeds in and migrates through virtually all the Plains states.

Migration: The range of 136 initial spring sightings is from March 2 to May 29, with a median of April 28. Half of the records fall within the period April 18 to May 6. Seventy-two final fall sightings are from July 21 to October 15, with a median of September 3. Half of the records fall within the period August 23 to September 15 .

Habitats: This is an open-country swallow species, often found near rivers or creeks having exposed ver- tical banks of clay or other materials that can be excavated to provide nest sites. Unlike the colonial bank swallow, this species is a solitary nester. Fifty nests of this species were reported during the second atlasing period of the Breeding Bird Atlas project, and nesting was confirmed in 242 survey blocks (Mollhoff, 2016), as compared with confirmed nestings in 87 blocks during the first survey (Mollhoff, 2001).

Comments: Rough-winged swallows are among the most common swallows in eastern Nebraska, especially near streams that have steepsided mud banks. They also nest in natural cavities in rocky outcrops, although perhaps less frequently, and even horizontal drainpipes. Breeding Bird Surveys between 1966 and 2015 indicate that the species collectively underwent a survey-wide population decline (0.53\% annually) during that period, versus a statistically questionable estimate (based on 46 survey routes) of a $1.57 \%$ rate of increase in Nebraska.

\section{Bank Swallow}

Riparia riparia

This species is a common spring and fall migrant in eastern Nebraska and a summer resident almost statewide but less frequently in western regions. It also breeds throughout most of the Plains states south to northeastern Kansas and is a regular migrant farther south.

Migration: The range of 104 initial spring sightings is from March 20 to June 8 , with a median of May 6 . Half of the records fall within the period April 28 to May 6. Sixty-five final fall 
sightings range from July 31 to October 29 , with a median of September 8 . Half of the records fall within the period August 23 to September 15.

Habitats: While in Nebraska this species occurs in a variety of open habitats, especially grasslands and croplands, but is typically found near water. Bank swallows are dependent on suitable potential nest sites in the form of vertical banks of clay, sand, or gravel that can be excavated by the birds. Thirty-nine nests of this species were reported during the second atlasing period of the Breeding Bird Atlas project, and nesting was confirmed in 55 survey blocks (Mollhoff, 2016), as compared with confirmed nestings in 39 blocks during the first survey (Mollhoff, 2001).

Comments: Bank swallows are local nesters in the state, requiring rather large areas of barren but stable road cuts to support a breeding colony. The nearly vertical loess banks that are common beside roads in the Missouri Valley provide a perfect nesting situation for these birds. Breeding Bird Surveys between 1966 and 2015 indicate that the species collectively underwent a survey-wide population decline (5.33\% annually) during that period, and an estimated $1.2 \%$ rate of annual decline in Nebraska.

\section{Cliff Swallow}

\section{Petrochelidon pyrrhonota}

This species is a common to abundant spring and fall migrant and summer resident statewide. It also breeds in or migrates through the entire Plains region.

Migration: The range of 125 initial spring sightings is from March 22 to
June 10, with a median of April 28. Half of the records fall within the period April 29 to May 18. The range of 101 final fall sightings is from July 22 to October 30, with a median of September 4. Half of the records fall within the period August 20 to September 15 .

Habitats: This species occurs over open areas of farmlands, towns, near cliffs, around bridges, and in other areas where mud supplies and potential nest sites exist on vertical and overhanging surfaces. Cliff swallows are highly colonial and often nest in the same location year after year. Fifty nests of this species were reported during the second atlasing period of the Breeding Bird Atlas project, and nesting was confirmed in 242 survey blocks (Mollhoff, 2016), as compared with confirmed nestings in 136 blocks during the first survey (Mollhoff, 2001).

Comments: Few if any locations in America support larger numbers of cliff swallows than the bridges, culverts, and similar structures of the central and western Platte Valley. Breeding colonies supporting up to several thousand nests are present in some locations, and the numbers of mosquitoes, midges, and similar aerial insects that are consumed in a summer must be astronomical. Charles Brown and Mary Bomberger Brown and their colleagues have extensively researched this species in the Platte Valley (Brown \& Brown, 1992, 1996; Brown et al., 2017). Breeding Bird Surveys between 1966 and 2015 indicate that the species collectively underwent a survey-wide population increase (0.72\% annually) during that 
period, and a $3.95 \%$ rate of annual increase in Nebraska.

\section{Cave Swallow}

Petrochelidon fulva

Accidental; five records have accrued through 2013. Two birds were caught and banded in Keith County on May 31, 1991, and June 26, 1995; the species was also reported there July 1 , 1988, and July 8, 2003 (Brown et al., 1996; Brown, Dinsmore, \& Brown, 2012), as well as at Harvard Waterfowl Production Area on July 20, 2013 (Nebraska Bird Review 81:115). On June 12, 2014, a hybrid male cave $\times$ barn swallow was discovered at a barn swallow nest near Roscoe, Keith County. The nest, and others of the colony, apparently failed, and all were abandoned by early July (Brown \& Page, 2015). The nearest breeding area of this species is in northern Texas.

\section{Barn Swallow}

Hirundo rustica

This species is an abundant spring and fall migrant and summer resident statewide. Judging from migration and breeding records, it might be the most common of the Nebraska swallows. It breeds in and migrates through the entire Plains region.

Migration: The range of 155 initial spring sightings is from March 9 to June 10, with a median of April 23. Half of the records fall within the period April 18-30. The range of 119 final fall sightings is from August 5 to October 6, with a median of September 30. Half of the records fall between September 19 and October 6 .
Habitats: Extremely widespread during the summer, this species occupies open forests, farmlands, suburbs, and rural areas, usually nesting on or inside buildings that have horizontal beams available for nesting sites. Typically colonial, it sometimes nests near or among cliff swallows. Twentyeight nests of this species were reported during the second atlasing period of the Breeding Bird Atlas project, and nesting was confirmed in 277 survey blocks (Mollhoff, 2016). Fifty nests of this species were reported during the second atlasing period of the Breeding Bird Atlas project, and nesting was confirmed in 242 survey blocks (Mollhoff, 2016), as compared with confirmed nestings in 342 blocks during the first survey (Mollhoff, 2001).

Comments: The barn swallow is one of the most familiar of our swallows, and few farms in the state lack at least one pair of these graceful birds. Sometimes they will also nest in urban areas, often choosing porch eaves or carports for nest sites. Breeding Bird Surveys between 1966 and 2015 indicate that the species collectively underwent a survey-wide population decline (1.19\% annually) during that period, and an estimated $0.25 \%$ rate of annual decline in Nebraska. 


\section{Family Paridae (Chickadees and Titmice)}

\section{(Carolina Chickadee)}

Poecile carolinensis

Hypothetical. Specimens identified as this species were captured in Fontenelle Forest, Sarpy County, in July 1974 after the species had been heard in the forest (Nebraska Bird Review 42:57). Its song is higher in pitch and faster than that of the very similar black-capped chickadee. These records were not accepted by the NOU Records Committee (1997). The species' nearest breeding area is the southern third of Kansas.

\section{Black-capped Chickadee}

Poecile atricapillus

This species is a common permanent resident statewide. The population increases during winter months with the arrival of migrants from farther north. It was also breeds widely in the Plains states south to southern Kansas and occurs as a migrant slightly farther south.

Habitats: Throughout the year this species is found in deciduous and coniferous forests as well as in orchards and woodlots. Nesting often occurs in edge situations or open areas of forests, but during the winter period the birds frequently appear at residential feeding stations, especially where suet is available. No nest cavities of this species were examined during the first atlasing period of the Breeding Bird Atlas project, although nesting was confirmed in 108 survey blocks (Mollhoff, 2001). Fifty nests of this species were reported during the second atlasing period of the Breeding Bird Atlas project, and nesting was confirmed in 242 survey blocks (Mollhoff, 2016), as compared with confirmed nestings in 108 blocks during the first survey (Mollhoff, 2001).

Comments: Nearly everybody knows the chickadee by both voice and appearance, as it is a regular visitor at feeding stations. It is a very hardy little bird, able to survive subzero temperatures for long periods. Breeding Bird Surveys between 1966 and 2015 indicate that the species collectively underwent a surveywide population increase (0.61\% annually) during that period, versus an estimated average annual decline of $\mathbf{2 . 1 4} \%$ in Nebraska.

\section{Mountain Chickadee}

Poecile gambeli

This species is an extremely rare winter visitor in western Nebraska. It has been reported at least eleven times in Scotts Bluff County, and one or more times in Lincoln, Dawson, and Sioux counties. It has also been observed in western South Dakota, southwestern Kansas, and northwestern Oklahoma.

Migration: Records for this rare winter vagrant extend from October 5 to May 23. Most records are for October (5), November (4) and December (4), followed by February and April with two each.

Habitats: The mountain chickadee is normally associated with montane coniferous forests throughout the year, but winter vagrants may appear at residential feeding stations.

Comments: This species tends to replace the black-capped in conifer- 
ous forests, but they are very similar in size and behavior. Its whistled feebee call is extended to three or four notes that descend in pitch. The nearest breeding area of this species is in eastern Wyoming.

(Boreal Chickadee)

Poecile hudsonicus

Hypothetical. A single individual was observed during the winter of 197273 in Lancaster County (Nebraska Bird Review 41:43). It has also been reported a few times in South Dakota and North Dakota. The boreal chickadee breeds in northern Minnesota.

\section{Tufted Titmouse}

Baeolophus bicolor

This species is a common permanent resident in eastern Nebraska, with breeding largely limited to the Missouri River's forested valley, north probably to the South Dakota border (it breeds in adjacent South Dakota), and west in southern Nebraska probably to Saline and Thayer counties. During the atlasing years no birds were reported north of Washington County. It breeds from Iowa southward through Missouri and eastern Kansas to Oklahoma and Texas.

Habitats: Throughout most of its range, this species is generally found in coniferous or deciduous forests, orchards, woodlots, and suburban areas. At the edge of its range in Nebraska it is confined to bottomland deciduous forest. No nest cavities of this species were examined during the second atlasing period of the Breeding Bird Atlas project, although nesting was confirmed in eight survey blocks from Douglas to Richardson counties (Mollhoff, 2016), Likewise, no nests of this species were examined during the second atlasing period of the Breeding Bird Atlas project, but nesting was confirmed in eight survey blocks (Mollhoff, 2016), as compared with confirmed nestings in four blocks during the first survey (Mollhoff, 2001).

Comments: The loud Peter, Peter, Peter call of this species is a certain indication of the presence of tufted titmice in an area, long before the bird is usually visible. Near Lincoln it is mostly limited to the mature forests of Wilderness Park, but it is more common along the Missouri Valley. Breeding Bird Surveys between 1966 and 2015 indicate that the species had a survey-wide population increase (1.08\% annually) during that period, and a statistically unreliable estimate (based on only four survey routes) of an annual decline of $0.66 \%$ in Nebraska.

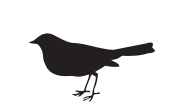

\section{Family Sittidae (Nuthatches)}

\section{Red-breasted Nuthatch \\ Sitta canadensis}

This species is a common winter visitor in the Pine Ridge region; it is generally uncommon elsewhere in the state. There is a 1980 nesting re- 
cord for the Nebraska National Forest, Cherry County, and nestings are probable east along the Niobrara Valley to Rock County. During the atlasing years, confirmed nestings were reported from Sioux, Cherry, Blaine, Boyd, and Scotts Bluff counties (Mollhoff, 2001, 2016). The red-breasted nuthatch also breeds in the Black Hills and occurs as a migrant throughout the Plains states.

Migration: Seventy-two initial fall sightings range from August 10 to December 31, with a median of October 9. Half of the records fall within the period September 18 to October 17 . Thirty-nine final spring sightings are from January 4 to June 8 , with a median of April 3. Half of the records fall within the period March 3 to April 23.

Habitats: Except for the northern Panhandle, where the species probably breeds in coniferous forests, this bird is likely to be found in conifer plantations, in mixed woodlands, and sometimes at feeding stations during winter. No nest cavities of this species were examined during the second atlasing period of the Breeding Bird Atlas project, although nesting was confirmed in eight survey blocks of Sioux, Cherry, Thomas, and Blaine counties (Mollhoff, 2016) Nesting in the Niobrara Valley occurs east to the Niobrara Valley Preserve (Nebraska Bird Review 83:119). By comparison, there were confirmed nestings in four blocks during the first survey (Mollhoff, 2001).

Comments: Over most of Nebraska this species is a winter visitor, especially around coniferous plantings. Its voice is similar to that of the whitebreasted nuthatch, but the notes are more rapid and higher in pitch.

\section{White-breasted Nuthatch}

Sitta carolinensis

This species is an uncommon permanent resident in eastern Nebraska, breeding in wooded habitats locally as far west as the Pine Ridge region in the Niobrara Valley and to at least Morrill County in the North Platte Valley. It also breeds widely in other Plains states, mainly in the eastern portions but west locally to the Black Hills.

Habitats: In Nebraska this species is generally associated with fairly mature floodplain forests during the breeding season, while during the rest of the year it is more widespread and often visits residential feeding stations, especially where suet is provided. One nest of this species was reported during the second atlasing period of the Breeding Bird Atlas project, and nesting was confirmed in 39 survey blocks (Mollhoff, 2016). By comparison there were confirmed nestings in 22 blocks during the first survey (Mollhoff, 2001).

Comments: The long, sharp beak of nuthatches adapts them to probing in the crevices of tree bark, feeding on some of the same insects that woodpeckers consume. The distinctive voice of this species is like a toy trumpet or the bleating of a miniature sheep. Breeding Bird Surveys between 1966 and 2015 indicate the species collectively underwent a survey-wide population increase (1.71\% annually) during that period. 


\section{Pygmy Nuthatch}

Sitta pygmaea

This species is a local but regular permanent resident of the Pine Ridge region and Wildcat Hills. A single nesting record had existed for Sioux County (Nebraska Bird Review 40:70) until studies proved it to also be nesting in Dawes, Sioux, and Sheridan counties (Nebraska Bird Review 65:150-158). In the Wildcat Hills, Scotts Bluff County nesting was first fully documented in 1996; probably it occurs throughout the Wildcat Hills (Nebraska Bird Review 84:77). It also probably nests in Banner County (American Birds 50:296-300; Mollhoff, 2001) and the McKelvie unit of the Nebraska National Forest, Cherry County (Mollhoff, 2016). Vagrants sometimes appear east to Lancaster County. It is a permanent resident of the Black Hills.

Habitats: Throughout the year this species is generally associated with ponderosa pines, especially those growing in open, parklike situations. In the winter, vagrants may appear along cottonwood-lined rivers, often in small flocks. One nest of this species was reported during the second atlasing period of the Breeding Bird Atlas project, and nesting was confirmed in 18 survey blocks east to Sheridan County (Mollhoff, 2016). By comparison, there was one confirmed nesting in a Dawes County block during the first survey (Mollhoff, 2001). Breeding Bird Surveys between 1966 and 2015 indicate that the species collectively underwent a survey-wide population decline ( $0.43 \%$ annually) during that period.
Comments: Pygmy nuthatches are tiny nuthatches that feed in the same manner as the larger species, and they have a voice that is even higher pitched and the notes more rapid than that of the red-breasted nuthatch. There are only a few definite nest records for the state, for at least Sioux, Dawes, Sheridan, Scotts Bluff, and Banner counties, plus probable nesting in Cherry County.

\section{Brown-headed Nuthatch}

Sitta pusilla

Accidental. Two adults were seen and photographed at Holmes Lake Park, Lincoln, during November 8, 2010, through mid-January, 2011 (Nebraska Bird Review 79:16, 136-138). The nearest breeding area of this species is in eastern Oklahoma.

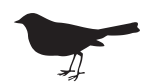 \\ Family Certhiidae (Creepers)}

\section{Brown Creeper}

Certhia americana

This species is a common winter visitor in eastern Nebraska and the Pine Ridge, less frequent elsewhere in the state. There are several early nesting records and two for 1975 and 1977 in Sarpy County (Nebraska Bird Review 43:80, 46:14). Two nests were found at Fontenelle Forest in 2016 (Nebraska Bird Review 84:76). Nesting has also been observed in the Pine 
Ridge near Crawford, Dawes County (Nebraska Bird Review 72:157). The brown creeper breeds in the Black Hills and northern Minnesota and occurs throughout the Plains states as a migrant or winter visitor.

Migration: Ninety-two initial fall sightings range from August 5 to December 30 , with a median of October 17. Half of the records fall within the period September 17 to October 17 . Forty-four final spring sightings are from January 8 to May 29, with a median of March 22. Half of the records fall within the period March 3 to April 23. In a few regions the species breeds and must be considered a permanent resident.

Habitats: While breeding, these birds are associated with fairly mature deciduous or coniferous forests, but in the winter the birds move to wooded streams, wooded parks, suburbs, and the like. No nests of this species were reported during the second atlasing period of the Breeding Bird Atlas project, but nesting was confirmed in two survey blocks of Washington and Sarpy counties (Mollhoff, 2016).

Comments: This small and inconspicuous bark-hugging species virtually blends into its background when it is not moving. The nests are hidden behind loose bark and very difficult to locate, which accounts for the scanty nesting records.

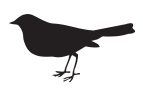

\section{Family Troglodytidae (Wrens)}

\section{Rock Wren}

Salpinctes obsoletus

This wren is a common and conspicuous spring and fall migrant in western Nebraska, becoming rare eastwardly, and a common summer resident in western regions, generally exclusive of the Sandhills, with local breeding as far east as Cherry, Custer, Lincoln, Hitchcock, and Red Willow counties. It also breeds from the western North Dakota southward through western South Dakota, western Kansas, and western Oklahoma.

Migration: Eighty-three initial spring sightings range from April 2 to June 9, with a median of May 2. Half of the records fall within the period April 22 to May 13. Thirty-three final fall sightings are from August 18 to October 29, with a median of October 27. Half of the records fall within the period September 17 to October 6 . There are at least two December records (Nebraska Bird Review 85:15).

Habitats: In Nebraska this species occurs on eroded slopes and badlands, rocky outcrops, cliff walls, talus slopes, and similar generally arid environments. No nests of this species were reported during the second atlasing period of the Breeding Bird Atlas project, but nesting was confirmed in 15 survey blocks east to Red Willow County (Mollhoff, 2016). By comparison there were confirmed nestings in 12 blocks during the first survey (Mollhoff, 2001). 
Comments: Rock wrens make their presence known by their loud trilling songs, which echo up and down the steep canyons they usually inhabit. The nests are well hidden in rock crevices, but their entrance is often lined with tiny pebbles.

\section{Canyon Wren}

Catherpes mexicanus

Accidental. Individuals have been seen on two occasions in Dawes County (Nebraska Bird Review 42:16, 78), and it was also reported in Sioux and Knox counties. As of 2016 there had been five documented records, the fifth in Cherry County, October 28 to December 31, 2016 (Nebraska Bird Review $84: 172,85: 15)$. The species is an uncommon permanent resident in the Black Hills and Oklahoma and is very rare in southwestern Kansas.

\section{House Wren}

\section{Troglodytes aedon}

This species is a common spring and fall migrant and summer resident throughout Nebraska, becoming abundant in the Platte and Missouri Valley forests. It breeds widely in the Plains states, from North Dakota and Minnesota south to northern Oklahoma and northeastern New Mexico, and it occurs farther south as a migrant.

Migration: The range of 136 initial spring sightings is from March 10 to May 24, with a median of April 24. Half of the records fall within the period April 19 to May 2. The range of 131 final fall sightings is from July 24 to October 22, with a median of September 26. Half of the records fall within the period September 10 to October 7.
Habitats: Originally associated with deciduous forests and open woods, this species now is also adapted to the city and frequently nests in birdhouses. However, it is also abundant in riverbottom forests, cottonwood groves, and wooded hillsides or canyons. Eighteen nests of this species were reported during the second atlasing period of the Breeding Bird Atlas project, and nesting was confirmed in 150 survey blocks (Mollhoff, 2016). By comparison there were confirmed nestings in 115 blocks during the first survey (Mollhoff, 2001).

Comments: One of the worst mistakes bird lovers can make is to put up nest boxes in their backyard for house wrens. Their presence is likely to cause losses of all other cavitynesting birds, such as chickadees, tree swallows, and bluebirds, because of the predatory nature of house wren males on the eggs and chicks of other hole-nesting birds. Breeding Bird Surveys between 1966 and 2015 indicate that the species collectively underwent a survey-wide population increase (0.26\% annually) during that period.

\section{Winter Wren}

\section{Troglodytes troglodytes}

This species is a spring and fall migrant and winter resident, ranging from uncommon in eastern Nebraska (north to Washington and Colfax counties and west to Gage County) to rare in western regions. It breeds in northern Minnesota and occurs throughout the Plains states as a migrant or winter visitor.

Migration: The range of 38 initial fall sightings is from August 30 to De- 
cember 26, with a median of October 16. Half of the records fall within January 21 to May 29, with a median of April 13. Half of the records fall within the period April 5-23.

Habitats: While in Nebraska this inconspicuous species is usually found among dense ravine thickets along streams, but it sometimes also occurs in suburban gardens, parks, and other habitats.

Comments: This tiny but very beautiful wren is too rarely seen in $\mathrm{Ne}$ braska, and its wonderfully loud and lilting song is probably never uttered here. In spite of its tiny size, this wren has somehow found its way to Asia and Europe, and has a larger breeding range than other single wren species.

\section{Pacific Wren}

Troglodytes pacificus

Accidental. This recently described western counterpart species of the winter wren was netted and banded at Chadron State Park on September 14, 2017, providing the first state record for Nebraska (Nebraska Bird Review 78:144).

\section{Sedge Wren}

Cistothorus platensis

This species is an uncommon spring and fall migrant in eastern Nebraska and an occasional summer resident in the eastern third of the state, mostly east of a line from Knox to Gage counties but west to at least Hall County and perhaps to Lincoln County (Mollhoff, 2001, 2016). Elsewhere in the Plains states, it breeds from North Dakota and Minnesota southward to eastern Kansas and migrates through most of the region.
Migration: Twenty-five initial spring sightings range from April 16 to June 3, with a median of May 8. Half of the records fall within the period May 1-12. Seventeen final fall sightings are from July 29 to October 22, with a median of September 28 . Half of the records fall within the period September 11 to October 9. Many birds also seem to arrive in midsummer and begin nesting at that time.

Habitats: In Nebraska and the northern plains, these birds breed in wet meadows, typically those dominated by sedges and tall grasses, and less often in the emergent vegetation of marshes or retired croplands and hayfields. Four nests of this species were reported during the second atlasing period of the Breeding Bird Atlas project, and nesting was confirmed in four survey blocks west to Valley County (Mollhoff, 2016). By comparison there were confirmed nestings in two blocks of Hall and Boone counties during the first survey (Mollhoff, 2001).

Comments: Sedge wrens are common breeders in southeastern $\mathrm{Ne}$ braska, where they arrive and begin to sing in early May. Then, in midJuly or August a new song cycle begins. Evidently these later singers are late-arriving birds, perhaps from farther north where they may have been unsuccessful breeders (Nebraska Bird Review 84:126). A similar summer migration occurs in marsh wrens ( $\mathrm{Ne}$ braska Bird Review 64:99).

\section{Marsh Wren}

Cistothorus palustris

This species is a common spring and fall migrant statewide and a locally 
common summer resident, mostly north of the Platte River with local or infrequent breeding south of the Platte in the Rainwater Basin ( $\mathrm{Ne}$ braska Bird Review 39:47). It breeds from North Dakota and Minnesota south to Nebraska, with local breeding in Colorado, and it occurrs elsewhere as a migrant in the Plains states. Differing eastern and western song types occur in the state (Nebraska Bird Review 82:128-130), the dividing line passing southeast through O'Neill approximately along the Elkhorn River valley (Nebraska Bird Review 64:99), or along the eastern edge of the Sandhills (Mollhoff, 2001). Birds singing the western song type have been heard east to Butler County (Nebraska Bird Review 82:64).

Migration: Seventy-eight initial spring sightings range from March 13 to June 9, with a median of May 5 . Half of the records fall within the period April 26 to May 15. Thirty-two final fall sightings are from August 9 to November 22, with a median of October 2 . Half of the records fall within the period September 8 to October 10 .

Habitats: During the breeding season these birds are primarily found in freshwater marshes that have extensive tall emergent vegetation, such as bulrushes and cattails. They also nest along the banks of slowly flowing brackish tidal marshes. Eighteen nests of this species were reported during the second atlasing period of the Breeding Bird Atlas project, and nesting was confirmed in 21 survey blocks (Mollhoff, 2016). By comparison there were confirmed nestings in 25 blocks during the first survey (Mollhoff, 2001).
Comments: The marsh wrens of Nebraska pose a problem in evolution, with two distinct song types occurring in the state, as noted. Perhaps the two types represent "sibling species" that seem to differ only in their vocalizations but act biologically as distinct species. Breeding Bird Surveys between 1966 and 2015 indicate that the species collectively underwent a survey-wide population increase $(1.71 \%$ annually) during that period.

\section{Carolina Wren}

Thryothorus ludovicianus

This species is an uncommon permanent resident in eastern Nebraska, extending locally to Knox, Lancaster, Cuming, and Nuckolls counties, and west along most of the Republican River valley to at least Red Willow County (Nebraska Bird Review 85:16). A remarkable confirmed nesting occurred in Cherry County during the early atlasing years (Mollhoff, 2001). Vagrants have been seen west in the Platte Valley at least to North Platte. It is also resident in eastern Kansas, Oklahoma, and northern Texas.

Migration: Seventy-two initial spring sightings range from January 1 to June 4 , with a median of March 1. Nearly half occur in the month of January. Seven final fall sightings range from August 29 to December 31, with a mean of October 21. The data suggest that the species is primarily a permanent resident within its limited Nebraska breeding range and is a vagrant elsewhere.

Habitats: During the breeding season and probably also the rest of the year this species occupies riverbottom forests, forest edges, cutover forests, 
cultivated areas with brush heaps, and suburban parks and gardens. It is more closely associated with bottomland forests in Nebraska than is either the Bewick's wren or house wren, but all three species overlap in their ecological distributions. Eight nests of this species were reported during the second atlasing period of the Breeding Bird Atlas project, and nesting was confirmed in five survey blocks of Lancaster, Douglas, Sarpy, and Cass counties (Mollhoff, 2016). By comparison there were confirmed nestings in two blocks of Cherry and Jefferson counties during the first survey (Mollhoff, 2001).

Comments: The attractive Carolina wren reaches its distributional limit in southeastern Nebraska, mostly within a region bounded by Cuming, Lancaster, and Jefferson counties, from where it periodically seems to expand northward for a few years. Its usual song consists of repeated teakettle phrases. Breeding Bird Surveys between 1966 and 2015 indicate the species had a survey-wide population increase (1.04\% annually) during that period.

\section{Bewick's Wren}

Thryomanes bewickii

Perhaps extirpated, or nearly so. Until recently this species was a rare spring and fall migrant and previous summer resident in southern Nebraska. Breeding may have once been regular west to Gage County and exceptionally as far west as Buffalo County, but an early report of breeding in Lincoln County seems questionable. Elsewhere it breeds, or has bred, in east- ern Kansas north to within one county of the Nebraska border and in southeastern Colorado and south to Mexico. It is accidental in South Dakota.

Migration: Forty-four initial spring sightings range from March 26 to May 28, with a median of April 24. Half of the records fall within the period April 9 to May 8. Nine final fall sightings range from August 11 to October 3, with a mean of September 20.

Habitats: Habitats used during the breeding season include open woodlands, brushy habitats, farmsteads, and towns. In Colorado they are mostly associated with dry canyons and scrubby forests, but farther east they overlap with the house wren in its habitats.

Comments: Just where the Carolina wren reaches its northwestern range limits in eastern Nebraska, the Bewick's wren had its terminus in southern Nebraska. Its current status in $\mathrm{Ne}$ braska is dubious, but it was reported on some Breeding Bird Surveys, although no breeding records exist for this region nor for adjacent northwestern Kansas or northeastern Colorado. Few Nebraska records of this species exist for recent years; apparently its range has retracted. It has also become quite rare in the eastern states, perhaps because of undesirable interactions with house wrens. 


\section{Family Polioptilidae (Gnatcatchers)}

\section{Blue-gray Gnatcatcher \\ Polioptila caerulea}

This species is an increasingly common spring and fall migrant and summer resident in most of Nebraska except the Sandhills, with historic breeding limited to the Missouri River's forested valley in the southeast, west to about Lancaster and Jefferson counties. Breeding of the western race $P$. c. amoenissima now occurs widely elsewhere over most of western, northern, and southern Nebraska, except the Sandhills (Nebraska Bird Review 77:107, 78:144, 83:120).

Migration: Eighty-five initial spring sightings range from March 30 to June 6 , with a median of May 2. Half of the records fall within the period April 23 to May 10. Seven fall sightings are from July 26 to September 22, with a mean of September 1.

Habitats: Breeding occurs in deciduous bottomland forests of eastern Nebraska, but the western race amoenissima often favors scrubby woodlands. Eight nests of this species were reported during the second atlasing period of the Breeding Bird Atlas project, and nesting was confirmed in 18 survey blocks widely scattered from west to east (Mollhoff, 2016). By comparison there were confirmed nestings in five blocks during the first survey (Mollhoff, 2001).

Comments: This tiny sprite of a bird is usually seen high in the tree canopy, industriously searching for tiny insects. Breeding Bird Surveys between 1966 and 2015 indicate the species collectively underwent a survey-wide population increase (0.38\% annually) during that period.

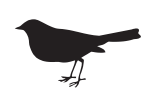

\section{Family Cinclidae (Dippers)}

\section{American Dipper}

Cinclus mexicanus

This species is an extremely rare vagrant. Individuals have been reported once each from Sioux, Dawes, Cherry, Holt, Chase, and Adams counties. There have been at least four records since 1960, including one from Cherry County (Nebraska Bird Review 45:52). It is a permanent resident in the Black Hills but is not reported from elsewhere in the Plains states.

Migration: The American dipper is probably an irregular vagrant. Records exist for May, June, October, and December.

Habitats: Throughout the year this species is normally associated with rapidly flowing mountain streams in wooded regions, but in winter the birds sometimes move to open water at lower elevations.

Comments: American dippers are sometimes called "water ouzels," and they are the only American songbirds that regularly dive into water and search for food at the bottom of fastmoving steams. It seems possible that some of the branch streams of the up- 
per Niobrara River might support a few breeding pairs of these fascinating birds.

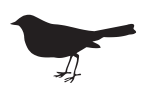

\section{Family Regulidae (Kinglets)}

\section{Golden-crowned Kinglet}

Regulus satrapa

This species is a common to uncommon spring and fall migrant, and an uncommon winter resident statewide, perhaps less common in western than eastern regions. Breeding occurs in the Black Hills and northern Minnesota, but the species is widespread through the Plains states as a migrant.

Migration: Seventy-five initial fall sightings range from August 13 to December 30, with a median of October 19. Half of the records fall within the period October 10-29. Fifty-nine final fall sightings are from November 6 to December 31, with a median of December 26 , suggesting that the species should be considered a winter resident. Fifty-three final spring records are from January 9 to May 29, with a median of April 10. Half of the records fall within the period April 3-26.

Habitats: While in Nebraska this species occupies a wide variety of woodlands, forests, and scrubby habitats, including both coniferous and hardwood but especially the former.

Comments: Kinglets are named for their brilliant golden or ruby-col- ored crown markings, although only in this species are these markings always exposed. The birds are tiny, and their voices are so high-pitched that older birders are likely to miss hearing them altogether.

\section{Ruby-crowned Kinglet}

Regulus calendula

This species is a common to uncommon spring and fall migrant statewide, and a rare and local winter resident. In Kansas it is a common migrant and a rare winter resident, mainly in the east (Thompson et al., 2011). Breeding in the Plains states is restricted to the Black Hills and probably northern Minnesota, but the species is found throughout the region on migration.

Migration: Seventy-four initial spring sightings range from January 12 to May 28, with a median of April 13. Half of the records fall within the period April 1-22. Forty-nine final spring sightings are from April 7 to May 22, with a median of May 10. Seventy-five initial fall sightings are from August 7 to December 10, with a median of September 23. Half of the records fall within the period September 10 to October 7. Sixty-nine final fall records are from August 16 to December 31, with a median of October 28. Less than a fourth of the final fall records are for December, suggesting that the species only rarely overwinters in Nebraska.

Habitats: While in Nebraska this species occurs in a wide variety of forested and shrubby habitats, including gardens and parks. It occurs in both deciduous and coniferous vegetation, showing no apparent preference for the latter. 
Comments: The ruby-crowned is the more common of the two kinglets, and it often pays little attention to humans as it clambers about on twigs and branches.

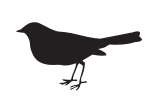

\section{Family Turdidae (Thrushes)}

(Northern Wheatear)

Oenanthe oenanthe

Hypothetical. In addition to an early sight record for Dawes County by John T. Zimmer, this Eurasian species was reported in Gage County in January 1970 (Nebraska Bird Review 39:18). It is considered hypothetical in South Dakota and Kansas, but there are apparently no specimen records from the Plains states.

\section{Eastern Bluebird}

Sialia sialis

This species is a spring and fall migrant statewide, most common in the east and infrequent in the extreme west. An uncommon to occasional summer resident in eastern regions, it breeds locally as far west as Dawes County in the White River drainage, Brown or Cherry County in the Niobrara Valley, and at the Colorado border in the South Platte and Republican Valleys. There is also local breeding in the eastern Sandhills where wooded habitats exist. Local overwintering sometimes occurs. Breeding occurs widely in the eastern portions of the Plains states and locally west to Colorado and Wyoming, and migrants occur throughout the region.

Migration: The range of 123 initial spring sightings is from January 1 to June 8, with a median of March 23. Half of the records fall within the period March 1 to April 25, and more than $10 \%$ of the records are for January. Seventy-four final fall sightings are from August 14 to December 31, with a median of November 5 . Half of the records are within the period October 8-27, and nearly a third are for December. The seasonal data indicate this species occasionally overwinters in Nebraska.

Habitats: During summer this species frequents open hardwood forests, especially those adjacent to grasslands. Forest edges, shelterbelts, city parks, farmsteads, and similar habitats are also used by breeding birds and migrants. Twenty-eight nests of this species were reported during the second atlasing period of the Breeding Bird Atlas project, and nesting was confirmed in 155 survey blocks (Mollhoff, 2016). By comparison there were confirmed nestings in 63 blocks during the first survey (Mollhoff, 2001).

Comments: After the disastrous decline of bluebirds and other songbirds in the 1960s, it has taken several decades for bluebirds to regain their original numbers as breeding birds. Bluebird nest-box programs have contributed greatly to this resurgence, although boxes used by bluebirds are often attacked by house wrens, which may destroy bluebird eggs and kill nestlings. In recent years, erection 
of bluebird boxes by the Bluebirds Across Nebraska program has greatly improved the Nebraska population. Breeding Bird Surveys between 1966 and 2015 indicate the species had a survey-wide population increase (1.50\% annually) in that period, and Nebraska has a 3.80\% rate of annual increase, based on 37 routes.

\section{Western Bluebird}

\section{Sialia mexicana}

This species is an extremely rare vagrant. Individuals have been observed during fall and spring in Dawes, Scotts Bluff, Webster, and Knox counties on at least five occasions. It is considered casual in Kansas and has been reported at least twice in Oklahoma. The nearest breeding area is in Colorado.

Migration: Five records of this rare migrant range from April 11 to October 16. There are two records for $\mathrm{Au}$ gust and October, and one for April.

Habitats: Migrants are associated with open plains and foothills, or similar habitats to those used by mountain bluebirds.

Comments: The western bluebird is by far the rarest bluebird species in Nebraska and is best searched for in the counties bordering Colorado.

\section{Mountain Bluebird}

Sialia currucoides

This species is a common spring and fall migrant in western Nebraska, sometimes being observed east to Douglas and Lancaster counties, and it is a common summer resident in the Panhandle, particularly in the Pine Ridge and Wildcat Hills regions. Overwintering in the state sometimes occurs and is common in Kansas. Breed- ing also occurs in western portions of the Dakotas, and migrants are fairly widespread in the western half of the region.

Migration: Eighty-four initial spring sightings are from January 1 to May 25, with a median of March 11. Half of the records fall within the period February 28 to March 2. Thirtyfive final fall sightings are from July 21 to December 31, with a median of October 16. Half of the records fall within the period October 8-27.

Habitats: During the breeding season, this species occupies open woodlands, especially open pine forest stands, burned or cutover areas, and aspen clumps. While on migration it often occurs in flocks in open country, perching on roadside fences or telephone wires. Six nests of this species were reported during the second atlasing period of the Breeding Bird Atlas project, and nesting was confirmed in 21 survey blocks east to Sheridan County (Mollhoff, 2016). By comparison there were confirmed nestings in six blocks during the first survey (Mollhoff, 2001).

Comments: Although perhaps not quite so attractive as the eastern bluebird, a flock of migrating mountain bluebirds making their way over the plains is a sight that will be long remembered. The birds seem to be more gregarious than eastern bluebirds (which generally migrate in very small groups or even singly).

\section{Townsend's Solitaire}

Myadestes townsendi

This species is an uncommon to locally common spring and fall migrant in western Nebraska and a locally 
common winter resident in juniperrich habitats of western and central Nebraska. There are two early reports of breeding in Sioux County, as well as a 1980 s nesting record (Mollhoff, 2001) and two probable recent nestings (Mollhoff, 2016), but it is uncertain if the species still has a viable population in the Pine Ridge region. Presumably the source of Nebraska's wintering population is the Black Hills of South Dakota. Vagrants may be seen east to the Missouri River in the winter. Breeding is limited to the Black Hills region, but migrants are widespread in the western High Plains region.

Migration: Fifty initial fall sightings are from August 23 to December 5 , with a median of September 26. Half of the records fall within the period September 17 to October 1 . Forty-five final spring sightings are from January 10 to May 25, with a median of March 20. Half of the records fall within the period February 9 to April 7. The species is sometimes seen during summer in northwestern Nebraska and perhaps rarely breeds there, but currently it must be considered only a winter visitor in Nebraska.

Habitats: Breeding habitats of this species are rather dense coniferous forests in mountainous regions. During migration the birds are often found on wooded slopes rich in juniper berries. No nests of this species were reported during the second atlasing period of the Breeding Bird Atlas project, but there were probable nestings in two survey blocks of Dawes County, and three other possible Pine Ridge nestings (Mollhoff, 2016). Breeding Bird Surveys between
1966 and 2015 indicate the species had a survey-wide population increase (0.28\% annually) in that period.

Comments: On first seeing a Townsend's solitaire a birder may be confused because it bears little similarity to thrushes, bluebirds, or robins. Its slim body and rufous wing markings may be more reminiscent of a thrasher or some other related bird, and the oddly spotted juveniles are even more puzzling. However, its song is a lovely thrush-like warble, and its eggs are similarly often pale bluish, with darker spotting.

\section{Veery \\ Catharus fuscescens}

This species is a spring and fall migrant statewide, being generally occasional to rare throughout but probably more common in eastern woodlands. It breeds in North Dakota and Minnesota, and occurs elsewhere through the Plains states as a migrant.

Migration: The range of 108 initial spring sightings is from March 10 to June 4 , with a median of May 15. Half of the records fall within the period May 10-21. Eighteen final spring sightings are within May 9-29, with a median of May 18. Seven fall sightings range from August 28 to September 23, with a mean of September 13 .

Habitats: Migrating birds are found in dense and damp bottomland deciduous forests close to flowing water.

Comments: This elusive thrush is more often heard than seen; its song sounds like a coin rolling down a large funnel. It is generally rusty in color above but not as bright on the tail as a hermit thrush nor as spotted on the breast as a wood thrush. 


\section{Gray-cheeked Thrush}

Catharus minimus

This species is a spring and fall migrant statewide, ranging from common in the east to uncommon or rare in the western areas. It occurs as a migrant throughout the entire Plains states. The nearest breeding area of this species is in northern Manitoba.

Migration: The range of 100 initial spring sightings is from March 20 to June 6 , with a median of May 9. Half of the records fall within the period May 4-13. Forty-one final spring sightings are from May 6 to June 5, with a median of May 17. Five initial fall sightings are from September 2 to October 22, with a mean of October 1.

Habitats: While on migration through Nebraska, this species occupies the same forested habitats as does the Swainson's thrush, namely heavy shrubbery and shady deciduous woodlands, often near creeks or rivers.

Comments: The gray-cheeked thrush arrives in Nebraska at the same time during spring as the Swainson's thrush and occupies the same woodland habitats but is less common. Both are secretive species that only infrequently sing while migrating.

\section{Swainson's Thrush}

Catharus ustulatus

This species is a common spring and fall migrant statewide and a very rare summer resident in the Pine Ridge region, with breeding records known only for Dawes County (Nebraska Bird Review 42:17, 73:19). It breeds in the Black Hills and in Minnesota and oc- curs elsewhere through the Plains states as a regular migrant.

Migration: The range of 141 initial spring sightings is from April 9 to May 30, with a median of May 6 . Half of the records fall within the period May 1-11. Seventy-four final spring sightings are from April 20 to June 9, with a median of May 27. Fifty-one initial fall sightings are from July 29 to October 14, with a median of September 8. Half of the records fall within the period September 3-16. Fifty-one final fall sightings are from September 11 to December 1, with a median of September 28.

Habitats: While on migration the Swainson's thrush occupies riverbottom forests, shelterbelts, and parks or shade trees in towns. In the Black Hills and probably also in the Pine Ridge region, it is limited to cool and dense coniferous forests having a fairly open understory allowing for easy ground foraging. No nests of this species were reported during the second atlasing period of the Breeding Bird Atlas project, but there were probable nestings in two survey blocks of Sioux and Dawes counties (Mollhoff, 2016). Breeding Bird Surveys between 1966 and 2015 indicate that the species had a survey-wide population decline ( $0.84 \%$ annually) in that period.

Comments: Although somewhat similar in plumage pattern to the gray-cheeked thrush, this species is more olive-toned (an older and more descriptive name was "olive-backed thrush") and has a conspicuous buffy ring around its eye, which the graycheeked thrush lacks. 


\section{Hermit Thrush}

Catharus guttatus

This species is an uncommon spring and fall migrant in eastern Nebraska, becoming rarer to the west and apparently quite rare in extreme western Nebraska. It has bred in the Black Hills, breeds regularly in Minnesota, and occurs as a migrant throughout the Plains states.

Migration: Except for one January record, the range of 94 initial spring sightings is from March 9 to June 3, with a median of April 20. Half of the records fall within the period April 10 to May 2. Twenty-six final spring sightings are from April 10 to May 26, with a median of April 26. Fourteen initial fall sightings are from September 4 to December 31, with a median of October 6 . Twelve final fall sightings are from September 11 to December 14 with a median of October 16 .

Habitats: Migrants are found in dense to semi-open regions of woodland, shrubbery, and vine-draped tangles, but they occasionally move into more open areas. Fairly heavy deciduous woodlands are the favored habitat in eastern Nebraska.

Comments: It is unfortunate that Nebraskans never have a chance to hear the song of the hermit thrush while it is in Nebraska; the song begins with a single fluty note that is followed by a cascade of ascending and descending phrases. The rufous tail and fairly heavily spotted breast of this forest thrush provide the best field marks.

\section{Wood Thrush}

Hylocichla mustelina

This species is a common to uncom- mon spring and fall migrant in eastern Nebraska and a local summer resident in wooded eastern regions, extending west locally to Cherry, Lincoln, and Thomas counties, and possibly to Sioux County. It breeds widely in the eastern parts of the region, from Minnesota south to eastern Kansas and eastern Oklahoma.

Migration: The range of 120 initial spring sightings is from April 1 to June 10, with a median of May 10. Half of the records fall within the period May 5-19. Thirty-one final fall sightings are from July 23 to October 6 , with a median of September 10. Half of the records fall within the period September 5-23.

Habitats: Migrants and breeding birds are associated with mature shady forests, especially deciduous woods, and also with wooded parks and gardens. The birds prefer breeding habitats with a dense understory, running water nearby, and tall trees for singing perches. No nests of this species were reported during the second atlasing period of the Breeding Bird Atlas project, but nesting was confirmed in seven survey blocks west to Lancaster County (Mollhoff, 2016). By comparison there were confirmed nestings in three blocks of Gage, Sarpy, and Dakota counties during the first survey (Mollhoff, 2001).

Comments: Wood thrushes somewhat resemble incompletely plumaged robins-they are of about the same size and have a distinctly robinlike profile and behavior. They also lay eggs that are robin-egg blue, as are those of the veery and hermit thrush. Breeding Bird Surveys between 1966 and 2015 indicate that the species collectively underwent a survey-wide 
population decline (1.91\% annually) during that period. A Nebraska estimate of a $2.97 \%$ annual increase was based on only four routes.

\section{American Robin}

\section{Turdus migratorius}

This species is an abundant spring and fall migrant and common summer resident statewide. Overwintering is frequent in some years and localities. Breeding occurs nearly throughout the Plains states, except for the extreme southwestern regions, where it is only a migrant.

Migration: Forty-five initial spring sightings are from January 1 to May 26 , with a median of February 20. Half of the records fall within the period February 2 to March 4 . Fifty-four final fall sightings are from September 1 to December 31, with a median of November 19. Half of the records fall within the period October 20 to December 14. Over a third of the records are for December, indicating that the species commonly overwinters in Nebraska. Winter movements from Nebraska are seemingly more of a random scattering than an organized north-south migration.

Habitats: Although this species was originally associated with open woodlands, it is probably most common in cities, suburbs, parks and gardens, and farmlands. Thirty-three nests of this species were reported during the second atlasing period of the Breeding Bird Atlas project, and nesting was confirmed in 351 survey blocks (Mollhoff, 2016). By comparison there were confirmed nestings in 298 blocks during the first survey (Mollhoff, 2001).

Comments: Everybody recognizes this familiar bird; it is tamer than any of the other thrushes and is completely at home close to humans. Its cheery song is one of the hallmarks of spring in Nebraska, and it is one of the last birds to leave in the autumn. Breeding Bird Surveys between 1966 and 2015 indicate that the species collectively underwent a survey-wide population increase ( $0.12 \%$ annually) during that period, and Nebraska had a $1.58 \%$ annual increase.

\section{Varied Thrush}

\section{Ixoreus naevius}

This species is a rare vagrant. Individuals have been observed in at least five counties, mostly during fall and spring months, but without any obvious geographical pattern, as is also true in Kansas. There were 32 state records through 2003. It has also been reported in the Dakotas, Kansas, Colorado, and Oklahoma.

Migration: Four fall records for this rare vagrant are from October 1 to December 4 , and three spring records are from February 18 to April 10. In Kansas it is considered a casual winter visitant, with records from September 22 to April 5 (Thompson et al., 2011).

Habitats: The varied thrush is normally associated with coniferous montane forests, but migrants move into more open woodlands on migration and during winter, sometimes wandering widely.

Comments: This is one of the most colorful of our typical thrushes; its striking pattern and musical song always come as a surprise to those not familiar with the species. The nearest breeding area of this species is in western Montana. 


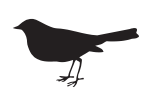

\section{Family Mimidae (Mockingbirds, Thrashers, and Catbirds)}

\section{Gray Catbird}

Dumetella carolinensis

This species is a common spring and fall migrant and summer resident over most of Nebraska, but it becomes rarer northwestwardly. It is now reportedly declining in the Pine Ridge region, where habitat is decreasing because of logging and forest fires. It breeds nearly throughout the Plains states, except in the driest and nearly treeless southwestern regions.

Migration: The range of 134 initial spring sightings is from March 20 to June 5, with a median of May 11. Half of the records fall within the period May 5-17. The range of 128 final fall sightings is from July 22 to December 11, with a median of September 24 . Half of the records fall within the period September 16 to October 2 .

Habitats: Breeding habitats include thickets, woodland edges, shrubby marsh borders, orchards, parks, and other brushy habitats. Fifteen nests of this species were reported during the second atlasing period of the Breeding Bird Atlas project, and nesting was confirmed in 65 survey blocks (Mollhoff, 2016). By comparison there were confirmed nestings in 53 blocks during the first survey (Mollhoff, 2001). Breeding Bird Surveys between 1966 and 2015 indicate that the species had a survey-wide population decline (0.01\% annually) in that period, whereas there was an estimated $0.26 \%$ increase in Nebraska, based on 36 survey routes.

Comments: The dull gray plumage and cat-like meow call make the catbird an easy species to identify; it is a poorer mimic of other species' songs than are the mockingbird or brown thrasher.

\section{Curve-billed Thrasher}

Toxostoma curvirostre

Extremely rare. There is a specimen from Lincoln County obtained in 1936 from a group of several birds, and another dead bird was found in Sioux County in 1962. Another individual that was tentatively identified as this species was obtained at Halsey, Blaine County, in 1970. One was observed in Red Willow County in early 1969 and another in June 1965 in southwestern Nebraska (Nebraska Bird Review 38:93, 39:73). A 1996 sighting was made in Scotts Bluff County on July 2 (Brogie, 1997). A male that appeared at a Sioux County ranch in 2002 finally disappeared in 2008 (Nebraska Bird Review 76:65). In 2016 the ninth documented state record was a bird at Calamus Reservoir, Loup County, seen from February to April, and one was also seen at Chadron State Park on October 7, 2016 (Nebraska Bird Review 84:79, 174). The nearest breeding area of this species is in southwestern Kansas and southeastern Colorado.

\section{Brown Thrasher}

Toxostoma rufum

This species is a common spring and fall migrant and summer resident 
virtually statewide, but it is becoming rarer in extreme western $\mathrm{Ne}$ braska south of the North Platte River. Breeding occurs nearly throughout the Plains states, except in the nearly treeless southwestern regions.

Migration: The range of 134 initial spring sightings is from January 1 to June 2, with a median of April 26. Half of the records fall within the period April 19 to May 4. The range of 164 final fall records is from July 22 to December 31, with a median of September 28. Half of the records fall within the period September 13 to October 11. More than 10\% of the records are for December, suggesting that the species overwinters occasionally, as is also true in Kansas.

Habitats: During summer this species frequents open brushy woods, scattered patches of brush, and small trees in open environments, shelterbelts, woodlands, and shrubby residential areas. Forty-two nests of this species were reported during the second atlasing period of the Breeding Bird Atlas project, and nesting was confirmed in 128 survey blocks (Mollhoff, 2016). By comparison there were confirmed nestings in 138 blocks during the first survey (Mollhoff, 2001).

Comments: This fox-colored, longtailed member of the "mimic thrush" family resembles an elongated thrush in shape but has a slightly curved bill. Its song consists of a series of short phrases that are each repeated once, followed by a brief pause, and the start of a new phrase. Breeding Bird Surveys between 1966 and 2015 indicate that the species collectively underwent a survey-wide population decline (1.04\% annually) during that period and an annual decline of $1.41 \%$ in Nebraska.

\section{Sage Thrasher}

Oreoscoptes montanus

This species is an uncommon spring and fall migrant, especially the latter, in the Wildcat Hills of western Nebraska, and a locally rare summer resident in at least Kimball (Mollhoff, 2016) and Sioux (Rosche, 1982) counties, and probably elsewhere in the Oglala National Grasslands. Vagrants have also been observed in Lincoln, Logan, and Garden counties. It breeds in western South Dakota and is a migrant in eastern Colorado, eastern New Mexico, and adjacent regions.

Migration: Three initial spring sightings are from March 23 to April 21, with a mean of April 17. Seven final fall sightings are from August 24 to October 12, with a mean of September 16. By 2015 there were at least ten summer records (Nebraska Bird Review 83:120).

Habitats: During the breeding season, this species is closely associated with sage-dominated grasslands and similar shrubby arid lands, but especially with big sagebrush. On migration it has a broader distribution, occurring in open prairies and also in ponderosa pine woodlands. No nests of this species were reported during the second atlasing period of the Breeding Bird Atlas project, but nesting was confirmed in one survey block of Dundy County (Mollhoff, 2016). There is a breeding record from Kimball County in 2009, and a record of probable breeding at Toadstool Geological Park in 2016 (Nebraska Bird Review 84:127). Breeding Bird Sur- 
veys between 1966 and 2015 indicate that the species had a survey-wide population decline (1.20\% annually) in that period.

Comments: Like the sage sparrow, this bird is rarely found far from sagebrush, and so it has a very restricted range in Nebraska. It is smaller and more umber in color than the brown thrasher, and its song is a more continuous outpouring of notes.

\section{Northern Mockingbird}

\section{Mimus polyglottos}

This species is an uncommon spring and fall migrant and summer resident in southern and eastern parts of $\mathrm{Ne}$ braska, becoming rarer to the west and north but rarely breeding as far northwest as Sioux County. It breeds widely from Kansas and eastern Colorado southward to Texas and rarely north to South Dakota.

Migration: The range of 132 initial spring sightings is from January 1 to June 10, with a median of May 2. Half of the records fall within the period April 21 to May 13, and about 6\% of the records are for January. Sixtyone final fall sightings are from July 22 to December 31, with a median of September 11. Half of the records fall within the period August 15 to October 13 , and nearly $10 \%$ of the records are for December. The data suggest that the species overwinters occasionally.

Habitats: A variety of habitats, ranging from open woodlands, forest edges, and farmlands, to parks and cities are utilized, but treeless plains and heavy forests are avoided. No nests of this species were reported during the second atlasing pe- riod of the Breeding Bird Atlas project, but nesting was confirmed in 12 widely scattered survey blocks (Mollhoff, 2016). Similarly, there were confirmed nestings in 12 blocks during the first survey (Mollhoff, 2001).

Comments: This famous mimic is one of Nebraska's less common breeding songbirds, but one that is notable for its loud songs, whose phrases are usually repeated several times, and whose flashing white wing and tail markings are apparent during flight. Breeding Bird Surveys between 1966 and 2015 indicate that the species collectively underwent a survey-wide population decline (0.46\% annually) during that period.

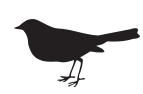

\section{Family Sturnidae (Starlings)}

\section{European Starling}

Sturnus vulgaris

This species is an introduced and common to abundant permanent resident throughout Nebraska, with numbers supplemented during fall and winter by migrants. The species now breeds throughout the entire Great Plains.

Habitats: This unwelcome species is found virtually everywhere throughout the year but is especially associated with human habitations, such as cities, suburbs, and farms, and with mature woodlands that have 
woodpecker holes or other tree cavities for nest sites. No nest cavities of this species were examined during the second atlasing period of the Breeding Bird Atlas project, but nesting was confirmed in 316 survey blocks (Mollhoff, 2016). By comparison there were confirmed nestings in 224 blocks during the first survey (Mollhoff, 2001).

Comments: Starlings arrived in eastern Nebraska in 1939, and since then have become abundant nesters, displacing bluebirds and other cavity-nesting birds that once were common here. They have adapted well to city life, and their large flocks in late fall make them among the most undesirable of our avian visitors. Breeding Bird Surveys between 1966 and 2015 indicate that the species collectively underwent a survey-wide population decline (1.46\% annually) during that period versus an estimated $0.81 \%$ rate of increase in Nebraska.

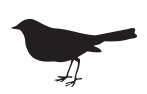

\section{Family Bombycillidae (Waxwings)}

\section{Bohemian Waxwing}

Bombycilla garrulus

This species is a rare winter visitor in Nebraska, irregular both in its geographic and yearly occurrence. It occurs widely throughout the northern parts of the Plains states but is very rarely encountered south of Nebraska.
The nearest breeding area of this species is in northern Manitoba.

Migration: The range of 11 initial fall sightings is from September 25 to December 27, with a median of November 20. Nineteen final spring sightings range from January 2 to May 22, with a median of February 28.

Habitats: Migrants are associated with fruit-bearing trees in woodlands, shelterbelts, and urban parks or gardens, often in association with cedar waxwings.

Comments: Only during unusually cold winters do Bohemian waxwings usually visit Nebraska. They are somewhat larger birds than the cedar waxwings, and they have rufous under tail-coverts and yellow wing-edgings, which makes them easy to recognize.

\section{Cedar Waxwing}

Bombycilla cedrorum

This species is a common spring and fall migrant statewide, a local breeder over much of the state, and an uncommon winter resident. It is erratic in timing of arrival and departure, and probably moves primarily in relation to available food supplies. It breeds from North Dakota and Minnesota south locally to northern Missouri but occurs throughout the Plains states as a migrant.

Migration: The range of 54 initial spring sightings is from January 2 to May 20, with a median of February 24. Half of the records fall within the period February 1 to April 23. Fortyfive initial fall sightings are from July 20 to December 28, with a median of October 4. Fifty-eight final fall sightings are in December, suggesting that the species rather frequently overwinters in the state. 
Habitats: Outside of the breeding season, this species occurs in flocks that concentrate in fruit-bearing trees such as crabapples, hackberries, and mountain ash, and tall shrubs, such as pyracantha, junipers, and sumac. Sometimes poisoning occurs during unusually cold weather, when the birds consume more fruit such as crabapples, which produce cyanide-containing glycosides ( $\mathrm{Ne}$ braska Bird Review 82:65). Breeding usually occurs in semi-open deciduous woodlands, including floodplain forests, upland woodlands, and sometimes parks, farmsteads or residential areas. Sixteen nests of this species were reported during the second atlasing period of the Breeding Bird Atlas project, and nesting was confirmed in 16 widely scattered survey blocks (Mollhoff, 2016). By comparison there were confirmed nestings in seven blocks during the first survey (Mollhoff, 2001).

Comments: Few birds are more aesthetically appealing than waxwings. Their soft colors are reminiscent of an oriental watercolor, and their gregarious nature is marked by a notable absence of aggressive interactions. The possible social functions of the seemingly decorative wax-like tips on their secondaries are apparently unstudied. Breeding Bird Surveys between 1966 and 2015 indicate that the species collectively underwent a survey-wide population increase (0.07\% annually) during that period versus a statistically questionable estimate (based on 33 survey routes) of an $11.7 \%$ rate of annual increase in Nebraska.

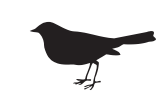

\section{Family Ptilogonatidae (Silky Flycatchers)}

\section{Phainopepla}

Phainopepla nitens

Accidental. One individual of this species was photographed at Alliance, Box Butte County, between January 1 and February 13, 1983 (Nebraska Bird Review 51:18). The nearest breeding area of this species is in western Texas.

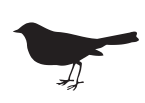

\section{Family Passeridae (Old World Sparrows)}

\section{House Sparrow}

Passer domesticus

This species is an abundant introduced permanent resident throughout Nebraska and the other Plains states.

Habitats: This species is always associated with humans, breeding in cities, suburbs, and around farm buildings. Nesting occurs in almost any kind of cavity or crevice, including those provided by buildings, dense vines growing against walls, tree cav- 
ities, old swallow nests, and other diverse locations. Thirteen nests of this species were reported during the second atlasing period of the Breeding Bird Atlas project, and nesting was confirmed in 288 survey blocks (Mollhoff, 2016). By comparison, there were 288 confirmed nesting blocks during the first survey (Mollhoff, 2001).

Comments: This familiar species hardly requires any descriptive comments. It is slowly becoming less numerous, as farms are declining in number, and as it is encountering competition from the house finch. Breeding Bird Surveys between 1966 and 2015 indicate that the species had a survey-wide population decline (1.61\% annually) during that period and an annual decline of $4.80 \%$ in $\mathrm{Ne}$ braska.

\section{Eurasian Tree Sparrow}

Passer montanus

Accidental. One individual was photographed at a feeder near Enola, February 1-4, 2007 (Nebraska Bird Review 75:118-120). The small range of this introduced species is currently mostly limited to southeastern Iowa, northeastern Missouri, and western Illinois.

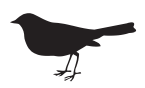

\section{Family Motacillidae (Pipits)}

\section{American Pipit}

Anthus rubescens

This Arctic- and alpine-breeding species is a common spring and fall migrant statewide and a rare winter resident. It is more abundant and much more conspicuous than the Sprague's pipit, and it occurs widely throughout the Plains states while on migration. The nearest breeding area of this species is in northern Manitoba.

Migration: The range of 125 initial spring sightings is from January 1 to May 21, with a median of April 23. Half of the records fall within the period April 13 to May 5. Eleven final spring sightings are from April 17 to May 23, with a median of April 28. Eighteen initial fall sightings are from August 24 to October 29, with a median of October 2. Sixteen final fall sightings are from September 14 to December 31, with a median of October 26. Probably overwintering is quite rare, judging from the limited number of late fall records.

Habitats: Migrating birds are found in open plains and fields and on bare shorelines. They generally favor moist to wet environments over dry ones.

Comments: Previously called the "water pipit," this species is rarely found far from water, whereas the Sprague's pipit is more adapted to upland habitats. Pipits are long-tailed and long-legged birds that nervously pump their tails up and down as they move about. 


\section{Sprague's Pipit}

Anthus spragueii

This grassland-adapted species is an uncommon spring and fall migrant, probably occurring statewide but with few records for the extreme western and eastern portions and most observations for central Nebraska (especially Webster and Adams counties). Breeding occurs in North Dakota and northern South Dakota, but migrants occur throughout the Plains states.

Migration: The range of 41 initial spring sightings is from March 17 to May 21, with a median of April 20. Half of the records fall within the period April 8-27. Five final spring sightings are from April 5 to May 23, with a mean of April 21. Seventeen initial fall sightings are from September 14 to October 19, with a median of September 26. Eleven final fall sightings are from October 2 to November 8, with a median of October 23.

Habitats: Associated with dense, grassy vegetation of plains and prairies, the Sprague's pipit-unlike the American pipit-is not often found in bare areas close to water. It also differs from that species in not usually moving in flocks, and it is thus more often overlooked.

Comments: This is one of Nebraska's least-seen regular migrants. Like that of other pipits, its territorial song is uttered in flight, and in this species the song is a high-pitched belllike whistling. Nationally the species has declined $75 \%$ since 1966 , based on annual Breeding Bird Survey data. Breeding Bird Surveys between 1966 and 2015 indicate the species had a survey-wide population decline (3.10\% annually) during that period.

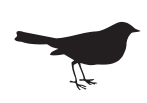

\section{Family Fringillidae \\ (Finches)}

\section{Brambling}

Fringilla montifringilla

Accidental. This Eurasian finch was initially photographed at Scottsbluff in April 1999 (Nebraska Bird Review 67:70, 68:8). The second state record was a male seen in Hall County, April 8, 2006, and the third was a female at a Lincoln County feeder that stayed from mid-December 2014 to January 31, 2015 (Nebraska Bird Review 83:19; Padelford \& Padelford, 2017). By 2017 four records had accrued; the fourth was a male photographed during January 2017 in Bellevue, Sarpy County.

\section{Gray-crowned Rosy-Finch}

Leucosticte tephrocotis

This species is a rare and irregular winter visitor to Nebraska, mainly in the Panhandle, especially Scotts Bluff National Monument, where up to 200 might be seen roosting in cliff swallow nests (Nebraska Bird Review 83:20). Outside of this region, the species has also been seen in Brown, Perkins, and Gage counties. It is a winter visitor in Colorado and a sporadic visitor to the Black Hills.

Migration: Six fall sightings range from October 1 to November 6, with a median of October 25. Thirteen spring sightings are from January 1 to March 11, with a median of February 12.

Habitats: During winter this spe- 
cies is usually found on open plains, fields, and weedy areas.

Comments: This is an alpine-nesting bird that descends to foothills and plains during winter and sometimes reaches western Nebraska. The nearest breeding area is in northwestern Montana.

\section{Black Rosy-Finch}

Leucosticte atrata

Accidental. Two sight records were from Sioux County in 2000 (Nebraska Bird Review 68:175), and there was a sighting of one or two in a flock of gray-crowned rosy-finches at Scotts Bluff National Monument in JanuaryFebruary 2013 (Nebraska Bird Review 81:19). The nearest breeding area of this alpine species is in northwestern wyoming.

\section{Pine Grosbeak}

Pinicola enucleator

This species is a rare and irregular winter visitor to Nebraska, with vagrants appearing at various places in the state, but with few recent records. It had been reported from Douglas, Lancaster, Hall, Brown, Madison, and Antelope counties in earlier years (Bruner, Wolcott, \& Swenk, 1904).

Migration: Fourteen initial fall sightings range from October 21 to December 31, with a median of November 24. Thirteen final spring sightings are from January 15 to May 22, with a median of March 10. There is no clustering of fall or spring records.

Habitats: During the winter this species is normally associated with seed-bearing trees, including both coniferous and deciduous species.

Comments: Like many of the other finches, the pine grosbeak is an irruptive species, with winter movements related to changes in food supplies. The nearest breeding area of this pine-dependent species is in northwestern Wyoming.

\section{House Finch}

Haemorhous mexicanus

This species is a locally common permanent resident in both western and eastern Nebraska, as a result of a rapid immigration into the state (mainly through cities) from both directions during recent decades. During the early atlasing years the species bred east to Hall and Adams counties (Mollhoff, 2001). The entire state is now effectively occupied.

Habitats: Associated with open woods, riverbottom thickets, scrubby vegetation, ranchlands, and (in $\mathrm{Ne}$ braska) suburbs and towns. Sixteen nests of this species were reported during the second atlasing period of the Breeding Bird Atlas project, and nesting was confirmed in 38 survey blocks (Mollhoff, 2016). By comparison there were confirmed nestings in 17 blocks during the first survey (Mollhoff, 2001).

Comments: House finches arrived in eastern Nebraska in the late 1980s from western Iowa, and at the present rate should encounter their western relatives in only a few years, probably along the Platte River. The entire eastern population derives from a few birds released in New York City in the 1940s, when commercial pet dealers dumped their illegally captive birds in order to escape arrest and prosecution. Breeding Bird Surveys between 1966 and 2015 indicate the species collec- 
tively underwent a survey-wide population increase (0.12\% annually) during that period, and Nebraska had a statistically questionable estimate of a 9.88\% rate of annual increase, although their rate of expansion in Nebraska during the 1990 s was certainly notable.

\section{Purple Finch}

\section{Haemorhous purpureus}

This species is an uncommon migrant and winter visitor in eastern Nebraska and the Pine Ridge region; it is rare elsewhere in the state. Breeding occurs in northern Minnesota. During the winter the species is rather widespread in northern and eastern North America.

Migration: Thirty-seven initial fall sightings range from August 14 to December 26 , with a median of October 27. Half of the records fall within the period October 15 to November 6 . Forty-nine final spring sightings are from January 2 to June 5, with a median of April 23. Half of the records fall within the period April 16 to May 8.

Habitats: Nonbreeding birds are associated with woodland streams and sometimes also appear at bird feeders during winter, wherever very small seeds suitable for finches are available.

Comments: This irregular winter visitor strongly resembles the house finch, and birders must look closely to determine the distinctions between them. Females have a more contrasting face pattern than do female house finches, and among purple finch males the raspberry red color extends down the entire back and rump area. The Cassin's finch is even more similar to the purple finch but is much rarer in Nebraska. Breeding Bird Surveys between 1966 and 2015 indicate that the species collectively underwent a survey-wide population decline of $1.73 \%$ annually during that period.

\section{Cassin's Finch}

\section{Haemorhous cassinii}

This species is a rare migrant and winter visitor in the Panhandle, but it has also been repeatedly observed in Logan County and rarely in Boone, Adams, and Webster counties. It is also a winter visitor to eastern Colorado and western Oklahoma but is rare or absent elsewhere in the Plains states. Possible breeding has been suggested in the Panhandle (Nebraska Bird Review 79:135), but there are no specific records yet, and the nearest breeding is in the Black Hills.

Migration: The only fall records are for October 26 and 27. Thirteen winter and spring records range from January 1 to May 14, with a median of April 12. Half of the records fall between March 30 and May 3. Kansas records are nearly all from September 22 to April 28 but mainly extend from October to March (Thompson et al., 211).

Habitats: Normally associated with open coniferous forests during winter, this finch usually forages on the ground for seeds. No nests of this species were reported during the second atlasing period of the Breeding Bird Atlas project, but a probable nesting was confirmed in one survey block of Dundy County (Mollhoff, 2016).

Comments: Compared to the very similar purple finch, males of this species have only the crown area bright red, and females have a less contrasting facial pattern and narrower breast striping. Breeding Bird Surveys be- 
tween 1966 and 2015 indicate that the species collectively underwent a survey-wide population decline of $2.5 \%$ annually during that period.

\section{Red Crossbill}

\section{Loxia curvirostra}

This species is an irregular winter visitor and migrant throughout $\mathrm{Ne}$ braska, probably most common in the Panhandle, and a local but regular breeder in the Pine Ridge region (Nebraska Bird Review 40:71). It has also bred in Scotts Bluff, Banner, and Holt counties (Mollhoff, 2001). Breeding is regular in South Dakota and Minnesota, and erratic in North Dakota. During winter the species occurs south to Texas.

Migration: Thirty-one initial fall sightings range from July 26 to December 29, with a median of November 12. Half of the records fall within the period October 28 to December 14 . Forty-four final spring sightings are from January 1 to June 2, with a median of April 1. Half of the records fall within the period March 19 to May 19.

Habitats: During the breeding season this species is primarily associated with coniferous forests. Migrants and wintering birds are also largely confined to conifer plantings or forests, but sometimes flocks also may be found foraging in stands of sunflowers or ragweeds. No nests of this species were reported during the second atlasing period of the Breeding Bird Atlas project, but nesting was confirmed in five survey blocks of Dawes, Sheridan, Scotts Bluff, and Morrill counties (Mollhoff, 2016). By comparison there were confirmed nestings in four blocks of Sioux, Scotts Bluff, Banner, and Holt counties during the first survey (Mollhoff, 2001).

Comments: Red crossbills periodically appear in eastern Nebraska, especially around coniferous plantations, where they can pry seeds out of cones using their uniquely crossed beak tips, which can be twisted screwdriver-like to pry apart the seed-containing bracts. Different populations around the species' range vary in beak shape and flight and alarm calls, suggesting that there may be several populations that possibly are best considered as subspecies (Faulkner, 2012). The "Type 2" call is most common is Nebraska (benti), and these birds are adapted to feeding on the seeds of ponderosa pine (Nebraska Bird Review 78:62, 81:20). Breeding Bird Surveys between 1966 and 2015 indicate that the species collectively underwent a survey-wide population decline (0.83\% annually) during that period.

\section{White-winged Crossbill}

\section{Loxia leucoptera}

This species is a rare and irregular winter visitor and spring migrant, mostly in eastern Nebraska. Most records are from Douglas-Sarpy, Lancaster, and Adams counties, but the species has been seen as far west as Scotts Bluff County. There was an incursion into the state in the winter of 2011-12, with up to 25 seen locally (Nebraska Bird Review 80:71) Known breeding is limited to northern Minnesota, but during winter the species appears south as far as Kansas and rarely to Oklahoma.

Migration: Three fall records are from October 16 to November 24 . 
Twenty-two spring sightings range from January 1 to June 14 , with a median of March 6. Half of the records fall within the period February 4 to April 20.

Habitats: In our region this crossbill is associated with coniferous forests or plantations, especially pines, throughout the year.

Comments: The white-winged crossbill is another irruptive winter finch, feeding in the same manner as the red crossbill. Like other fringilline finches, the young are fed on regurgitated seeds; thus the birds can begin nesting at almost any time of the year, especially after a bumper crop of conifer seeds has matured. The nearest breeding area of this species is in central Manitoba.

\section{Common Redpoll}

\section{Acanthis flammea}

This species is an occasional winter visitor statewide-locally common in some winters but absent in others. It is generally widespread through the Plains states as a migrant or a winter visitor.

Migration: Twenty initial fall sightings range from August 8 to December 30, with a median of November 26 . Thirty final spring sightings are from January 10 to May 30, with a median of March 17. Half of the records fall within March 7-26.

Habitats: While in Nebraska this species is associated with conifers, deciduous thickets, and weedy fields. It sometimes visits bird feeders.

Comments: Like most other fringilline finches, this species has a rather short notched tail and red in the head region, specifically on the forehead in the case of the redpoll. Another finch trait is a high degree of sociality, sometimes even during the breeding season. The nearest breeding area of this species is in northern Manitoba.

\section{Hoary Redpoll}

Acanthis hornemanni

This species is an extremely rare winter visitor to Nebraska. Redpolls assigned to this taxonomically dubious species have been observed in Lancaster, Custer, Scotts Bluff, and Sarpy counties, but intergrades or hybrids with common redpolls also occur and confuse identification (Nebraska Bird Review 40:85, 44:35). Recent (2015) genetic research published in the journal Molecular Ecology indicates that the two forms vary only slightly genetically and should be treated as a single species.

Migration: As of 2013 there were ten fairly recent reports, all but one in January and February (Nebraska Bird Review 81:20). The bird is rare in South Dakota and not reported for Kansas or Oklahoma.

Habitats: The hoary redpoll is usually found in the same habitats as, and in company with, common redpolls. The nearest breeding area of this species is in high-Arctic northeastern Canada.

\section{Pine Siskin}

Spinus pinus

This species is an irregular but sometimes common migrant and winter visitor statewide and an occasional summer resident throughout. Regular breeding is limited to the Pine Ridge region, but sporadic nestings have occurred widely in the state, including 
several eastern and southeastern counties following cold springs (Wilson Bulletin 41:77). It regularly breeds in western South Dakota and Minnesota, and is an erratic breeder in eastern South Dakota, North Dakota, and Kansas. It also occurs widely through the Plains states during migration or winter.

Migration: Sixty initial fall sightings range from July 25 to December 31 , with a median of October 16 . Half of the records fall within the period October 1 to November 18 . Thirty-five final springs sightings range from January 19 to June 9, with a median of May 12. Half of the records fall within the period May 8 to June 1 . No nests of this species were reported during the second atlasing period of the Breeding Bird Atlas project, but nesting was confirmed in four survey blocks from Sioux County east to Thomas, Lincoln, and Dawson counties (Mollhoff, 2016). By comparison there were confirmed nestings in five blocks during the first survey (Mollhoff, 2001).

Habitats: Nonbreeding birds occur in both wooded and treeless regions, often feeding in small flocks on weed seeds. Breeding occurs in both conifers and deciduous trees (including evergreen plantings), ornamental shrubs such as lilacs, and vines in a diversity of rural to suburban or urban locations.

Comments: This goldfinch-sized species may be very common at a locality one year and absent the next, in an unpredictable manner. Like the goldfinch, it has yellow present on its body plumage, but in this case the yellow is mainly located near the bases of the flight feathers, while the breast is heavily streaked. Breeding Bird Sur- veys between 1966 and 2015 indicate that the species had a survey-wide population decline (3.67\% annually) in that period.

\section{Lesser Goldfinch}

Spinus psaltria

This bird is a local but increasingly summering southwestern species in the Panhandle. As of the early 2ooos, only a total of nine state records existed (Nebraska Bird Review 68:126), but since then the species has become regular in western Nebraska, with 45 banded at the Wildcat Hills Nature Center in the fall of 2011 (Nebraska Bird Review 76:154, 79:135). The first known probable state breeding was in Banner County, June 19, 2010 ( Nebraska Bird Review 78:103).

Migration: Normally only a summer species, arriving in late May, there are two winter records from Cass County (December-January) and Scottsbluff (February) (Nebraska Bird Review 85:18, 74).

Habitats: No nests of the lesser goldfinch were reported during the second atlasing period of the Breeding Bird Atlas project, but nesting was confirmed in two blocks of Scotts Bluff and Banner counties (Mollhoff, 2016).

\section{American Goldfinch}

\section{Spinus tristis}

This species is a common permanent resident statewide. Winter populations vary from year to year. Breeding occurs almost throughout the Plains states, except the southernmost regions.

Habitats: During the fall and winter, flocks of this species may often be found foraging in fields of tall weeds such as ragweeds and sunflowers. 
Breeding usually occurs in rather open grazing country, farmyards, swamps, weedy fields, and other open habitats where thistles and cattails (the down of which is used for nest lining and the seeds for feeding the young) are abundant. Seven nests of this species were reported during the second atlasing period of the Breeding Bird Atlas project, and nesting was confirmed in 29 survey blocks (Mollhoff, 2016). Similarly there were confirmed nestings in 29 blocks during the first survey (Mollhoff, 2001).

Comments: Sometimes called "wild canaries" or "thistle-birds," American goldfinches delay their breeding until the latter part of summer, when thistle down (with which they line their nests) and thistle seeds (which they feed their young) are available in quantity. Breeding Bird Surveys between 1966 and 2015 indicate the species collectively underwent a survey-wide population decline (0.17\% annually) during that period, whereas Nebraska had a statistically reliable estimate (based on 51 survey routes) of a $1.63 \%$ rate of annual increase.

\section{Evening Grosbeak}

Coccothraustes vespertinus

This species is an irregular and rare winter visitor, reported from the entire state but seen most often in the Panhandle. Local breeding occurs in the Black Hills and in northern Minnesota, but during winter the species is widespread in northern regions of the Great Plains.

Migration: Thirty-four initial fall sightings are from September 3 to December 31 , with a median of November 9. Half of the records fall within the period October 19 to November 29. Fifty-two final spring sightings are from January 5 to May 28, with a median of April 25. Half of the records fall within the period April 21 to May 20.

Habitats: While in Nebraska this species is usually associated with streamside woodlands having seedbearing deciduous trees, and it sometimes also appears at bird-feeding stations.

Comments: This large, massivebilled finch is especially fond of sunflower seeds and can easily crack any hard seeds that it encounters. Its bright yellow eyebrows and white wing-patches make identification easy. Breeding Bird Surveys between 1966 and 2015 indicate that the species collectively underwent a surveywide population decline of $6.36 \%$ annually during that period. The nearest breeding area of this species is in the Black Hills, where it is rare.

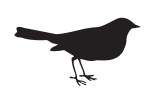

\section{Family Calcariidae (Longspurs and Snow Buntings)}

\section{Lapland Longspur}

Calcarius lapponicus

This species is a locally common migrant and winter visitor statewide and probably the commonest of the longspurs in Nebraska during winter. It occurs as a migrant or winter visitor nearly throughout the Plains region but is rarer southwardly. 
Migration: Fifty-six initial fall sightings are from September 25 to December 31, with a median of November 12. Half of the records fall within the period October 25 to November 21. Forty-four final spring records are from January 3 to May 10, with a median of February 27. Half of the records fall within the period February 24 to March 23.

Habitats: Migrants and wintering birds occur in open, grassy plains, stubble fields, overgrazed pastures, and similar grassy or low-stature habitats.

Comments: One should look for Lapland longspurs in open fields that are at least partly snow-free, or along the sides of gravel roads that also are free of snow. There flocks of longspurs may mingle with horned larks, trying to find small seeds on which to survive the winter. The nearest breeding area of this species is in northern Manitoba.

\section{Chestnut-collared Longspur \\ Calcarius ornatus}

This species is a migrant and winter visitor over most of Nebraska, ranging from common in the north to occasional in the eastern part of the state, and a summer resident in the northwestern corner, from southern Sioux and Box Butte counties east to Sheridan County and perhaps northern Cherry County, and also south to western Kimball County. It also breeds in the Dakotas and western Minnesota and occurs throughout the region as a migrant or winter visitor.

Migration: Thirty initial spring sightings in northwestern Nebraska are from March 18 to June 3, with a median of April 12. Sixteen final fall sightings are from September 22 to October 22, with a median of October 8. Like that of the McCown's longspur, the migration pattern of this species is extremely difficult to estimate in Nebraska because in various regions it may be a summer resident, a spring and fall migrant, or a winter visitor.

Habitats: Migrants and wintering birds occur on open plains and grassy fields, including those at airports. Breeding usually occurs on short-grass or cut mixed-grass prairies, and less frequently in the low meadow zones around ponds or disturbed grasslands such as grazed pasture lands. Three nests of this species were reported during the second atlasing period of the Breeding Bird Atlas project, and nesting was confirmed in two Sioux County survey blocks (Mollhoff, 2016). By comparison there were no confirmed nestings during the first survey (Mollhoff, 2001).

Comments: Although the chestnutcollared longspur breeds in some of the same regions as McCown's longspur, that species is predominantly white on its underparts, and displaying males have a much different visual aspect when displaying overhead. Also, the McCown's song is an extended rattle and is quite different from the chestnut-collared's double-syllable kettle note. Breeding Bird Surveys between 1966 and 2015 indicate that the chestnut-collared species collectively underwent a survey-wide population decline (4.19\% annually) during that period. 


\section{Smith's Longspur}

Calcarius pictus

This species is a rare to occasional migrant and winter visitor, mainly in east to central Nebraska, with the largest number of records from Adams and Webster counties. It has been reported east to Lancaster County and west to Sioux and Scotts Bluff counties. It is also a local migrant or winter resident in the Dakotas, Kansas, and Oklahoma but is rare or absent from Colorado and New Mexico.

Migration: Ten fall sightings range from September 18 to December 17, with a median of November 5. Six spring records are from February 5 to May 22, with a mean of April 8. As of 2013 there were only about 20 accepted spring records, all from March 21 to May 3 (Nebraska Bird Review 81:70).

Habitats: Migrants are associated with open grassy plains and pastures, and even airports, preferring those covered by thick, short grass.

Comments: Smith's longspur is another wintering longspur, which is more uniformly brown than the others, at least during the season that these birds are present in Nebraska. The nearest breeding area of this species is in northern Manitoba.

\section{McCown's Longspur}

Rhynchophanes mccownii

This species is a migrant and winter visitor over most of Nebraska, common to uncommon in the west, becoming rarer eastwardly but occasionally seen in eastern counties. It is a summer resident in the Panhandle, from central Sioux County west to the Wyoming line and south to western
Kimball County. Breeding also occurs in western North Dakota and eastern Colorado, and migrants are regular in western portions of the entire region.

Migration: Twenty-six initial spring sightings in northwestern Nebraska are from March 16 to May 21, with a median of April 3. Six final fall sightings are from September 5 to November 26, with a mean of October 1. Elsewhere in the state this species is a spring and fall migrant, and sometimes a winter visitor, so its migration status statewide is impossible to summarize easily.

Habitats: Migrants inhabit shortgrass plains, pasture lands, and plowed fields. Breeding occurs in short-grass and mixed-grass prairies, stubble fields, and newly sprouted grain fields. Seven nests of this species were reported during the second atlasing period of the Breeding Bird Atlas project, and nesting was confirmed in one Sioux County survey block (Mollhoff, 2016). By comparison there were confirmed nestings in five blocks of Sioux and Kimball counties during the first survey (Mollhoff, 2001).

Comments: McCown's longspur is one of Nebraska's two breeding longspur species. Both have distinctive white tail markings that are evident only during flight, and both have song-flight displays performed above the male's breeding territory. In the chestnut-collared species the dark underparts are highly visible during such aerial display; the birds resemble giant blackish butterflies as they hover above the ground in full song. Breeding Bird Surveys between 1966 and 2015 indicate that the McCown's 

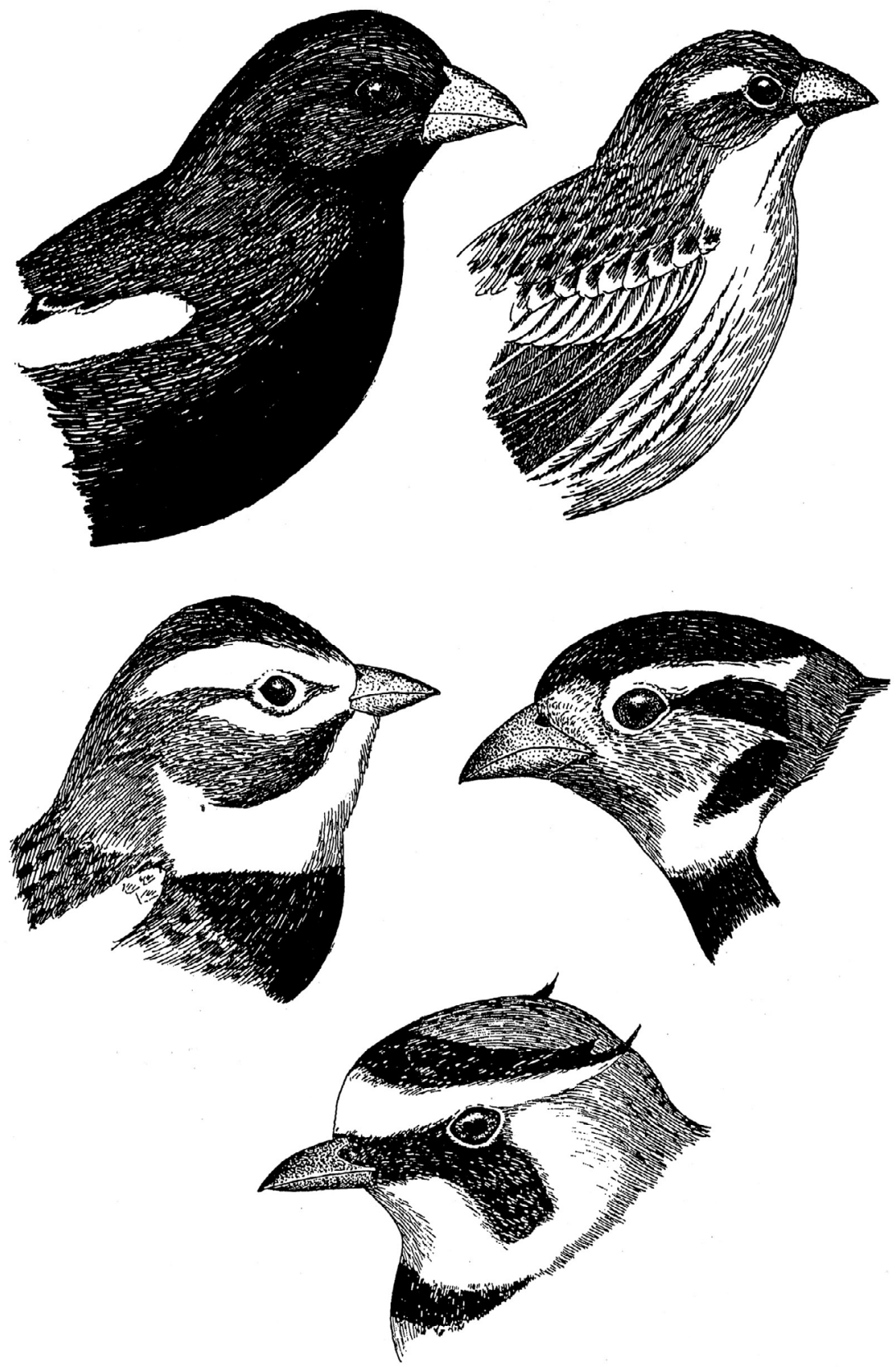

Figure 12. Grassland songbirds: lark bunting pair (top), male McCown's longspur (middle left), male chestnut-collared longspur (middle right), and adult horned lark (bottom) 
species collectively underwent a survey-wide population decrease $(5.9 \%$ annually) during that period.

\section{Snow Bunting}

Plectrophenax nivalis

This species is a rare to occasional winter visitor to Nebraska, appearing only very irregularly and probably mainly in northern counties. It is a regular winter visitor in the Dakotas but is rare or absent south of $\mathrm{Ne}$ braska.

Migration: Eleven initial fall sightings are from October 19 to December 24 , with a median of November 16. Thirty-one final spring sightings are from January 1 to March 23, with a median of February 10.

Habitats: Migrants and wintering birds are associated with open plains and snow-covered fields.

Comments: This mostly white sparrow-like bird is appropriately colored for the Arctic, but it tends to be conspicuous on bare plowed fields in the Great Plains. It only infrequently migrates south of the winter snow line. The nearest breeding area of this species is in Nunavut.

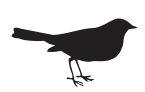

\section{Family Emberizidae (Sparrows)}

\section{Green-tailed Towhee}

Pipilo chlorurus

This species is an uncommon but regular spring and fall migrant in west- ern Nebraska, mostly in the Panhandle, and is rarely recorded east to McPherson, Logan, and Lancaster counties. Breeding is limited in the Great Plains region to sage-dominated regions of New Mexico, Colorado, and Wyoming, but migrants are regular from eastern Colorado to the Texas Panhandle.

Migration: Nineteen initial spring sightings range from February 18 to May 31, with a median of May 10. Half of the records fall within the period May 3-20. Three final fall sightings are from September 6 to 29 .

Habitats: Migrants are associated with thickets and dense shrubbery in rather arid environments, including sagebrush-covered plains.

Comments: The green-tailed towhee is a rather dull-colored bird, except for its bright brown crown, being mostly olive-green on the tail and upperparts and grayish below.

\section{Spotted Towhee}

Pipilo maculatus

Collectively, the eastern and spotted towhees are common spring and fall migrants and summer residents in Nebraska. Local breeding by towhees occurs west to Colorado in the Platte and Republican Valleys and to Sioux County in the White River and Niobrara Valleys. Breeding is very local in the Sandhills but extends from the Colorado and Wyoming borders (mainly maculatus phenotypes) east in the Platte Valley, where the population is composed of mainly erythropthalmus phenotypes in northeastern and southeastern Nebraska. Many of the summering birds along the Platte and North Platte Rivers are apparent 
hybrids (Sibley, Short, \& West, 1959; Brown et al., 1996). Breeding by relatively typical erythropthalmus phenotypes occurs from Manitoba and northeastern North Dakota (Turtle Mountains) south to eastern Kansas and northeastern Oklahoma. Predominantly maculatus phenotypes breed from the Missouri Valley of the western and central Dakotas south to the Nebraska Panhandle and central Niobrara Valley, northeastern Colorado, and south into New Mexico. Migrants occur throughout the region.

Migration: Sixty-nine initial spring sightings range from February 7 to May 30, with a median of April 22. Half of the records fall within the period April 10-30. Ninety-three final fall records are from July 24 to December 31, with a median of October 15. Half of the records fall within the period September 30 to October 31. Nearly $20 \%$ of the records are for December, suggesting that overwintering is fairly frequent.

Habitats: While in Nebraska these towhees occur in brushy fields, thickets, woodland edges or openings, second-growth forests, and city parks or suburbs with trees and tall shrubbery. Three spotted towhee nests were reported during the second atlasing period of the Breeding Bird Atlas project, and nesting was confirmed in eight survey blocks east to Rock County. Two eastern towhee nests were reported during the second atlasing period of the Breeding Bird Atlas project, and nesting was confirmed in nine survey blocks west to Hitchcock County (Mollhoff, 2016). By comparison there were confirmed nestings for all Nebraska towhees in 16 blocks during the first survey, which occurred west of the 98th meridian. Most eastern towhees breed east of a line from Cedar, Platte, Hall, and Harlan counties.

Comments: It seems likely that the nomenclature committee of the American Ornithologists' Society will eventually have to reverse itself and again merge these two "species" of towhees, which collectively were once known as the red-eyed towhee before their hybridization rates and distributions were studied in the Platte Valley (Sibley, Short, \& West, 1959). The zone of hybridization is especially wide in Nebraska; farther south in Kansas there is a geographic break between breeding habitats of the two taxa that make the situation there less confusing. Breeding Bird Surveys between 1966 and 2015 indicate that the species collectively underwent a survey-wide population decline (0.03\% annually) during that period, and $\mathrm{Ne}$ braska had a statistically doubtful estimate (based on 12 survey routes) of a 3.83\% rate of annual increase (Mollhoff, 2016).

\section{Eastern Towhee}

Pipilo erythropthalmus

See the spotted towhee account. Phenotypically "pure" eastern towhees can be found west to Dawson County, but most birds there are spotted or hybrids (Sibley, Short, \& West, 1959; Nebraska Bird Review 73:16-18). Unlike the spotted towhee, the eastern towhee rarely winters in Nebraska, except in the extreme southeast. Two eastern towhee nests were reported during the second atlasing period of the Breeding Bird Atlas project, and nesting was confirmed in nine survey blocks west 
to Hitchcock County (Mollhoff, 2016). Breeding Bird Surveys between 1966 and 2015 indicate that the eastern towhee underwent a survey-wide population decline (1.34\% annually) during that period, and Nebraska had a statistically questionable estimate (based on 21 survey routes) of a $0.93 \%$ rate of annual increase.

\section{(Canyon Towhee)}

Melozone fusca

Hypothetical. One individual of this southwestern species was reported in Scotts Bluff County in September 1975 (Nebraska Bird Review 44:30). The record was not accepted by the NOU Records Committee (1997). It is a permanent resident in northwestern Oklahoma and is casual in southwestern Kansas.

\section{Cassin's Sparrow}

Peucaea cassinii

This southwestern sparrow is a rare or irregular spring and fall migrant and summer resident in southwestern Nebraska. The species has been reported from a number of counties, but actual breeding records exist only for Perkins and Dundy counties (Nebraska Bird Review 42:56, 47:14). Singing males have been seen in Keith and Garden counties (Brown et al., 1996), and probable breeding has occurred near Kilpatrick Lake, Box Butte County (Birding 26:416). The species is apparently irruptive, moving north to breed periodically but normally restricted to the southern and western portions of the Plains region (American Birds 31:133). In 2011 a major influx arrived in Nebraska during a drought in the Southwest (Nebraska Bird Review
78:96). No nests of Cassin's sparrow were reported during the second atlasing period of the Breeding Bird Atlas project, but nesting was confirmed in one Sioux County survey block (Mollhoff, 2016). There were no confirmed nestings during the first survey (Mollhoff, 2001).

\section{American Tree Sparrow}

Spizelloides arborea

This sparrow is a common migrant and winter visitor statewide. It is widespread throughout the entire Plains Region during winter and on migration.

Migration: The range of 127 initial fall sightings is from September 3 to December 31, with a median of October 21. Half of the records fall within the period October 12 to November 2 . Sixty-five final spring sightings range from January 24 to May 27, with a median of April 6. Half of the records fall within the period March 27 to April 22.

Habitats: During migration and winter periods this species is found in flocks among thickets, brushy areas, and shrubby or weedy grasslands.

Comments: Tree sparrows are attractive winter residents in Nebraska; these tiny birds seem to thrive under bitterly cold conditions so long as sufficient food is available and the snow cover is not too great. The nearest breeding area of this species is in northern Manitoba.

\section{Chipping Sparrow}

Spizella passerina

This sparrow is a common spring and fall migrant statewide and a common summer resident in all parts of $\mathrm{Ne}$ - 
braska except possibly for the Republican River valley. It breeds widely in the Plains, from North Dakota south to Colorado and eastern Oklahoma, and winters throughout the remainder of the region.

Migration: The range of 100 initial spring sightings is from January 14 to June 3, with a median of April 23. Half of the records fall within the period April 6 to May 2. Ninety-nine final fall records range from July 23 to December 20, with a median of October 2 . Half of the records fall within the period September 17 to October 16 .

Habitats: While in Nebraska this species is associated with the margins of deciduous forests, parks, gardens, residential areas, farmsteads, orchards, and other open areas with nearby or scattered trees and few or no shrubs. Eleven nests of this species were reported during the second atlasing period of the Breeding Bird Atlas project, and nesting was confirmed in 85 survey blocks (Mollhoff, 2016). By comparison there were confirmed nestings in 50 blocks during the first survey (Mollhoff, 2001).

Comments: The sewing-machinelike trill of these birds is a certain sign of spring in Nebraska; they appear with the first warblers and the leafing out of the trees. Courtship or rival chases among competing males are common then, and the birds lend an air of excitement and optimism to the days of early spring. Breeding Bird Surveys between 1966 and 2015 indicate the species collectively underwent a survey-wide population decline (0.6\% annually) during that period versus a statistically slightly questionable estimate (based on 44 survey routes) of a $5.3 \%$ rate of annual increase in Nebraska.

\section{Clay-colored Sparrow}

Spizella pallida

This sparrow is a common spring and fall migrant, and an apparently accidental summer resident in Nebraska, with a record from Hall County in 1973 as the only definite breeding report (Nebraska Bird Review 42:9). Probably the species nests locally in northern counties, since it regularly breeds in South Dakota. It also breeds in North Dakota and Minnesota, and appears throughout the rest of the region on migrations.

Migration: The range of 124 initial spring sightings is from March 3 to May 29, with a median of May 3. Half of the records fall within the period April 28 to May 8. Eighty-nine final spring sightings range from April 24 to June 1, with a median of May 16. Forty-one initial fall sightings are from July 23 to November 2, with a median of September 9. Half of the records fall within the period August 30 to September 18. Thirty-nine final fall sightings are from August 27 to December 18, with a median of October 8.

Habitats: Migrants occur in thickets and weed patches among grassland. Breeding birds move to similar habitats, which provide a mixture of medium-stature grasses and scattered shrubs or low trees, or to disturbed lands such as cutover or burned woodlands.

Comments: Although rather plain in color, the species' strongly striped head and distinctive gray half-collar makes identifying this species easy. Its slow, buzzy song is rather insect- 
like and much lower in pitch than the chipping sparrow's. Breeding Bird Surveys between 1966 and 2015 indicate that the species collectively underwent a survey-wide population decrease (1.14\% annually) during that period.

\section{Brewer's Sparrow}

Spizella breweri

This sparrow is a common spring and fall migrant in western Nebraska, and a local summer resident in the western Panhandle from Sioux County south to Dundy County and east to western Box Butte County. An extralimital breeding record also exists for Howard County (Nebraska Bird Review 41:8). Breeding in the Great Plains region is mostly limited to the western parts of the Dakotas, south locally to western Nebraska.

Migration: Twenty-seven initial spring sightings range from April 18 to May 21, with a median of May 5. Half of the records fall within the period April 29 to May 12. Fifteen final fall records range from August 18 to October 12, with a median of September 7 .

Habitats: The Brewer's sparrow in Nebraska is associated with open scrublands, especially short-grass plains with sagebrush, rabbitbrush, or other semiarid shrubs. No nests of this species were reported during the second atlasing period of the Breeding Bird Atlas project, but nesting was confirmed in two Box Butte County and three Dundy County survey blocks (Mollhoff, 2016). There were no confirmed nestings during the first survey (Mollhoff, 2001).

Comments: This is a modestly plumaged sparrow that seems to fit in well with its usual sagebrush hab- itat. Another ecologically separated form nests at timberline in the western mountains; this "timberline sparrow" may eventually prove to be a separate species.

\section{Field Sparrow}

Spizella pusilla

This sparrow is a common spring and fall migrant and a locally common summer visitor almost statewide, excepting the Panhandle. Local nesting occurs at least as far west as the eastern end of Lake McConaughy, Keith County. Breeding occurs widely in the Plains states, excepting the drier southwestern regions and northern parts of Minnesota and North Dakota.

Migration: Eighty-one initial spring sightings range from February 11 to June 6, with a median of April 20. Half of the records fall within the period April 4 to May 6. Eighty-three final fall sightings are from August 1 to December 26, with a median of October 6. Half of the records fall within the period September 23 to October 25.

Habitats: During the breeding season this species occurs in brushy open woodlands, forest edges, brushy ravines or draws, sagebrush flats, abandoned hayfields, forest clearings, and similar open habitats having scattered shrubs or low trees. It is similar to the chipping sparrow in its habitat but depends more on shrubs and less on trees for nesting. Nine nests of this species were reported during the second atlasing period of the Breeding Bird Atlas project, and nesting was confirmed in 40 survey blocks (Mollhoff, 2016). By comparison there were confirmed nestings in 73 blocks during the first survey (Mollhoff, 2001). 
Comments: Field sparrows are among the dullest-colored of all grassland sparrows, but their song, a series of whistled notes that increase in pitch and frequency through the series, is unique. Breeding Bird Surveys between 1966 and 2015 indicate that the species collectively underwent a survey-wide population decline (2.33\% annually) during that period, and a Nebraska decline rate of $2.05 \%$ annually.

\section{Vesper Sparrow}

\section{Pooecetes gramineus}

This sparrow is a common spring and fall migrant statewide and a probable regular but local summer resident over most of the state, except that portion lying south of the Platte River. Breeding occurs from North Dakota and Minnesota south to Colorado and Missouri, and migrants are regular in southern portions of the Plains region.

Migration: Eighty initial spring sightings are from March 4 to May 24, with a median of April 18. Half of the records fall within the period April 13-27. Eighty-three final fall sightings range from August 13 to November 24, with a median of October 9. Half the records fall within the period September 26 to October 18 .

Habitats: Migrants and breeding birds frequent overgrown fields, prairie edges, and similar habitats where grasslands join or are mixed with shrubs and scattered low trees. Five nests of this species were reported during the second atlasing period of the Breeding Bird Atlas project, and nesting was confirmed in 16 survey blocks (Mollhoff, 2016). By comparison there were confirmed nestings in four blocks during the first survey (Mollhoff, 2001).

Comments: The well-named vesper sparrow has a sweet song somewhat like that of a song sparrow, but it usually has only two introductory or "grace" notes. Its white outer tail feathers and white eye-ring also help to separate it visually from song sparrows. Breeding Bird Surveys between 1966 and 2015 indicate that the species collectively underwent a survey-wide population decline ( $0.85 \%$ annually) during that period, whereas Nebraska had a statistically questionable estimate (based on 33 survey routes) of a $\mathbf{2 . 5 3} \%$ rate of annual increase.

\section{Lark Sparrow}

\section{Chondestes grammacus}

This sparrow is a common spring and fall migrant statewide and a common summer resident in grasslands throughout Nebraska, but especially in the Sandhills and Panhandle. Breeding occurs widely through the Plains states, except in the northeastern regions where the species is a migrant.

Migration: The range of 125 initial spring sightings is from April 5 to June 10 , with a median of May 5 . Half of the records fall within the period April 28 to May 13. Seventy-six final fall sightings range from July 23 to November 13, with a median of September 3. Half of the records fall within the period August 22 to September 18 .

Habitats: While in Nebraska, this species occupies natural grasslands or weedy fields that adjoin or include scattered trees, shrubs, and weeds. Twelve nests of this species were reported during the second atlasing pe- 
riod of the Breeding Bird Atlas project, and nesting was confirmed in 157 survey blocks (Mollhoff, 2016). By comparison there were confirmed nestings in 167 blocks during the first survey (Mollhoff, 2001).

Comments: The lark sparrow is among the most attractive of Nebraska's breeding sparrows. The complex chestnut head markings allow for easy recognition, which is also aided by the white markings on the corners of the tail. Its song is rather lark-like but always has a few buzzy phrases, as if the bird suddenly forgot what it was supposed to be singing and substituted buzzy insertions. Breeding Bird Surveys between 1966 and 2015 indicate that the species collectively underwent a survey-wide population decline (0.78\% annually) during that period.

\section{Black-throated Sparrow}

Amphispiza bilineata

Extremely rare. This southern sparrow was first reported from Sioux County in June 1972 and in Douglas County during the winter of 197374 (Nebraska Bird Review 40:72, 42:18). It was also observed May 26, 1984, near Keystone, Keith County (Rosche \& Johnsgard, 1984), and photographed near Wakefield, Dixon County, and in Lincoln, Lancaster County, in the winter and spring of 1993 (Nebraska Bird Review 64:33). One was banded on December 20, 1997, in Omaha (Nebraska Bird Review 65:179), where it remained until April. Another was seen in Antelope County, January 4, 1998 (Nebraska Bird Review 66:16). One seen at Creighton during December-January
2015-16 was the seventh Nebraska record (Nebraska Bird Review 84:20). South Dakota has a single record as do six Kansas counties (Thompson et al., 2011). The nearest breeding area of this species is southeastern Colorado and adjacent Oklahoma.

\section{Sagebrush Sparrow}

Artemisiospiza nevadensis

Accidental. Previously known as the sage sparrow (Amphispiza belli) until 2017, this Great Basin species was observed at Sowbelly Canyon, Sioux County, on August 6, 1989 (Nebraska Bird Review 58:27). The nearest breeding area is in eastern Wyoming.

\section{Lark Bunting}

Calamospiza melanocorys

This sparrow is a common spring and fall migrant and summer resident in western and central Nebraska, or generally west of a line from Boyd County to Nuckolls County, with sporadic breeding farther east, and rarely to northwestern Missouri (Wilson Bulletin 82:465). Breeding also occurs north to North Dakota and south to central Oklahoma and the Texas Panhandle.

Migration: The range of 104 initial spring sightings is from April 8 to June 10, with a median of May 10. Half of the records fall within the period May 4-16. Sixty-five final fall sightings are from July 20 to October 13 , with a median of August 30. Half of the records fall within the period $\mathrm{Au}$ gust 20 to September 8.

Habitats: While in Nebraska, this species is usually found in mixed short-grass prairie and sage-dominated areas, but it also occurs in areas 
of taller grasses with scattered shrubs and along weedy roadsides, in retired croplands, and in fields of alfalfa or clover. Outside the breeding season it is highly gregarious, and it is colonial even during the nesting period. One nest of this species was reported during the second atlasing period of the Breeding Bird Atlas project, and nesting was confirmed in 17 survey blocks east to Kearney County (Mollhoff, 2016). By comparison there were confirmed nestings in 28 blocks east to Clay County during the first survey (Mollhoff, 2001).

Comments: The lark bunting is a rather puzzling species as to its abundance in parts of western Nebraska, such as near Cedar Point Biological Station in Keith County. There it may be very common one year, only to be gone the following, and then return again some years later. Perhaps local precipitation or irrigation variations cause its periodic appearance and disappearance. Breeding Bird Surveys between 1966 and 2015 indicate the species collectively underwent a survey-wide population decline $(2.9 \%$ annually) during that period, and $\mathrm{Ne}$ braska had an estimated $1.85 \%$ rate of annual decline.

\section{Savannah Sparrow}

Passerculus sandwichensis

This sparrow is a common spring and fall migrant statewide and a rare or uncommon summer resident north and west of a line from Scotts Bluff County to the southeastern corner of South Dakota but mainly in the northern Panhandle region. Breeding in the Sandhills seems to be limited to the western and northern parts of this re- gion. The species also breeds throughout the Dakotas and Minnesota and occurs as a migrant in southern parts of the Plains states.

Migration: The range of 69 initial spring sightings is from March 17 to June 5, with a median of April 22. Half of the records fall within the period April 15-29. Thirty-eight final spring sightings are from April 10 to May 30, with a median of May 10. Thirty-nine initial fall sightings range from July 28 to October 9, with a median of September 19. Half of the records fall within the period September 5-28. Thirty-nine final fall sightings are from October 2 to November 22, with a median of October 19.

Habitats: Migrants are usually found in open grasslands, lightly grazed pastures, and brushy edges. Breeding occurs in wet-meadow zones of wetlands and in tall-grass to midgrass prairies. No nests of this species were reported during the second atlasing period of the Breeding Bird Atlas project, and no nesting was confirmed for any of the survey blocks for the species (Mollhoff, 2016).

Comments: Savannah sparrows seem to be poorly named because their breeding habitats certainly do not consist of savannah; however, the species was actually named after Savannah, Georgia. The birds in Nebraska usually have a yellowish area in front of the eyes (the lores), and the tail is much shorter than that of a song sparrow or vesper sparrow. Breeding Bird Surveys between 1966 and 2015 indicate that the species collectively underwent a survey-wide population decline (1.36\% annually) during that period. 


\section{Grasshopper Sparrow}

Ammodramus savannarum

This sparrow is a common spring and fall migrant and summer resident statewide. Breeding occurs widely in the Plains states, except in the southwestern regions where the species occurs as a migrant.

Migration: The range of 85 initial spring sightings is from March 14 to June 10, with a median of May 6 . Half of the records fall within the period April 27 to May 15. Sixty-seven final fall sightings range from July 26 to November 6, with a median of September 9. Half of the records fall within the period August 12 to September 29.

Habitats: Migrants and breeding birds occur in mixed-grass prairies, pasturelands, short-grass prairies, sage prairies, and to a limited extent in tall-grass prairies. Areas that have grown up to shrubs are avoided, but scattered trees in grassland are sometimes used for song perches. A total of 190 nests of this species were reported during the second atlasing period of the Breeding Bird Atlas project, and nesting was confirmed in 74 survey blocks (Mollhoff, 2016). By comparison there were confirmed nestings in 82 blocks during the first survey (Mollhoff, 2001).

Comments: Few grassland sparrows in Nebraska can be as common as the grasshopper sparrow, but it is so secretive that birders can be in the field all day without seeing a single one. Yet its grasshopper-like buzz may be evident almost everywhereand if a bird is seen, its rather large beak and striped head pattern is quite distinctive. The birds feed largely on grasshoppers during their time in Nebraska, which might help account for their strong beak. Breeding Bird Surveys between 1966 and 2015 indicate that the species collectively underwent a survey-wide population decline (2.52\% annually) during that period, and an estimated $1.91 \%$ rate of annual decline rate in Nebraska.

\section{Baird's Sparrow}

\section{Ammodramus bairdii}

This sparrow is an uncommon spring and fall migrant over most of $\mathrm{Ne}$ braska but probably is less common eastwardly and rare in the extreme eastern counties. Breeding occurs in North Dakota and northern South Dakota, and migrants appear throughout the western portions of the region. Probable breeding in Sioux County, Nebraska, occurred in 1996, when three territorial males were seen (Audubon Society Field Notes 50:967). A singing male was reported from Banner County in 1996 (Brogie, 1997), and three were found in Sioux County in 2010 (Nebraska Bird Review 78:59).

Migration: The range of 44 spring sightings is from March 24 to June 8, with a median of April 29. Half of the records fall within the period April 19 to May 5. Fifteen initial fall sightings are from July 26 to October 21, with a median of September 26. Fifteen final fall sightings are from September 10 to November 11, with a median of October 18. Half of the total fall sightings fall within the period September 23 to October 8.

Habitats: Migrants are associated with prairies and other natural grasslands. 
Comments: This is one of the least abundant but most attractive of the prairie endemic sparrows. It has been declining in recent years, presumably because of losses in prairie habitats. Breeding Bird Surveys between 1966 and 2015 indicate the species collectively underwent a survey-wide population decline (2.17\% annually) during that period.

\section{Henslow's Sparrow}

Ammodramus henslowii

This sparrow is a local spring and fall migrant and summer resident in southeastern Nebraska (Nebraska Bird Review 75:13-16, 53-6o, 116). Most records are for Adams and Webster counties, but the species has been seen west to Lincoln, Logan, and Keith counties. Breeding records extend west to Hall County, where the birds are common nesters at the Crane Trust (Nebraska Bird Review 75:84). It also breeds in southern Minnesota, western Iowa, and eastern Kansas, and it migrates through eastern Oklahoma.

Migration: Twenty-one initial spring sightings range from April 6 to May 29, with a median of April 29. Half of the records fall within the period April 25 to May 4. Thirteen final fall sightings are from August 5 to October 23, with a median of September 26.

Habitats: While in Nebraska, this species is found in weedy pastures and meadows, neglected grassy fields, and pasturelands, especially those that are low-lying and rather damp. Scattered low bushes are also often present in breeding habitats, providing song perches, but nesting is done on the ground. No nests of this species were reported during the second atlasing period of the Breeding Bird Atlas project, but nesting was confirmed in one Hall County survey block (Mollhoff, 2016). There were no confirmed nestings during the first survey (Mollhoff, 2001).

Comments: The development of the Conservation Reserve Program in southeastern Nebraska has evidently helped this rare resident. Henslow's sparrow seems to favor overgrown, weedy fields that result from letting land lie fallow for several years. However, nationally the species has declined by more than 90\% during the past several decades and may soon be a candidate for the endangered species list. Breeding Bird Surveys between 1966 and 2015 indicate that the species collectively underwent a survey-wide population decline $(1.53 \%$ annually) during that period.

\section{LeConte's Sparrow}

Ammodramus leconteii

This sparrow is an inconspicuous but regular and probably uncommon spring and fall migrant in eastern Nebraska, rare or absent westwardly. Breeding occurs in North Dakota and northern Minnesota, and migrants are found in the eastern portions of the Plains region.

Migration: Fifty-four initial spring sightings are from April 1 to June 7, with a median of April 29. Half of the records fall within the period April 21 to May 8. Thirteen final spring sightings are from April 17 to May 19, with a median of May 2. Twenty-one initial fall sightings are from July 25 to October 15, with a median of Septem- 

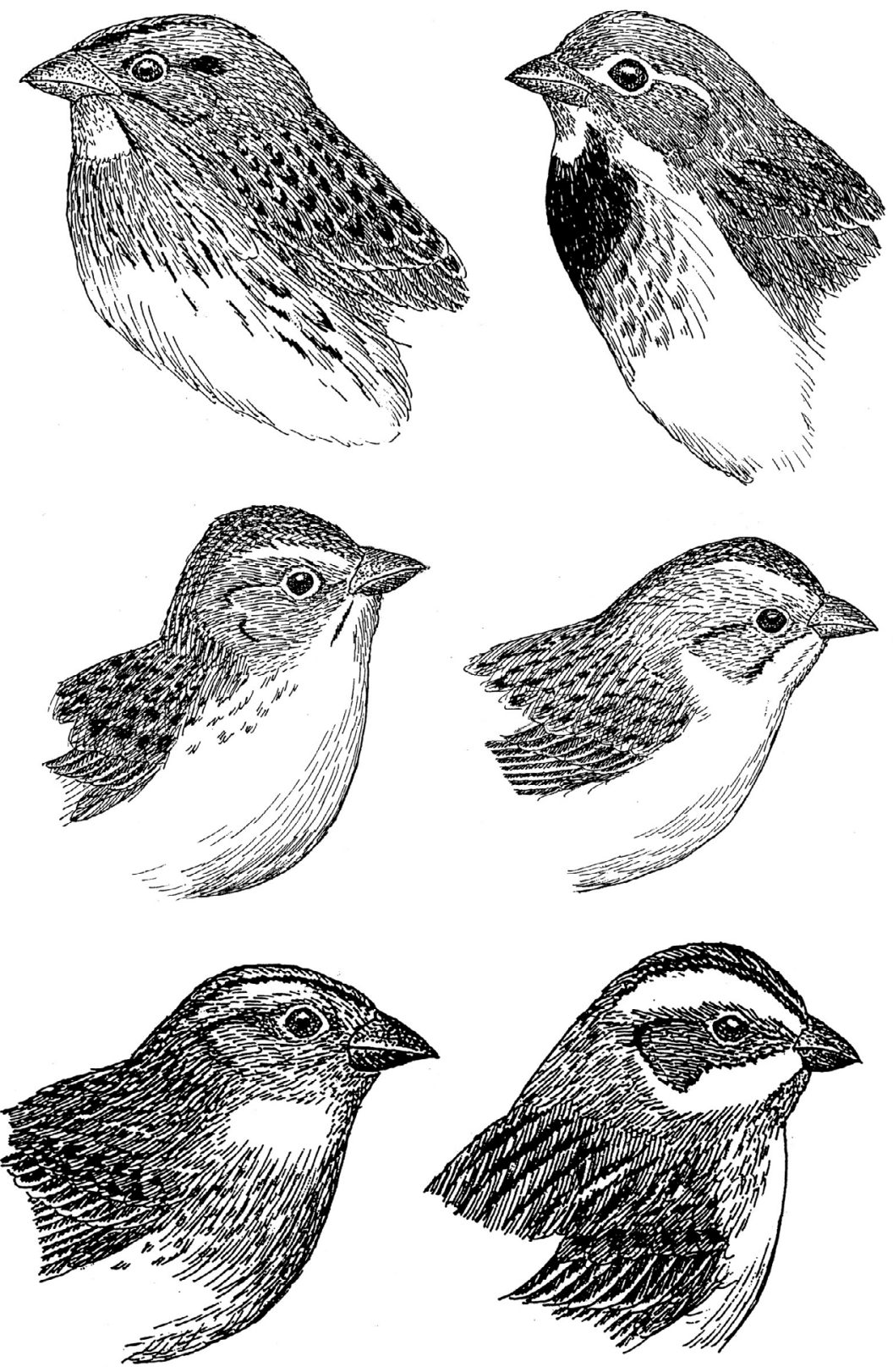

Figure 13. Grassland songbirds: Henslow's sparrow (top left), dickcissel (top right), Cassin's sparrow (middle left), Brewer's sparrow (middle right), grasshopper sparrow (bottom left), and clay-colored sparrow (bottom right) 
ber 22. Seventeen final fall sightings are from July 26 to November 9, with a median of October 20.

Habitats: Migrants are found in wet meadows and marshy edges with sedges, cattails, and deep grasses.

Comments: This bird is one of those hard-to-see sparrows that is highly memorable. On rare occasions, a LeConte's sparrow perches on the top of a marshy grass stem long enough to see and appreciate its rich golden eye-stripe and heavily striped head and back.

\section{Nelson's Sparrow}

Ammodramus nelsoni

This sparrow is an inconspicuous and seemingly rare spring and fall migrant in eastern Nebraska, with relatively few records available. Most of the sightings are from the eastern half of the state, but it has been seen west to Custer, Cherry, and Sheridan counties. It has been reported more often in Lancaster County than elsewhere in the state. Breeding occurs in North Dakota and adjacent areas, and migrants occur in eastern portions of the region.

Migration: Five spring sightings are from March 29 to May 30, with a mean of May 5. Three of the records are for the month of May. Nine fall records are from September 7 to October 21, with a mean of September 30. Five of the records are for the month of October.

Habitats: Migrants are found along the wet edges of marshes and sloughs, usually in even wetter habitats than those used by the LeConte's sparrow.

Comments: Perhaps even harder to see than the LeConte's sparrow, the Nelson's sparrow is also a bird of dense marshy vegetation. It is even more golden-tinted than the LeConte's but has a dark brown crown rather than a strongly striped one.

\section{Fox Sparrow}

Passerella iliaca

This sparrow is a spring and fall migrant statewide, ranging from common to uncommon in eastern areas to rare or very rare in western parts of the state. It also occurs throughout the Plains states as a migrant or wintering form, becoming vary rare westwardly.

Migration: Fifty-three initial spring sightings are from January 4 to June 4 , with a median of March 30. Half of the records fall within the period March 17 to April 18. Twenty-two final spring sightings are from April 1 to 23, with a median of April 10. Thirtyone initial fall records are from $\mathrm{Au}$ gust 2 to November 11, with a median of October 11. Half of the records fall within the period October 5-17. Twenty-eight final fall sightings are from August 18 to December 31, with a median of November 11 .

Habitats: Migrants are usually associated with brushy woodlands, streamside thickets, and sometimes residential shrubbery.

Comments: The fox sparrow is perfectly named; it has an overall foxbrown plumage cast, and it moves about secretively on the ground, usually in fairly dense cover, where it scratches towhee-like for food. It looks something like an oversized song sparrow, as its breast is patterned in a similar way, and its tail is fairly long. 


\section{Song Sparrow}

Melospiza melodia

This sparrow is a common spring and fall migrant and uncommon winter visitor statewide, and an uncommon summer resident. Breeding is probably limited mostly to the eastern parts of the state. Recent eastern records are for at least Antelope, Cuming, Boone, Polk, Platte, Colfax, Lancaster, Gage, and Nemaha counties, and others west to Buffalo, Hall, Valley, Phelps, and Webster counties. Breeding occurs from North Dakota and Minnesota southward to Colorado and northeastern Kansas, and migrants are regular to the south of these regions.

Migration: Forty-five initial spring sightings are from January 1 to June 6, with a median of April 8. Forty-five final spring sightings are from January 12 to June 3, with a median of April 30. Seventy-six initial fall sightings are from August 2 to November 2, with a median of September 30. Fortyfour final fall sightings are from October 6 to December 31, with a median of December 20. The data suggest that this species commonly overwinters in Nebraska and that its migration tendencies are very poorly defined.

Habitats: Migrants and wintering birds occur in weedy areas, thickets, and streamside woodland edges. Breeding occurs in similar habitats, including forest margins, shrubby swamps, the brushy edges of ponds, shelterbelts, and farmsteads. Three nests of this species were reported during the second atlasing period of the Breeding Bird Atlas project, and nesting was confirmed in 29 survey blocks west to Morrill County (Moll- hoff, 2016). By comparison there were confirmed nestings in 12 blocks during the first survey (Mollhoff, 2001).

Comments: One of the most appealing of Nebraska's native sparrows, the song sparrow's typical song begins something like Beethoven's third symphony, with three well-spaced introductory whistles, followed by a melodious phrase. This sparrow has a blotchy spot in the middle of its streaked breast, and it pumps its longish tail in flight. Breeding Bird Surveys between 1966 and 2015 indicate the species collectively underwent a survey-wide population decline (0.76\% annually) during that period versus a statistically questionable estimate (based on 16 survey routes) of a $5.76 \%$ rate of increase in Nebraska.

\section{Lincoln's Sparrow}

\section{Melospiza lincolnii}

This sparrow is a common spring and fall migrant statewide. It also occurs throughout the other Plains states as a migrant or wintering species.

Migration: Ninety-four initial spring sightings are from January 2 to May 29, with a median of April 26. Half of the records fall within the period April 19 to May 7. Sixty-two final spring sightings are from April 20 to May 31, with a median of May 13. Forty-eight initial fall sightings are from September 2 to October 12, with a median of September 15. Half of the records fall within the period September 7-17. Twenty-five final fall sightings are from September 20 to December 29, with a median of October 19.

Habitats: Migrants are associated with streamside thickets, thick weedy areas, and other rather dense grassy 
or weedy areas close to water, occurring less frequently in residential shrubbery.

Comments: The Lincoln's sparrow was not named in honor of Abraham Lincoln but rather by John James Audubon for his young field assistant, who thus certainly was one of the youngest persons ever to have a bird named after him. The grayish cheeks, supraorbital stripes, and hindneck of this species help to identify it, as does a soft grayish buff breast-band. The nearest breeding area of this species is in Wyoming's Bighorn Mountains (Faulkner, 2012; Canterbury, Johnsgard \& Downing, 2013).

\section{Swamp Sparrow}

\section{Melospiza georgiana}

This sparrow is a spring and fall migrant statewide, ranging from uncommon in the eastern to central counties to very rare in western regions. It is a local summer resident in many central Nebraska marshes, including Antelope, Boone, Brown, Garden, Howard, Loup, Phelps, Rock, Sheridan, and Wheeler counties; very locally in the Rainwater Basin; and perhaps along the Missouri River. Breeding occurs in Minnesota and the eastern portions of the Dakotas, and migrants are regular in eastern portions of the Plains region.

Migration: Thirty-three initial spring sightings are from March 30 to June 6, with a median of April 23. Half of the records fall within the period April 10-30. Fourteen final spring sightings are from April 13 to May 25, with a median of May 7. Nineteen initial fall sightings are from July 21 to October 21, with a median of September 30 . Thirteen final fall sightings are from October 2 to December 29, with a median of October 24 .

Habitats: Migrants are found in marshy areas, and during the breeding season nesting occurs in marshes or other wetlands having such vegetation as cattails, phragmites, and shrubs or small trees. Three nests of this species were reported during the second atlasing period of the Breeding Bird Atlas project, and nesting was confirmed in four survey blocks of Garden, Rock, Hall, and Valley counties (Mollhoff, 2016). By comparison there were confirmed nestings in six blocks during the first survey (Mollhoff, 2001).

Comments: The swamp sparrow is a semicolonial nester whose habitat needs seemingly limit it to only a few known nesting locations in Nebraska. Its song rather strongly resembles that of a chipping sparrow, but the trills are slower and more melodious. Breeding Bird Surveys between 1966 and 2015 indicate the species collectively underwent a survey-wide population increase (0.93\% annually) during that period.

\section{White-throated Sparrow}

\section{Zonotrichia albicollis}

This sparrow is a spring and fall migrant statewide, common in eastern Nebraska and becoming uncommon to rare westwardly, and a locally common winter visitor. The species breeds in northern parts of North Dakota and Minnesota, and throughout the entire Plains region as a migrant or wintering form.

Migration: Sixty-five initial fall sightings range from September 18 to November 25, with a median of Octo- 
ber 3. Half of the records fall within the period September 25 to October 5. Fifty-two final spring sightings are from February 2 to June 4, with a median of May 12. Half of the records fall within the period May 6-17.

Habitats: Migrants are associated with woodland edges, thickets, weedy fields, and sheltered areas near water, and they sometimes come to feeding stations during winter.

Comments: People who feed birds through the winter soon come to recognize this rather robust sparrow; in Nebraska many of these whitethroated birds have a golden cast in the loral area in front of the eyes. Its beak is pinker and its throat whiter than those field marks in the similar white-crowned sparrow. The nearest breeding area of this species is in northern Minnesota.

\section{Harris's Sparrow}

Zonotrichia querula

This sparrow is a spring and fall migrant statewide, abundant in eastern counties and common farther west. Wintering is regular in the southern parts of the state. The species occurs throughout the entire Plains region as a migrant or wintering form.

Migration: The range of 115 initial fall sightings is from August 13 to December 31, with a median of October 14. Half of the records fall within the period October 4-22. Ninety-five final spring sightings are from February 8 to June 10, with a median of May 12 . Half of the records fall within the period May 9-16.

Habitats: Migrants and wintering birds occur in rural, suburban, or urban areas that have shrubs, low trees, and tall weedy plants, often near streamside woodland edges or thickets.

Comments: Nebraskans can count themselves lucky for being in the heart of the migratory route of the Harris's sparrow. It is the largest of the "crowned" sparrows and one of the prettiest, with a variably black throat during winter (the black gradually becomes more evident during spring) and a bright pink beak. The nearest breeding area of this species is in northern Manitoba.

\section{White-crowned Sparrow}

\section{Zonotrichia leucophrys}

This sparrow is a common spring and fall migrant statewide and a locally common winter visitor. The species occurs throughout the entire region as a migrant or wintering form.

Migration: Ninety-eight initial fall sightings range from August 25 to December 29, with a median of October 3. Half of the records fall within the period September 21 to October 16 . Eighty-two final spring sightings are from February 1 to May 27, with a median of May 15. Half of the records fall within the period May 2-8.

Habitats: Migrants are associated with thickets, woodland edges, and weedy areas, sometimes moving to farmyards and feeding stations in winter.

Comments: About the same size as the white-throated sparrow, this species has a more grayish throat but a whiter beak than does the whitethroated sparrow. Both come to winter feeders, but in Nebraska the 
white-crowned is much rarer under such conditions. The nearest breeding area of this species is in western Wyoming.

\section{Golden-crowned Sparrow}

Zonotrichia atricapilla

Extremely rare. Nebraska's first golden-crowned sparrow was banded in Thomas County in May 1950. Other singles were seen repeatedly in eastern Cherry County in April 1962, in Scotts Bluff County in May 1966, in McPherson County in October 1966 (Nebraska Bird Review 18:68, 34:70, $35: 24)$, and in Harlan County on December 18, 1998 (Brogie, 1999). The first winter record (January 2017), in Knox County, was the sixth for the state (Nebraska Bird Review 85:21). The nearest breeding area of this species is in southwestern Alberta.

\section{Dark-eyed Junco}

\section{Junco hyemalis}

This sparrow is a common migrant and winter visitor statewide, and a local summer resident in the Pine Ridge region of Sioux and Dawes counties. The species also breeds in western South Dakota and Minnesota, and occurs throughout the region during migration or winter. The Oregon phenotype (consisting of several races, including the so-called "pink-sided" mernsi) is fairly common through the state, and the gray-headed race caniceps is an irregular and occasional winter visitor in western $\mathrm{Ne}$ braska, sometimes occurring as far east as Lincoln, Webster, Adams, and Lancaster counties. The somewhat larger and paler white-winged race is a breeder in the Black Hills and adjacent Pine Ridge region, and it winters in the Panhandle. The relatively little-studied cismontanus race ("Cassiar" junco) of the Pacific Northwest is now thought to be an intergrade between the Oregon and slate-colored forms and is fairly common statewide during winter (Nebraska Bird Review 81:87-93; 82:71; 84:22, 178; 85:21).

Migration: The range of 105 initial fall sightings is from September 1 to December 31, with a median of October 6 . Half of the records fall within the period September 26 to October 15. Seventy-five final spring sightings are from January 1 to May 20, with a median of April 15. Half of the records fall within the period March 27 to April 25. Four initial fall sightings of caniceps are from September 21 to October 21, with a mean of October 3. Twenty final spring sightings are from January 1 to May 18, with a median of March 23.

Habitats: Migrants and wintering birds are widely distributed in woodlands, suburbs, and residential areas, foraging on the ground and often visiting feeding stations. Breeding in the Black Hills occurs in coniferous forests, aspen groves, and deciduous woodlands in hollows, canyons, and gulches, and in the Pine Ridge region similar habitats are probably used. One nest of this species were reported during the second atlasing period of the Breeding Bird Atlas project, but nesting was confirmed in seven survey blocks of Sioux, Dawes, and Sheridan counties (Mollhoff, 2016). There were no confirmed nestings during the first survey (Mollhoff, 2001). 
Comments: One of the commonest of Nebraska's wintering sparrows, the dark-eyed junco often betrays its identity by flashing its white outer tail feathers as it is flushed and disappears into heavy cover. Breeding Bird Surveys between 1966 and 2015 indicate that the species collectively underwent a survey-wide population decline (1.38\% annually) during that period.

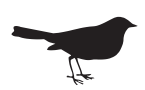

\section{Family Icteriidae (Chats)}

\section{Yellow-breasted Chat \\ Icteria virens}

This warbler-like species was previously a common spring and fall migrant and summer resident statewide in suitable habitats, but in recent years the population of its eastern race in the Missouri Valley and eastern Platte Valley has nearly disappeared. It is still uncommon to occasional in the western parts of the state. Breeding is widespread in the Plains states, especially southwardly, but eastern Great Plains populations have been in sharp decline.

Migration: The range of 120 initial spring sightings is from April 23 to June 7 , with a median of May 15 . Half of the records fall within the period May 10-21. The range of 63 final fall sightings is from July 21 to October 16, with a median of September 9. Half of the records fall within the period August 21 to September 23.
Habitats: Breeding birds usually favor ravine or streamside thickets, especially those with small trees and tall shrubs, as well as forest edges, dense stands of tree saplings, and clumps of shrubs in overgrazed pastures. Two nests of this species were reported during the second atlasing period of the Breeding Bird Atlas project, and nesting was confirmed in eight survey blocks east to Morrill County, whereas during the first atlas surveys six confirmed nesting blocks extended east to Loup County and probable nestings to Douglas County (Mollhoff, 2001, 2016).

Comments: This bird is easily the largest and most vocal (thus the name "chat") of all the warbler-like species. A displaying male utters an extended series and variety of bizarre whistles, squawks, and rattles, both while perched and while in flight. During flight display it lowers its legs, pumps its tail, and and flies rather jerkily with deep wing strokes, while its throat feathers are fluffed so the area appears to be inflated, a posture rendered admirably by J. J. Audubon in his iconic painting of the species (male on left). In 2017 the chat was removed from the warbler group and placed in a new monotypic family (Ictariidae) of still uncertain relationships. Breeding Bird Surveys between 1966 and 2015 indicate that the species collectively underwent a surveywide population decline (0.5\% annually) during that period.

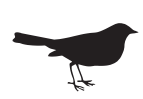




\section{Family Icteridae (Blackbirds, Orioles, and Meadowlarks)}

\section{Bobolink}

Dolichonyx oryzivorus

This species is a spring and fall migrant throughout Nebraska and is fairly common in central Nebraska but less common in the eastern and western regions. It is a summer resident throughout most of the state, west to Sioux County in the Panhandle and Garden County in the Sandhills, and within the southern limits occurring between the Platte and Republican Rivers. Breeding occurs from North Dakota and Minnesota south locally to central Kansas, and migrants are regular to the south of this region.

Migration: The range of 116 initial spring sightings is from March 20 to June 20, with a median of May 16 . Kansas spring records are from April 2 to June 11, and the fall records are mostly from August 15 to November 7, with a median of October 9 (Thompson et al., 2011).

Habitats: While in Nebraska, this species is usually found in ungrazed to lightly grazed medium-height to tall-grass prairies, wet meadows, and retired croplands; it occasionally extends into small-grain croplands. There were 76 probable and 15 confirmed nesting blocks during the first Breeding Bird Atlas survey, mostly located between the Platte and Republican Rivers and especially in the Sandhills, and 98\% of the nesting blocks were in grassland habitat (Mollhoff, 2001). A total of 128 probable nests of this species were reported during the second atlasing period of the Breeding Bird Atlas project, and there were 9 confirmed nesting blocks (Mollhoff, 2016). Forty-seven percent of the 91 nests documented during the second survey had been parasitized by cowbirds, one of the highest levels of cowbird parasitism reported in the literature (Johnsgard, 1997a).

Comments: Breeding Bird Surveys between 1966 and 2015 indicate that the bobolink collectively underwent a survey-wide population decline (2.06\% annually) during that period versus an estimated $1.8 \%$ rate of increase in Nebraska, based on 40 survey routes.

\section{Red-winged Blackbird}

Agelaius phoeniceus

This species is an abundant spring and fall migrant statewide and a common to abundant summer resident throughout Nebraska in suitable habitats. It overwinters fairly frequently, and large numbers of migrants pass through the state every spring and fall. The species is a migrant or breeder throughout the Plains states.

Migration: The range of 90 initial spring sightings is from January 1 to May 26, with a median of March 3 . Half of the records fall within the period February 17 to March 17. Eighty final fall sightings range from August 8 to December 31, with a median of November 21. Half of the records fall within the period November 3 to December 21.

Habitats: Breeding occurs on a wide range of habitats, from deep marshes or the emergent zones of lakes and impoundments, through progressively 
drier habitats such as wet meadows, ditches, brushy patches in prairie, hayfields, and weedy croplands or roadsides. Migrants often are seen in flocks of other blackbird species, feeding in fields or elsewhere, but roosting is typically done in wet areas rather than in residential locations. A total of 45 nests of this species were reported during the second atlasing period of the Breeding Bird Atlas project; there were 227 confirmed nesting blocks and 188 probables (Mollhoff, 2016). Forty-seven percent of the 45 nests found during the second survey had been parasitized by cowbirds, the same percentage as were found in bobolink nests. There were 209 confirmed nesting blocks and 188 probable nestings during the first survey period (Mollhoff, 2001).

Comments: The red-winged blackbird is one of Nebraska's most abundant breeding birds, numbering in the tens of millions, and also one of the most attractive. Like several other grassland nesting birds, this species experiences a big impact caused by brown-headed cowbirds; few nests of redwings in Nebraska seem to survive without being parasitized. Breeding Bird Surveys between 1966 and 2015 indicate the species collectively underwent a survey-wide population decline (0.93\% annually) during that period, and an estimated $0.25 \%$ rate of annual decline in Nebraska.

\section{Eastern Meadowlark}

Sturnella magna

This species is a common spring and fall migrant in eastern Nebraska, becoming rarer westwardly, and a summer resident in southeastern coun- ties and locally elsewhere. The species is a fairly common breeder east of a line from Gage to Thurston counties, and there is local breeding along river courses and wet meadows as far west as Sioux and Morrill counties. The redwing is also common throughout the western Sandhills, and it extends west along the South Platte to the Colorado border, where hybridization with the western meadowlark is apparently quite frequent (Transactions Kansas Academy of Sciences 75:19). Sometimes it overwinters in Nebraska. The species also breeds in Minnesota, Iowa, eastern Kansas, and most of Oklahoma.

Migration: Fifty-nine initial spring sightings range from January 1 to May 30, with a median of April 8. Half of the records fall within the period March 17 to May 6. Thirty final fall sightings are from August 2 to December 31, with a median of October 10. Half of the records fall within the period September 20 to November 20.

Habitats: Breeding birds are associated with tall-grass prairies, meadows, and open croplands of small grain as well as weedy orchards and similar open, grass-dominated habitats. At the western edge of its range in the Sandhills and along the Platte River it is limited to low and rather moist habitats around marshes and in wet meadows. A total of 99 nests of this species were reported during the second atlasing period of the Breeding Bird Atlas project, and there were 16 confirmed nesting blocks (Mollhoff, 2016). Thirty-eight percent of the nests found during the second survey had been parasitized by cowbirds. There were 30 confirmed nest- 
ing blocks during the first survey (Mollhoff, 2001).

Comments: Although national populations of the eastern meadowlark have decreased by $53 \%$ since 1966 , the birds are still common in eastern Nebraska, and around Lincoln and Omaha the two species of meadowlarks are about equally common. In these regions the eastern species can usually be found on meadows near water, and the westerns on drier hilltops. Breeding Bird Surveys between 1966 and 2015 indicate that the species collectively underwent a survey-wide population decline (3.28\% annually) during that period, and an estimated 1.34 rate of decline in Nebraska.

\section{Western Meadowlark}

Sturnella neglecta

This familiar and well-loved species is a common spring and fall migrant statewide and a common summer resident virtually throughout Nebraska, except perhaps in the extreme southeastern counties. It overwinters in the state fairly frequently. The species also breeds almost throughout the Plains states, except the eastern parts of Kansas and Oklahoma.

Migration: Sixty-one initial spring sightings range from January 1 to May 26, with a median of March 4. Half of the records fall within the period February 9 to March 21. Forty-three final fall sightings are from August 20 to December 31, with a median of October 28. Half of the records fall within the period October 10 to November 21. Apparently the western meadowlark is an earlier spring and later fall migrant than is the eastern meadowlark, and it is also more prone to overwintering.
Habitats: In Nebraska this species is associated with tall-grass and mixed-grass prairies, hayfields, wet meadows, the weedy borders of croplands, retired croplands, and to a limited extent with short-grass and sagedominated plains, where it is limited to moister situations. A total of 235 nests of this species were reported during the second atlasing period of the Breeding Bird Atlas project, and there were 219 confirmed nestings (Mollhoff, 2016). Forty-three percent (100) of the nests found during the second survey had been parasitized by cowbirds. By comparison, there were 228 confirmed nesting blocks during the first survey, and 6 nests were found (Mollhoff, 2001).

Comments: This is the state bird of Nebraska (and also of several other states), which is a reflection of the affection our citizens have for meadowlarks. The overall range of the western meadowlark is much greater than that of the eastern, and it has not suffered as much from land-use changes. Breeding Bird Surveys between 1966 and 2015 indicate that the species collectively underwent a survey-wide population decline (1.29\% annually) in that period, and an estimated $1.34 \%$ rate of annual decline in Nebraska.

\section{Yellow-headed Blackbird}

Xanthocephalus xanthocephalus

This species is a common to abundant spring and fall migrant statewide, and a locally common summer resident in permanent marshes throughout Nebraska. Breeding occurs from North Dakota and Minnesota south locally to Kansas and southern Colorado. 
Migration: The range of 103 initial spring sightings is from January 1 to June 5, with a median of April 21. Half of the records fall within the period April 11 to May 1. Eighty-two final fall sightings range from July 23 to December 28, with a median of September 18. Half of the records fall within the period September 4-30.

Habitats: During the breeding season the yellow-headed blackbird occurs in deep marshes, the marsh zones of lakes or shallow impoundments, and wherever else there are extensive stands of cattails, bulrushes or phragmites. It is often found breeding in association with red-winged blackbirds, utilizing the deeper portions of the marsh. Migrants are sometimes seen flying or perching with groups of redwinged blackbirds, but more often they remain separate from them. A total of 38 nests of this species were reported during the second atlasing period of the Breeding Bird Atlas project, and there were 26 confirmed nestings (Mollhoff, 2016). By comparison, there were 50 confirmed nesting blocks during the first survey (Mollhoff, 2001).

Comments: This very attractive species breeds in deeper, more open wetlands than does the red-winged blackbird, and it seems to prefer somewhat alkaline marshes to freshwater; thus it becomes more common in the Sandhills marshes as one proceeds westward. Breeding Bird Surveys between 1966 and 2015 indicate that the species collectively underwent a survey-wide population decline (0.06\% annually) during that period, and Nebraska had an estimated $0.01 \%$ rate of annual decline.

\section{Rusty Blackbird}

\section{Euphagus carolinus}

This species is an uncommon to occasional fall, winter, and spring migrant in eastern Nebraska, becoming rarer westwardly, and rare or irregular in extreme western counties. It overwinters frequently in the state. The species migrates through the entire Plains states.

Migration: Forty-five initial spring sightings range from January 1 to May 19, with a median of March 22. Twenty-one final spring sightings range from January 5 to May 23, with a median of April 14. Twenty-five initial fall sightings are from August 10 to December 17, with a median of November 3. Twenty-one final fall sightings are from October 4 to December 31, with a median of December 26. The large proportion of final sightings in late December suggest that this species overwinters rather frequently in Nebraska, as is true in Kansas.

Habitats: Migrants and wintering birds are usually found in deciduous woodlands near streams, rather than in the open marshlands, grasslands, and croplands favored by other species of blackbirds in Nebraska.

Comments: The rusty blackbird is the only blackbird that occurs in Nebraska strictly as a winter resident. There is an early report of nesting in Hall County, but this seems highly questionable, considering the known breeding range of this species. The nearest breeding area is in central Manitoba. This is a seriously declining species; Breeding Bird Surveys between 1966 and 2015 indicate that it collectively underwent a survey-wide 
population decline (3.53\% annually) during that period.

\section{Brewer's Blackbird}

Euphagus cyanocephalus

This species is a common spring and fall migrant statewide, becoming very common in the Panhandle, where it is a summer resident from Sioux to Sheridan counties and south to Scotts Bluff County. It might also breed southwest of the Wildcat Hills (Nebraska Bird Review 78:102). Brewer's blackbird overwinters in the state infrequently. Breeding occurs from North Dakota and Minnesota south to eastern Colorado, and migrants appear throughout the entire region.

Migration: Sixty-three initial spring sightings range from January 1 to May 25, with a median of April 12. Half of the records fall within the period March 22 to April 24. Fortyfive final fall sightings are from September 1 to December 31, with a median of November 5 . There is a much lower proportion of late December records for the Brewer's blackbird than for the rusty blackbird, which suggests that overwintering is rather rare in this species.

Habitats: Migrants are usually seen in pastures, barnyards, and grain fields, often in the company of other kinds of blackbirds. During the breeding season, the birds favor low-stature grasslands, such as mowed roadsides or burned areas near railroads, residential areas, and farmsteads. Areas that have a combination of grassy habitats, scattered shrubs or small trees, and nearby water are especially favored. Two nests of this spe- cies were reported during the second atlasing period of the Breeding Bird Atlas project, and there were 11 confirmed nestings (Mollhoff, 2016). By comparison, there were four confirmed nesting blocks during the first survey (Mollhoff, 2001).

Comments: Although frequent in western Nebraska during summer, there are few records of breeding in the state. However, nesting has been documented in Sioux County (Smiley Canyon) and near Harrison (Nebraska Bird Review 73:19). Breeding Bird Surveys between 1966 and 2015 indicate that the species had a survey-wide population decline (2.25\% annually) in that period.

\section{Common Grackle}

Quiscalus quiscula

This species is a common to abundant spring and fall migrant and summer resident statewide and an occasional winter resident, especially in southern counties. The species breeds throughout the entire Plains states, except in the most arid portions of the southwest.

Migration: Eighty-two initial spring sightings range from January 22 to June 7, with a median of March 26. Half of the records fall within the period March 16 to April 6. Ninety final fall records are from August 9 to December 30, with a median of October 28. Half of the records fall within the period September 30 to December 3. Nearly half of the records are for December, so overwintering may occur fairly frequently, as is also the case in Kansas, especially near feedlots (Thompson et al., 2011). 
Habitats: During the breeding season, this species frequents woodland edges or areas partially planted to trees, such as residential areas, parks, farmsteads, shelterbelts, and the like. Tall shrub thickets near croplands or marshlands are also used. Migrants are often seen in large flocks in residential and rural areas. A total of 12 nests of this species were reported during the second atlasing period of the Breeding Bird Atlas project, and there were 276 confirmed nestings (Mollhoff, 2016). By comparison, there were 259 confirmed nesting blocks during the first survey (Mollhoff, 2001).

Comments: Like the other "blackbirds," this grackle is especially abundant during fall migration, when vast mixed flocks appear during late September and October on their way southward. Common grackles are also egg stealers and nestling eaters, so they sometimes cause some damage to the reproductive efforts of other nesting songbirds. Breeding Bird Surveys between 1966 and 2015 indicate that the species collectively underwent a survey-wide population decline (1.75\% annually) during that period, and an estimated $0.49 \%$ rate of annual decline in Nebraska.

\section{Great-tailed Grackle}

Quiscalus mexicanus

This large southern grackle is an increasingly regular and now locally uncommon spring and fall migrant, and a local summer resident throughout Nebraska, north into eastern South Dakota. The species was first found breeding in the state in 1976, when nesting was detected in Adams and
Douglas counties (Nebraska Bird Review 45:18). During the early atlasing years nesting was confirmed in Adams, Fillmore, Gage, Lancaster, and Otoe counties (Mollhoff, 2001). It was later found nesting rather widely in wetlands south of the Platte River, including Funk Waterfowl Production Area and Kiowa Springs, and at wetlands near Hastings, Grand Island, and Ogallala.

Migration: Five initial spring sightings are from March 31 to May 14, with a mean of April 21. Most breeding birds depart by the end of August; the latest fall record is November 27. The migration chronology is similar to that of the common grackle ( $\mathrm{Ne}$ braska Bird Review 83:19). In Kansas migrants usually arrive about midMarch, but hundreds to thousands often overwinter in the southern and northeastern parts of the state (Thompson et al., 2011).

Habitats: Breeding occurs in a wide variety of habitats, but these usually include both open ground and nearby water, so this bird is common in irrigated croplands. A total of 42 nests of this species were reported during the second atlasing period of the Breeding Bird Atlas project, and there were 20 confirmed nestings (Mollhoff, 2016). By comparison, there were seven confirmed nesting blocks during the first survey (Mollhoff, 2001).

Comments: It is regrettable that great-tailed grackles have made their way into Nebraska because they are efficient predators of the eggs and young of other species of songbirds. Yet, they are interesting to watch, and probably not nearly so destructive as brown-headed cowbirds. Breeding 
Bird Surveys between 1966 and 2003 indicate that the species collectively underwent a survey-wide population increase (1.99\% annually) during that period, and a statistically unreliable (based on ten survey routes) estimate of $27.19 \%$ rate of annual increase in Nebraska. This is Nebraska's only icterid species that isn't nationally declining in population.

\section{Brown-headed Cowbird}

\section{Molothrus ater}

This species is a common to abundant spring and fall migrant, and a common summer resident statewide. Breeding also occurs throughout the entire Great Plains.

Migration: Eighty-three initial spring sightings range from January 6 to May 26, with a median of April 17. Half of the records fall within the period April 2 to May 1. Eighty-five final fall sightings are from August 1 to December 31, with a median of October 7. Half of the records fall within the period September 11 to November 27. Nearly $20 \%$ of the records are for December, suggesting that some overwintering may occur, as is common in Kansas.

Habitats: Breeding by this socially parasitic species usually occurs in woodland edges, brushy thickets, and other habitats where low and scattered trees are interspersed with grasslands. Migrants are often found in fields among cattle. Prairie and edge-nesting host species are most often parasitized, including both meadowlarks, dickcissel, bobolink, and grasshopper sparrow, but some woodland-nesting birds such as wood thrush, red-eyed vireo, and American redstart are also vulnerable. A total of 394 nests involving 28 host species of this brood parasite were reported during the second atlasing period of the Breeding Bird Atlas project, and nesting was confirmed in 84 survey blocks. There were 276 confirmed nestings involving cowbird eggs during the second atlasing period of the Breeding Bird Atlas project (Mollhoff, 2016), and 76 confirmed nestings during the first survey (Mollhoff, 2001). Considering both surveys, the most frequently parasitized hosts were the western meadowlark (88 records), bobolink (86 records), grasshopper sparrow (69 records), dickcissel (62 records), eastern meadowlark (42 records), and red-winged blackbird (27 records). Other hosts that were parasitized two or more times included the eastern phoebe, brown thrasher, common yellowthroat, yellow warbler, chipping sparrow, field sparrow, lark sparrow, northern cardinal, blue grosbeak, and orchard oriole (Mollhoff, 2001, 2016). A total of 28 species were parasitized among the 394 host nests found during the second survey period. Cowbird eggs were present at a rate of $93 \%$ to $98 \%$ of the 413 blocks that were surveyed during both of the two study periods, and the cowbird was the second most commonly reported species statewide. The number of cowbird eggs present per nest ranged from one (155 nests) to nine (one dickcissel nest) (Mollhoff, 2001, 2016). The great majority of cowbird eggs are laid before June, so late-nesting host species, or their repeated nesting efforts, are more likely to escape being parasitized. 
Comments: Brown-headed cowbirds are very serious (often lethal) brood parasites for dozens of species of Great Plains songbirds, with the two meadowlarks, dickcissel, bobolink, red-winged blackbird, chipping sparrow, and field sparrow being among the species most frequently exploited (Johnsgard, 1979a). Unlike the common cuckoo (Cuculus canorum) of Europe, the newly hatched cowbird does not eject the eggs or young of its host species from the nest, but by its constant begging manages to get the majority of the food brought to the nest, often causing starvation of the host's own chicks (Johnsgard, 1997a). The brownheaded cowbird evidently evolved in a foraging symbiosis with bison on the western Plains. Following the migrating herds and feeding on insects stirred up by the feet of these constantly moving ungulates produced an evolutionary advantage by which it was more advantageous for females to drop their eggs along the way in nests encountered by serendipity, than to remain behind, incubate their own eggs, and rear their young. Only by laying a great many eggs per season (often about 50) and only because the eggs and young are sufficiently like those of many hosts that the eggs are accepted and the young reared is such a biologically risky breeding strategy practical. Breeding Bird Surveys between 1966 and 2015 indicate that the species collectively underwent a survey-wide population decline (0.66\% annually) during that period, and an estimated $0.18 \%$ rate of decline in Nebraska.

\section{Orchard Oriole}

Icterus spurius

This species is a common spring and fall migrant throughout Nebraska, being most common in the eastern half, and is a summer resident virtually statewide, becoming less common in the extreme western regions. The species breeds widely from North Dakota and Minnesota south to Oklahoma and the Texas Panhandle.

Migration: The range of 188 initial spring sightings is from March 24 to June 10, with a median of May 9. Half of the records fall within the period May 3-14. The range of 115 final fall sightings is from July 21 to October 9, with a median of August 24. Half of the records fall within the period August 14 to September 5 .

Habitats: During the breeding season this species occupies lightly wooded riverbottoms, scattered trees in open country, shelterbelts, farmsteads, orchards, and residential areas. Relatively open woodlands are preferred, but areas of low junipers or even grasslands may be used, especially if nearby nest sites are available. Nine nests of this species were reported during the second atlasing period of the Breeding Bird Atlas project, and nesting was confirmed in 160 survey blocks (Mollhoff, 2016). By comparison, there were 169 confirmed nesting blocks during the first survey (Mollhoff, 2001).

Comments: Orchard orioles are surprisingly abundant along the riparian woodlands that extend west along the Platte Valley to Colorado and Wyoming. At Cedar Point Biological Station they are much more abun- 
dant than Baltimore and Bullock's orioles. All of these orioles are prone to nest in trees already occupied by nesting kingbirds, since they evidently gain some protection from the highly territorial and aggressive kingbirds (Bergin, 1987; Scharf and Kren, 2010). Breeding Bird Surveys between 1966 and 2015 indicate that the species collectively underwent a surveywide population decline (0.87\% annually) during that period versus an estimated $2.65 \%$ rate of annual increase in Nebraska.

\section{Hooded Oriole}

Icterus cucullatus

Accidental. There is a sight record of this southwestern species from Columbus, Platte County, during May 1965 (Nebraska Bird Review 33:65). An adult male was also seen at a feeding station in Garrison, Butler County, over the Memorial Day weekend, 2013 (Nebraska Bird Review 81:77; Gubanyi, 2013). This species' nearest breeding area is southwestern New Mexico.

\section{Bullock's Oriole}

Icterus bullockii

Collectively, the Bullock's and Baltimore orioles are common spring and fall migrants and are summer residents statewide. The eastern taxon (Baltimore oriole) is present over most of Nebraska during summer, but in the Panhandle counties many of the birds are of the western (Bullock's oriole) phenotype, or are apparent hybrids (Sibley \& Short, 1964; Brown et al., 1996). Collectively these two poorly distinguished species breed throughout the entire Plains states.
Migration: The range of 192 initial spring sightings (both taxa combined) is from April 16 to June 5, with a median of May 6. Half of the records fall within the period May 1-10. The range of 136 final fall sightings is from July 26 to October 25, with a median of September 7. Half of the records fall within the period September 2-13.

Habitats: During the breeding season this species occupies wooded riverbottoms, upland forests, shelterbelts, and partially wooded residential areas and farmsteads. In extreme western Nebraska, riverbottom stands of cottonwoods and willows are the usual habitat of bullockii-type birds or apparent hybrids. No nests of this species were reported during the second atlasing period of the Breeding Bird Atlas project, but nesting was confirmed in 27 survey blocks east to Sheridan and Morrill counties, as compared with 17 confirmed nesting blocks in the first survey (Mollhoff, 2001, 2016).

Comments: Breeding Bird Surveys between 1966 and 2015 indicate that the Bullock's oriole underwent a survey-wide population decline of $0.66 \%$ annually during that period versus an estimated $1.03 \%$ rate of increase in Nebraska.

\section{Baltimore Oriole}

Icterus galbula

See the Bullock's oriole account. So many of the orioles that breed along the North Platte Valley are probable hybrids that it is impossible to accurately map the breeding range limits of these two orioles. From the 1950s until 1995 they had been regarded as 
a single species, owing to extensive hybridization in the central Great Plains (Sibley \& Short, 1964), but in 1995 they were "split" taxonomically as evidence accumulated that the rate of hybridization was declining and that they are not as close genetically as once assumed (Rising, 1968, 1970; Brown et al., 1996). One nest of this species was noted during the second atlasing period of the Breeding Bird Atlas project, and nesting was confirmed in 162 survey blocks (Mollhoff, 2016). Similarly, there were 156 confirmed study blocks during the first survey (Mollhoff, 2001). Breeding Bird Surveys between 1966 and 2015 indicate that the Baltimore oriole underwent survey-wide population declines during that period of $1.49 \%$ annually and an estimated $0.27 \%$ rate of decline in Nebraska.

\section{Scott's Oriole}

Icterus parisorum

Accidental. There are three sight records for this southwestern oriole. The first was in Hall County in 1975, when the species was observed from late May to late June (Nebraska Bird Review 43:66). It was later observed in McPherson County in 1978 ( Nebraska Bird Review 46:67), and again in Hall County, on July 2, 1997. The nearest breeding area for Scott's oriole is western Colorado.

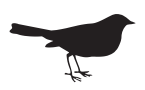

\section{Family Parulidae (New World Warblers)}

\section{Ovenbird}

Seiurus aurocapilla

This forest-nesting species is an uncommon to common spring and fall migrant statewide and a locally common summer resident, mainly in the Missouri River's forested valley, the Niobrara Valley west at least to Cherry County, and the Pine Ridge region. Breeding occurs widely in eastern and northern parts of the Great Plains, and migrants appear throughout the region.

Migration: The range of 140 initial spring sightings is from April 21 to June 2, with a median of May 13. Half of the records fall within the period May 7-18. Forty final fall records are from July 25 to October 11, with a median of September 11. Half of the records fall within the period September 3-18.

Habitats: In the summer these birds are mostly limited to well-drained bottomland deciduous forests and to mature and shaded upland forests. Four nests of this species were reported during the second atlasing period of the Breeding Bird Atlas project, and nesting was confirmed in seven survey blocks, east from Sioux County to Dakota County (Mollhoff, 2016). By comparison, there was one confirmed nesting block in Douglas County during the first survey (Mollhoff, 2001).

Comments: The loud teacher, teacher, teacher song of this woodland warbler is a sure sign of its presence. The song increases in volume, unlike 
the repeated Peter notes of the tufted titmouse.

\section{Worm-eating Warbler}

Helmitheros vermivorum

This species is an extremely rare migrant or vagrant, mostly in eastern counties. It historically but erroneously was believed to be a summer resident in southern Nebraska. It has been most often reported in Lancaster and Douglas-Sarpy counties, but has been reported west as far as Box Butte County. The species nests in Oklahoma, is a rare migrant and possible summer resident in Kansas, and has been observed several times in South Dakota.

Migration: The range of 17 spring sightings is from April 21 to May 25, with a median of May 8. Half of the records fall within the period May 4-13. There were about 50 spring records as of 2014 (Nebraska Bird Review 82:65). Three fall records are from September 3 to October 8, with a mean of September 15 .

Habitats: Normally this species is associated with dense riverbottom woodlands or second-growth mediumsized woodlands on hillsides with a shrubby undercover.

Comments: This is a ground-foraging warbler of dense undergrowth, and it is only rarely reported in the state.

\section{Louisiana Waterthrush}

Parkesia motacilla

This moist woodland species is a rare to uncommon spring and fall migrant in southeastern Nebraska, becoming rarer to the west and north. It is reported from as far west as Lincoln and Garden counties. Confirmed breeding during the early atlasing years was limited to Washington and Richardson counties (Mollhoff, 2001) and breeding has been suggested or confirmed for Fontenelle Forest, Neale Woods, and Indian Cave and Platte River state parks (Nebraska Bird Review 83:121, 175-176). Singing birds have been reported northwest to Dakota County. Breeding is regular in eastern Kansas and the eastern half of Oklahoma.

Migration: Seventy-six initial spring sightings range from March 30 to May 29, with a median of May 8 . Half of the records fall within the period May 2-14. Ten final spring sightings are from April 29 to May 29, with a median of May 15. Ten fall sightings are from July 29 to September 24 , with a median of August 29.

Habitats: This species is closely associated with forested hills and ravines near fairly swift streams; the birds forage in moist areas. No nests of this species were reported during the second atlasing period of the Breeding Bird Atlas project, but four probable nestings were confirmed in 157 survey blocks, from Sarpy County south to Richardson County (Mollhoff, 2016). By comparison, there were two confirmed nesting blocks in Richardson and Washington counties during the first survey (Mollhoff, 2001).

Comments: This waterthrush may be expanding its range in eastern $\mathrm{Ne}$ braska; at least it has been reported during summer more frequently in recent years.

\section{Northern Waterthrush}

Parkesia noveboracensis

This woodland warbler is an uncommon spring and fall migrant statewide, perhaps becoming rarer west- 
wardly, and is considerably less common than the ovenbird. Breeding occurs in Minnesota and northern North Dakota, and migrants may appear anywhere in the Plains states.

Migration: The range of 135 initial spring sightings is from April 10 to May 27, with a median of May 7. Half of the records fall within the period May 2-11. Twenty-six final spring sightings are from May 3 to 21, with a median of May 14. Eight initial fall sightings are from August 10 to September 10, with a mean of August 29. Seven final fall sightings range from September 9 to October 12, with a mean of September 22.

Habitats: While in Nebraska this species is associated with deciduous forests or woodlands near streams; the birds often forage on or near the ground.

Comments: The song of this species somewhat resembles the loud song of the ovenbird; however, it does not rise in pitch and volume but rather drops toward the end. Like the ovenbird, waterthrushes feed on the ground, often in damp locations.

\section{Golden-winged Warbler}

Vermivora chrysoptera

This species is an extremely rare spring and fall migrant in eastern counties, with vagrants reaching Logan and Keith counties. It is considered a rare migrant in South Dakota and is a rare to uncommon migrant in Kansas. The nearest breeding area is in northern Minnesota.

Migration: Eight spring sightings range from May 5 to 25, with a mean of May 15. There are fall records for September 6 and 7. In Kansas spring sightings extend from April 28 to May 28, with most from May 2 to 10 , and fall sightings are from August 15 to October 23.

Habitats: Migrating and breeding golden-winged warblers are usually found in second-growth woodlands or scrubby thickets and overgrown pastures.

Comments: Males of this wellnamed species have large golden wing-coverts and also a golden crown.

\section{Blue-winged Warbler}

Vermivora cyanoptera

Once erroneously believed to be a summer resident in southern $\mathrm{Ne}$ braska, this warbler is a rare spring and fall migrant in eastern Nebraska. It has been observed several times in Custer County and as far west as Cherry County. It is considered a rare to uncommon migrant in eastern Kansas, a casual migrant in South Dakota, and an accidental in North Dakota. The nearest breeding area is in eastern Oklahoma.

Migration: Twenty-two spring sightings range from August 25 to June 1, with a median of May 12. Half of the records fall within the period May 5-14. There are four fall sightings from July 6 to September 16, with a mean of August 15.

Habitats: Migrating and breeding birds are usually found in woodland edges, abandoned fields, and pastures and tickets, often in slightly wetter habitats than the goldenwinged warbler.

Comments: Although none have been reported in Nebraska, hybrids between the blue-winged and goldenwinged warblers are not rare, and two 
of the hybrid variants have mistakenly been named as distinct species.

\section{Black-and-white Warbler}

Mniotilta varia

This species is a common spring and fall migrant statewide, and a local and uncommon summer resident in the forested valleys of the Missouri and Niobrara Rivers, probably reaching Cherry County in the Niobrara Valley, and also nesting in the Pine Ridge region. Breeding occurs locally from North Dakota southward to eastern Oklahoma, and migrants occur throughout the Great Plains.

Migration: Ninety-two initial spring sightings range from March 25 to June 10, with a median of May 4 . Half of the records fall within the period April 25 to May 9. Forty final fall sightings are from August 21 to October 6 , with a median of September 12 . Half of the records fall within the period September 4-20.

Habitats: On migration this species occurs in deciduous woodlands along rivers and streams, and in parks and residential areas. Foraging is done in a creeper-like fashion on the trunk and larger branches. Nesting usually is in semiopen upland stands of deciduous or coniferous forest, especially those having immature or scrubby trees, and in hillside or ravine groves with thin understories. No nests of this species were reported during the second atlasing period of the Breeding Bird Atlas project, but probable nestings were confirmed in four survey blocks of Sheridan County (Mollhoff, 2016). The species was not reported during the first survey (Mollhoff, 2001).
Comments: The simple but attractive black-and-white plumage pattern of this species proves that bright coloration is not necessary to produce beauty among the warblers. The highpitched song of this species consists of a series of we-see notes. Breeding Bird Surveys between 1966 and 2015 indicate that the species collectively underwent a survey-wide population decline (0.86\% annually) during that period.

\section{Prothonotary Warbler}

Protonotaria citrea

This species is an uncommon or occasional spring and fall migrant in southeastern Nebraska and a local summer resident as far north as Sarpy County (Nebraska Bird Review 47:57). Vagrants sometimes appear farther west in the state, rarely to Dawes County, and more rarely to eastern Colorado. Breeding also occurs in eastern Kansas and the eastern half of Oklahoma.

Migration: Thirty-six initial spring sightings range from April 19 to May 24, with a median of May 12. Half of the records fall within the period May 5-17. Four final fall sightings range from July 26 to October 4 , with a mean of September 11.

Habitats: This species is restricted during summer to moist bottomland forests and wooded swamps or periodically flooded woodlands, in the vicinity of running water or pools. During migration vagrants may appear in other wooded habitats. No nests of this species were reported during the second atlasing period of the Breeding Bird Atlas project, but one nesting was confirmed in a survey block of Dodge 
County (Mollhoff, 2016). The species was not encountered during the first survey (Mollhoff, 2001).

Comments: The prothonotary warbler is another species that occurs locally in the mature riparian forests of Fontenelle Forest and regularly nests there. There is also an early breeding record for Otoe County. Breeding Bird Surveys between 1966 and 2015 indicate that the species collectively underwent a survey-wide population decline (1.10\% annually) during that period.

\section{Swainson's Warbler}

Limnothlypis swainsonii

Accidental. There is an early specimen record of this species for Buffalo County in April 1905, and the species was also reported in Lancaster County in May 1977 (Nebraska Bird Review 45:46). The species breeds in Oklahoma, is a rare vagrant in Kansas, and is unreported for the Dakotas.

\section{Tennessee Warbler}

Oreothlypis peregrina

This species is a common spring and fall migrant in eastern Nebraska, becoming uncommon in western parts of the state. Breeding occurs in northern Minnesota, and migrants may appear throughout the entire region.

Migration: Ninety-five initial spring sightings range from April 1 to June 4, with a median of May 8. Half of the records fall within the period May 4-14. Forty-seven final spring sightings are from April 30 to June 9, with a median of May 23. Thirty-one initial fall sightings are from August 19 to October 22, with a median of September 8. Half of the records fall within the period August 28 to September 15. Twentyseven final fall sightings range from September 9 to October 27, with a median of October 5 .

Habitats: Migrants are associated with deciduous woodlands and forests, where they usually forage in the upper portions of rather tall trees.

Comments: This is one of the very common warblers in Nebraska. It arrives a few days later on average than the yellow-rumped warbler and forages in similar locations, such as around budding trees or emerging catkins.

\section{Orange-crowned Warbler}

Oreothlypis celata

This species is a common spring and fall migrant throughout Nebraska as well as a migrant throughout the entire Plains states.

Migration: The range of 112 initial spring sightings is from April 8 to May 30, with a median of April 30. Half of the records fall within the period April 25 to May 5. Seventy-four final spring sightings are from April 25 to May 30, with a median of May 13. Sixty-one initial fall sightings are from August 11 to October 12, with a median of September 19. Half of the records fall within the period September 14-28. Sixty final fall sightings are from September 11 to November 6, with a median of October 15 .

Habitats: Migrants are associated with deciduous forests, woodlands, and brushy thickets. They also forage in stands of tall sunflowers and ragweeds and shrubs, often fairly close to the ground. 
Comments: Orange-crowned warblers are notable in that they are almost devoid of field marks; like Sherlock Holmes's dog that didn't bark, they can be identified by the field marks that are lacking. The so-called orange crown is scarcely visible, even when the bird is being handled, and is invisible under most field conditions.

\section{Nashville Warbler}

Oreothlypis ruficapilla

This species is a common spring and fall migrant almost statewide but is perhaps less common westwardly. Historically it was wrongly believed to nest in the Missouri Valley region. Breeding occurs in northern Minnesota, and migrants appear almost throughout the region but are increasingly rare in western regions.

Migration: Eighty-one initial spring sightings range from March 29 to June 3, with a median of May 7. Half of the records fall within the period May 1-13. Thirty-four final spring sightings are from April 30 to June 2, with a median of May 14. Forty-one initial fall sightings are from July 28 to September 27, with a median of September 10. Half of the records fall within the period September 3-15. Forty final fall records are from September 13 to October 30 (median October 8).

Habitats: Migrating Nashville warblers are associated with secondgrowth woodlands having a brushy undercover. Foraging occurs in tall weeds as well as shrubs and low trees.

Comments: This is a rather dullplumaged warbler whose favored nesting habitat of spruce bogs is lacking in Nebraska.

\section{Virginia's Warbler}

Oreothlypis virginiae

Extremely rare. In addition to an early sight record from Hitchcock County, this southwestern species was observed during April 1964 in North Platte, Lincoln County (Nebraska Bird Review 32:67). It was also observed in Scotts Bluff County on May 22, 1995 (Nebraska Bird Review 64:136), and at Bushnell on April 17, 1998 (Nebraska Bird Review 66:48). It is an uncommon migrant in western Kansas and extreme northwestern Oklahoma. It breeds in northeastern Wyoming and locally in the southwestern Black Hills of South Dakota, so it should be a regular if rare migrant in western Nebraska. There have been at least eight state records.

\section{Connecticut Warbler \\ Oporornis agilis}

This species is a rare to occasional spring and fall migrant in eastern Nebraska, rarely occurring as far west as Cherry, Lincoln, and McPherson counties. It is a casual migrant in eastern Kansas.

Migration: Twenty spring records range from April 25 to June 6, with a median of May 18. Half of the records fall within the period May 10-19. Ten initial fall sightings are from September 1 to October 11, with a median of September 30. This is one of the few warblers that seems to be more common in fall than during spring. As of 2013 there were about 45 spring records (Nebraska Bird Review 81:58).

Habitats: Generally associated with low woodlands having brushy tangles, the Connecticut warber forages on or near the ground. 
Comments: One of several grayheaded and yellow-bellied warblers in Nebraska, this species has a conspicuous white eye-ring in both sexes.

\section{MacGillivray's Warbler \\ Geothlypis tolmiei}

This species is a rare spring and fall migrant in western Nebraska, with most records from the Panhandle, but at least five each are for McPherson and Adams counties, and it has been reported as far east as Platte and Lancaster counties. Breeding occurs in the Black Hills, so migration through the Panhandle should be regular, and it is known to migrate through eastern Colorado.

Migration: Twenty-eight spring sightings range from May 5 to June 2, with a median of May 15. Half of the records fall within the period May 1017. Thirteen fall records range from August 21 to October 10, with a median of September 6. Half of the records fall within the period August 29 to September 16.

Habitats: This species is usually associated with dense undergrowth near streams, but migrants can also be found on hillside brush and in dense stands of weeds such as thistle and sunflowers.

Comments: In contrast to the two preceding gray-headed and yellow-bellied warblers (Nashville and Connecticut), the MacGillivray's warbler has an incomplete white eye-ring present only above and below each eye.

\section{Mourning Warbler}

Geothlypis philadelphia

This species is an uncommon spring and fall migrant in eastern Nebraska, becoming rarer westwardly, but it has been reported west to at least Lincoln, Sheridan, and Scotts Bluff counties. Reportedly it formerly bred in southeastern Nebraska (Bruner, Wolcott, \& Swenk, 1904), but there is no current evidence of breeding in the state. Breeding does occur in Minnesota and North Dakota, and migrants appear widely throughout the region.

Migration: Eighty-seven initial spring sightings range from March 20 to May 30, with a median of May 19. Half of the records fall within the period May 15-23. Nineteen final spring sightings are from May 18 to June 10, with a median of May 28. Eighteen initial fall sightings are from September 1 to October 20, with a median of September 8. Eighteen final fall sightings are from September 26 to October 24, with a median of October 7 .

Habitats: Breeding birds are usually found in dense undergrowth along streams, but during migration the birds often inhabit various thickets and tall weedy areas, usually foraging rather close to the ground.

Comments: The mourning warbler closely resembles the Connecticut warbler but lacks white around the eyes. It tends to hop while foraging on the ground, whereas Connecticut warblers walk.

\section{Kentucky Warbler}

Geothlypis formosa

This species is a rare to uncommon spring and fall migrant in southeastern Nebraska and is a summer resident in the lower part of the Missouri River's forested valley, north to at least Sarpy County. It has nested at Platte River State Park, and as of 2012 
there were six state nesting records (Nebraska Bird Review 80:66). It is considered a casual visitor in South Dakota, and it breeds in eastern Kansas and the eastern half of Oklahoma.

Migration: Forty-six initial spring sightings range from April 30 to June 2, with a median of May 10. Half of the records fall within the period May 5-14. Twelve fall records range from July 21 to October 7 , with a median of August 29.

Habitats: During the breeding season this species is found in shrubby moist ravines and bottomlands. No nests of this species were reported during the second atlasing period of the Breeding Bird Atlas project, but two nestings were confirmed in survey blocks from Richardson County (Mollhoff, 2016). There was a confirmed nesting in one block of Richardson County during the first survey (Mollhoff, 2001).

Comments: This very attractive warbler is very dark above and bright yellow below, with yellow eyebrows and a dark ear-patch. It has a surprisingly loud, wren-like song. Breeding Bird Surveys between 1966 and 2015 indicate that the species collectively underwent a survey-wide population decline (0.9\% annually) during that period.

\section{Common Yellowthroat}

Geothlypis trichas

This species is a common to abundant spring and fall migrant and summer resident statewide. It also breeds or migrates throughout the Plains states.

Migration: The range of 107 initial spring sightings is from April 5 to June 10, with a median of May 7.
Half of the records fall within the period May 2-13. The range of 114 final fall sightings is from July 20 to October 29, with a median of September 13. Half of the records fall within the period August 30 to October 3.

Habitats: While in Nebraska this species is found near moist or aquatic sites, especially in tall grasses, emergent vegetation, and shrubs or trees along shorelines. Occasionally it is also seen in upland shrub thickets, retired croplands, weedy residential areas, and overgrown orchards. Nest totals of this species were not reported during the second atlasing period of the Breeding Bird Atlas project, but nestings were confirmed in 24 survey blocks from Sarpy County south to Richardson County (Mollhoff, 2016). By comparison, there were confirmed nestings in 31 blocks during the first survey (Mollhoff, 2001).

Comments: The yellowthroat is another favorite of students when taking ornithology field quizzes; its repeated witchety notes emanate from weedy or shrubby thickets and reveal the species' identity long before the bird itself is generally seen. Breeding Bird Surveys between 1966 and 2015 indicate that the species collectively underwent a survey-wide population decline (1.01\% annually) during that period, and an estimated $0.33 \%$ rate of annual decline in Nebraska.

\section{Hooded Warbler}

Setophaga citrina

This species is a rare spring and fall migrant in eastern Nebraska, having been reported west to Cherry and Dawes counties. Most sightings are from the Douglas-Sarpy counties 
area, but it has also been observed more than once in several other eastern counties, especially Lancaster and Adams. About 50 state records had accumulated through 2003. Vagrants have reached eastern Colorado. Regular breeding is limited to eastern Oklahoma and southeastern Kansas.

Migration: Twenty-four spring sightings range from April 21 to May 27, with a median of May 11. Half of the records fall within the period May 7-15. Five fall records are from August 7 to September 12, with a mean of August 20. There have been six fall records from 2000 to 2016 (Nebraska Bird Review 84:175).

Habitats: Although breeding birds are associated with moist, mature forests having considerable undergrowth, or wooded swamps, migrants are sometimes found in planted woodlands, city parks, and sometimes residential areas.

Comments: The hooded warbler is a stunning bird, the males having a black "executioner's" hood over their head and neck, except for a golden opening that extends back across the forehead and past the eyes to the ears. It is usually seen at ground level in wet locations.

\section{American Redstart}

\section{Setophaga ruticilla}

This species is a common spring and fall migrant throughout Nebraska and a common summer resident in eastern counties. It breeds throughout the Missouri River's forested valley, the Pine Ridge region, probably the entire Niobrara Valley, locally in the Sandhills (Bessey Unit of Nebraska National Forest), and locally in the
Platte Valley west to Adams County or perhaps Phelps County.

Migration: The range of 131 initial spring sightings is from April 10 to June 3, with a median of May 12. Half of the reports fall within the period May 7-16. Ninety final fall sightings range from August 11 to October 19, with a median of September 10. Half of the records fall within the period September 3-17.

Habitats: Breeding usually occurs in moist bottomland woods, usually deciduous and especially in young or second-growth stands, and near the margins of openings in mature forests. Six nests of this species were reported during the second atlasing period of the Breeding Bird Atlas project, and nestings were confirmed in 13 survey blocks, from Sarpy County south to Richardson County (Mollhoff, 2016).

Comments: Probably the breeding range of this species in Nebraska is slowly expanding, as riparian forests along the Platte and other rivers gradually mature. Redstarts resemble little flaming candles as they flit about high in tree canopies, and their variable song is louder than those of most other brilliantly colored species. Breeding Bird Surveys between 1966 and 2015 indicate the species collectively underwent a survey-wide population decline (0.28\% annually) during that period versus a statistically unreliable (based on five survey routes) estimated $2.51 \%$ rate of increase in Nebraska.

\section{Cape May Warbler}

Setophaga tigrina

This species is an uncommon to occasional spring and fall migrant in east- 
ern Nebraska, observed west to Buffalo, Webster, and Hall counties. Breeding occurs in northern Minnesota.

Migration: Fourteen spring records range from April 29 to May 24, with a median of May 12. Five fall records range from September 28 to October 4 , with a mean of September 30. As of 2013 there had been fewer than 30 spring records since 1982 (Nebraska Bird Review 81:71).

Habitats: Migrating birds occupy a variety of habitats, ranging from coniferous or deciduous forests to parks and suburban gardens.

Comments: Another beautiful warbler that visits Nebraska in mid-May, the male Cape May has a chestnut ear-patch and both sexes have heavily striped underparts.

\section{Cerulean Warbler}

Setophaga cerulea

This species is an uncommon spring and fall migrant in eastern Nebraska and a rare, local summer resident along the Missouri River in southeastern Nebraska. It has regularly nested at Fontenelle Forest, Sarpy County (Nebraska Bird Review 46:86), and has also nested in Dakota County. Recent evidence indicates a very small Nebraska breeding population (Nebraska Bird Review 73:124-130). Breeding also occurs in Kansas and Oklahoma.

Migration: Thirty-eight initial spring sightings range from April 26 to June 10, with a median of May 14 . Half of the records fall within the period May 5-18. Eight fall sightings range from July 21 to September 3, with a mean of August 15. Three Kansas records range from September 3 to 21 (Thompson et al., 2011).
Habitats: During the summer this species occurs in moist deciduous bottomland forests as well as mature upland woods. Rather open forests, with large trees and rather sparse undergrowth, seem to be preferred breeding habitats. No nests of this species were reported during the second atlasing period of the Breeding Bird Atlas project, but two probable nestings were confirmed in survey blocks from Sarpy County (Mollhoff, 2016).

Comments: Males of the wellnamed cerulean warbler have a deep blue back color, much like that of the black-throated blue warbler, but the cerulean has a white throat. It is a species of high conservation concern in Nebraska.

\section{Northern Parula}

Setophaga americana

This species is an uncommon spring and fall migrant in eastern Nebraska and a local summer resident in the immediate Missouri Valley, especially from near Omaha south to the Kansas line. A local summer resident in Sarpy County, this species has consistently been observed during summer months in Fontenelle Forest, and an adult was once seen carrying food. Rosche (1994) reported a possible but distinctly extralimital breeding in the Pine Ridge region, and a total of 19 Panhandle records had accrued by 2016. It also breeds in northern Minnesota and eastern Kansas and Oklahoma.

Migration: Thirty-four spring sightings are from April 2 to May 27, with a median of May 5. Half of the records fall within the period April 20 to May 14 . Nine fall records are from 
August 24 to October 2, with a mean of September 12.

Habitats: During summer this species is restricted to swampy woods, especially those rich in Spanish moss or Usnea lichens. On migration they also occur in parks, orchards, and along roadsides. One nest of this species was reported from Dakota County during the second atlasing period of the Breeding Bird Atlas project, and probable breedings occurred in five counties from Richardson north to Sarpy (Mollhoff, 2016).

Comments: Although typical breeding habitat is lacking in Nebraska, the northern parula's regular summer occurrence at Fontenelle Forest deserves further study to better understand its breeding status there. Breeding Bird Surveys between 1966 and 2015 indicate that the species collectively underwent a survey-wide population increase (1.11\% annually) during that period.

\section{Magnolia Warbler}

Setophaga magnolia

This species is an uncommon spring and fall migrant in eastern Nebraska, becoming rarer westwardly. Breeding occurs in northern Minnesota, and migrants appear nearly throughout the Plains states.

Migration: The range of 121 initial spring sightings is from April 20 to June 4 , with a median of May 15 . Half of the records fall within the period May 10-19. Fifteen final spring sightings are from May 14 to June 4, with a median of May 19. Thirteen initial fall sightings range from August 25 to October 5, with a median of September 9 . Twelve final fall sightings are from September 9 to October 24, with a median of October 1.

Habitats: Migrant birds are associated with a wide array of deciduous and coniferous habitats, but they are often in rather thick woods, foraging 20 to 30 feet above ground.

Comments: The magnolia warbler is only one of the many attractive spring migrants that are seen all too rarely, usually during the middle of May. The birds resemble yellow-rumped warblers but have gray crowns and yellow underparts.

\section{Bay-breasted Warbler \\ Setophaga castanea}

This species is an uncommon spring and fall migrant in eastern Nebraska, becoming rarer westwardly but observed as far west as Scotts Bluff County. Breeding occurs in northern Minnesota, and migrants occur through the eastern half of the region.

Migration: Forty-one initial spring sightings range from April 29 to May 27, with a median of May 17. Half of the records fall within the period May 11-19. Eleven final spring sightings are from May 12 to 28, with a median of May 19. Seven initial fall sightings are from September 4 to 20 , with a mean of September 14. Seven final fall sightings are from September 17 to October 14, with a mean of September 22.

Habitats: During migration, the bay-breasted warbler occurs in diverse coniferous and deciduous forest types, favoring conifers, but is also found around residential plantings and shrubbery, usually foraging well above the ground.

Comments: The chestnut or bay- 
colored breast and flank markings of males in this species are its best field marks, and both sexes also have yellowish patches behind the darker ears.

\section{Blackburnian Warbler}

Setophaga fusca

This species is an uncommon spring and fall migrant in eastern Nebraska, becoming rare to the west. It has been reported as far west as Dawes and Scotts Bluff counties. Breeding occurs in northern Minnesota, and migrants are regular in the eastern half of the region.

Migration: Seventy-six initial spring sightings range from April 5 to June 4 , with a median of May 14. Half of the records fall within the period May 10-20. Sixteen final spring sightings are from May 8 to June 8 , with a median of May 17. Ten initial fall sightings range from August 20 to September 30, with a median of September 3. Ten final fall sightings are from September 1 to October 9, with a median of October 3 .

Habitats: Migrating birds are usually found in tall trees, foraging near their tops, and in either hardwood or coniferous forests.

Comments: Probably most people remember vividly the first Blackburnian warbler of their life; the male's intense golden-orange throat and its black-and-gold facial markings render it a sight to remember with fondness.

\section{Yellow Warbler}

\section{Setophaga petechia}

This species is a common spring and fall migrant and summer resident statewide. The species occurs throughout the entire Plains states as a breeder or migrant. In more westerly regions it is limited to rivers or moist wooded habitats.

Migration: The range of 126 initial spring sightings is from March 20 to May 30, with a median of May 7. Half of the records fall within the period May 1-11. The range of 120 final fall sightings is from July 23 to November 6 , with a median of September 3 . Half of the records fall within the period August 21 to September 16.

Habitats: During the breeding season, these birds prefer rather wet habitats, such as brushy edges of swamps, marshes, or creeks, but they also nest commonly in roadside thickets, hedgerows, orchards, and forest edges, avoiding both heavy forests and grassy environments lacking both trees and shrubs. Fifteen nests of this species were reported during the second atlasing period of the Breeding Bird Atlas project, and nestings were confirmed in 53 survey blocks (Mollhoff, 2016).

Comments: Perhaps the commonest of our nesting arboreal warblers, the yellow warbler sings an anglicized song of Sweet, sweet sweet, I am sweet that permeates our summer woodlands, and its flash of golden color confirms its identification. It is often parasitized by brown-headed cowbirds and, being unable to expel the cowbird's large eggs, simply adds a new nest lining over its old clutch and starts over. Breeding Bird Surveys between 1966 and 2015 indicate that the species collectively underwent a survey-wide population decline (0.61\% annually) during that period versus a $2.36 \%$ rate of annual increase in Nebraska. 


\section{Chestnut-sided Warbler}

Setophaga pensylvanica

This species is an uncommon spring and fall migrant in eastern Nebraska, becoming rarer westwardly but observed as far west as Dawes and Scotts Bluff counties. It has bred at least twice in the state, including a 1975 nesting in Scotts Bluff County (Nebraska Bird Review 44:10) and an 1894 record for the vicinity of Omaha. It breeds in North Dakota and Minnesota, and is a migrant through the Plains states except for the westernmost regions.

Migration: Sixty-one initial spring sightings are from April 25 to June 4, with a median of May 15. Half of the records fall within the period May 1219. Nineteen final spring sightings are from May 6 to June 4, with a median of May 23. Six initial fall sightings are from August 17 to September 19, with a mean of September 2. Seven final fall sightings are from September 1 to October 16, with a mean of September 26.

Habitats: Migrants are usually found in thickets along woodland edges, and when breeding the species occurs in low shrubbery, briar thickets, forest clearings or edges, overgrown pastures, and similar low-stature habitat.

Comments: This species is rather puzzling because it should nest in the state, but there are only two records, and they are situated at opposite ends of Nebraska. There are no nesting records for South Dakota, so perhaps these two records are simply flukes. Breeding Bird Surveys between 1966 and 2015 indicate the species collectively underwent a survey-wide pop- ulation decline (1.15\% annually) during that period.

\section{Blackpoll Warbler}

Setophaga striata

This species is a common spring and fall migrant in eastern Nebraska, becoming uncommon to rare in western parts of the state. Migrants occur through most of the Plains states, mostly in the eastern half. Breeding does not occur south of Canada.

Migration: The range of 120 initial spring sightings is from April 9 to June 2, with a median of May 12. Half of the records fall within the period May 8-18. Forty-seven final spring sightings are from May 1 to 30, with a median of May 20. Seven initial fall sightings are from August 28 to September 22, with a mean of September 9. Seven final fall sightings are from September 1 to October 21, with a mean of September 26.

Habitats: During migration this species is usually found in tall deciduous trees, such as cottonwoods, and generally occurs in streamside forests.

Comments: Blackpoll warblers are one of the two warbler species that are essentially all black and white in plumage; the rather similar blackand-white warbler has darker cheeks and a white stripe above the eyes.

\section{Black-throated Blue Warbler}

Setophaga caerulescens

This species is a rare spring and fall migrant in eastern Nebraska, observed in at least 11 counties west as far as Garden and Scotts Bluff counties, as well as in Colorado. It has been seen three or more times in 
Douglas-Sarpy, Lancaster, Adams, and McPherson counties. Breeding occurs in northern Minnesota, and migrants are most common in the eastern half of the region.

Migration: Nine spring records range from April 23 to May 24, with a mean of May 10. Twenty-seven fall records range from August 5 to October 20, with a median of September 23. Half of the records fall within the period September 19 to October 5 . The species is notably more common in fall than during spring. As of 2016 there were still only 32 spring records for the state (Nebraska Bird Review 84:81).

Habitats: While on migration this species tends to occur in low shrubby areas, such as woodlands, parks, and residential gardens.

Comments: Males of this stunning warbler are dark indigo blue above and contrastingly white below, except for a black throat and upper chest. Like many of the most attractive warblers, it is present in the state for only a few weeks.

\section{Palm Warbler}

\section{Setophaga palmarum}

This species is an uncommon spring and fall migrant in eastern Nebraska, becoming rare westwardly. It has been reported from as far west as Dawes County. Breeding occurs in northern Minnesota.

Migration: April 16 to June 2, with a median of May 5. Half of the records fall within the period May 1-9. Ten final spring sightings are from April 19 to May 24, with a median of May 9. Ten fall records range from September 2 to November 10, with a median of October 5 . Half of the records fall within the period October 1-6.

Habitats: Generally associated with brushy fields, open wooded areas, or wooded edges or clearings in woods, where the birds can forage on the ground.

Comments: Palm warblers probably never are found in palm trees except on their subtropical or tropical wintering grounds. They are prone to wagging their tails are they forage, often at ground level.

\section{Pine Warbler}

Setophaga pinus

This species is a rare migrant or vagrant in eastern Nebraska. Most of the Nebraska records are for Lancaster County. Except for Oklahoma, where it breeds, it is casual to accidental throughout the Plains states. By 2011 there were 21 state records, but only seven documented (Nebraska Bird Review 79:64), and 41 fall reports by 2015 (Nebraska Bird Review 83:178). There are at least four Panhandle records (Nebraska Bird Review 76:150).

Migration: Ten spring sightings range from April 17 to May 27, with a median of May 13. By 2016 there were still only eight fully documented spring records for Nebraska (Nebraska Bird Review 81:73). Four fall records are from September 7 to 22, with a mean of September 13. Most fall Kansas records range from mid-September to early October (Thompson et al., 2011).

Habitats: Migrating pine warblers are associated with a wide variety of forests, especially pine forests, but they also utilize deciduous forests and orchards. 


\section{Yellow-rumped Warbler}

Setophaga coronata

This species is a common to abundant spring and fall migrant statewide, and a local summer resident in the Pine Ridge region. Breeding also occurs in the Black Hills and northern Minnesota, and migrants occur throughout the entire Plains states.

Migration: The range of 75 initial spring sightings is from February 14 to May 24, with a median of April 23. Half of the records fall within the period April 12-29. Fifty-three final spring sightings are from April 27 to May 29, with a median of May 14. Eighty initial fall sightings are from August 10 to November 1, with a median of September 28. Half of the records fall within the period September 20 to October 3. Seventy-seven final fall sightings are from September 10 to December 18 , with a median of October 22.

Habitats: The species is widespread in wooded habitats during migration, arriving well before the leaves appear, and often wintering as far north as southern Oklahoma where it forages on juniper berries. Breeding birds occupy coniferous forests, usually nesting in scattered trees, open plantings, or streamside thickets rather than dense, mature forests. No nests of this species were reported during the second atlasing period of the Breeding Bird Atlas project, but nestings were confirmed in five survey blocks in Sioux, Dawes, and Sheridan counties (Mollhoff, 2016).

Comments: This species is usually the first warbler to return to Nebraska in spring, usually arriving just as the first hardwood trees are leafing out, and during the fall sometimes persisting until late December. In the eastern part of the state, most birds are of the white-throated (Myrtle) taxon, whereas in the Panhandle the majority are of the yellow-throated (Audubon's) race.

\section{Yellow-throated Warbler}

Setophaga dominica

This species is a rare to occasional migrant in eastern Nebraska, becoming very rare westwardly. A very local breeding population is present in Fontenelle Forest (Nebraska Bird Review 62:113). It has been observed west to Scotts Bluff and Sheridan counties and has been seen several times in Lincoln, Adams, and Thayer counties. It normally breeds from extreme southeastern Kansas southward through Oklahoma. It is accidental in eastern South Dakota and eastern Colorado.

Migration: Twenty-one spring sightings range from April 11 to May 28, with a median of May 8 . Half of the records fall within the period May 3-15. Five fall records range from July 14 to October 1 , with a mean of September 9 .

Habitats: This species is normally associated with rather swampy forests, especially those rich in Spanish mosses. Farther north it occurs in streamside sycamore forests, usually foraging high in the trees. No nests of this species were reported during the second atlasing period of the Breeding Bird Atlas project, but nestings were confirmed in Seward and Douglas counties (Mollhoff, 2016).

Comments: Like the northern parula and prothonotary warblers, the yellow-throated warbler evidently 
nests as an isolated population at Fontenelle Forest.

\section{Prairie Warbler}

Setophaga discolor

This species is an extremely rare vagrant in eastern Nebraska. There are two questionable early records of breeding in Richardson and Dakota counties. The species has been reported from as far west as McPherson County and has also been sighted in Buffalo and Adams counties in southcentral Nebraska. It is accidental in South Dakota and a summer resident in eastern Kansas and Oklahoma.

Migration: Eight spring records are from April 21 to June 1, with a mean of May 10. There were 18 spring records as of 2014 (Nebraska Bird Review 82:68). One fall record is for September 23. Fall records in Kansas are from September 2 to 23 (Thompson et al., 2011).

Habitats: This species is generally associated with old pastures, hillsides with scattered woody vegetation, and similar shrubby or woodland habitats but not true prairie.

\section{Grace's Warbler}

Setophaga graciae

Accidental. A male of this southwestern species was photographed at Crescent Lake National Wildlife Refuge, May 16, 2008 (Nebraska Bird Review 77:85). Its nearest breeding area is southwestern Colorado.

\section{Black-throated Gray Warbler}

Setophaga nigrescens

This southwestern species is an extremely rare vagrant. It has been observed during May and August in Lan- caster, Adams, Scotts Bluff, Cherry, Garden, and McPherson counties. It was seen at Oliver Reservoir on May 1, 1999 (Nebraska Bird Review 67:62) and again on September 7, $2001(\mathrm{Ne}-$ braska Bird Review 69:183). One was seen August 25, 2002, at Arbor Day Farm, Nebraska City, and one hit a Lincoln window on September 1, 2002 (Nebraska Bird Review 70:160).

Habitats: This species is normally associated with dry slopes, thickets, and oak or pine woodlands. Its nearest breeding area is western Wyoming.

\section{Townsend's Warbler}

Setophaga townsendi

This western species is an extremely rare vagrant, with at least nine spring and six fall records. It was initially collected in 1911 in Dawes County, but during the 1970s it was observed in numerous locations, including at least seven counties. It has also been reported in South Dakota, Kansas, and Oklahoma.

Migration: Six spring records date from April 25 to May 17, with a mean of May 7. There were 11 spring records as of 2014 (Nebraska Bird Review 82:69). Six fall sightings are from August 30 to September 17, with a mean of September 9.

Habitats: This species is often associated with low oak, juniper, or pine woodlands on migration but is found in tall coniferous forests during the breeding season. Its nearest breeding area is central Idaho.

\section{Hermit Warbler}

Setophaga occidentalis

Accidental. This far-western warbler was photographed at Crescent Lake 
National Wildlife Refuge on May 11, 2010 (Nebraska Bird Review 78:9, 5657). It was also reported near Creighton on May 15, 2002 (Nebraska Bird Review 70:72). There is a sight record for McPherson County in September 1973 (Nebraska Bird Review 42:42). Its nearest breeding area is in California.

\section{Black-throated Green Warbler}

Setophaga virens

This species is an uncommon spring and fall migrant in eastern Nebraska, rarely reported as far west as Lincoln and McPherson counties, but it has straggled to Colorado. It breeds in northern Minnesota, and migrants occur in the eastern half of the region.

Migration: Fifty-four initial spring sightings range from April 18 to June 4, with a median of May 9. Half of the records fall within the period May 3-15. Six final spring sightings are from May 9 to 24, with a mean of May 16. Sixteen initial fall sightings are from August 30 to October 2, with a median of September 18. Sixteen final fall sightings are from September 12 to October 21, with a median of October 5 .

Habitats: Associated with a wide variety of deciduous or coniferous woodlands on migration but most often seen in second-growth forest, especially in willows and elms.

Comments: This warbler is not particularly "green" but is instead olivegreen above with a mostly golden face and a black throat and upper breast.

\section{Canada Warbler}

Cardellina canadensis

This species is an occasional spring and fall migrant in the eastern third of Nebraska, and is rarely reported as west to McPherson County. Breeding occurs in Minnesota, and migrants are regular in the eastern half of the Plains states.

Migration: Twenty-eight spring sightings range from April 28 to June 6 , with a median of May 20. Half of the records fall within the period May 17-25. Fourteen initial fall sightings range from August 10 to October 2, with a median of September 1 . Thirteen final fall sightings are from September 3 to October 8, with a median of September 16.

Habitats: Migrants are usually found in brushy areas near streams, but they sometimes also range well up into trees at a considerable distance from water.

Comments: The attractive black "beaded necklace" that drapes down over the yellow breast of male Canada warblers provides for instant identification of this species. Even in females a shadowy brown necklace is visible.

\section{Wilson's Warbler}

\section{Cardellina pusilla}

This species is a common spring and fall migrant in eastern Nebraska, becoming uncommon in the western half of the state. Elsewhere, the species is a regular migrant throughout the Plains states.

Migration: The range of 101 initial spring sightings is from April 14 to June 4, with a median of May 12. Half of the records fall within the period May 5-16. Thirty-six final spring sightings range from April 28 to May 30, with a median of May 19. Sixty-nine initial fall sightings range from August 9 to September 26, with a median of 
September 1 . Half of the records fall within the period August 26 to September 7. Sixty-nine final fall records are from September 2 to October 22, with a median of September 26.

Habitats: Migrants are associated with rank stands of weeds and low, shrubby vegetation, often near streams.

Comments: The little black skullcap that sits atop the crown of males is the most distinctive field mark of this species. Like the hooded warbler, it too likes moist to boggy habitats.

\section{Family Cardinalidae (Cardinals, Tanagers, and Grosbeaks)}

\author{
Hepatic Tanager \\ Piranga flava \\ Accidental. This southwestern tana- \\ ger was photographed at West Point, \\ Cuming County, on January 6, 1999. \\ Its nearest breeding area is southern \\ Colorado.
}

\section{Summer Tanager}

Piranga rubra

This species is an uncommon spring and fall migrant and a summer resident in southeastern Nebraska (especially the Indian Cave area) north to Fontenelle Forest and Platte River State Park. It is occasionally seen farther west, rarely to Scotts Bluff County. By 2016 there had been 12 Panhandle records (Nebraska Bird Re- view 84:58). Breeding also occurs in eastern Kansas and Oklahoma.

Migration: Twenty-nine initial spring sightings range from April 25 to May 31, with a median of May 15. Half of the records fall within the period May 12-20. Two late fall sightings are for September 5 and 15. Fall Kansas records range from early September to October 27 (Thompson et al., 2011).

Habitats: Like the scarlet tanager, the summer tanager favors mature deciduous forests, especially bottomland forests, and often nests in tall oak trees. It also nests in mixed and sometimes open coniferous forests, and in general it may favor slightly lower and more open woodlands than does the scarlet tanager. One nest of this species from Sarpy County was reported during the second atlasing period of the Breeding Bird Atlas project, and nestings were confirmed in two survey blocks (Mollhoff, 2016). There also was one confirmed nesting in Sarpy County during the first survey period.

Comments: Perhaps the summer tanager is expanding its breeding range in southeastern Nebraska; Schramm Park is now (2018) a nearly certain location for seeing these birds, and they have increasingly appeared in Lincoln.

\section{Scarlet Tanager}

Piranga olivacea

This species is an uncommon spring and fall migrant in eastern Nebraska, becoming rare westwardly; it rarely occurs as far west as Keith, Garden, and Dawes counties. It is a summer resident in the Missouri River's 
forested valley, westward in the Niobrara Valley to at least Cherry County, and west in the Platte Valley to about Douglas County. It is believed to have bred as far west as Lincoln County. Breeding also occurs in the eastern Dakotas and eastern parts of Kansas and Oklahoma.

Migration: The range of 132 initial spring sightings is from April 5 to June 10, with a median of May 10. Half of the records fall within the period May 5-15. Twenty-three final fall records are from July 21 to October 3, with a median of August 23. Half of the records fall within the period August 5 to September 16 .

Habitats: In Nebraska this species is restricted primarily to mature hardwood forests in river valleys, hill slopes, and valleys; less frequently it is found in city parks and mature orchards. No nests of this species were reported during the second atlasing period of the Breeding Bird Atlas project, but nestings were confirmed in five blocks in Sarpy and Dixon counties (Mollhoff, 2016). There were also confirmed nestings in three blocks of Sarpy and Dixon counties during the first survey (Mollhoff, 2001).

Comments: Few Nebraska birds are more brilliantly plumaged than male scarlet tanagers; they are as bright as male northern cardinals, and their jet-black wings make them even more memorable, as well as separated from summer tanagers. Breeding Bird Surveys between 1966 and 2015 indicate that the species collectively underwent a survey-wide population decline (0.22\% annually) during that period versus an estimated $2.59 \%$ rate of annual increase in Nebraska.

\section{Western Tanager}

\section{Piranga ludoviciana}

This species is an uncommon spring and fall migrant in western Nebraska, and a summer resident in the Pine Ridge region, possibly extending east in the Niobrara Valley far enough to come into contact occasionally with the scarlet tanager (Nebraska Bird Review 29:19). Breeding also occurs in western South Dakota, and migrants are encountered east to western Kansas and western Oklahoma.

Migration: Sixty-three initial spring sightings range from May 3 to June 8, with a median of May 19. Half of the records fall within the period May 13-24. Twenty-two final fall records are from August 14 to October 10, with a median of September 15 . Half of the records fall within the period September 4-23.

Habitats: In the Black Hills and Pine Ridge regions, this species is mainly associated with pine forests and secondarily with deciduous forests along rivers or in gulches and canyons. No nests of this species were reported during the second atlasing period of the Breeding Bird Atlas project, but nestings were confirmed in six blocks in Sioux, Dawes, and Sheridan counties (Mollhoff, 2016). There were confirmed nestings in two blocks of Sheridan and Dawes counties during the first survey (Mollhoff, 2001).

Comments: Although birders in western Nebraska may long to see scarlet and summer tanagers, the western tanager is a very satisfactory substitute for these. Its bright red head and golden yellow body with contrasting black wings, tail, and back make a visual treat. Breeding Bird 
Surveys between 1966 and 2015 indicate the species collectively underwent a survey-wide population increase (1.28\% annually) during that period.

\section{Northern Cardinal}

Cardinalis cardinalis

This species is a common permanent resident in eastern Nebraska, becoming uncommon to occasional in western Nebraska. Of the Panhandle records, most (more than 50) are from Scotts Bluff and the North Platte Valley (Nebraska Bird Review 85:22). It breeds west at least to Morrill County along the North Platte River, and to the Colorado border in the South Platte and Republican Valleys, but it is nearly absent from the western Sandhills and the Pine Ridge region. It breeds widely in the Plains states, north to southern North Dakota and locally west to eastern Colorado and the Texas Panhandle.

Habitats: Throughout the year this species is associated with forest edges or brushy forest openings, parks and residential areas planted to shrubs and low trees, second-growth woods, and riverbottom gallery forests in grasslands. Fifteen nests of this species were reported during the second atlasing period of the Breeding Bird Atlas project, and nestings were confirmed in 42 survey blocks (Mollhoff, 2016). There were confirmed nestings in 40 blocks during the first survey (Mollhoff, 2001).

Comments: Nearly everyone in $\mathrm{Ne}-$ braska is familiar with the northern cardinal except for those living in the northwestern corner of the state. They are among the first birds to be- gin singing in spring and are early nesters as well. They are often parasitized by brown-headed cowbirds. Breeding Bird Surveys between 1966 and 2015 indicate the species collectively underwent a survey-wide population increase (0.32\% annually) during that period, and Nebraska had an estimated $1.77 \%$ rate of annual increase.

\section{Rose-breasted Grosbeak}

Pheucticus ludovicianus

This species is a common spring and fall migrant and a summer resident in eastern Nebraska. It breeds west to at least Holt, Garfield, and Phelps counties, with the western limits confused by hybridization with the black-headed grosbeak. Breeding occurs from central North Dakota south through South Dakota, eastern Kansas, and eastern Oklahoma.

Migration: The range of 134 initial spring sightings is from April 10 to June 3, with a median of May 7. Half of the records fall within the period May 1-10. Seventy-one final fall sightings are from July 23 to November 22, with a median of September 10. Half of the records fall within the period August 23 to September 24.

Habitats: During the breeding season this species occurs in relatively open deciduous forests on floodplains, slopes, and bluffs. A denser understory is apparently not so important to this species as it is to the blackheaded grosbeak. No nests of this species were reported during the second atlasing period of the Breeding Bird Atlas project, but nestings were confirmed in 23 survey blocks (Mollhoff, 2016). There were confirmed nest- 
ings in 35 blocks during the first survey (Mollhoff, 2001).

Comments: Rose-breasted grosbeaks hybridize fairly frequently with black-headed grosbeaks in the western Platte Valley, which produces some very strange-looking birds (West, 1962). Breeding Bird Surveys between 1966 and 2015 indicate that the species collectively underwent a survey-wide population decline (0.86\% annually) during that period, and Nebraska had an estimated $2.12 \%$ rate of annual decline.

\section{Black-headed Grosbeak}

Pheucticus melanocephalus

This species is a common spring and fall migrant and summer resident in western Nebraska. It breeds eastward locally to at least Rock, Garfield, and Hall counties, but the eastern limits are confused by hybridization with the rose-breasted grosbeak (West, 1962). Individuals have been seen as far east as Douglas County. Breeding also occurs west of the Missouri River in the Dakotas and in western Kansas and eastern Colorado.

Migration: The range of 114 initial springs sightings is from April 23 to June 8, with a median of May 14. Half of the records fall within the period May 10-19. Thirty-six final fall sightings are from July 20 to September 30, with a median of August 29. Half of the records fall within the period $\mathrm{Au}$ gust 20 to September 8.

Habitats: While in Nebraska this species occupies relatively open stands of deciduous forest in floodplains or uplands, especially those with well-developed understories. It also occurs in orchards, brushy wood- lands, and parks or suburbs with many trees. One nest of this species was reported during the second atlasing period of the Breeding Bird Atlas project, and nestings were confirmed in 13 survey blocks east to Gosper County (Mollhoff, 2016). There were confirmed nestings in eight blocks east to Harlan County during the first survey (Mollhoff, 2001).

Comments: As noted for the rosebreasted grosbeak, the black-headed grosbeaks of western Nebraska are affected by rose-breasted grosbeaks, and breeding records of the past were more widespread than those that are more recent. Thus the species may be retreating under the influence of competition and interbreeding effects from rose-breasted grosbeaks. Breeding Bird Surveys between 1966 and 2015 indicate that the species collectively underwent a survey-wide population decline (0.72\% annually) during that period, and Nebraska had an estimated $1.31 \%$ rate of annual increase.

\section{Blue Grosbeak}

Passerina caerulea

This species is an uncommon spring and fall migrant and a local summer resident nearly statewide. It is very uncommon and highly local in the southeastern counties and rare in the Pine Ridge region. Breeding occurs from central South Dakota and western Iowa southward throughout the Plains states.

Migration: The range of 129 initial spring sightings is from April 18 to June 10, with a median of May 20. Half of the records fall within the period May 16-24. Eighty-eight final fall 

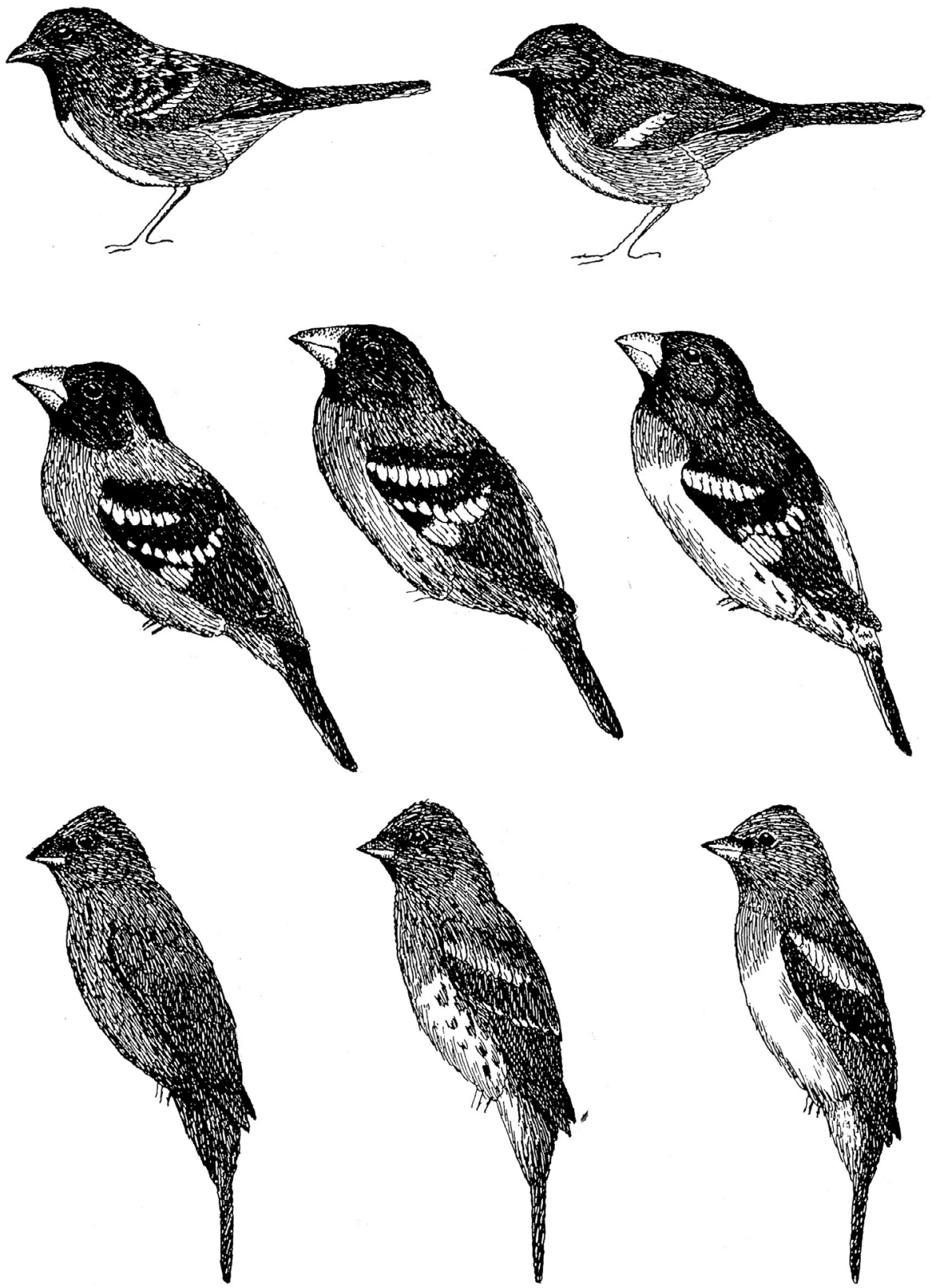

Figure 14. Males of western (left) and eastern replacement species and their hybrids, including spotted and eastern towhees (top), black-headed and rosebreasted grosbeaks (middle), and lazuli and indigo buntings (bottom) 
sightings are from July 20 to October 13, with a median of August 27. Half of the records fall within the period August 12 to September 6.

Habitats: During the breeding season, this species prefers weedy pastures, old fields with scattered saplings, forest edges, streamside thickets, and hedgerows. Like the dickcissel, it is frequently parasitized by brown-headed cowbirds in these habitats. Several nests of this species were reported during the second atlasing period of the Breeding Bird Atlas project, and nestings were confirmed in 32 survey blocks (Mollhoff, 2016). There were confirmed nestings in 21 blocks during the first survey (Mollhoff, 2001).

Comments: This attractive and, in the case of males, sky-blue bird seems out of place in a Nebraska prairie pasture. Males may be easily confused with the smaller indigo bunting, but the grosbeaks have bright brown edges on their upper wing-coverts. Breeding Bird Surveys between 1966 and 2015 indicate that the species had a survey-wide population increase (0.81\% annually) in that period, and Nebraska exhibited an estimated 1.8\% rate of increase.

\section{Lazuli Bunting}

Passerina amoena

This species is an uncommon spring and fall migrant and a summer resident in western Nebraska. Breeding is generally limited to a region west of a line from Keith County to eastern Cherry County and is most prevalent in the Panhandle. Eastern limits are confused by hybridization with the indigo bunting (Sibley \& Short,
1959; Emlen, Rising, \& Thompson, 1975). However, breeding generally occurs in the western parts of the Dakotas, eastern Colorado, western Kansas, and the panhandles of Texas and Oklahoma.

Migration: The range of 113 initial spring sightings is from March 18 to June 9, with a median of May 16 . Half of the records fall within the period May 10-20. Twenty final fall sightings are from July 21 to September 30, with a median of August 25. Half of the records fall within the period August 19-30.

Habitats: During the breeding season, this species occupies the same habitats as does the indigo bunting, namely successional habitats offering a diversity of shrubs, low trees, and herbaceous vegetation. One nest of this species was reported during the second atlasing period of the Breeding Bird Atlas project, and nestings were confirmed in three survey blocks of Banner, Scotts Bluff, and Dawes counties (Mollhoff, 2016). There were confirmed nestings in three blocks of Scotts Bluff and Sioux counties during the first survey (Mollhoff, 2001).

Comments: This sparrow-sized bird is one of several western species that reach the eastern edges of its range in western Nebraska. Females of the two species are almost impossible to distinguish, and hybrids make the matter even worse. Breeding Bird Surveys between 1966 and 2015 indicate the species collectively underwent a survey-wide population decline (0.21\% annually) during that period, and $\mathrm{Ne}$ braska had an estimated $0.91 \%$ rate of annual increase. 


\section{Indigo Bunting}

Passerina cyanea

This species is an uncommon spring and fall migrant and a summer resident in eastern Nebraska. Breeding extends west locally to the Pine Ridge region, central Sandhills, and the Wyoming and Colorado borders along the Platte Rivers. It is nearly absent from the Panhandle and western Sandhills, but the range limits are confused by hybridization with the lazuli bunting (Short, 1961). Breeding also occurs widely in the other Plains states, west to the Black Hills and eastern Colorado.

Migration: The range of 99 initial spring sightings is from March 24 to June 8, with a median of May 10. Half of the records fall within the period May 5-16. Fifty-seven final fall sightings are from July 29 to October 28, with a median of August 28. Half of the records fall within the period August 15 to September 10.

Habitats: During the breeding season, this species occurs in relatively open forests on floodplains or uplands. It is typically found at forest edges or other locations where the shrub density is rather high and the forest canopy is open, and thus it is often associated with second-growth or disturbed vegetation. One nest of this species was reported during the second atlasing period of the Breeding Bird Atlas project, and nestings were confirmed in 15 survey blocks east to Gosper County (Mollhoff, 2016). There were confirmed nestings in 22 blocks west to Scotts Bluff County during the first survey (Mollhoff, 2001).

Comments: Many people gasp involuntarily when they first see a male indigo bunting in bright sunlight; it rivals the blue grosbeak in the intensity of its blue coloration. This coloring is produced by light scattering, just as the "blue" of a clear sky is generated. In shade the birds are transformed into gray tones. Breeding Bird Surveys between 1966 and 2015 indicate the species had a survey-wide population decline (0.73\% annually) in that period, and Nebraska had an estimated $1.15 \%$ rate of annual decline.

\section{Painted Bunting}

Passerina ciris

Extremely rare. This southern bunting was photographed at the Crane Trust Nature Center, Hall County, May 3031, 1996. Sight records exist for Scotts Bluff County in May 1927, Adams County in May 1962, Kearney County in April 1960, and Sarpy County in May 1967. It was also reported from Morrill County on May 12, 1996, and Hall County on May 30, 1996 (Brogie, 1997). Nine state records existed through 2003, the most recent being May 23, 2003 (Nebraska Bird Review 73:81). Its nearest breeding area is in northern Kansas.

\section{Dickcissel}

Spiza americana

This species is a spring and fall migrant and a summer resident nearly statewide, except the extreme northwestern and southwestern parts of Nebraska, or generally east of a line from Sioux County to Dundy County. It is uncommon to rare in the Panhandle but a common to abundant summer resident elsewhere in the state. Breeding occurs in all the other Plains states, but it is rare in the western- 
most regions and absent from northern Minnesota.

Migration: The range of 199 initial spring sightings is from April 16 to June 10, with a median of May 16. Half of the records fall within the period May 6-24. The range of 105 final fall sightings is from July 21 to October 30, with a median of August 22. Half of the records fall within the period August 10 to September 2.

Habitats: While in Nebraska this species is associated with grasslands having a combination of tall grasses, forbs, and shrubs, and with various croplands, especially alfalfa, clover, and timothy. Although generally abundant in eastern Nebraska, dickcissels are heavily parasitized by brownheaded cowbirds. Ninety-two nests of dickcissels were reported during the second atlasing period of the Breeding
Bird Atlas project ( $67 \%$ of the nests were parasitized by cowbirds), and nestings were confirmed in 62 survey blocks east to Gosper County (Mollhoff, 2016). There were confirmed nestings in 52 blocks west to Cheyenne County during the first survey (Mollhoff, 2001).

Comments: Dickcissels are still common over much of Nebraska, but their numbers have greatly declined nationwide. In part this decline has resulted from poisoning by pesticides on their wintering grounds in South America, and perhaps also because of their sensitivity to parasitism by cowbirds. Breeding Bird Surveys between 1966 and 2015 indicate the species collectively underwent a survey-wide population decline (0.36\% annually) during that period, and Nebraska had an estimated $1.04 \%$ rate of annual decline.

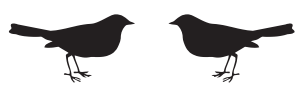




\section{References}

Abraham, K. F., R. L. Jefferies, and R. T. Alisauskas. 2005. The dynamics of landscape change and Snow Geese in midcontinent North America. Global Change Biology 11:841-855.

Alisauskas, R. T., R. F. Rockwell, K. W. Dufour, E. G. Cooch, G. Zimmerman, K. L. Drake, J. O. Leafloor, T. J. Moser, and E. T. Reed. 2011. Harvest, Survival, and Abundance of Mid-continent Lesser Snow Geese Relative to Population Reduction Efforts. Wildlife Monographs 179. The Wildlife Society, Bethesda, MD.

American Ornithologists' Union (AOU). 1998. The AOU Checklist of North American Birds. 7th ed. AOU, Washington, DC (and annual supplements in Auk to 2017).

Banko, W. 196o. The trumpeter swan. US Fish and Wildlife Service, North American Fauna 63:1-214.

Baskett, T. S. 1947. Nesting and production of the ring-necked pheasant in north-central Iowa. Ecological Monographs 17:1-30.

Baxter, W. L., and C. W. Wolfe. 1973. The Ring-necked Pheasant in Nebraska. Nebraska Game and Parks Commission, Lincoln, NE.

Bent, A. C. 1919. Life Histories of North American Diving Birds. US National Museum Bulletin 107:1-245. (Gaviidae, Podicipedidae, Alcidae)

- 1921. Life Histories of North American Gulls and Terns. US National Museum Bulletin 113:1-345. (Laridae)

- 1922. Life Histories of North American Petrels and Pelicans and Their Allies. US National Museum Bulletin 121:1-339. (Diomedidae, Hydrobatidae, Phaethontidae, Sulidae, Anhingidae, Phalacrocoracidae, Pelecanidae)

- 1923. Life Histories of North American Wild Fowl, Part 1. US National Museum Bulletin 126:1-245.
(Most Anatinae except Mergini and

Dendrocygninae)

- 1925. Life Histories of North American Wild Fowl, Part 2. US

National Museum Bulletin 130:1-276.

(Mergini, Anserinae, Dendrocygninae)

- 1926. Life Histories of North

American Marsh Birds. US National

Museum Bulletin 135:1-490. (Ardeidae,

Gruidae, Rallidae)

- 1927. Life Histories of North

American Shore Birds. Part I. US

National Museum Bulletin 142:1-420.

(Scolopacidae, part)

—. 1929. Life Histories of North

American Shore Birds. Part II. US

National Museum Bulletin 146:1-412.

(Scolopacidae, part)

_. 1932. Life Histories of North

American Gallinaceous Birds. US

National Museum Bulletin 162:1-490.

(Galliformes)

- 1937. Life Histories of North

American Birds of Prey. Part 1. US

National Museum Bulletin 167:1-409.

(Falconiformes except Falconidae)

- 1938. Life Histories of North

American Birds of Prey. Part 2. US

National Museum Bulletin 170:1-428.

(Falconidae, Tytonidae, Strigidae)

_ 1939. Life Histories of North

American Woodpeckers. US National

Museum Bulletin 174:1-322. (Picidae)

- 1940. Life Histories of North

American Cuckoos, Goatsuckers,

Hummingbirds, and Their Allies. US

National Museum Bulletin 176:1-506.

(Psittacidae, Cuculidae, Alcedinidae,

Caprimulgidae, Apodidae, Trochilidae)

_ 1942. Life Histories of North

American Flycatchers, Larks, Swallows, and Their Allies. US National Museum Bulletin 179:1-555. (Tyrannidae, Alaudidae, Hirundinidae)

- 1946. Life Histories of North

American Jays, Crows, and Titmice. US 
National Museum Bulletin 191:1-495. (Corvidae, Paridae)

- 1948. Life Histories of North

American Nuthatches, Wrens, Thrashers, and Their Allies. US National Museum Bulletin 195:1-475. (Sittidae, Certhiidae, Cinclidae, Troglodytidae, Mimidae)

\section{- 1949. Life Histories of North} American Thrushes, Kinglets, and Their Allies. US National Museum Bulletin 196:1-454. (Turdidae, Polioptilidae, Regulidae)

- 1950. Life Histories of North American Wagtails, Shrikes, Vireos, and Their Allies. US National Museum Bulletin 197:1-411. (Motacillidae, Bombycillidae, Ptilogonatidae, Laniidae, Sturnidae, Vireonidae)

- 1953. Life Histories of North American Wood Warblers. US National Museum Bulletin 203:1-734. (Parulidae, Ictariidae)

- 1958. Life Histories of North American Blackbirds, Orioles, Tanagers, and Allies. US National Museum Bulletin 211:1-549. (Icteridae, Thraupidae)

Bent, A. C., et al. 1968. Life Histories of North American Cardinals, Grosbeaks, Buntings, Towhees, Finches, Sparrows, and Allies. Parts 1-3. US National Museum Bulletin 237. 1,248 pp. (Part 1: Cardinalidae, Fringillidae, part; Part 2: Emberizidae, part; Part 3: Emberizidae, part, Calcariidae)

Bergin. T. 1987. A multivariate hierarchical examination of habitat selection in Tyrannis verticalis. MS thesis, University of Nebraska-Lincoln, Lincoln, NE.

Bicak, T. K. 1977. Some eco-ethological aspects of a breeding population of long-billed curlews (Numenius americanus) in Nebraska. MA thesis, University of Nebraska at Omaha, Omaha, NE.

Bleed, A., and C. Flowerday (eds.). 1989. An Atlas of the Sand Hills. Conservation and Survey Division, Institute of Agriculture and Natural Resources, University of Nebraska-Lincoln, Lincoln, NE. 238 pp. (2nd ed., 1990; 3rd ed., 1998)

Bock, C. E., and W. C. Scharf. 1994. A nesting population of Cassin's sparrows in the Sandhills of Nebraska. Journal of Field Ornithology 65:472-475.

Bomberger, M. B. 1982. Aspects of the breeding biology of Wilson's Phalarope in western Nebraska. MS thesis, University of Nebraska-Lincoln, Lincoln, NE.

- 1984. Nesting habitat of Wilson's phalarope in western Nebraska. Wilson Bulletin 96:126-128.

Boyle, W. J., and R. H. Bauer. 1994. Birdfinding in Forty National Forests and Grasslands. Birding (supplement) 26(2):186 pp.

Bray, T. E., P. K. Padelford, and W. R. Silcock. 1986. The Birds of Nebraska: A Critically Evaluated List. Bellevue, NE: Published by the authors. 109 pp.

Brogie, M. A. 1997. 1996 (Eighth) report of the NOU Records Committee. Nebraska Bird Review 65(3):115-126.

-.1999. 1998 (Tenth) report of the NOU Records Committee. Nebraska Bird Review 67(4):141-152.

- 2009. The official list of the birds of Nebraska: 2009. Nebraska Bird Review 77(3):112-131. https://digitalcommons. unl.edu/nebbirdrev/1080/

- 2010a. Nebraska Ornithologists' Union Records Committee: A review of the first 25 years (1985-2009). Nebraska Bird Review 78(4):155167. https://digitalcommons.unl.edu/ nebbirdrev/1153/

- 2010b. English and scientific alpha code for the birds of Nebraska. Nebraska Bird Review 78(2):70-82. https://digitalcommons.unl.edu/ nebbirdrev/1144/

- 2015. 2014 (26th) report of the NOU Records Committee. Nebraska Bird Review 83:125-138. 
- 2016. 2015 (27th) report of the NOU Records Committee. Nebraska Bird Review 84:138-150.

Brogie, M. A., and M. J. Mossman. 1983. Spring and summer birds of the Niobrara Valley Preserve area, Nebraska. Nebraska Bird Review 51(2):44-51. https://digitalcommons. unl.edu/nebbirdrev/822/

Brogie, M. A., W. R. Silcock, and J. Jorgensen. 2016. The mute swan in Nebraska: History and current status. Nebraska Bird Review 84:86-95.

Brown, C. R., and C. E. Page. 2015. A hybrid cliff $\times$ barn swallow from western Nebraska. Nebraska Bird Review 83(1):31-35.

Brown, C. R., and M. B. Brown. 1992. First record of the cave swallow for Nebraska. Nebraska Bird Review 6o(1):36-40. https://digitalcommons. unl.edu/nebbirdrev/435/

-1996. Coloniality in the Cliff Swallow: The Effect of Group Size on Social Behavior. University of Chicago Press, Chicago, IL. 580 pp.

- 1999. Barn Swallow (Hirundo rustica), version 2.0. In: The Birds of North America, edited by A. F. Poole and F. B. Gill. Cornell Lab of Ornithology, Ithaca, New York. https:// doi.org/10.2173/bna.452

- 2001. Birds of the Cedar Point Biological Station. Occasional Papers of the Cedar Point Biological Station, No. 1. $36 \mathrm{pp}$.

Brown, C. R., M. B. Brown, P. A. Johnsgard, J. Kren, \& W. C. Scharf. 1996. Birds of the Cedar Point Biological Station area, Keith and Garden Counties, Nebraska: Seasonal occurrence and breeding data. Transactions of the Nebraska Academy of Sciences 23:91-108.

Brown, M. B., and J. G. Jorgensen. 2010. Observations of piping lovers (Charadrius melodus) color banded in Nebraska and re-sighted on the United States Gulf Coast.
Nebraska Bird Review 78(1):30-34.

https://digitalcommons.unl.edu/

nebbirdrev/1137/

Brown, M. B., and P. A. Johnsgard. 2013. Birds of the Central Platte River Valley and Adjacent Counties. Conservation and Survey Division, Institute of Agriculture and Natural Resources, University of NebraskaLincoln, Lincoln, NE. 182 pp. https:// digitalcommons.unl.edu/zeabook/15/

Brown, M. B., C. R. Brown, P. Pyle, and M. A. Patten. 2017. Cliff Swallow (Petrochelidon pyrrhonota), version 3.o. In: The Birds of North America, edited by P. G. Rodewald. Cornell Lab of Ornithology, Ithaca, New York. https://doi.org/10.2173/bna.cliswa.03 Brown, M. B., J. G. Jorgensen, and S. E. Rehme. 2008. Endangered species responses to natural habitat declines: Nebraska's interior least terns (Sternula antillarum athalassos) and piping plovers (Charadrius melodus) nesting in a human-created habitat. Nebraska Bird Review 76(2):72-80. https://digitalcommons.unl.edu/ nebbirdrev/1047/

Brown, M. B., S. J. Dinsmore, and C. R. Brown. 2012. Birds of Southwestern Nebraska: An Annotated Check-List of Species in the North and South Platte River Valleys and at Lake McConaughy. Conservation and Survey Division, Institute of Agriculture and Natural Resources, University of NebraskaLincoln, Lincoln, NE. 152 pp.

Bruner, L. 1896. A list of Nebraska birds, together with notes on their abundance, migrations, breeding, food-habits, etc. Nebraska State Horticultural Society 27th Annual Report. Lincoln, NE.

Bruner, L., R. H. Wolcott, and M. H. Swenk. 1904. A preliminary review of the birds of Nebraska. Klopp and Bartlett, Omaha, NE.

Busby, W. H., and J. L. Zimmerman. 2001. Kansas Breeding Bird Atlas. University 
Press of Kansas, Lawrence, KS.

Butts, K. O., and J. C. Lewis. 1982. The importance of prairie dog towns to burrowing owls in Oklahoma. Proceedings of the Oklahoma Academy of Science 62:46-52.

Cade, T. J. 1982. The Falcons of the World. Cornell University Press, Ithaca, NY.

Canterbury, J., and P. A. Johnsgard. 2000. A century of breeding birds in Nebraska. Nebraska Bird Review 68:89-101. https://digitalcommons. unl.edu/biosciornithology/15/

Canterbury, J. L. 2001. A conservation strategy for the non-game birds of Nebraska. MS thesis, University of Nebraska-Lincoln, Lincoln NE.

Canterbury, J. L., P. A. Johnsgard, and H. F. Downing. 2013. Birds and Birding in Wyoming's Bighorn Mountains Region. 2013. University of Nebraska-Lincoln DigitalCommons and Zea Books. 260 pp. https://digitalcommons.unl.edu/ zeabook/18/

Chesser, R. T., K. J. Burns, C. Cicero, J. L. Dunn, A. W. Kratter, I. J. Lovette, P. C. Rasmussen, J. V. Remsen, Jr., J. D. Rising, D. F. Stotz, and K. Winker. 2017. Fifty-eighth supplement to the American Ornithological Society's Check-list of North American Birds. Auk 134:751-773.

Clawson. S. D. 1980. Comparative ecology of the northern oriole and the orchard oriole in western Nebraska. MS thesis, University of Nebraska-Lincoln, Lincoln NE.

Colt, C. J. 1995. Breeding bird use of riparian forests along the central Platte River: A spatial analysis. MS thesis, University of Nebraska-Lincoln, Lincoln, NE.

Currier, P. J., G. R. Lingle, and J. G. VanDerwalker. 1985. Migratory Bird Habitat on the Platte and North Platte Rivers in Nebraska. Whooping Crane Habitat Maintenance Trust, Grand Island, NE. 177 pp.

Davis, C. A. 2001. Abundance and habitat association of birds wintering in the Platte River Valley, Nebraska. Great Plains Research 11:233-248.

- 2005 . Breeding bird communities in riparian forests along the central Platte River, Nebraska. Great Plains Research 15:199-211.

DeLara, K., and M. Smith. 2013. First documented Nebraska record of blackchinned hummingbird (Archiolochus alexandri). Nebraska Bird Review 81(1):30-32. https://digitalcommons. unl.edu/nebbirdrev/1316/

Desmond M. J., J. A. Savidge, and K. M. Eskridge. 200o. Correlations between burrowing owl and black-tailed prairie dog declines: A 7-year analysis. Journal of Wildlife Management 64:1067-1075.

Dinan, L. R., J. G. Jorgensen, and M. B. Brown. 2012. Interior least tern power line collision on the lower Platte River. Prairie Naturalist 44:109-110.

Dinsmore, S. J., and W. R. Silcock. 1993. First record of a Ross's gull for Nebraska. Nebraska Bird Review 61(2):88-89. https://digitalcommons. unl.edu/nebbirdrev/463/

Dority, B. L., E. Thompson, S. Kaskie, and L. Tschauner. 2017. The Economic Impact of the Annual Crane Migration on Central Nebraska. University of Nebraska-Kearney, Kearney, NE. 22 pp.

Ducey, J. E. 1988. Nebraska Birds: Breeding Status and Distribution. Simmons-Boardman Books, Omaha, NE.

- 2000. Birds of the Untamed West: The History of Birdlife in Nebraska, 1750-1875. Making History Press, Omaha, NE.

Dundas, H., and J. Jensen. 1994-95. Burrowing owl status and conservation programs. Bird Trends 4:32-33.

eBird. 2017. eBird: An online database of bird distribution and abundance. Cornell Lab of Ornithology, Ithaca, NY. https://ebird.org/home

Emlen, S. T., J. D. Rising, and W. L. Thompson. 1975. A behavioral and 
morphological study of sympatry in the indigo and lazuli buntings of the Great Plains. Wilson Bulletin 87:145-79.

Evans, R. D., and C. W. Wolfe. 1967. Waterfowl production in the Rainwater Basin area of Nebraska. Journal of Wildlife Management 33:788-794.

Faanes, C. A., and G. R. Lingle. 1999. Breeding Birds of the Platte River Valley of Nebraska. Northern Prairie Wildlife Research Center, Jamestown, ND.

Farrar, J. (ed.). 1985. Birds of Nebraska. NEBRASKAland (special issue) 63(1):1146.

-. 2004. Birding Nebraska. NEBRASKAland (special issue) 82(1):1179 .

Faulkner, D. W. 2012. Birds of Wyoming. Roberts \& Co., Greenwood Village, CO. $403 \mathrm{pp}$.

Fiala, K. L. 1970. The birds of Gage County, Nebraska. Nebraska Bird Review 38(3):42-72. https:// digitalcommons.unl.edu/ nebbirdrev/630/

Gaines, S. 1984. A test of the optimal foraging hypothesis on flocks of wintering American tree sparrows. MS thesis, University of Nebraska-Lincoln.

Glover, F. A. 1953. Nesting ecology of the pied-billed grebe in northwestern Iowa. Wilson Bulletin 65:32-39.

Green, G. A., and R. G. Anthony. 1989. Nesting success and habitat relationships of burrowing owls in the Columbia Basin, Oregon. Condor 92:347-354.

Gubanyi, J. 1997. The official list of the birds of Nebraska. Nebraska Bird Review 65(1):3-16. https:// digitalcommons.unl.edu/ nebbirdrev/283/

- 2013. First documented record of hooded oriole (Icterus cucullatus) in Nebraska. Nebraska Bird Review 81(4):161-164. https://digitalcommons.unl.edu/ nebbirdrev/1330/

Haecker, F. W., R. A. Moser, and J. B.
Swenk. 1945. Check-list of the birds of Nebraska. Nebraska Bird Review 13(1):1-40. https://digitalcommons. unl.edu/nebbirdrev/889/

Haig, S. M. 1992. Piping plover (Charadrius melodus). In: The Birds of North America, no. 2, edited by A. Poole, P. Stettenheim, and F. Gill. The Academy of Natural Sciences, Philadelphia, PA, and American Ornithologists' Union, Washington, DC. Harding, R. G. 1986. Waterfowl nesting preferences and productivity in the Rainwater Basin, Nebraska. MS thesis, Kearney State College, Kearney, NE.

Haug, E. A, B. A. Millsap, and M. S. Martell. 1993. Burrowing owl (Athene cunicularia). In: The Birds of North America, no. 61, edited by A. Poole and F. Gill. The Academy of Natural Sciences, Philadelphia, PA, and American Ornithologists' Union, Washington, DC.

Holcomb, L. C. 1972. Traill's flycatcher breeding biology. Nebraska Bird Review 40(3):50-68. https://digitalcommons. unl.edu/nebbirdrev/638/

Hoogland, J. L. 1995. The Black-tailed Prairie Dog: Social Life of a Burrowing Animal. University of Chicago Press, Chicago, IL. 562 pp.

Hoogland, J. L. (ed.). 2006. Conservation of the Black-tailed Prairie Dog: Saving North America's Western Grasslands. Island Press, Washington, DC. 342 pp.

Hunt, K. L., L. Dinan, M. J. Friedrich, M.B. Brown, J. G. Jorgensen, D. H, Catlin, and J. D. Fraser. 2015. Double brooding of piping plovers (Charadrius melodus) in the Northern Great Plains. Waterbirds 38:321-329.

Jacobs, B. 2001. Birds in Missouri. Missouri Department of Conservation, Jefferson City, MO.

Jacobs, B., and J. D. Wilson. 1997. Missouri Breeding Bird Atlas. Missouri Department of Conservation, Jefferson City, MO.

James, P. C., and R. H. M. Espie. 1997. 
Current status of the burrowing owl in North America: An agency survey. In: The Burrowing Owl: Its Biology and Management, Including the Proceedings of the First Burrowing Owl Symposium, edited by J. L. Lincer and K. Steenhof, 3-5. Research Report No. 9. Raptor Research Foundation, Boise ID. 177 pp. Jenkins, A. (ed.) 1993. The Platte River: An Atlas of the Big Bend Region. University of Nebraska-Kearney, Kearney, NE. 194 pp.

Johnsgard, P. A. 1967. Sympatry changes and hybridization incidence in mallards and black ducks. American Midland Naturalist 77:51-63.

_. 1973. Grouse and Quails of North America. University of Nebraska Press, Lincoln, NE. 553 pp.

- 1976. The grassy heartland. In: Our Continent: A Natural History of North America, 234-263. National Geographic Society, Washington, DC.

- 1978. The triumphant trumpeter: Once reduced to a few bevies, this magnificent swan is on the road to recovery. Natural History 87(9):7277. https://digitalcommons.unl.edu/ biosciornithology/18/

- 1979a. Birds of the Great Plains:

Breeding Species and Their Distribution. University of Nebraska Press, Lincoln, NE. (See also 2009 edition.)

- 1979b. The breeding birds of Nebraska. Nebraska Bird Review 47(1):3-16. https://digitalcommons. unl.edu/johnsgard/10/

-1979c. Copulatory behavior in the American bittern. Auk 97:868-869.

- 1980a. An analysis of migration schedules of non-passerine birds in Nebraska. Nebraska Bird Review 48(2):26-36. https://digitalcommons. unl.edu/nebbirdrev/734/

- 1980 ob. An analysis of migration schedules of passerine birds in Nebraska. Nebraska Bird Review 48(3):46-57. https://digitalcommons. unl.edu/nebbirdrev/175/
- 1980c. Where have all the curlews gone? Natural History 89(8): 30-

34. https://digitalcommons.unl.edu/ biosciornithology/23/

- 1983a. The Grouse of the World. University of Nebraska Press, Lincoln, NE. 410 pp.

- 1983b. The Platte: A river of birds. Nature Conservancy News 33(5):6-15.

_.1987a. Diving Birds of North

America. University of Nebraska Press, Lincoln, NE. 286 pp.

- 1987b. The ornithogeography of the Great Plains states. Prairie Naturalist 10:97-112. https://digitalcommons.unl. edu/johnsgard/8/

- 1990a. Additional observations on the birds of the Lake McConaughy region. Nebraska Bird Review 58(2):5254. https://digitalcommons.unl.edu/ nebbirdrev/546/

- 199ob. Hawks, Eagles, and Falcons of North America: Biology and Natural History. Smithsonian Institution Press, Washington, DC. 403 pp.

-. 1990c. Survey for least terns and other birds on the North and South Platte rivers, eastern Keith County. Nebraska Bird Review 58(3):84-87. https://digitalcommons.unl.edu/ nebbirdrev/559/

- 1993. Cormorants, Darters, and Pelicans of the World. Smithsonian Institution Press, Washington, DC. 445 pp.

—. 1996. This Fragile Land: A Natural History of the Nebraska Sandhills. University of Nebraska Press, Lincoln, NE. 256 pp.

- 1997a. The Avian Brood Parasites:

Deception at the Nest. Oxford University Press, New York. 409 pp. - 1997b. The Hummingbirds of North America. 2nd ed. Smithsonian Institution Press, Washington, DC. 277 pp.

- 1998a. Endemicity and regional biodiversity in Nebraska's breeding birds. Nebraska Bird Review 66(4):115- 
21. https://digitalcommons.unl.edu/ nebbirdrev/203/

- 1998b. A half-century of winter bird surveys at Lincoln and Scottsbluff, Nebraska. Nebraska Bird Review 66(3):74-84. https://digitalcommons. unl.edu/nebbirdrev/38/

- 2000a. A century of ornithology in Nebraska: A personal view. In: Contributions to the History of North American Ornithology, Volume II, edited by W. E. Davis, Jr., and J. A. Jackson, 347-371. Nuttall Ornithological Club, Cambridge, MA. https://digitalcommons.unl.edu/ biosciornithology/26/

- 200ob. Ecogeographic aspects of greater prairie-chicken leks in southeastern Nebraska. Nebraska Bird Review 68(4):179-184. https://digitalcommons.unl.edu/ biosciornithology/3/

- 2001a. The Nature of Nebraska: Ecology and Biodiversity. University of Nebraska Press, Lincoln, NE. 402 pp. - 2001b. Prairie Birds: Fragile Splendor in the Great Plains. University Press of Kansas, Lawrence, KS. 331 pp.

- 2002a. Grassland Grouse and Their Conservation. Smithsonian Instituion Press, Washington, DC. 157 pp.

- 2002b. North American Owls: Biology and Natural History. 2nd ed. Smithsonian Institution Press, Washington, DC. 298 pp.

- 2003a. Faces of the Great Plains: Prairie Wildlife. University Press of Kansas, Lawrence, KS. 190 pp.

- 2003b. Great gathering on the Great Plains. National Wildlife 41(3):20-29. https://digitalcommons. unl.edu/johnsgard/38/

- 2003c. Great Wildlife of the Great Plains. University Press of Kansas, Lawrence, KS. 309 pp.

- 2003d. Lewis and Clark on the Great Plains: A Natural History. University of Nebraska Press, Lincoln, NE. 143 pp.

—. 2004. Prairie Dog Empire: A Saga of the Shortgrass Prairie. University of Nebraska Press, Lincoln, NE. 142 pp.

- 2006. Recent changes in winter bird numbers at Lincoln, Nebraska. Nebraska Bird Review 74:16-22. https://digitalcommons.unl.edu/ nebbirdrev/294/

- 2007a. A dozen squaretails and a sharpy. Nebraska Life, March-April. pp. 8o-86.

- 2007b. A Guide to the Natural

History of the Central Platte Valley of

Nebraska. University of NebraskaLincoln DigitalCommons. 156 pp. https://digitalcommons.unl.edu/ biosciornithology/40/

- 2007c. The Niobrara: A River Running Through Time. University of Nebraska Press, Lincoln, NE. 373 pp. - 2008a. A Guide to the Tallgrass Prairies of Eastern Nebraska and Adjacent States. University of Nebraska-Lincoln DigitalCommons. 156 pp. https://digitalcommons.unl. edu/biosciornithology/39/

- 2008b. The Platte: Channels in Time. 2nd ed. University of Nebraska Press, Lincoln, NE.

- 2009a. Birds of the Great

Plains: Breeding Species and Their Distribution, New Expanded Edition. (Revised electronic ed.) University of Nebraska-Lincoln Libraries, Lincoln, NE. https://digitalcommons.unl.edu/ bioscibirdsgreatplains/ (See also 1979 edition.)

- 2009b. A Nebraska Bird-Finding Guide. University of Nebraska-Lincoln DigitalCommons and Zea Books. 152 pp. https://digitalcommons.unl.edu/ biosciornithology/51/

- 2009c. The wings of March. Prairie

Fire, March 2009, pp. 1, 17, 18, 19. http://www.prairiefirenewspaper. com/2009/03/nature-notes-wings-ofmarch

-. 2010a. The drums of April.

Prairie Fire, April 2010, pp. 12-13. http://www.prairiefirenewspaper. 
com/2010/04/the-drums-of-april

- 2010b. The peregrine falcons of Nebraska. Prairie Fire, August 2010, pp. 12-14. http://www. prairiefirenewspaper.com/2010/08/ the-peregrine-falcons-of-nebraska - 2010c. Snow geese on the Great Plains. Prairie Fire, February 2010, pp. 12-15. http://www. prairiefirenewspaper.com/2010/02/ snow-geese-on-the-great-plains

- 2011a. The feathers of winter. Prairie Fire, December 2011, pp. 1720. http://www.prairiefirenewspaper. com/2011/12/the-feathers-of-winter —. 2011b. Raptors of Nebraska. Prairie Fire, November 2011, pp. 1415. http://www.prairiefirenewspaper. com/2011/11/the-raptors-of-nebraska

- 2011c. Rocky Mountain Birds: Birds and Birding in the Central and Northern Rockies. University of NebraskaLincoln DigitalCommons and Zea Books. 274 pp. https://digitalcommons. unl.edu/zeabook/7/

- _.2011d_Sandhill and Whooping Cranes: Ancient Voices over America's Wetlands. University of Nebraska Press, Lincoln, NE. 155 pp.

- 2011e. The secretive shorebirds: Nebraska's phantom migrants. Prairie Fire, April 2011. pp. 10-11. http://www. prairiefirenewspaper.com/2011/04/ the-secretive-shorebirds-nebraskasphantom-migrants

—. 2012a. The birds of Nebraska's boondocks. Prairie Fire, April 2012, pp. 8-10. http://www. prairiefirenewspaper.com/2012/04/ the-birds-of-nebraskas-boondocks

— 2012b. Birds of the tallgrass prairies. Prairie Fire, July 2012, pp.1619. http://www.prairiefirenewspaper. com/2012/07/birds-of-the-tallgrassprairies

- 2012c. A dazzle of hummingbirds. Prairie Fire, September 2012, pp. 1213. http://www.prairiefirenewspaper. com/2012/og/a-dazzle-of- hummingbirds

- 2012d.The eagles of Nebraska.

Prairie Fire, December 2012, pp. 9, 1416. http://www.prairiefirenewspaper. com/2012/12/the-eagles-of-nebraska —. 2012e. Nebraska's Wetlands: Their Wildlife and Ecology. Conservation and Survey Division, University of Nebraska-Lincoln, Lincoln, NE. Water Survey Paper No. 78. 202 pp.

- 2012f. The owls of Nebraska.

Prairie Fire, February 2012, pp. 15, 20. http://www.prairiefirenewspaper. com/2012/02/the-owls-of-nebraska - 2012g. Wetland Birds of the Central Plains: South Dakota, Nebraska, and Kansas. University of NebraskaLincoln DigitalCommons and Zea Books. 275 pp. https://digitalcommons. unl.edu/zeabook/8/

- 2013a. The Birds of Nebraska, Revised Edition 2013. University of Nebraska-Lincoln DigitalCommons and Zea Books. 150 pp. https:// digitalcommons.unl.edu/zeabook/17/

- 2013b. The greater prairie chicken: Spirit of the tallgrass prairie. Prairie Fire, April 2013, pp. 14-15. http://www.prairiefirenewspaper. com/2013/04/the-greater-prairiechicken-spirit-of-the-tallgrass-prairie - 2013c. The grouse with the pointed tail. Prairie Fire, April 2013, pp. 1618. http://www.prairiefirenewspaper. com/2013/04/the-grouse-with-thepointed-tail

- 2013d. Nebraska bird-feeder birds: What's in your backyard? Prairie Fire, February 2013, pp. 2, 5, 6. http://www. prairiefirenewspaper.com/2013/02/ nebraska-bird-feeder-birds-whats-inyour-backyard -. 2013e. A plethora of pelicans. Prairie Fire, March 2013, pp. 9-11. http://www.prairiefirenewspaper. com/2013/03/a-plethora-of-pelicans . 2013f. The swans of Nebraska.

Prairie Fire, January 2013, pp. 12-13. http://www.prairiefirenewspaper. 
com/2013/01/the-swans-of-nebraska

- 2013g. Wings over the Great Plains: Bird Migrations of the Central Flyway. University of Nebraska-Lincoln DigitalCommons and Zea Books. 249 pp. https://digitalcommons.unl.edu/ zeabook/13/

- 2014. What are blue Ross's geese? Nebraska Bird Review 82:81-85.

_. 2015a. Birding Nebraska's Central Platte Valley and Rainwater Basin. University of Nebraska-Lincoln DigitalCommons and Zea Books. 54 pp. https://digitalcommons.unl.edu/ zeabook $/ 36 /$

- 2015b. A Chorus of Cranes. The Cranes of North America and the World. University Press of Colorado, Boulder, CO. $242 \mathrm{pp}$.

-. 2015c. Global Warming and Population Responses among Great Plains Birds. University of NebraskaLincoln DigitalCommons and Zea Books. 384 pp. https://digitalcommons. unl.edu/zeabook/26/

- 2016a. Bittern surprise. BirdWatching 30(2):36-39.

- 2016b. The North American Geese: Their Biology and Behavior. University of Nebraska-Lincoln DigitalCommons and Zea Books. 159 pp. https:// digitalcommons.unl.edu/zeabook/44/

- 2016c. The North American Grouse: Their Biology and Behavior. University of Nebraska-Lincoln DigitalCommons and Zea Books. 183 pp. https:// digitalcommons.unl.edu/zeabook/41/

- 2016d. The North American Sea Ducks: Their Biology and Behavior. University of Nebraska-Lincoln DigitalCommons and Zea Books. 256 pp. https://digitalcommons.unl.edu/ zeabook $/ 50 /$

- 2016e. Swans: Their Biology and Natural History. University of Nebraska-Lincoln DigitalCommons and Zea Books. 114 pp. https:// digitalcommons.unl.edu/zeabook/38/

- 2017a. The North American Perching and Dabbling Ducks: Their Biology and Behavior. University of NebraskaLincoln DigitalCommons and Zea Books. 228 pp. https://digitalcommons. unl.edu/zeabook/53/

- 2017b. The North American Quails, Partridges, and Pheasants. University of Nebraska-Lincoln DigitalCommons and Zea Books. 131 pp. https:// digitalcommons.unl.edu/zeabook/58/

- 2017c. The North American

Whistling-Ducks, Pochards, and Stifftails. University of NebraskaLincoln DigitalCommons and Zea Books. 188 pp. https://digitalcommons. unl.edu/zeabook/54/

Johnsgard, P. A., and J. Dinan. 2005. Habitat associations of Nebraska birds. Nebraska Bird Review 73(1):2025. https://digitalcommons.unl.edu/ nebbirdrev/1104/

Johnsgard, P. A., and K. Gil. 2011. Sandhill cranes: Nebraska's avian ambassadors at large. Prairie Fire, February 2011, pp. 14, 15, 20. http://www.prairiefirenewspaper. com/2011/02/sandhill-cranes-ouravian-ambassadors-at-large

Johnsgard, P. A., and M. Carbonell. 1996. Ruddy Ducks and Other Stifftails: Their Behavior and Biology. University of Oklahoma Press, Norman, OK. 284 pp. Johnsgard, P. A., and R. DiSilvestro 1976. Seventy-five years of changes in mallard-black duck ratios in eastern North America. American Birds 30(5):905-908. https://digitalcommons.unl.edu/ biosciornithology/58/

Johnsgard, P. A., and R. Redfield._1977. Sixty-five years of whooping crane records in Nebraska. Nebraska Bird Review 45(4):54-56. https:// digitalcommons.unl.edu/johnsgard/9/ Johnsgard, P. A., and R. W. Wood. 1968. Distributional changes and interactions between prairie chickens and sharp-tailed grouse in the Midwest. Wilson Bulletin 8o(2):173- 
88. https://digitalcommons.unl.edu/ biosciornithology/7/

Johnsgard, P. A., and T. G. Shane. 2009. Four Decades of Christmas Bird Counts in the Great Plains: Ornithological Evidence of a Changing Climate. University of NebraskaLincoln DigitalCommons. 334 pp. https://digitalcommons.unl.edu/ biosciornithology/46/

Johnson, D. H. (ed.). Various dates. Effects of Management Practices on Grassland Birds. Northern Prairie Wildlife Research Center, Jamestown, ND. https://www.npwrc.usgs.gov/ Effects-of-Management-Practiceson-Grassland-Birds-links (Species documented include American bittern, Baird's sparrow, bobolink, Brewer's sparrow, burrowing owl, chestnut-collared longspur, claycolored sparrow, dickcissel, eastern meadowlark, ferruginous hawk, field sparrow, golden eagle, grasshopper sparrow, greater prairie-chicken, greater sage-grouse, Henslow's sparrow, horned lark, lark bunting, lark sparrow, Le Conte's sparrow, lesser prairie-chicken, loggerhead shrike, long-billed curlew, marbled godwit, McCown's longspur, merlin, mountain plover, Nelson's sharp-tailed sparrow, northern harrier, prairie falcon, Savannah sparrow, sedge wren, short-eared owl, Sprague's pipit, Swainson's hawk, upland sandpiper, vesper sparrow, western meadowlark, willet and Wilson's phalarope.)

(Also archived in the University of Nebraska-Lincoln DigitalCommons.)

Johnson, R. R., L. T. Haight, M. F. Riffey, and J. M. Simpson. 1980. Sage-steppe bird populations. In: Workshop Proceedings: Management of Western Forests and Grasslands for Nongame Birds, edited by R. M. DeGraaf and N. G. Tilghman, 98-112. USDA Forest Service Gen. Tech. Rep. INT-86, Ogden, UT.
Johnson, S. R., and A. Bouzaher (eds.). 1996. Conservation of Great Plains Ecosystems. Boston, MA: Kluwer Academic Publishers. 435 pp.

Jones, S. R. 2000. The Last Prairie: A Sandhills Journal. McGraw-Hill, New York. 244 pp.

Jones, S. R., and R. C. Cushman. 2004. The North American Prairie. Houghton Mifflin, Boston.

Jorde, D. G., G. L. Krapu, R. D. Crawford. 1983. Feeding ecology of mallards wintering in Nebraska. Journal of Wildlife Management 47:1044-1053.

Jorde, D. G., G. L. Krapu, R. D. Crawford, and M. A. Hay. 1984. Effects of weather on habitat selection and behavior of mallards wintering in Nebraska. Condor 86:258-265.

Jorgensen, J. G. 2004. An Overview of the Shorebird Migration in the Eastern Rainwater Basin, Nebraska. Lincoln, NE: Nebraska Ornithologists' Union Occasional Paper No. 8. 68 pp.

- 2012. Birds of the Rainwater

Basin, Nebraska. Nebraska Game and Parks Commission, Lincoln, NE. https://digitalcommons.unl.edu/ nebgamestaff/55/

Jorgensen, J. G., and M. B. Brown. 2017. Temporal shifts in whooping crane (Grus americana) migration across North America. Waterbirds 40:195206.

Jorgensen, J. G., and W. R. Silcock. 1998. Nebraska's first curlew sandpiper (Calidris ferruginea). Nebraska Bird Review 66:3. https://digitalcommons. unl.edu/nebbirdrev/1005/

- 2015. First nesting record and status review of the glossy ibis in Nebraska. Nebraska Bird Review 83:139-148.

Jorgensen, J. G., M. B. Brown, and A. J. Tyre. 2012. Channel width and interior least tern and piping plover nesting incidence on the lower Platte River, Nebraska. Great Plains Research 22:5967. 
Kaul, R. B., D. M. Sutherland, and S. B. Rolfsmeier. 2001. The Flora of Nebraska. 2nd ed. University of Nebraska-Lincoln, Lincoln, NE. 967 pp.

Kim, D. H., W. E. Newton, G. R. Lingle, and F. Chavez-Ramirez. 2008. Influence of grazing and available moisture on breeding densities of grassland birds in the central Platte Valley, Nebraska. Wilson Journal of Ornithology 120:820-829.

Kingery, H. (ed.). 1998. Colorado Breeding Bird Atlas. Colorado Division of Wildlife, Denver. 600 pp.

Krapu, G. L., D. A. Brandt, and R. R. Cox, Jr. 2005. Do Arctic-nesting geese compete with sandhill cranes for waste corn in the central Platte River Valley, Nebraska? Proceedings of the North American Crane Workshop 9:185-191.

Krapu, G. L., D. E. Facey, E. K. Fritzell, and D. H. Johnson. 1984. Habitat use by migrant sandhill cranes in Nebraska. Journal of Wildlife Management 48:407-417.

Kren, J. 1996. Proximate and ultimate mechanisms of red-winged blackbird (Agelaius phoeniceus) responses to interspecific brood parasitism. PhD diss., University of Nebraska-Lincoln, Lincoln, NE.

Kroodsma, R. L. 1970. North Dakota species pairs. I. Hybridization in buntings, grosbeaks, and orioles. II. Species' recognition behavior of territorial male rose-breasted and black-headed grosbeaks (Pheucticus). PhD diss., North Dakota State University, Fargo, ND.

Labedz, T. 1989. Birds. In: An Atlas of the Sand Hills, edited by A. Bleed and C. Flowerday, 161-180. Resource Atlas No. 5. Conservation and Survey Division, Institute of Agriculture and Natural Resources, University of NebraskaLincoln, Lincoln, NE.

Ladd, W. N., Jr. 1990. Status of wood ducks in the Central Flyway. In: Proceedings of the 1988 North American
Wood Duck Symposium, edited by L. H. Fredrickson, G. V. Burger, S. P. Havera, D. A. Graber, R. E. Kirby, and T. S. Taylor, 121-126. St. Louis, MO.

LaGrange, T. 2005. Guide to Nebraska's Wetlands and Their Conservation Needs. 2nd ed. Nebraska Game and Parks Commission, Lincoln, NE.

Lingle, G. R. 1994. Birding Crane River: Nebraska's Platte. Harrier Publishing, Grand Island, NE.

Low, J. B. 1941. Nesting of the ruddy duck in Iowa. Auk 58:506-17.

_. 1945. Ecology and management of the redhead, Nyroca americana, in Iowa. Ecological Monographs 15:35-69.

Lumsden, H. G. 1965. Displays of the Sharptail Grouse. Ontario Department of Lands and Forests Technical Series Research Report No. 66. Maple, ON.

Martin, D. 1973. Selective aspects of burrowing owl ecology and behavior. Condor 75:446-56.

McGregor, C., E. Bruster, M. B. Brown, L. R. Dinan, and J. G. Jorgensen. 2016. A documented occurrence of black rail (Laterallus jamaicensis) in Nebraska. Nebraska Bird Review 84:132-138.

Mollhoff, W. J. 2001. The Nebraska Breeding Bird Atlas, 1984-1989. Nebraska Ornithologists' Union Occasional Paper No. 7 and Nebraska Game and Parks Commission Technical Series No. 20. Lincoln, NE. 233 pp. - 2014. First documented nest of northern saw-whet owl in Nebraska. Nebraska Bird Review 82:189-193.

_ 2016. The Second Nebraska Breeding Bird Atlas. Bulletin of the University of Nebraska State Museum, Vol. 29. Lincoln, NE. 304 pp.

Nebraska Ornithologists' Union Records Committee. 1987-2016. Reports of the NOU Records Committee. Nebraska Bird Review 55:79-85, 57:42-47, 58:90-97, 6o:150-155, 64:38-42, 65:115-126, 66:147-159, 67:141152, 69:85-91, 70:84-90, 71:97102, 71:136-142, 72:59-65, 73:78- 
84, 74:69-74, 75:86-94, 76:111-119, 77:80-90, 78:16o-168, 79:99-111,

81:120-130, and 84:138-150.

- 2009. The official list of the birds of Nebraska: 2009. Nebraska Bird Review 77:112-131. https://digitalcommons. unl.edu/nebbirdrev/1080//See also Nebraska Bird Review 73:84, 72:108126, 65:3-16, and 56:86-96).

Oberholser, H. C., and W. L. McAtee. 1920. Waterfowl and their food plants in the Sandhills region of Nebraska. United States Department of Agriculture Bulletin 794:1-79.

Orabona, A., S. Patla, L. Van Fleet, M. Grenier, B. Oakleaf, and Z. Walker. 2009. Atlas of Birds, Mammals, Amphibians, and Reptiles in Wyoming. Wyoming Game and Fish Department, Lander. $227 \mathrm{pp}$.

Padelford, L., and B. Padelford. 2017. Brambling in Bellevue, Sarpy County. Nebraska Bird Review 85:32-33.

Palmer, R. S. (ed.). 1962. Handbook of North American Birds, Vol. I. Loons through Flamingos. Yale University Press, New Haven, CT. 567 pp.

- 1976. Handbook of North American Birds. Vols. 2 and 3. Waterfowl. Yale University Press, New Haven, CT. 521 and $569 \mathrm{pp}$.

- 1988. Handbook of North American Birds. Vols. 4 and 5. Diurnal Raptors. Yale University Press, New Haven, CT. 433 and 465 pp.

Panella, M. 2010. Nebraska's At-Risk Wildlife. Nebraska Game and Parks Commission, Lincoln, NE. 196 pp.

Pearse, A. T., M. J. Harner, D. M. Baasch, G. D. Wright, A. J. Caven, and K. L. Metzger. 2017. Evaluation of Nocturnal Roost and Diurnal Sites Used by Whooping Cranes in the Great Plains, United States. U.S. Geological Survey Open-File Report 2016-1209. 29 pp. https://pubs.er.usgs.gov/publication/ ofr20161209

Pearse, A. T., R. T. Alisauskas, G. L. Krapu, and R. R. Cox, Jr. 2012. Spring snow goose hunting influences body composition of waterfowl staging in Nebraska. Journal of Wildlife Management 76:1393-1400.

Peterson, R. A. 1995. The South Dakota Breeding Bird Atlas. South Dakota Ornithologists' Union, Aberdeen, SD. Pettingill, O. S., Jr. 1981. A Guide to BirdFinding West of the Mississippi. 2nd ed. Oxford University Press, New York.

Poole, A., and F. Gill. 1992-1997. The Birds of North America. Nos. 1-320. The Academy of Natural Sciences, Philadelphia, PA, and American Ornithologists' Union, Washington, DC.

- 1992-1997. The Birds of North America. Nos. 321-716. The Birds of North America, Inc., Philadelphia.

Porter, D., and M. Porter. 2018. Pocket binoculars. Bird Watcher's Digest. January-February, 40(3):48-61.

Poulin, R. G. 2003. Relationships between burrowing owls (Athene cunicularia), small mammals, and agriculture. $\mathrm{PhD}$ diss., University of Saskatchewan, Regina.

Poulin, R. G., G. L. Krapu, D. A. Brandt, and P. J. Kinzel. 2010. Changes in agriculture and abundance of snow geese affect carrying capacity of sandhill cranes in Nebraska. Journal of Wildlife Management 74:479-488.

Poulin, R. G., G. L. Krapu, R. R. Cox, Jr., and B. E. Davis. 2011. Spring migration ecology of northern pintails in southcentral Nebraska. Waterbirds 34:10-18.

Price, J., S. Droege, and A. Price. 1995. The Summer Atlas of North American Birds. Academic Press, San Diego, CA.

Rapp, W. F., Jr., J. L. C. Rapp, H. E. Baumgartner, and R. A. Moser. 1958. Revised Checklist of Nebraska Birds. Nebraska Ornithologists' Union Occasional Papers No. 5. Lincoln, NE. $36 \mathrm{pp}$.

Raynor, E. J., C. E. Whalen, M. B. Brown, L. A. Powell. 2017. Grassland bird community and acoustic complexity appear unaffected by proximity to a 
wind energy facility in the Nebraska Sandhills. Condor 119:484-496.

Rich, T. C., et al. (eds.). 2004. North American Landbird Conservation Plan. Partners in Flight and Cornell University Laboratory of Ornithology, Ithaca, NY.

Rising, J. D. 1968. The Great Plains hybrid zones. Current Ornithology 1:131-157.

-. 1970. Morphological variation and evolution in some North American orioles. Systematic Zoology 19:315-351.

Rohwer, S. A. 1971. Systematics and evolution of Great Plains meadowlarks, genus Sturnella. PhD diss., University of Kansas, Lawrence.

Rosche, R. C. 1982. Birds of Northwestern Nebraska and Southwestern South Dakota. Published by the author, Chadron, NE. 100 pp.

- 1994. Birds of the Lake McConaughy Area and the North Platte Valley, Nebraska. Published by the author, Chadron, NE. 115 pp.

Rosche, R. C., and P. A. Johnsgard. 1984. Birds of Lake McConaughy and the North Platte Valley, Oshkosh to Keystone. Nebraska Bird Review 52:2635. https://digitalcommons.unl.edu/ nebbirdrev/1199/

Samson, F. H., and F. L. Knopf. 1996. Prairie Conservation: Preserving North America's Most Endangered Ecosystem. Island Press, Washington, DC. $240 \mathrm{pp}$.

Sauer, J., et al. 2017. The North American Breeding Bird Survey, Results and Analysis, 1966-2015. Patuxent Wildlife Research Center, Laurel, MD.

Savage, C. 2004. Prairie: A Natural History. Greystone Books, Vancouver, BC. $320 \mathrm{pp}$.

Scharf, W. C. 2007. Woodland bird use of in-channel islands in the central Platte River, Nebraska. Prairie Naturalist 39:15-28.

Scharf, W. C., and J. Kren. 1997. Summer diet of orchard orioles in southwestern Nebraska. Southwestern Naturalist 42:127-131.
- 2010. Orchard Oriole (Icterus spurius), version 2.o. In: The Birds of North America, edited by A. F. Poole. Cornell Lab of Ornithology, Ithaca, NY. https://doi.org/10.2173/bna.255

Scharf, W. C., J. Kren, P. A. Johnsgard, and L. R. Brown. 2008. Body weights and species distributions of birds in Nebraska's central and western Platte Valley. 35 pp. https://digitalcommons. unl.edu/biosciornithology/43/

Schukman, J. N. 1974. Comparative nesting ecology of the eastern phoebe (Sayornis phoebe) and Say's phoebe (Sayornis saya) in west-central Kansas. MS thesis, Fort Hays State College, Fort Hays, KS.

Sharpe, R. S., W. R. Silcock, and J. G. Jorgensen. 2001. Birds of Nebraska: Their Distribution and Temporal Occurrence. University of Nebraska Press, Lincoln. 520 pp.

Short, L. L., Jr. 1961. Notes on bird distribution in the central Plains. Nebraska Bird Review 29(1):2-22. https://digitalcommons.unl.edu/ nebbirdrev/907/

Short, L. L., Jr. 1965. Hybridization in the flickers (Colaptes) of North America. Bulletin of the American Museum of Natural History 129:309-428.

Sibley, C. G., and L. L. Short, Jr. 1959. Hybridization in the buntings (Passerina) of the Great Plains. Auk 76:443-63.

- 1964 . Hybridization in orioles of the Great Plains. Condor 66:130-50.

Sibley, C. G., L. L. Short, Jr., and D. A. West. 1959. Hybridization in the rufous-sided towhees of the Great Plains. Auk 76:326-38.

Sidle, J. G., M. Ball, T. Byer, J. J. Chynoweth, G. Foli, R. Hodorff, G. Moravek, R. Peterson, and D. N. Svingen. 2001. Occurrence of burrowing owls in black-tailed prairie dog colonies on Great Plains national grasslands. Journal of Raptor Research 35:316-321. 
Sisson, L. H. 1970. Distribution and selection of sharp-tailed grouse dancing grounds in the Nebraska sand hills. Proceedings of the 8th Conference of the Prairie Grouse Technical Council, 1969.

- 1976. The Sharp-tailed Grouse in Nebraska. Nebraska Game and Parks Commission, Lincoln.

Smith, J. A., M. B. Brown, C. A. Davis, E. D. Holcomb, T. W. Matthews, L. P. Negus, L. A. Powell, and J. S. Taylor. 2015. Prey selection by ring-necked pheasant (Phasianus colchicus) broods in Nebraska. American Midland Naturalist 173:318-325.

Steinauer, G., and S. B. Rolfsmeier. 2003. Terrestrial Natural Communities of Nebraska. Nebraska Game and Parks Commission, Lincoln. 162 pp.

Swenk, M. H. 1915. The birds and mammals of Nebraska. Nebraska Blue Book. State of Nebraska, Lincoln.

Tallman, D. A., D. L. Swanson, and J. S. Palmer. 2002. Birds of South Dakota. South Dakota Ornithologists' Union, Aberdeen.

Tanner, W. D., Jr., and Hendrickson, G. O. 1954. Ecology of the Virginia rail in Clay County, Iowa. Iowa Bird Life 24:65-70.

Thompson, B. C., J. A. Jackson, J. Burger, L. A. Hill, E. M. Kirsch, and J. L. Atwood. 1997. Least Tern. In: The Birds of North America, no. 290, edited by A. Poole, P. Stettenheim, and F. Gill. The Academy of Natural Sciences, Philadelphia, PA, and American Ornithologists' Union, Washington, DC. Thompson, M. C., and C. Ely. 1989, 1992. Birds in Kansas. 2 vols. University Press of Kansas, Lawrence.

Thompson, M. C., C. Ely, B. Gress, C. Otte, S. T. Patti, D. Seibel, and E. A. Young. 2011. Birds of Kansas. University Press of Kansas, Lawrence.

Tout, W. 1947. Lincoln County Birds. Published by the author, North Platte, NE.
Twedt, C. M. 1974. Characteristics of sharp-tailed grouse display grounds in the Nebraska Sandhills. PhD diss., University of Nebraska-Lincoln, Lincoln, NE.

US Fish and Wildlife Service. 1981. The Platte River Ecology Study: Special Research Report. Northern Prairie Wildlife Research Station, Jamestown, ND. 186 pp.

- 2005. Rainwater Basin Wetland Management District Bird List. US Department of the Interior, Washington, DC.

- 2006. Platte River Recovery

Program: Final Environmental Impact Statement. US Department of the Interior, Washington, DC.

- 2017. Waterfowl population status, 2017. US Department of the Interior, Washington, DC.

US Department of the Interior, US Fish and Wildlife Service, US Department of Commerce, and US Census Bureau. 2016. 2016 National Survey of Fishing, Hunting, and Wildlife-Associated Recreation. US Department of the Interior, Washington, DC. 132 pp. https://wsfrprograms.fws.gov/ subpages/NationalSurvey/2016 Survey.html

Vance, J., and N. Payothong. 2012. Save the Last Dance: A Story of North American Grassland Grouse. Noppadol Paothong Photography, Columbia, MO.

Vodehnal, W. L. 1999. Status and management of the greater prairiechicken in Nebraska. In: The Greater Prairie Chicken: A National Look, edited by W. D. Svedarsky, R. H. Hier, and J. J. Silvy, 81-98. Misc. Pub. 9-1999. University of Minnesota, St. Paul, MN.

Vrtiska, M. P., and N. Lyman. 2004. Wintering Canada geese along the Platte Rivers of Nebraska, 1960-200o. Great Plains Research 14:115-128.

Vrtiska, M. P., and S. Comeau. 2009. Trumpeter Swan Survey of the High Plains Flock, Interior Population. 
Nebraska Game and Parks Commission, Lincoln.

Vrtiska, M. P., and S. Sullivan. 2009. Abundance and distribution of lesser snow and Ross's geese in the Rainwater Basin and Central Platte Valley of Nebraska. Great Plains Research 19:147-155.

Weaver, J. E. 1964. North American Prairie. Johnson Publishing, Lincoln, NE. 357 pp.
1968. Prairie Plants and Their Environment. University of Nebraska Press, Lincoln. 276 pp.

Weaver, J. E., and F. W. Alberson. 1956. Grasslands of the Great Plains: Their Nature and Use. Johnson Publishing, Lincoln, NE. 395 pp.

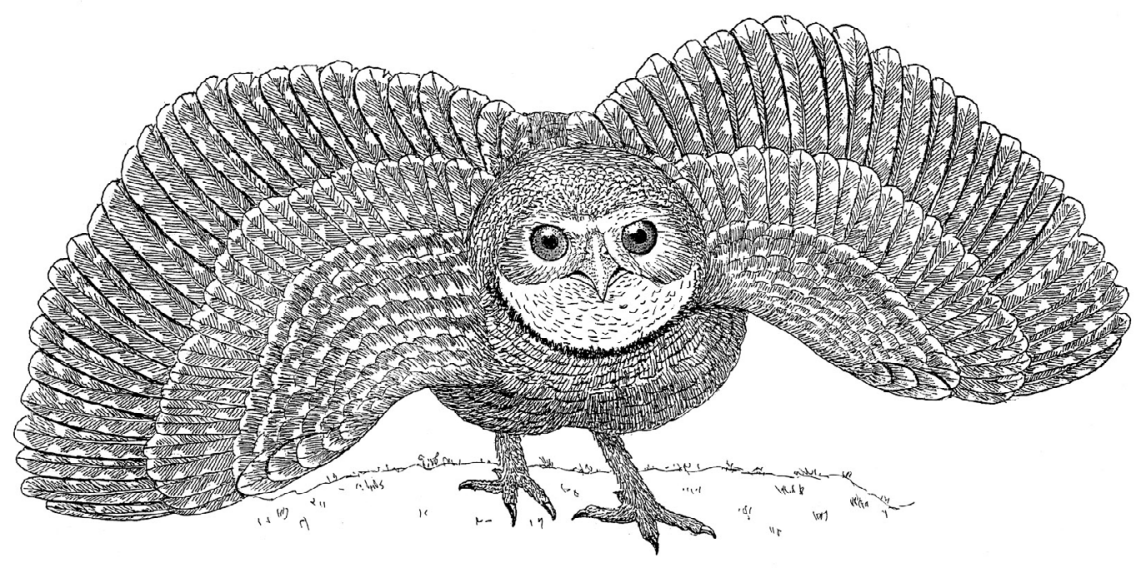




\section{Index of species}

Acadian Flycatcher, 180

Accipitridae, 151-161

Acorn Woodpecker, 170

Alaudidae, 197

Alcedinidae, 167-168

Alcidae, 127

Alder Flycatcher, 180

American Avocet, 109

American Bittern, 140

American Black Duck, 63

American Coot, 100

American Crow, 196

American Dipper, 212

American Golden-Plover, 104

American Goldfinch, 231

American Kestrel, 174

American Pipit, 225

American Redstart, 270

American Robin, 219

American Three-toed Woodpecker, 172

American Tree Sparrow, 238

American White Pelican, 139

American Wigeon, 61

American Woodcock, 119

Anatidae, 51-74

Ancient Murrelet, 127

Anhinga, 139

Anna's Hummingbird, 94

Apodidae, 91-93

Arctic Tern, 134

Ardeidae, 140-147

Ash-throated Flycatcher, 184

Auks, 127

Avocets, 109

Baird's Sandpiper, 115

Baird's Sparrow, 244

Bald Eagle, 152

Baltimore Oriole, 261

Band-tailed Pigeon, 84

Bank Swallow, 200

Barn Owl, 161

Barn Swallow, 202

Barnacle Goose, 55

Barred Owl, 165

Barrow's Goldeneye, 71

Bay-breasted Warbler, 272

Bell's Vireo, 189

Belted Kingfisher, 167

Bewick's Wren, 211

Black Rail, 96
Black Rosy-Finch, 227

Black Scoter, 69

Black Tern, 134

Black Vulture, 149

Black-and-white Warbler, 265

Black-backed Woodpecker, 172

Black-bellied Plover, 104

Black-bellied Whistling-Duck, 51

Black-billed Cuckoo, 86

Black-billed Magpie, 195

Blackbirds, 253-259

Blackburnian Warbler, 273

Black-capped Chickadee, 203

Black-capped Vireo, 189

Black-chinned Hummingbird, 93

Black-crowned Night-Heron, 146

Black-headed Grosbeak, 282

Black-headed Gull, 128

Black-legged Kittiwake, 127

Black-necked Stilt, 108

Blackpoll Warbler, 274

Black-throated Blue Warbler, 274

Black-throated Gray Warbler, 277

Black-throated Green Warbler, 278

Black-throated Sparrow, 242

Blue Grosbeak, 282

Blue Jay, 194

Blue-gray Gnatcatcher, 212

Blue-headed Vireo, 191

Blue-winged Teal, 58

Blue-winged Warbler, 264

Bobolink, 253

Bobwhite, 75

Bohemian Waxwing, 223

Bombycillidae, 223

Bonaparte's Gull, 128

Boobies, 137

Boreal Chickadee, 204

Boreal Owl, 167

Brambling, 226

Brant, 54

Brewer's Blackbird, 257

Brewer's Sparrow, 240

Broad-tailed Hummingbird, 94

Broad-winged Hawk, 157

Brown Booby, 137

Brown Creeper, 206

Brown Pelican, 140

Brown Thrasher, 220

Brown-headed Cowbird, 259

Brown-headed Nuthatch, 206 
Buff-breasted Sandpiper, 117

Bufflehead, 70

Bullock's Oriole, 261

Burrowing Owl, 163

Cackling Goose, 54

Calcariidae, 232-235

California Gull, 130

Calliope Hummingbird, 95

Canada Goose, 55

Canada Warbler, 278

Canvasback, 65

Canyon Towhee, 238

Canyon Wren, 208

Cape May Warbler, 270

Caprimulgidae, 87-89

Cardinalidae, 279-286

Cardinals, 281

Carolina Chickadee, 203

Carolina Parakeet, 177

Carolina Wren, 210

Caspian Tern, 133

Cassin's Finch, 228

Cassin's Kingbird, 185

Cassin's Sparrow, 238

Cassin's Vireo, 190

Catbirds, 220

Cathartidae, 149-150

Cattle Egret, 145

Cave Swallow, 202

Cedar Waxwing, 223

Certhiidae, 206-207

Cerulean Warbler, 271

Charadriidae, 104-108

Chats, 252

Chestnut-collared Longspur, 233

Chestnut-sided Warbler, 274

Chickadees, 203-204,

Chihuahuan Raven, 196

Chimney Swift, 91

Chipping Sparrow, 238

Chuck-will's-widow, 88

Chukar, 76

Ciconiidae, 137

Cinclidae, 212

Cinnamon Teal, 59

Clapper Rail, 96

Clark's Grebe, 83

Clark's Nutcracker, 195

Clay-colored Sparrow, 239

Cliff Swallow, 201

Columbidae, 83-85

Common (Eurasian) Crane, 103

Common Eider, 68
Common Gallinule, 98

Common Goldeneye, 71

Common Grackle, 257

Common Ground-Dove, 84

Common Loon, 136

Common Merganser, 72

Common Nighthawk, 87

Common Poorwill, 88

Common Raven, 196

Common Redpoll, 230

Common Tern, 134

Common Yellowthroat, 269

Connecticut Warbler, 267

Cooper's Hawk, 154

Coots, 100

Cordilleran Flycatcher, 182

Cormorants, 138

Corvidae, 193

Costa's Hummingbird, 94

Cranes, 101-104

Creepers, 206-207

Crested Caracara, 174

Crows, 196-197

Cuckoos, 86

Cuculidae, 86

Curlew Sandpiper, 114

Curve-billed Thrasher, 220

Dark-eyed Junco, 251

Dickcissel, 285

Dippers, 212

Double-crested Cormorant, 138

Doves, 84-85

Downy Woodpecker, 171

Dunlin, 115

Dusky Flycatcher, 182

Eagles, 152, 160

Eared Grebe, 81

Eastern Bluebird, 214

Eastern Kingbird, 186

Eastern Meadowlark, 254

Eastern Phoebe, 183

Eastern Screech-Owl, 162

Eastern Towhee, 237

Eastern Whip-poor-will, 89

Eastern Wood-Pewee, 179

Egrets, 143-145

Elegant [Crested] Tinamou, 51

Emberizidae, 236-252

Emperor Goose, 51

Eskimo Curlew, 111

Eurasian Collared-Dove, 84

Eurasian Tree Sparrow, 225 
Eurasian Wigeon, 61

European Starling, 222

Evening Grosbeak, 232

Falcons, 174-176

Ferruginous Hawk, 159

Field Sparrow, 240

Finches, 226-232

Fish Crow, 196

Flammulated Owl, 161

Flycatchers, 178-187

Forster's Tern, 134

Fox Sparrow, 247

Franklin's Gull, 129

Fregatidae, 137

Frigatebirds, 137

Fringillidae, 226-232

Gadwall, 6o,

Garganey, 58

Gaviidae, 135-136

Glaucous Gull, 132

Glaucous-winged Gull, 132

Glossy Ibis, 148

Gnatcatchers, 212

Golden Eagle, 160

Golden-crowned Kinglet, 213

Golden-crowned Sparrow, 251

Golden-winged Warbler, 264

Grace's Warbler, 277

Grackles, 257-258

Grasshopper Sparrow, 244

Gray Catbird, 220

Gray Flycatcher, 182

Gray Jay, 193

Gray Partridge, 76

Gray-cheeked Thrush, 217

Gray-crowned Rosy-Finch, 226

Great Black-backed Gull, 132

Great Blue Heron, 142

Great Crested Flycatcher, 184

Great Egret, 143

Great Gray Owl, 165

Great Horned Owl, 162

Greater Prairie-Chicken, 79

Greater Sage-Grouse, 77

Greater Scaup, 67

Greater White-fronted Goose, 53

Greater Yellowlegs, 123

Great-tailed Grackle, 258

Grebes, 80-83

Green Heron, 146

Green-tailed Towhee, 236

Green-winged Teal, 64
Groove-billed Ani, 87

Grosbeaks, 227, 232, 281-282

Grouse, 77-79

Gruidae, 101-104

Gulls, 127-132

Gyrfalcon, 175

Hairy Woodpecker, 172

Hammond's Flycatcher, 182

Harlequin Duck, 68

Harris's Hawk, 156

Harris's Sparrow, 250

Hawks, 154-16o

Henslow's Sparrow, 245

Hepatic Tanager, 279

Hermit Thrush, 218

Hermit Warbler, 277

Herons, 142-147

Herring Gull, 130

Hirundinidae, 198-204

Hoary Redpoll, 230

Hooded Crane, 104

Hooded Merganser, 72

Hooded Oriole, 261

Hooded Warbler, 269

Horned Grebe, 81

Horned Lark, 197

House Finch, 227

House Sparrow, 224

House Wren, 208

Hudsonian Godwit, 112

Hummingbirds, 93-95

Ibises, 148

Iceland Gull, 131

Icteridae, 253-262

Icteriidae, 252

Inca Dove, 84

Indigo Bunting, 285

Jaegers, 126

Jays, 193-195

Junco, 251

Kentucky Warbler, 268

Killdeer, 107

King Eider, 68

King Rail, 97

Kingfishers, 167-168

Kinglets, 213-214

Laniidae, 187-188

Lapland Longspur, 232

Laridae, 127-135

Lark Bunting, 242 
Lark Sparrow, 241

Larks, 197

Laughing Gull, 128

Lazuli Bunting, 284

Least Bittern, 142

Least Flycatcher, 181

Least Sandpiper, 116

Least Tern, 133

LeConte's Sparrow, 245

Lesser Black-backed Gull, 131

Lesser Goldfinch, 231

Lesser Prairie-Chicken, 79

Lesser Scaup, 67

Lesser Yellowlegs, 122

Lewis's Woodpecker, 168

Lincoln's Sparrow, 248

Little Blue Heron, 144

Little Gull, 128

Loggerhead Shrike, 187

Long-billed Curlew, 111

Long-billed Dowitcher, 119

Long-eared Owl, 165

Longspurs, 232-235,

Long-tailed Duck, 70

Long-tailed Jaeger, 126

Loons, 135-136

Louisiana Waterthrush, 263

MacGillivray's Warbler, 268

Magnificent Frigatebird, 137

Magnolia Warbler, 272

Magpies, 195

Mallard, 62

Marbled Godwit, 112

Marsh Wren, 209

McCown's Longspur, 234

Meadowlarks, 254-255

Merlin, 175

Mew Gull, 129

Mimidae, 220-222

Mississippi Kite, 151

Mockingbirds, 222

Monk Parakeet, 177

Motacillidae, 225-226

Mottled Duck, 63

Mountain Bluebird, 215

Mountain Chickadee, 203

Mountain Plover, 107

Mourning Dove, 85

Mourning Warbler, 268

Mute Swan, 56

Nashville Warbler, 267

Nelson's Sparrow, 247
Neotropic Cormorant, 138

Nightjars, 87-89

Northern Bobwhite, 75

Northern Cardinal, 281

Northern Flicker, 173

Northern Goshawk, 155

Northern Harrier, 153

Northern Hawk Owl, 163

Northern Mockingbird, 222

Northern Parula, 271

Northern Pintail, 63

Northern Rough-winged Swallow, 200

Northern Saw-whet Owl, 167

Northern Shoveler, 59

Northern Shrike, 188

Northern Waterthrush, 263

Northern Wheatear, 214

Nuthatches, 204-206

Odontophoridae, 75

Old World Sparrows, 224-225

Olive-sided Flycatcher, 178

Orange-crowned Warbler, 266

Orchard Oriole, 260

Orioles, 260-262

Osprey, 150

Ovenbird, 262

Owls, 161-167

Pacific Loon, 136

Pacific Wren, 209

Painted Bunting, 285

Palm Warbler, 275

Pandionidae, 150-151

Parasitic Jaeger, 126

Paridae, 203-204

Parrots, 177

Parulidae, 262-279

Passenger Pigeon, 84

Passeridae, 224-225

Pectoral Sandpiper, 117

Pelecanidae, 139-140

Peregrine Falcon, 176

Phaethontidae, 137

Phainopepla, 224

Phalacrocoracidae, 138

Phalaropes, 123-125

Pheasants, 76

Philadelphia Vireo, 191

Picidae, 168-174

Pied-billed Grebe, 80

Pigeons, 83-84

Pileated Woodpecker, 173

Pine Grosbeak, 227 
Pine Siskin, 230

Pine Warbler, 275

Pinyon Jay, 193

Piping Plover, 106

Pipits, 225-226

Plovers, 104-108

Plumbeous Vireo, 191

Podicipedidae, $80-83$

Polioptilidae, 212

Pomarine Jaeger, 126

Prairie Falcon, 176

Prairie Warbler, 277

Prothonotary Warbler, 265

Psittacidae, 177

Ptilogonatidae, 224

Purple Finch, 228

Purple Gallinule, 98

Purple Martin, 198

Pygmy Nuthatch, 206

Quails, 75

Rails, 95-97

Rallidae, 95-100

Recurvirostridae, 108-109

Red Crossbill, 229

Red Knot, 113

Red Phalarope, 125

Red-bellied Woodpecker, 170

Red-breasted Merganser, 73

Red-breasted Nuthatch, 204

Reddish Egret, 145

Red-eyed Vireo, 192

Redhead, 66

Red-headed Woodpecker, 169

Red-naped Sapsucker, 171

Red-necked Grebe, 81

Red-necked Phalarope, 125

Red-shouldered Hawk, 156

Red-tailed Hawk, 158

Red-throated Loon, 135

Red-winged Blackbird, 253

Regulidae, 213-214

Ring-billed Gull, 130

Ring-necked Duck, 66

Ring-necked Pheasant, 76

Rock Pigeon, 83

Rock Wren, 207

Roseate Spoonbill, 149

Rose-breasted Grosbeak, 281

Ross's Goose, 52

Ross's Gull, 128

Rough-legged Hawk, 159

Royal Tern, 135
Ruby-crowned Kinglet, 213

Ruby-throated Hummingbird, 93

Ruddy Duck, 74

Ruddy Turnstone, 113

Ruff, 114

Ruffed Grouse, 77

Rufous Hummingbird, 94

Rusty Blackbird, 256

Sabine's Gull, 127

Sage Thrasher, 221

Sagebrush Sparrow, 242

Sanderling, 115

Sandhill Crane, 101

Sandpipers, 110, 115-118

Savannah Sparrow, 243

Say's Phoebe, 183

Scarlet Tanager, 279

Scissor-tailed Flycatcher, 187

Scolopacidae, 110-125

Scott's Oriole, 262

Sedge Wren, 209

Semipalmated Plover, 105

Semipalmated Sandpiper, 117

Sharp-shinned Hawk, 154

Sharp-tailed Grouse, 77

Sharp-tailed Sandpiper, 114

Short-billed Dowitcher, 118

Short-eared Owl, 166

Shrikes, 187-188

Silky Flycatchers, 224

Sittidae, 204-206

Slaty-backed Gull, 132

Smith's Longspur, 234

Snipes, 119-120

Snow Bunting, 235

Snow Goose, 51

Snowy Egret, 144

Snowy Owl, 162

Snowy Plover, 105

Solitary Sandpiper, 121

Song Sparrow, 248

Sora, 97

Sparrows (see also Old World Sparrows), 236-252

Spoonbills, 149

Spotted Sandpiper, 121

Spotted Towhee, 236

Sprague's Pipit, 226

Starlings, 222,

Steller's Jay, 194

Stercorariidae, 126

Stilt Sandpiper, 114

Stilts, 108-109 
Strigidae, 161-167

Sturnidae, 222

Sulidae, 137

Summer Tanager, 279

Surf Scoter, 68

Swainson's Hawk, 157

Swainson's Thrush, 217

Swainson's Warbler, 266

Swallows, 198-204

Swallow-tailed Kite, 151

Swamp Sparrow, 249

Swifts, 91-93

Taiga Bean Goose, 54

Tanagers, 279-280

Tennessee Warbler, 266

Terns, 133-135

Thrashers, 220-222

Threskiornithidae, 148-149

Thrushes, 214-219

Tinamous, 51

Titmice, 204

Towhees, 236-238

Townsend's Solitaire, 215

Townsend's Warbler, 277

Tree Swallow, 199

Tricolored Heron, 145

Trochilidae, 93-95

Troglodytidae, 207-211

Tropicbirds, 137

Trumpeter Swan, 56

Tufted Duck, 67

Tufted Titmouse, 204

Tundra Swan, 57

Turdidae, 214-219

Turkey Vulture, 149

Turkeys, 80

Tyrannidae, 178-187

Tytonidae, 161

Upland Sandpiper, 110

Varied Thrush, 219

Veery, 216

Vermilion Flycatcher, 184

Vesper Sparrow, 241

Violet-green Swallow, 199

Vireonidae, 189-193

Virginia Rail, 97

Virginia's Warbler, 267

Vultures, 149-150

Warblers, 262-279

Warbling Vireo, 192
Waterfowl, 51-74

Waxwings, 223

Western Bluebird, 215

Western Grebe, 82

Western Kingbird, 186

Western Meadowlark, 255

Western Sandpiper, 118

Western Scrub-Jay, 195

Western Tanager, 280

Western Wood-Pewee, 178

Whimbrel, 110

White Ibis, 148

White-breasted Nuthatch, 205

White-crowned Sparrow, 250

White-eyed Vireo, 189

White-faced Ibis, 148

White-rumped Sandpiper, 116

White-tailed Kite, 151

White-tailed Tropicbird, 137

White-throated Sparrow, 249

White-throated Swift, 91

White-winged Crossbill, 229

White-winged Dove, 85

White-winged Scoter, 69

Whooping Crane, 103

Wild Turkey, 80

Willet, 122

Williamson's Sapsucker, 170

Willow Flycatcher, 180

Wilson's Phalarope, 123

Wilson's Snipe, 120

Wilson's Warbler, 278

Winter Wren, 208

Wood Duck, 57

Wood Stork, 137

Wood Thrush, 218

Woodpeckers, 168-174

Worm-eating Warbler, 263

Wrens, 207-211

Yellow Rail, 95

Yellow Warbler, 273

Yellow-bellied Flycatcher, 179

Yellow-bellied Sapsucker, 170

Yellow-billed Cuckoo, 86

Yellow-billed Loon, 136

Yellow-breasted Chat, 252

Yellow-crowned Night-Heron, 147

Yellow-headed Blackbird, 255

Yellow-rumped Warbler, 276

Yellow-throated Vireo, 190

Yellow-throated Warbler, 276

Zone-tailed Hawk, 158 
